\title{
MODELING AND ANALYSIS OF CAL POLY MICROGRID
}

\author{
A Thesis \\ presented to \\ the Faculty of California Polytechnic State University, \\ San Luis Obispo
}

\author{
In Partial Fulfillment \\ of the Requirements for the Degree \\ Master of Science in Electrical Engineering
}

by

Matthew Albert Guevara

April 2018 
(C) 2018

Matthew Albert Guevara

ALL RIGHTS RESERVED 
COMMITTEE MEMBERSHIP

TITLE: Modeling and Analysis of Cal Poly Microgrid

\begin{abstract}
AUTHOR: Matthew Albert Guevara
\end{abstract}
DATE SUBMITTED: April 2018

COMMITTEE CHAIR: Taufik, Ph.D.

Professor of Electrical Engineering

COMMITTEE MEMBER: Ahmad Nafisi, Ph.D.

Professor of Electrical Engineering

COMMITTEE MEMBER: Ali Shaban, Ph.D.

Professor of Electrical Engineering 


\section{ABSTRACT \\ Modeling and Analysis of Cal Poly Microgrid \\ Matthew Albert Guevara}

Microgrids - miniature versions of the electrical grid are becoming increasingly more popular as advancements in technologies, renewable energy mandates, and decreased costs drive communities to adopt them. The modern microgrid has capabilities of generating, distributing, and regulating the flow of electricity, capable of operating in both grid-connected and islanded (disconnected) conditions. This paper utilizes ETAP software in the analysis, simulation, and development of the Cal Poly microgrid. Additionally, an ETAP power system protection tutorial is created to aid students entering the power industry. Microprocessor-based relays are heavily utilized in both the ETAP model and hardware implementation of the system. Case studies in this project investigate electric power system load flow, short circuit, protection coordination, and transient stability analysis of the Cal Poly microgrid.

Keywords: microgrid, power systems education, ETAP 


\section{ACKNOWLEDGMENTS}

I would like to express my sincere gratitude to my advisor, Dr. Taufik, for his wisdom and guidance. This thesis would not have been complete without his continual support throughout the entire process. His selfless ability to encourage and assist his many students is unparalleled, and we are all privileged to have been under his superb instruction. Thank you, Dr. Taufik.

I would also like to thank my committee members, Dr. Ali Shaban and Dr. Ahmad Nafisi for their knowledge and support. Your excellent courses have cemented and steered my path towards the area of electric power systems, and for that I am very grateful.

Eric Osborn deserves utmost credit in taking over the microgrid project and moving it forwards. The success and survival of the project owes itself largely to Eric, and I wish him all the best in his future endeavors.

I would like to express my dearest appreciation to my friends and colleagues, especially: Kevin Hua, Eric Osborn, Grace Larson, Richard Liu, Calin Bukur, Elliott Winicki, Alex Marette, and the rest of the Electrical Engineering Graduate Resource Lab.

Finally, I would like to thank my family-especially my parents Hector and Hiromi Guevara. They have sacrificed immensely to provide me with what I have now, and for that I am forever grateful. 
TABLE OF CONTENTS

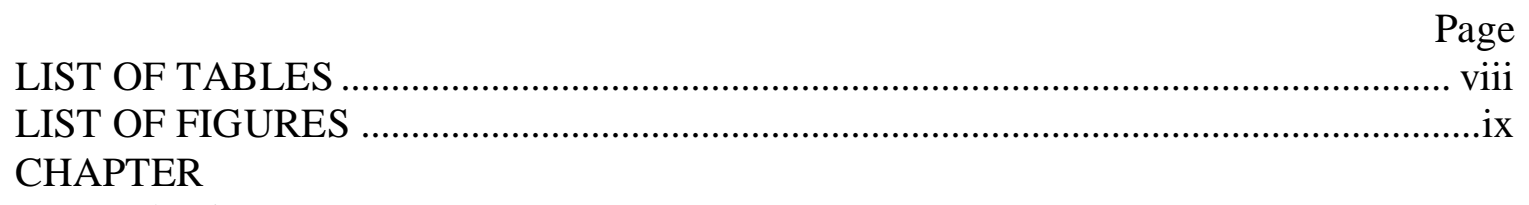

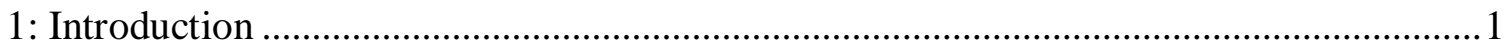

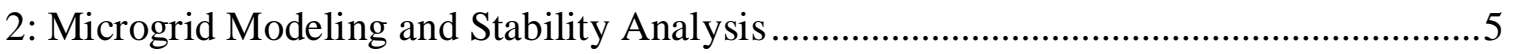

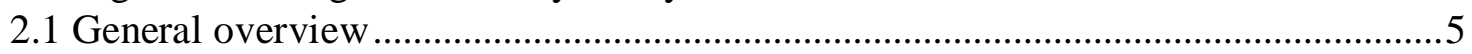

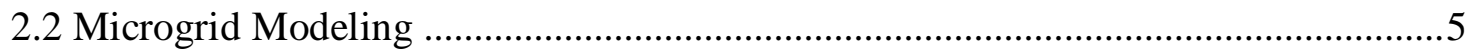

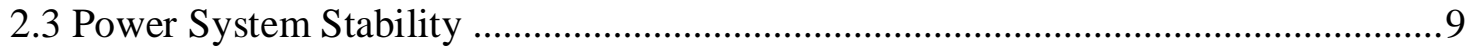

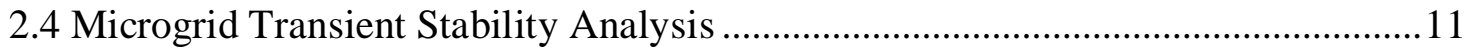

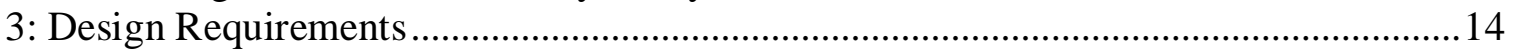

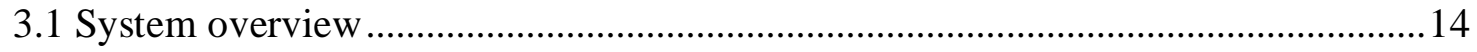

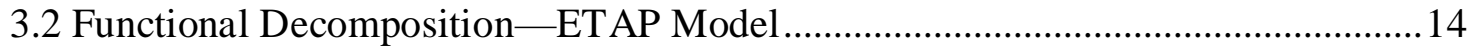

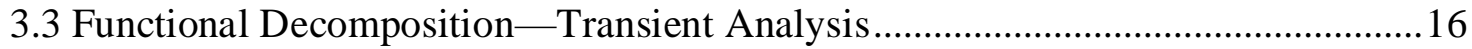

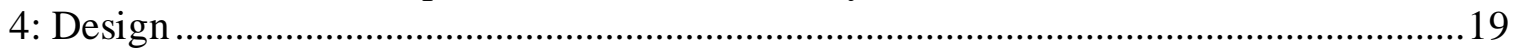

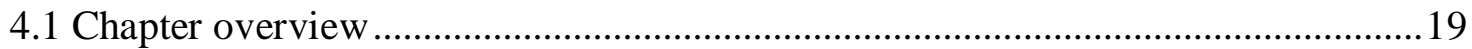

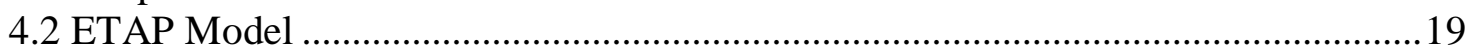

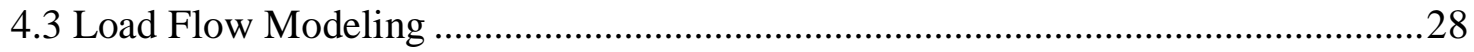

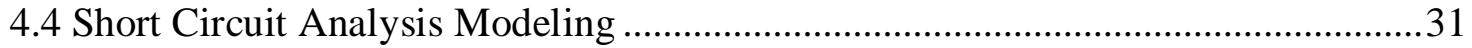

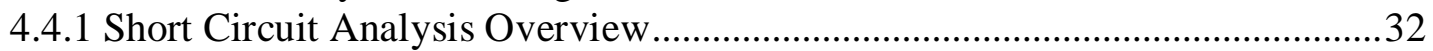

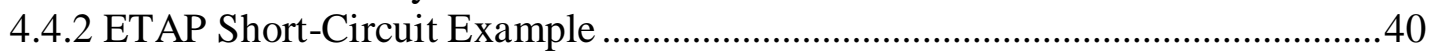

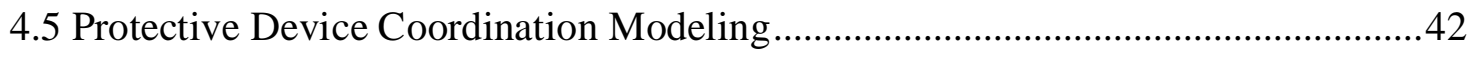

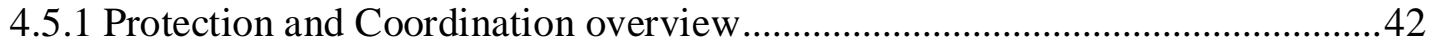

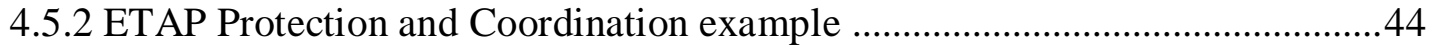

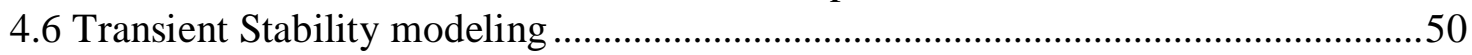

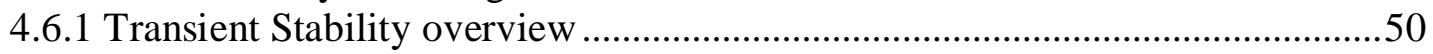

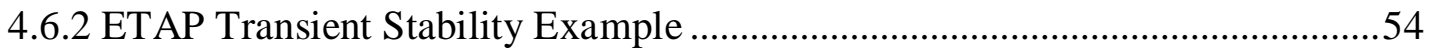

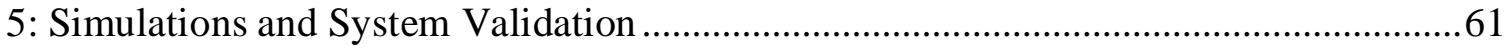

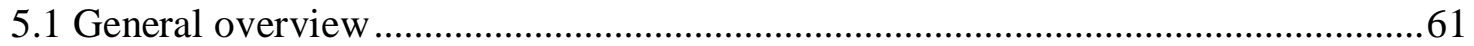

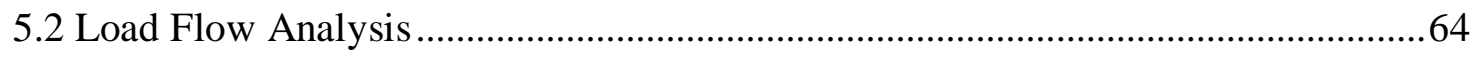

5.2.1 Case I: Bidirectional System, No Motor and Capacitors ....................................64

5.2.2 Case II: Bidirectional System, motor and capacitors ......................................67

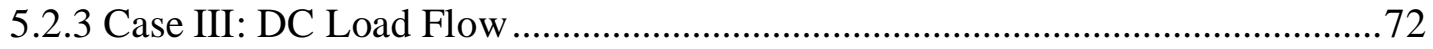

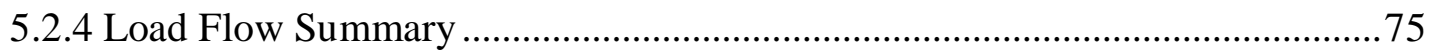

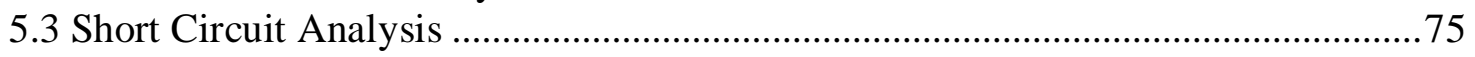

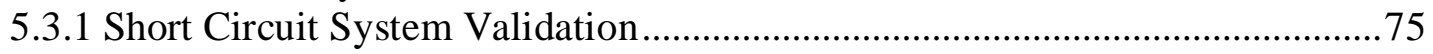

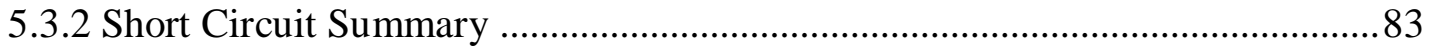

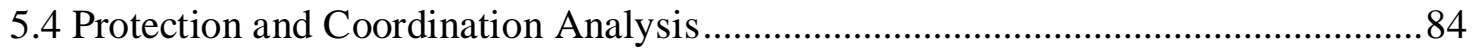

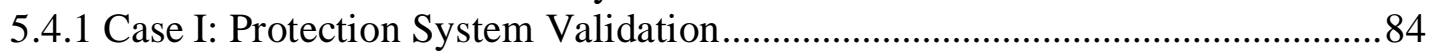

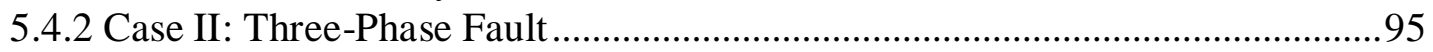

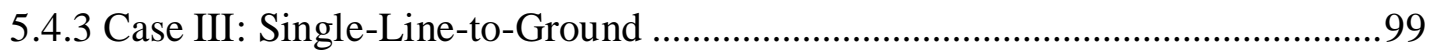

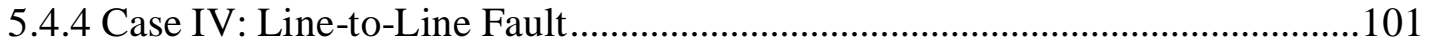

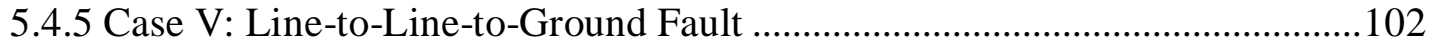

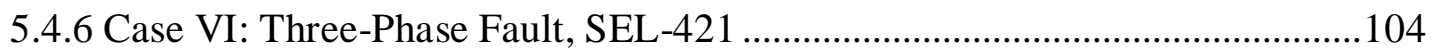




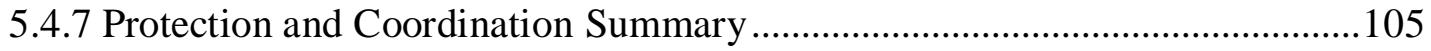

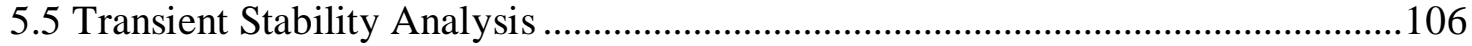

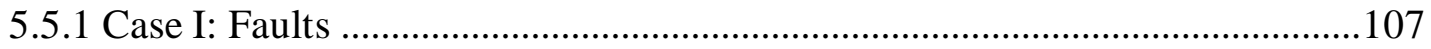

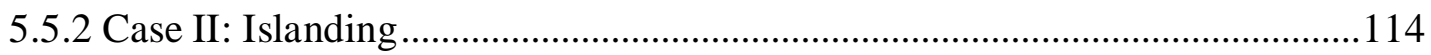

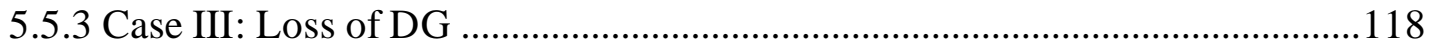

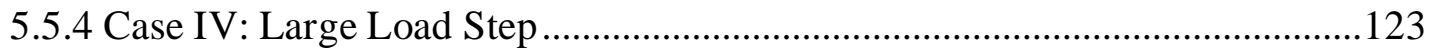

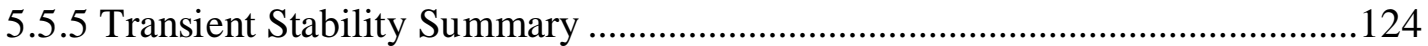

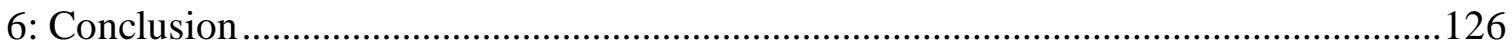

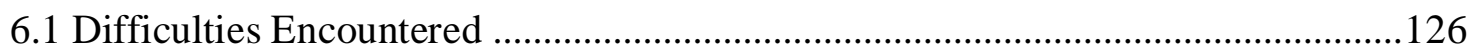

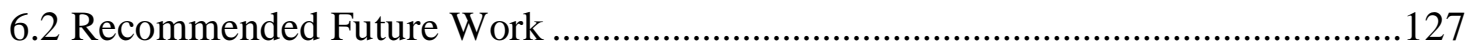

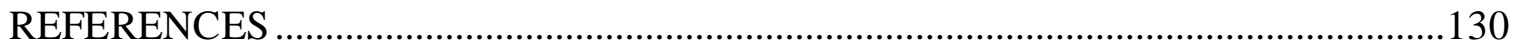

APPENDICES

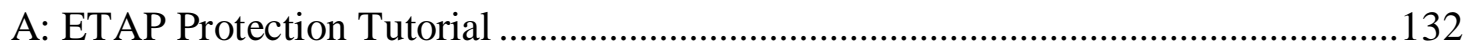

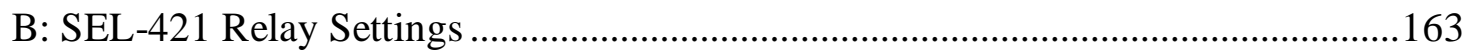

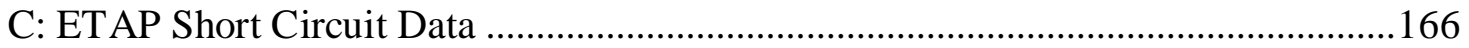

D: ETAP and SEL Overcurrent Protection settings ..................................................170 


\section{LIST OF TABLES}

Table

Page

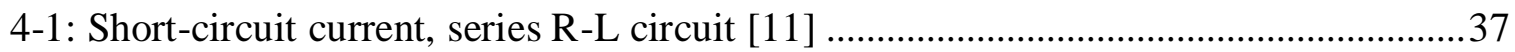

4-2: Short-circuit current, unloaded synchronous machine [11] ....................................40

5-1: System synchronized, no motor, no capacitors [14] ….........................................65

5-2: System Synchronized, with motor, no capacitors [14] ..........................................68

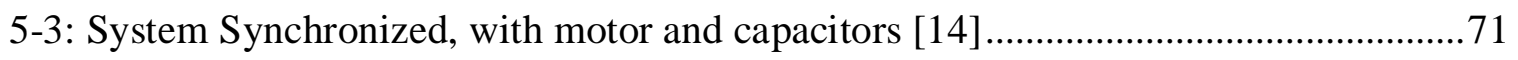

5-4: Bidrectional System Tripping for a Double-Line-to-Ground Fault [4] .....................87

5-5: Negative sequence time overcurrent settings, prior microgrid ................................. 88

5-6: Negative sequence time overcurrent settings, modified prior microgrid ...................92

5-7. Typical values of $\mathrm{H}$, thermal and hydraulic generating units [8] ............................ 107

5-8: Single-Reheat Steam-Turbine (ST1) parameters and definitions [10] .....................121

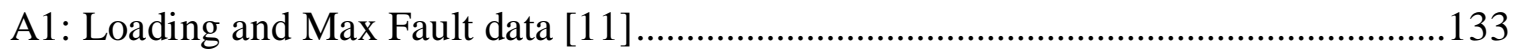

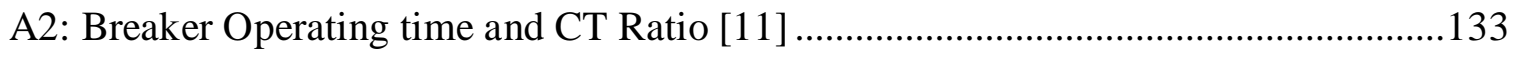

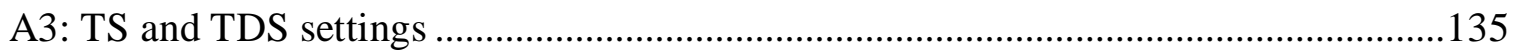




\section{LIST OF FIGURES}

Figure

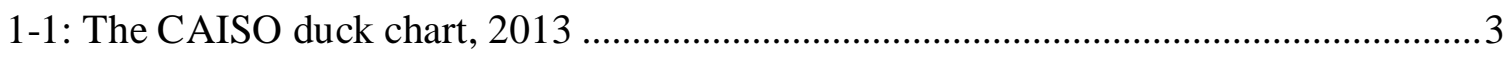

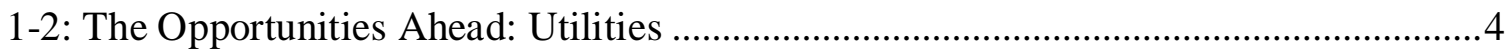

2-1: Bidirectional Network Single-Line Diagram [4] ................................................ 6

2-2: Bidirectional Network Single-Line Protection Diagram [4] .....................................

2-3: Classification of power system stability .............................................................

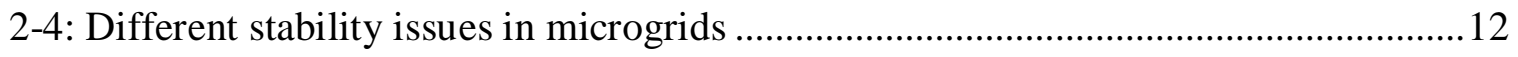

3-1: ETAP Model Block Diagram, Level 0 ................................................................ 14

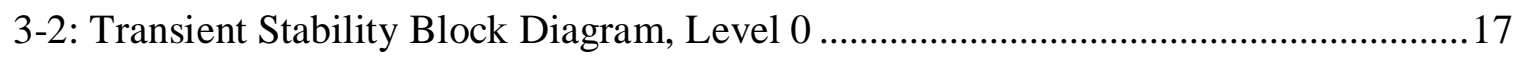

3-3: Microgrid Stability Improvement ................................................................... 18

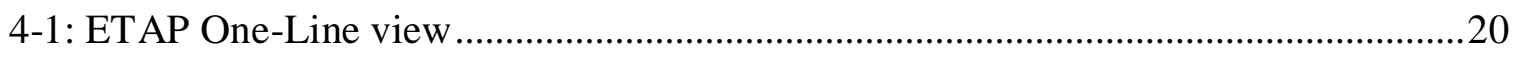

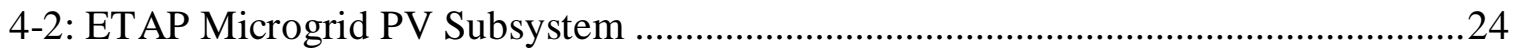

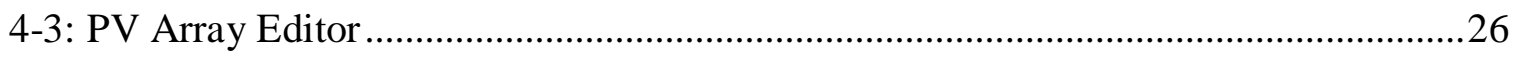

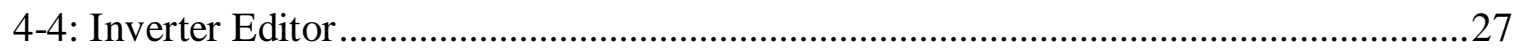

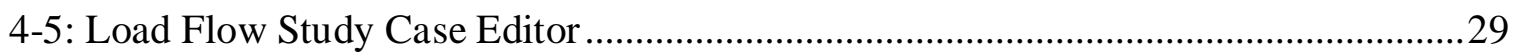

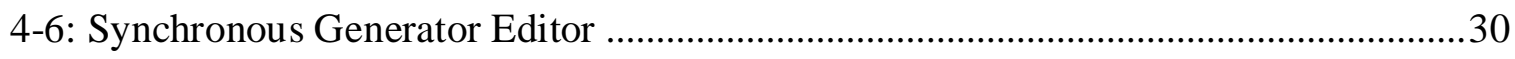

4-7: Symmetrical Components of three balanced phasors [8] .........................................33

4-8: Unbalanced voltage phasors, symmetrical components [12] ................................... 34

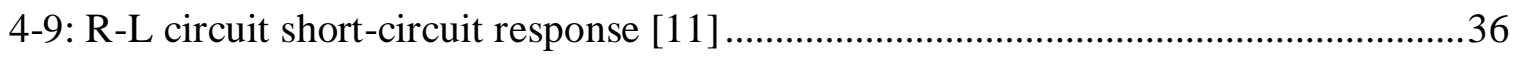

4-10: Armature short circuit current with dc offset removed ...........................................38

4-11: Extrapolation of asymmetrical AC fault current ................................................ 41

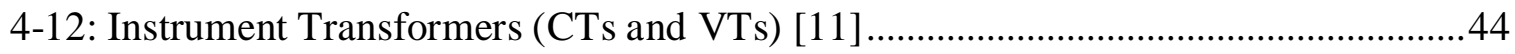


4-13: Single-line, Radial protection example [11] ...........................................................

4-14: ETAP Single-Line, Radial Protection example ...........................................................46

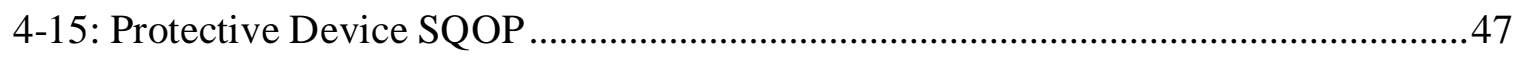

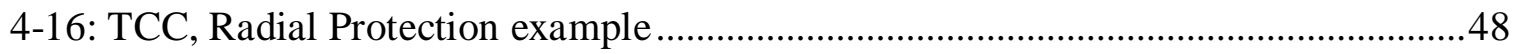

4-17: Bidirectional System with two sources [11] ...........................................................49

4-18: Mechanical analogy of transient stability [11] .....................................................51

4-19: Synchronous Generator operation, magnetic bars [9] ..............................................52

4-20: Three-phase synchronous machine, schematic [8] ...............................................53

4-21: ETAP implementation of faulted bus................................................................5

4-22: Rotor angle response, fault cleared in 0.05 seconds ................................................56

4-23: Electrical power output, fault cleared in 0.05 seconds............................................57

4-24: Unstable rotor angle response, fault cleared in 0.07 seconds ..................................59

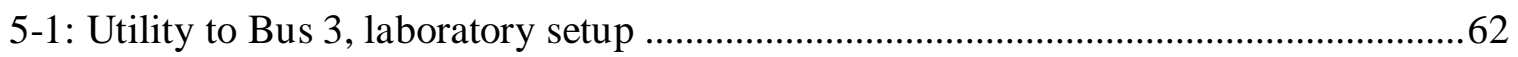

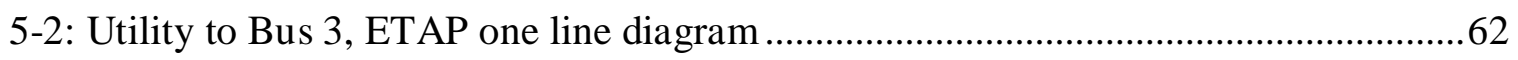

5-3: Generators to Bus 3, laboratory setup …………………………………………....63

5-4: Generators to Bus 3, ETAP one line diagram........................................................63

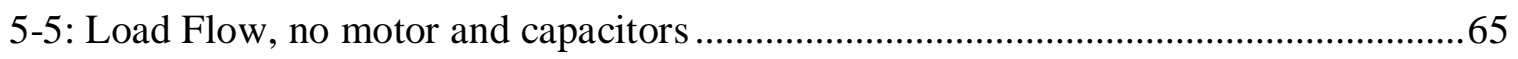

5-6: Load Flow, no motor and capacitors, MVAR mode …………………..........................67

5-7: ETAP Induction Motor loading conditions .................................................................69

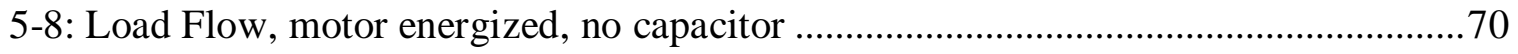

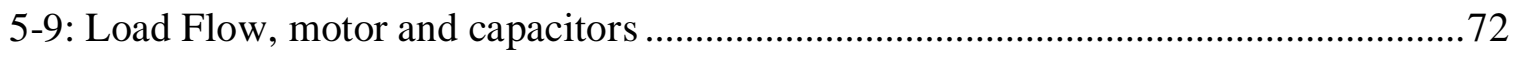

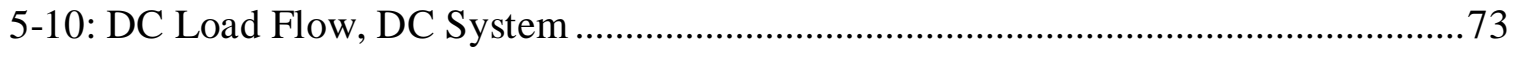

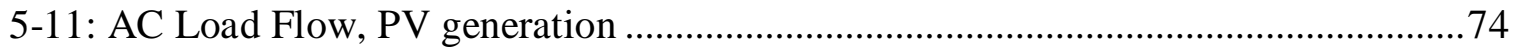


5-12: Three-phase short circuit test, synchronous generator .76

5-13: ETAP, three-phase short circuit test, synchronous generator .................................77

5-14: SEL Oscillogram, three-phase short circuit, synchronous generator ........................78

5-15: Generator short circuit terminal current, three-phase fault ....................................79

5-16: Maximum 3-phase SC (1/2 cycle) on generator terminals ..................................... 80

5-17: Minimum 3-phase SC (30 cycle) on generator terminals ...................................... 81

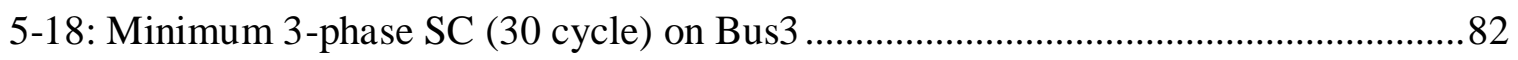

5-19: Double-Line-to-Ground Fault Bus 3, short circuit report ........................................ 83

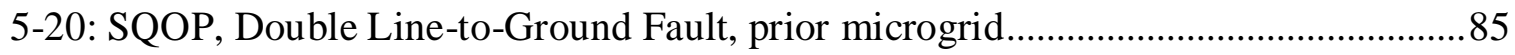

5-21: SQOP Report, Double Line-to-Ground, prior microgrid ........................................ 86

5-22: TCC Bidirectional Relay Coordination, prior microgrid ......................................90

5-23: TCC Modified Bidirectional Relay Coordination, prior microgrid ........................91

5-24: SQOP viewer, DLG fault improved selectivity .................................................93

5-25: SEL-387E Three-Phase Fault, Bus 1, Phases A, B, C [4] .......................................94

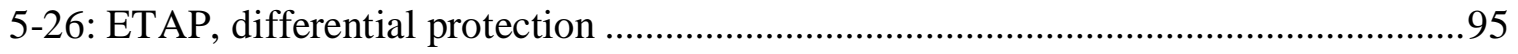

5-27: SQOP, Three-Phase Fault, Motor Terminals........................................................ 96

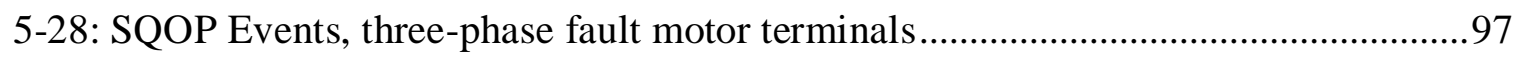

5-29: Three-Phase Fault, Motor Terminals, TCC …........................................................ 98

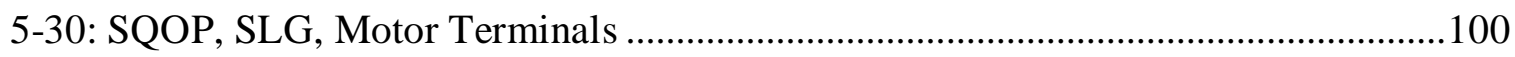

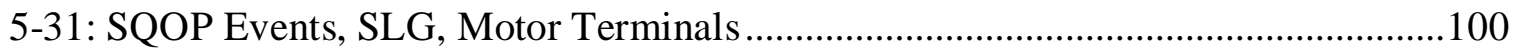

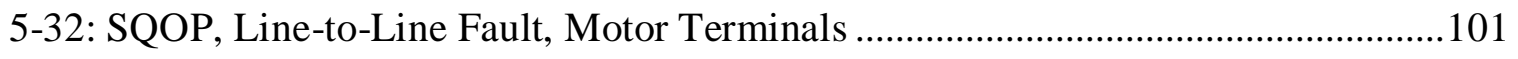

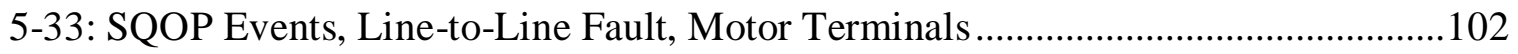

5-34: SQOP, Double Line-to-Ground, Motor Terminals ............................................. 103 
5-35: SQOP Events, Double Line-to-Ground, Motor Terminals 103

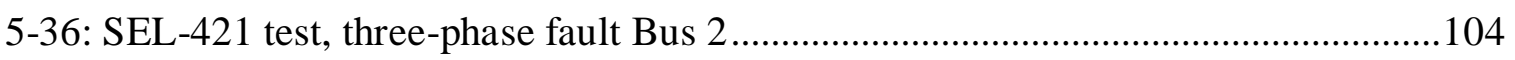

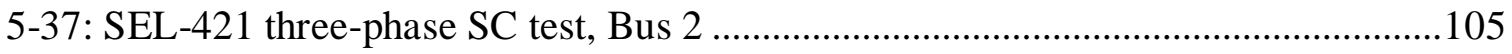

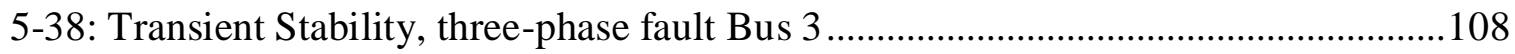

5-39: Rotor angle response, $\mathrm{H}=1 \mathrm{MW} \cdot \mathrm{s} / \mathrm{MVA}, 6$ cycle clear .......................................109

5-40: Rotor angle response, $\mathrm{H}=0.1 \mathrm{MW} \cdot \mathrm{s} / \mathrm{MVA}, 6$ cycle clear.....................................110

5-41: Rotor angle response, $\mathrm{H}=0.1 \mathrm{MW} \cdot \mathrm{s} / \mathrm{MVA}, 3$ cycle clear .....................................111

5-42: Generator terminal current response, $\mathrm{H}=0.1 \mathrm{MW} \cdot \mathrm{s} / \mathrm{MVA}, 3$ cycle clear .............112

5-43: Generator speed response, $\mathrm{H}=0.1 \mathrm{MW} \cdot \mathrm{s} / \mathrm{MVA}, 3$ cycle clear ............................113

5-44: Generator speed, islanded and no load shed ........................................................115

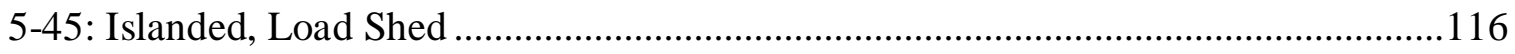

5-46: Bus 3 frequency, islanding load shed..............................................................117

5-47: Generator speed, islanded and load shed …………….............................................118

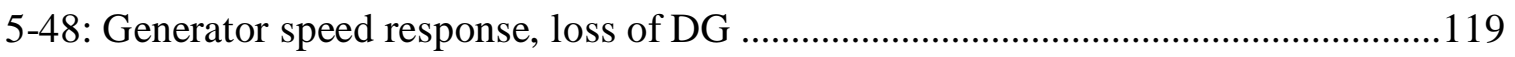

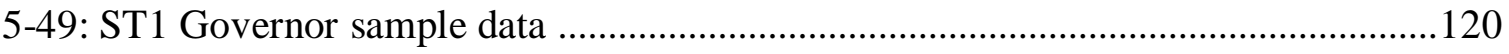

5-50: Generator speed response, governor control ………………………………......122

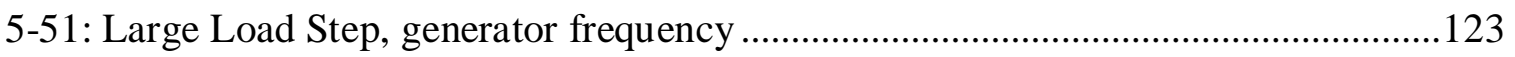

A1: Radial System [11] ................................................................................................132

A2: CO-8 time-delay overcurrent relay characteristics [11] ............................................134

A3: Max 3 phase fault for breaker CB3, Bus2 …………...............................................135

A4: Sequence-of-Operation for Figure A3 …………………………………………...136

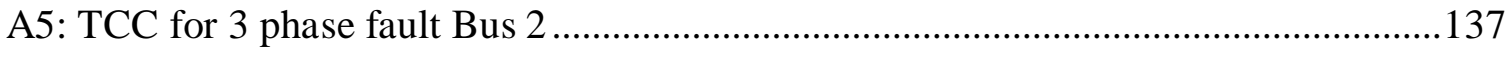

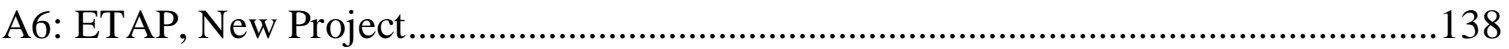


A7: ETAP, Placing AC Bus, one-line

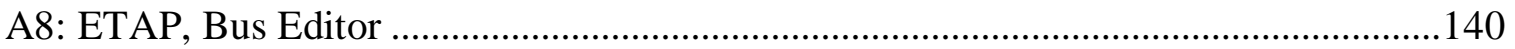

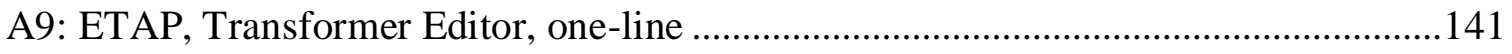

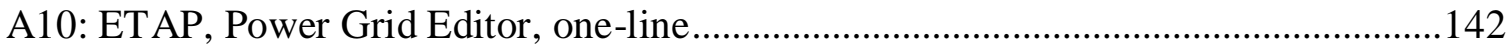

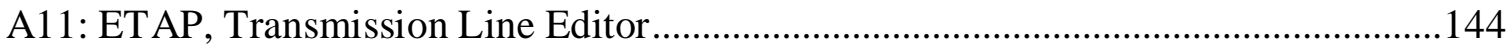

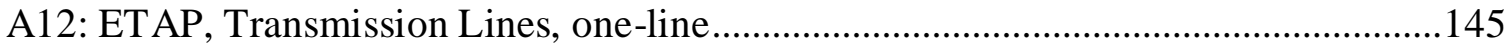

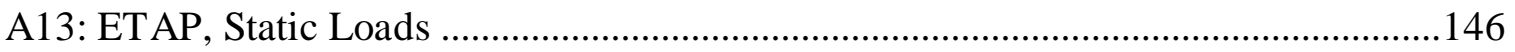

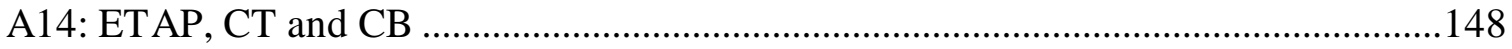

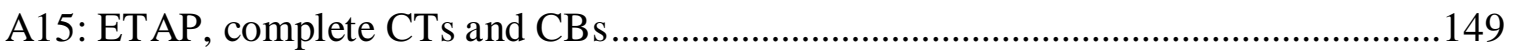

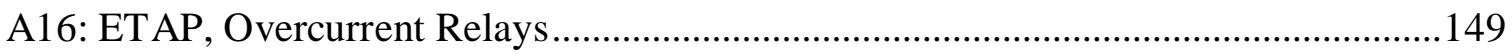

A17: ET AP, Current Transformer settings ..................................................................151

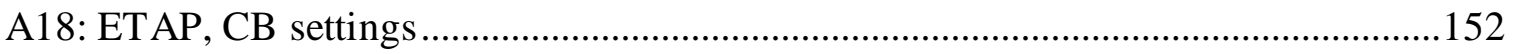

A19: ETAP, Relay OCR settings …………………………………………………......154

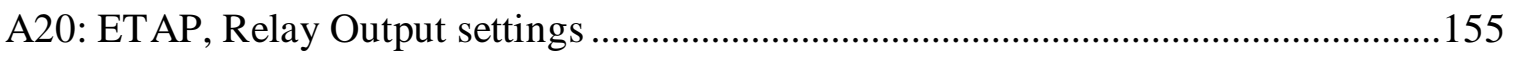

A21: ET AP, Star mode ………………………………………………………………157

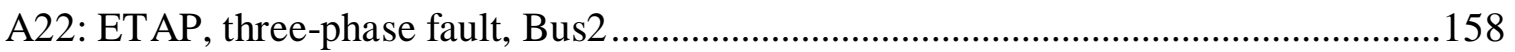

A23: ET AP, Sequence-of-Operation Events, 3 phase fault................................................160

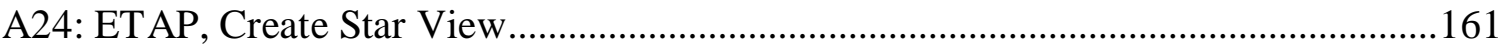

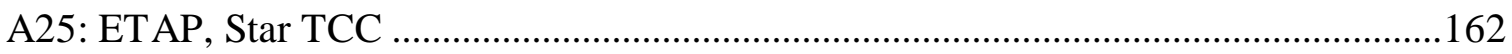




\section{Chapter 1: Introduction}

Microgrids - miniature, scaled down versions of our electrical grid are becoming increasingly more popular as greater energy independence and extreme weather conditions drive communities to adopt them. Conventionally, electrical power is delivered by utilities from large power generating stations far away from end users, transmitted across long distances, and ultimately distributed to meet the customers' electrical needs. Advancements in technologies, decreased costs, and renewable energy mandates are shifting the power industry away from this centralized generation model. Instead, utilities are observing their customers not only as energy consumers but also actively producing electrical power. The modern microgrid has capabilities of generating, distributing, and regulating electrical power locally, utilizing distributed energy resources (DERs) situated close to end users, including smaller power sources such as photovoltaics (solar) and battery energy storage systems to meet the electrical demands of the customer.

The microgrid has capabilities of operating in both grid-connected and islanded modes - that is, connected or disconnected from the larger electrical grid, respectively. From the customer perspective, this presents several advantages — for example, if a power outage were to occur on the main grid due to natural disasters or electrical faults, the microgrid can island from the grid and continue its generation and distribution of local power. Additionally, if the microgrid requires additional generation to meet the demands of the customer, the microgrid can reconnect with the main grid to help supplement the customers' energy needs. 
From the utility perspective, transitioning the microgrid from grid-connected to islanded conditions presents both advantages and disadvantages. A 2014 survey of over 250 utility executives concluded “...utilities said they find current interconnection standards inadequate for safety purposes, with $54 \%$ of utilities surveyed finding that to be the case" [1]. As microgrids continue to rise in popularity, it is imperative to study and implement reliable and robust protection schemes as microgrids transition between gridconnected and islanded conditions. Nonetheless, reference [2] claims “microgrids deployment of controllable resources, such as dispatchable generation units, energy storage, and adjustable loads, provides a quick and efficient response for changing the microgrid generation/load, which can be utilized for supporting the grid operation." Maintaining the balance between power supply and load has become problematic for utilities in recent years. Microgrids can be implemented to help control and supplement the supply-load balance by offering storage and generation services to the main grid.

Figure 1-1 shows a net load graph by California ISO (CAISO), displaying the net load in 2013 and forecasted future net loads [3]. The net load curves indicating years 2014-2020 can be interpreted as the net power needed to be supplied to California's customers from all sources of electrical power other than from renewables. The lowest points on the curve (the belly of the "duck") represents a point in which renewable generation is at a maximum. Data indicates that risks of overgeneration and necessary ramping power is increasing in future years largely due to growing solar photovoltaic proliferation onto the grid. Currently, grid operators need to closely monitor these curves and curtail or dispatch electrical power as needed. Microgrids can be utilized to help "flatten" this duck curve to maintain the supply-load balance and retain grid reliability in 
several ways. For example, when renewable penetration is at a maximum leading to risks of overgeneration, the microgrid can store excess energy with a battery energy storage system. As the sun begins to set after $4 \mathrm{pm}$ and aggregate solar penetration to the main grid begins to decrease, microgrids can help supply the necessary ramping power needed to meet the electrical demand of California's customers.

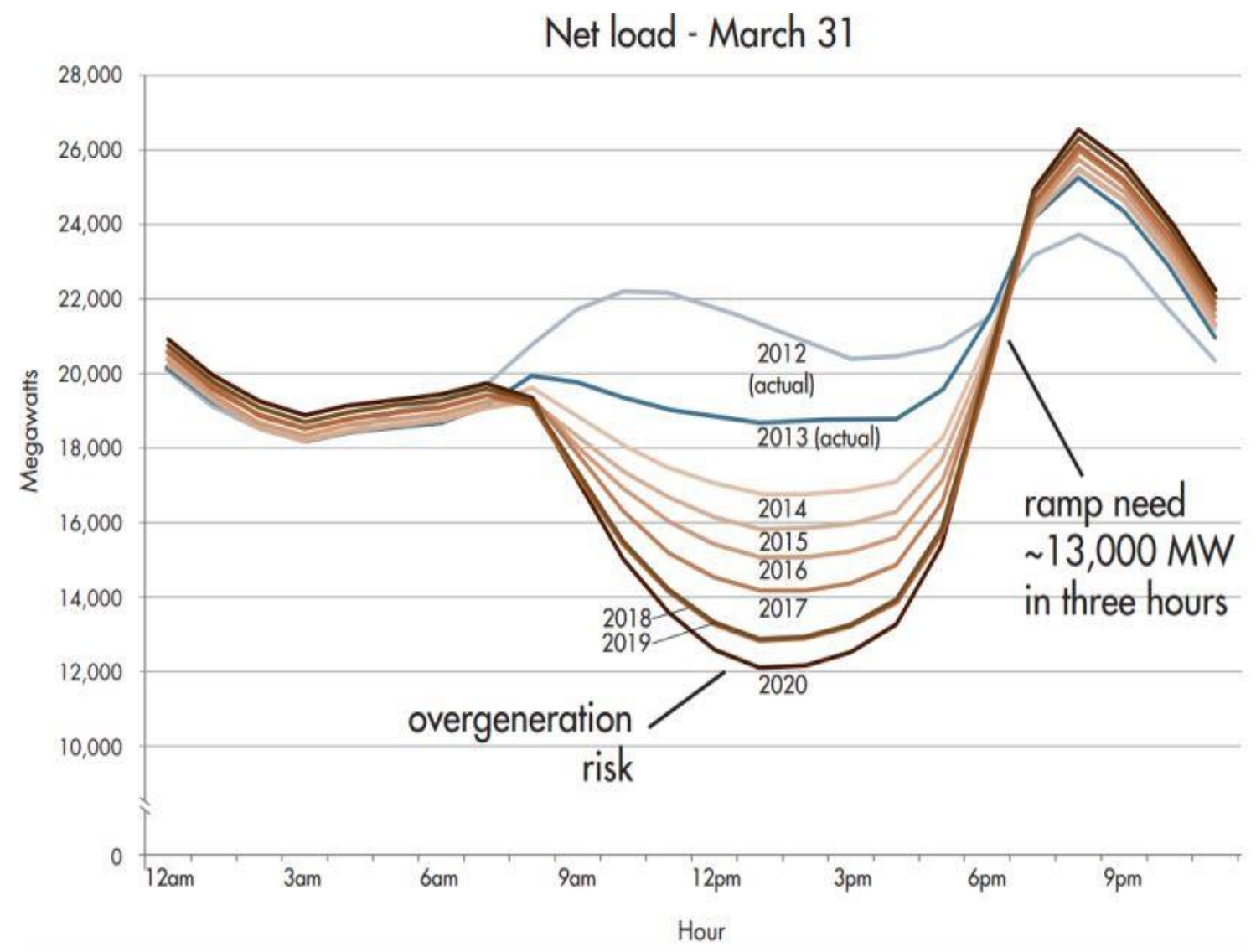

Figure 1-1: The CAISO duck chart, 2013

Figure 1-2 showcases the opportunities ahead for utilities, based on a survey of over 250 utility executives in 2014 [1]. A staggering 97\% of utility executives believe 
microgrids are a viable business opportunity within the next 10 years, with a majority of utilities already developing or planning to operate microgrids within the same timeframe.

Q When will microgrids become a viable business opportunity for utilities?

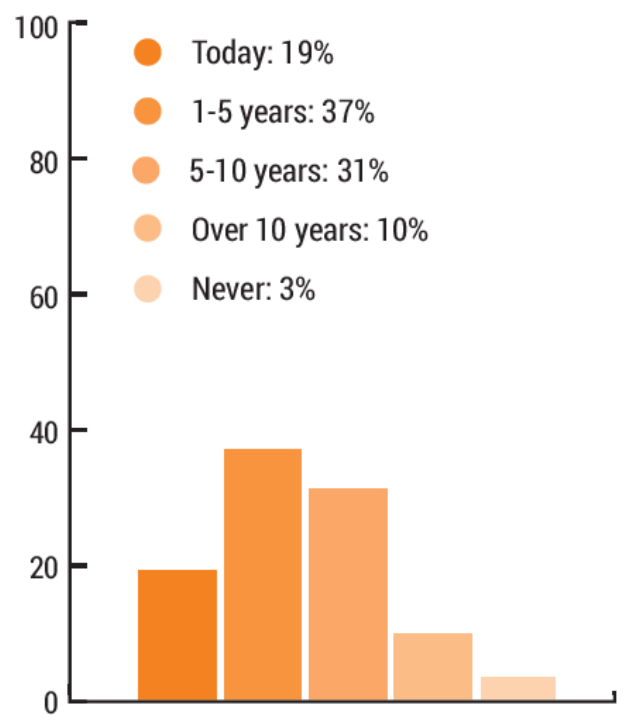

When does your utility plan to develop, own, and/or operate any microgrids?

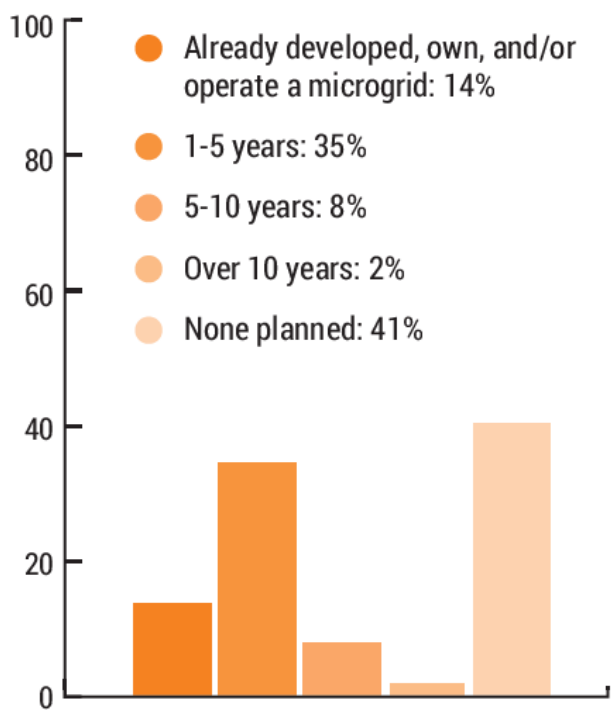

Figure 1-2: The Opportunities Ahead: Utilities

Microgrids are an inevitable reality_critical loads such as hospitals, data centers, and military bases can benefit greatly from increased reliability of electric power in both grid-connected and islanded conditions. Microgrids can also support grid operation by storing and dispatching electrical energy as necessary. It is then imperative for future power system engineers to expand their knowledge on fundamental power system components such as generators, transformers, and protective relaying to account for emerging technologies onto the grid. 


\section{Chapter 2: Microgrid Modeling and Stability Analysis}

\subsection{General overview}

Future trends of developing microgrids and their integration with the utility grid necessitate adequate tools for modeling and analysis purposes. In response for "facing a rapidly-changing power industry, the electrical engineering department at Cal Poly San Luis Obispo proposed Advanced Power Systems Initiatives to better prepare its students for entering the power industry" [4]. As such, this thesis heavily builds upon the work of [4], which developed the foundation of a microgrid laboratory at Cal Poly. To ultimately implement a microgrid capable of islanding capabilities, it is imperative to first develop an adequate model of the microgrid and perform a system stability analysis.

\subsection{Microgrid Modeling}

Figure 2-1 displays the single-line diagram of the bidirectional network designed and implemented in a laboratory environment by previous Cal Poly students per reference [4], which is to be utilized as the basis for the microgrid. The network represents two different radial power systems coupled together at bus 3. In this configuration multiple sources of power supply the loads at bus 3 , which include the induction motor and static loads. The power is supplied by three-phase AC voltages, modeled as infinite buses in Figure 2-1, ultimately supplied by the utility. Common power system components including power transformers and transmission lines (modeled with an inductor) are implemented, as well as resistors to limit the total current flowing in the system. 


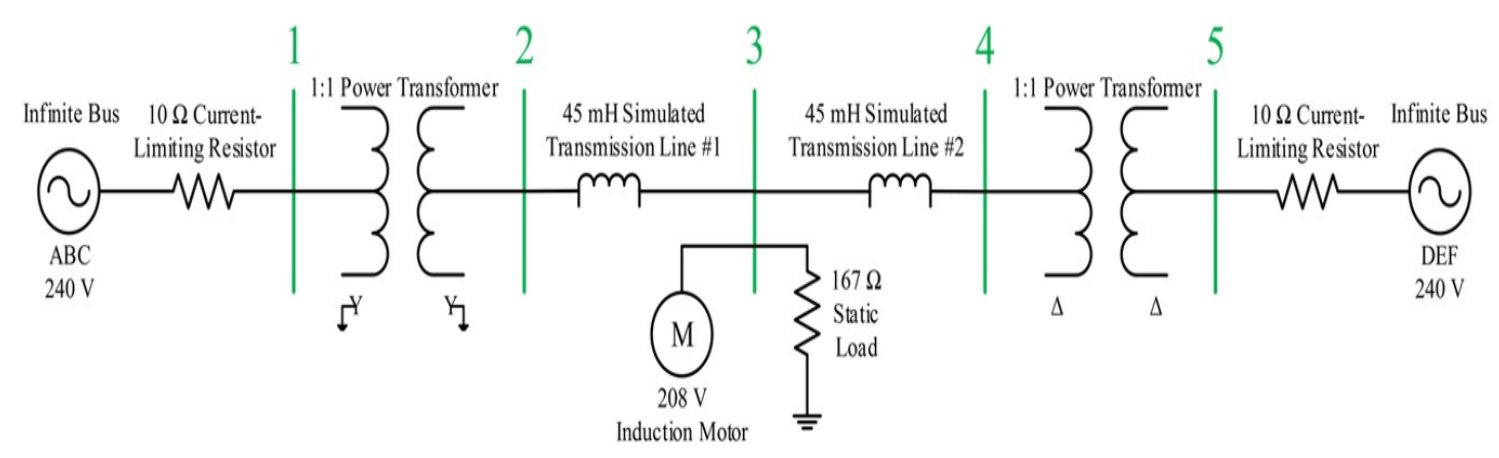

Figure 2-1: Bidirectional Network Single-Line Diagram [4]

Figure 2-2 displays the protective elements within the bidirectional network as it exists per reference [4], completed in May 2017. Schweitzer Engineering Laboratories (SEL) microprocessor based protective relays shown in blue are constantly measuring power system parameters such as voltages and currents, ultimately sending trip signals to nearby circuit breakers to protect nearby components in the event of a disturbance such as a fault. The SEL relays are programmed to trip circuit breakers on parameters such as the type of fault (e.g. single line-to-ground, line-to-line), equipment and zone of protection (e.g. transformer, transmission line), and protection coordination between relays (e.g. speed and backup coordination if one relay fails to operate). 


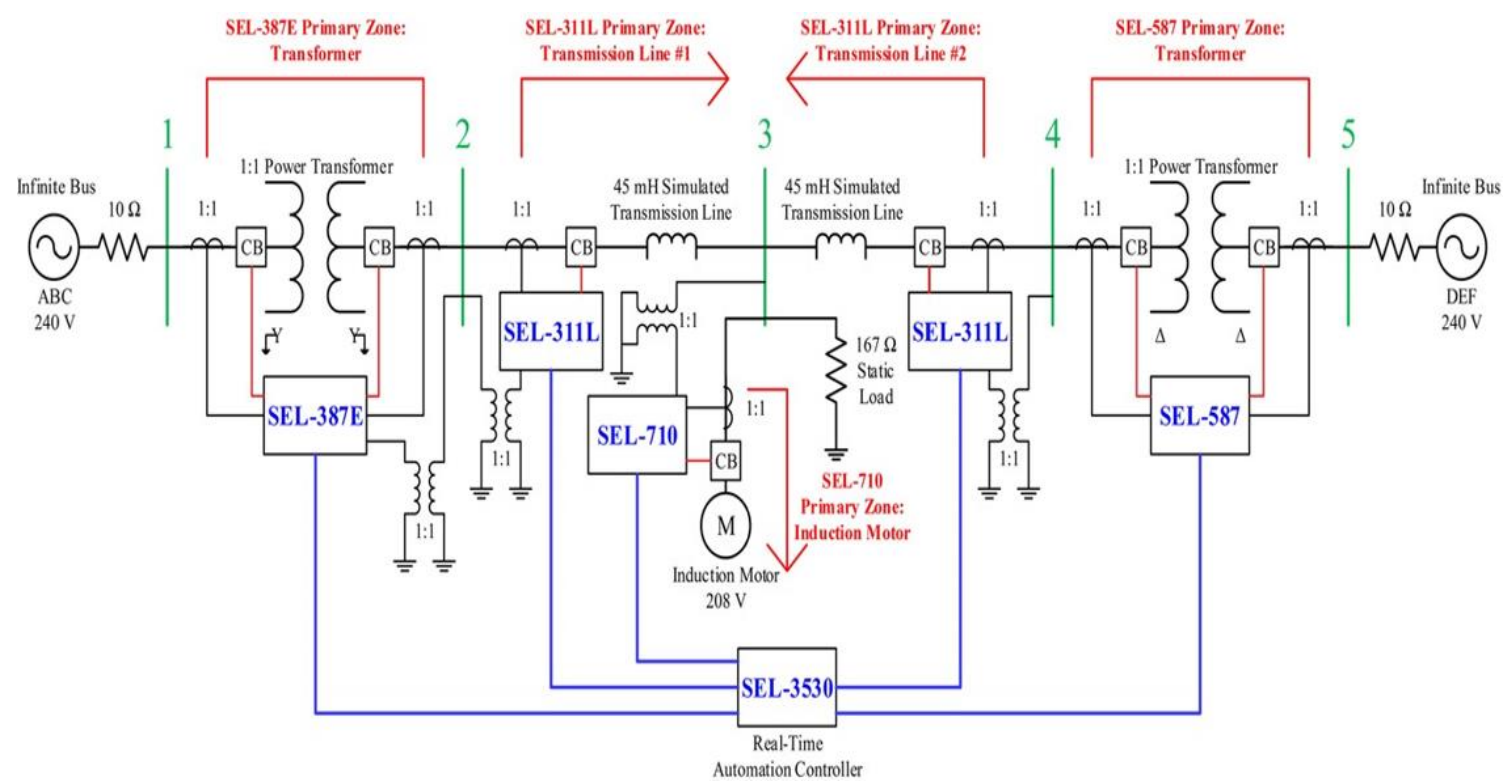

Figure 2-2: Bidirectional Network Single-Line Protection Diagram [4]

As discussed in Chapter 1, the modern microgrid typically has distributed energy resources (DERs) close to its proximity such as synchronous generators supplying power to the loads. As such, the bidirectional network in Figure 2-2 is currently being modified to replace one of the infinite buses with a synchronous generator instead. For example, the power supplied by infinite bus DEF connected to utility will instead be supplied by two synchronous generators along with its own protection scheme consisting of circuit breakers and relays. Additionally, the inclusion of the synchronous generator will ultimately provide the microgrid with islanded operation from the grid.

The future microgrid will additionally include other DERs such as photovoltaics and battery storage systems. As the microgrid expands in complexity with added equipment and functionality, it is necessary to develop an adequate model of the system. ETAP is a power system modeling, analysis, and optimization software available to Cal Poly faculty and students. Cal Poly's license of ETAP enables its users with several tools 
to accurately model power systems that will ultimately benefit the microgrid project moving forwards. For example, ETAP network analysis tools available to Cal Poly include standard load flow, short circuit, motor acceleration, and harmonic analysis. Protection and coordination tools include ETAP "STAR" modules to coordinate timecurrent curves associated with microgrid protective elements. Transient stability tools enable modeling of system dynamics and transients by simulating power system disturbances.

ETAP is sufficiently capable to meet all of Cal Poly's microgrid current modeling and simulation needs. As the microgrid begins to implement its DERs beginning with additional synchronous generators in Figure 2-2, synchronous generator protection and coordination can be adequately modeled in ETAP. Future additional DERs appended to Cal Poly's microgrid including photovoltaics and battery storage systems can be sufficiently modeled and analyzed in ETAP, laying the foundation for future senior projects and theses. It is ultimately the goal of this thesis to first develop, model, and analyze Cal Poly's microgrid complete with its protective elements shown in Figure 2-2. A system analysis will be performed including load flows, short circuits, and protection coordination studies. The latter portion of this thesis will then use ETAP's model of Cal Poly’s microgrid to perform a system stability analysis. 


\subsection{Power System Stability}

The bidirectional network in Figure 2-2 for use as the basis for the microgrid assumed two states — steady or faulted. Power systems are largely imbalanced in nature and consistently undergoing small scale disturbances. Reference [5] defines power system stability as "...the ability of an electric power system, for a given initial operating condition, to regain a state of operating equilibrium after being subjected to a physical disturbance, with most system variables bounded so that practically the entire system remains intact." Power system stability can then be observed as a single problem with many different classifications of instability that can result from various disturbances, with their forms generalized in Figure 2-3 from reference [5]. Rotor angle, frequency, and voltage stabilities will be briefly discussed, leading to a discussion of stability issues in the context of microgrids.

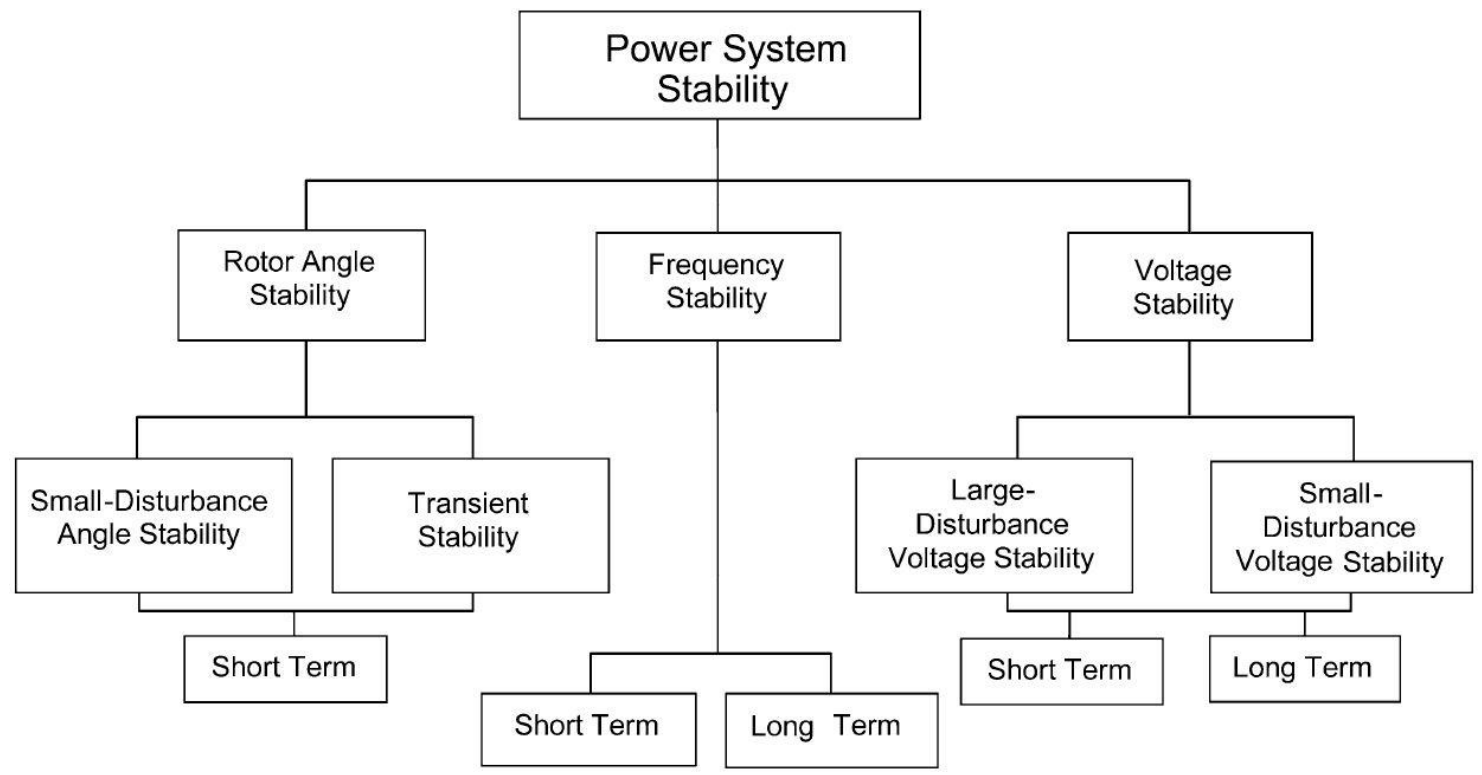

Figure 2-3: Classification of power system stability 
Rotor angle stability is concerned with synchronous machinery to retain synchronism after perturbed by a disturbance. That is, stability in synchronous machinery is largely concerned with a constant balancing of opposing electromagnetic and mechanical forces. In steady-state conditions synchronous generators are assumed to be operating at constant rotor angular speeds and electrical frequencies. However, the equilibrium between input mechanical and output electromagnetic torques are compromised as the generators experience a disturbance, with a deceleration or acceleration of machines in response. For example, an electrical fault occurring near the terminals of one generator can produce a large electromagnetic force, resulting in a momentary imbalance with the mechanical torque of its rotor, moving the machine into a transient state. As these machines begin to transfer power and attempt to reach a new equilibrium point with a different rotor angular position with respect to another machine, instability can result if synchronism cannot be achieved.

Voltage stability is largely concerned with variations in supply-load power equilibrium in a system and maintaining stable bus voltages following a disturbance. Reference [5] suggests "a major factor contributing to voltage instability is the voltage drop that occurs when active and reactive power flow through inductive reactance of the transmission network; this limits the capability of the transmission network for power transfer and voltage support.” Following a disturbance, loads can drive the system into instability by stressing power beyond equipment limitations and further varying bus voltages until supply can no longer meet the electrical demands of the loads.

Frequency stability is concerned with maintaining a steady system frequency following a disturbance in the system. Reference [5] claims "generally, frequency 
stability problems are associated with inadequacies in equipment responses, poor coordination of control and protection equipment, or insufficient generation reserve," with instability resulting in frequency swings leading to loss of loads or generating units. Ultimately, there is crossover between various forms of instability that can arise in a power system, with disturbances such as the clearing of a fault with a protective relay transitioning a power system into a transient state with varying system parameters. That is, power flow, bus voltages, and machine rotor speeds can all vary following the disturbance, with voltage and frequency variations as a result as system stability is compromised.

\subsection{Microgrid Transient Stability Analysis}

Stability in a microgrid shares similarities with classical power system stability classifications shown in Figure 2-3, with additional issues such as disturbances resulting from islanding. Reference [6] suggests "with micro sources with current limit, very little

spinning reserve and limited reactive support, it is essential to carry out detailed transient analysis with possible contingencies," with Figure 2-4 showcasing microgrid stability issues. Unlike microgrids with limited resources, the bulk power system typically has excess generating capacity, or operating reserves, to meet real and reactive demands to maintain stability. 


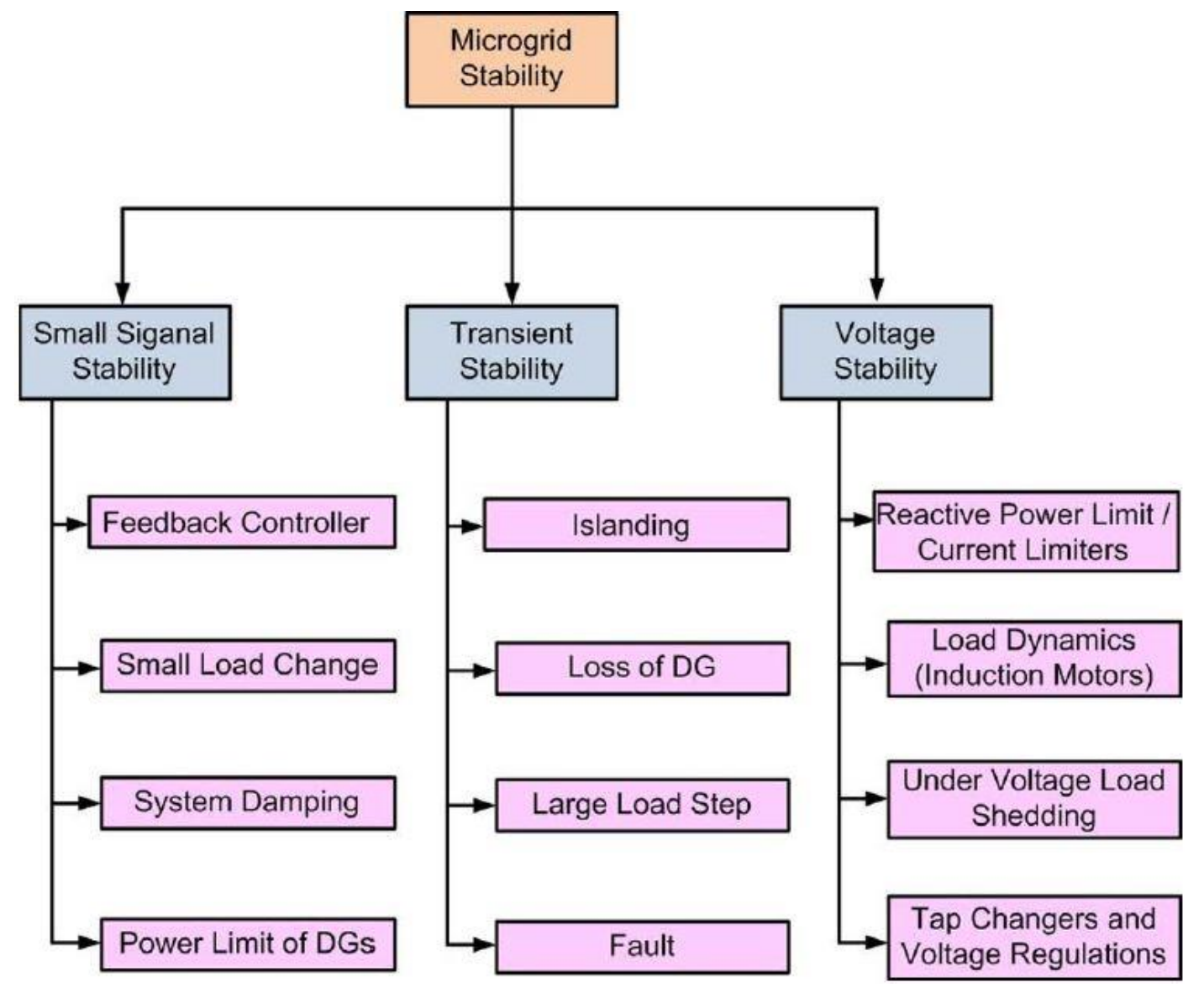

Figure 2-4: Different stability issues in microgrids

Discussed in Chapter 1, the modern microgrid has capabilities of operating in grid-connected or islanded mode, sending the system into a transient state when switching between the two. As the microgrid is islanded from the larger grid, it is typical that total generation is less than total load, with a reduction in frequency as a response. Load shedding, or disconnecting some loads from the system to reduce demand, can be implemented in an attempt to restore system frequency to a nominal value.

Loss of distributed generation (DG) will similarly send the microgrid into a transient state, with a power mismatch between generation and demand. For example, loss of DG may constitute the loss of one synchronous generator (out of many) powering 
a microgrid, or the disconnection of a PV array as a generating unit. Load shedding will again be required to maintain stability unless battery or storage devices are available to supply the necessary power.

Lastly, electrical faults of all kinds will send the system into a transient state. An ideal three-phase balanced power system will quickly transition into an unbalanced state following a fault. For example, the opening of a line by a protective relay following a fault will transition the system into a transient state with variations in load flow, bus voltages, machine speeds, and frequency fluctuations. It is imperative to perform a detailed system stability analysis to ultimately implement adequate islanding capabilities for Cal Poly's microgrid. As discussed in section 2.2, this thesis will first develop a complete model of Cal Poly's microgrid in ETAP with load flows, short circuits, and protection coordination studies, eventually implementing and modeling future distributed energy resources such as photovoltaics and battery storage systems. The latter portion of this thesis will then use the model of Cal Poly's microgrid in ETAP to ultimately perform a system stability analysis, largely focused on microgrid transient stability issues discussed and generalized in Figure 2-4. 


\section{Chapter 3: Design Requirements}

\subsection{System overview}

This chapter proposes the framework in which the thesis objectives outlined in Chapter 2 are to be achieved. The following decompositions characterizes the two main thesis objectives - modeling the Cal Poly microgrid and performing a transient stability analysis through ETAP software. Level zero decompositions establish the system-level characteristics, followed by a summarization of parameters and specifications.

\subsection{Functional Decomposition-ETAP Model}

Figure 3-1 shows a level zero block diagram for the first phase of this thesis, developing the ETAP model of the Cal Poly microgrid.

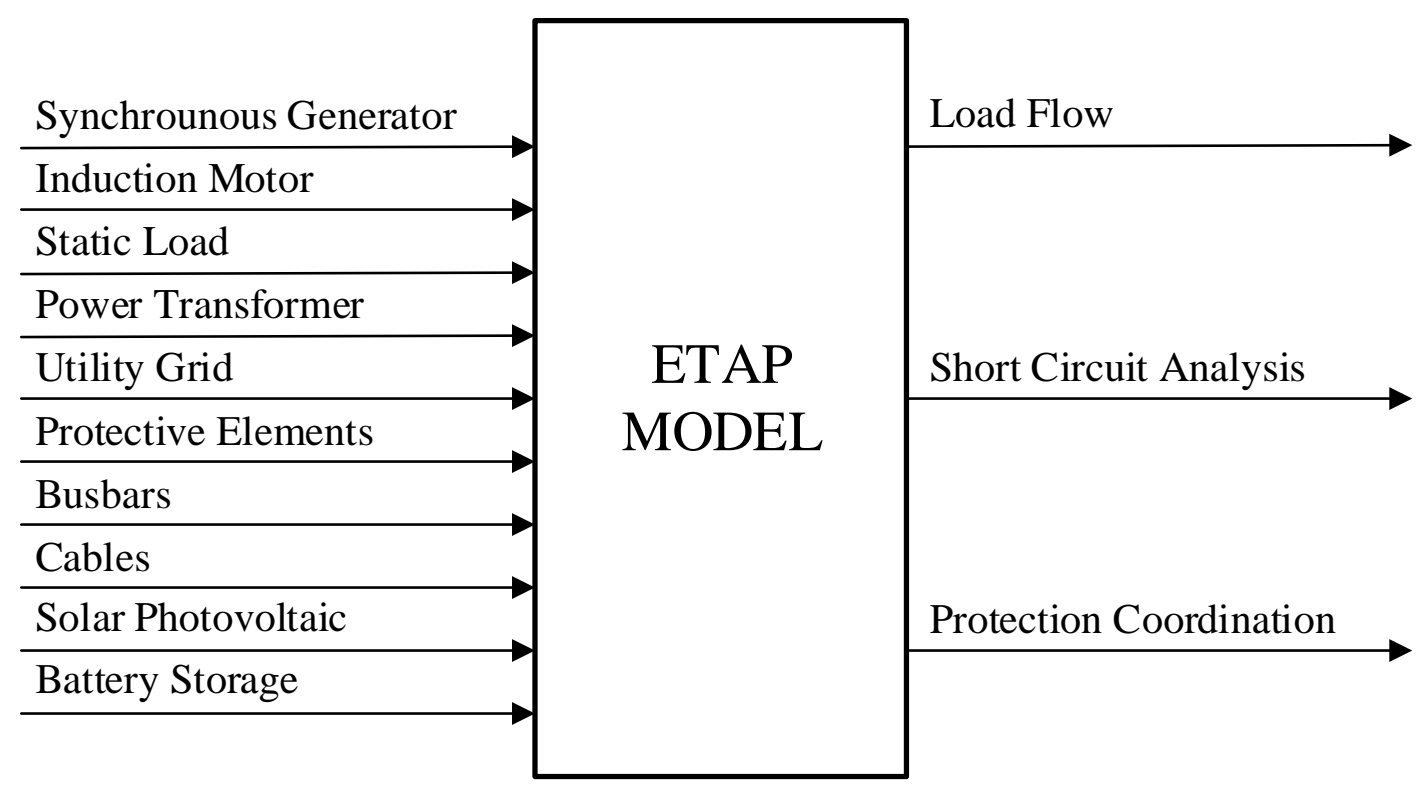

Figure 3-1: ETAP Model Block Diagram, Level 0 
Inputs to the ETAP model block diagram include the entirety of the existing Cal Poly microgrid including the synchronous generators, induction motor, static loads, power transformers, utility grid, protective elements (e.g. circuit breakers, relays), busbars, and cables. Input devices that are currently not implemented in the existing microgrid include solar photovoltaics and battery storage systems. However, these modules will ultimately be modeled in ETAP to explore and analyze the functionality of the microgrid as the project develops.

Outputs to the ETAP model block diagram in Figure 3-1 include load flow, short circuit analysis, and protection coordination. ETAP Load Flow Analysis module will be utilized to determine bus voltages, power factors, currents, and power flows throughout the Cal Poly microgrid system. Capable of integrating and modeling swing, voltage regulated, and voltage unregulated power supplies with several power grids and generator connections, load flow studies of the microgrid can be sufficiently conducted through ETAP software. To determine bus voltages, angles, and power flows, ET AP Load Flow allows several different load flow calculation methods including Newton-Raphson, FastDecoupled, and Gauss-Siedel. To perform the load flow study, each method contains different load flow converging characteristics, allowing flexibility to meet the microgrid system parameters including generation, loading conditions, and initial bus voltages. A complete analysis of load flow methods and simulations for the microgrid will be described and analyzed in future chapters of this thesis.

The ETAP Short Circuit analysis program will be utilized to analyze the fault currents for three-phase, line-to-ground, line-to-line, and line-to-line-ground faults in the microgrid. ETAP is able to calculate the total short circuit current contribution from 
microgrid elements including the synchronous generators, induction motor, and utility connections. ETAP includes both American National Standards Institute/Institute of Electrical and Electronics Engineers (ANSI/IEEE) and International Electrotechnical Commission (IEC) standards to perform its short circuit calculation methods. A complete analysis of short circuit methods and its simulations for the microgrid will be described and analyzed in future chapters.

The microgrid will utilize ETAP Star, the protection and coordination (selectivity) module within ETAP. ETAP Star is equipped with a comprehensive protective device library, able to accurately model protective elements (e.g. SEL relays) to perform equipment protection and device coordination studies. ETAP Star Time Current Characteristic (TCC) views will be generated to display device characteristic curves. ETAP Star is also capable of determining operating times of protective devices by simulating faults on the one-line diagram. A complete analysis of protection and device coordination methods and its simulations for the microgrid will be described and analyzed in future chapters.

\subsection{Functional Decomposition-Transient Analysis}

Figure 3-2 shows a level zero block diagram for the second phase of this thesis, performing a transient stability analysis of the Cal Poly microgrid through ETAP software. 


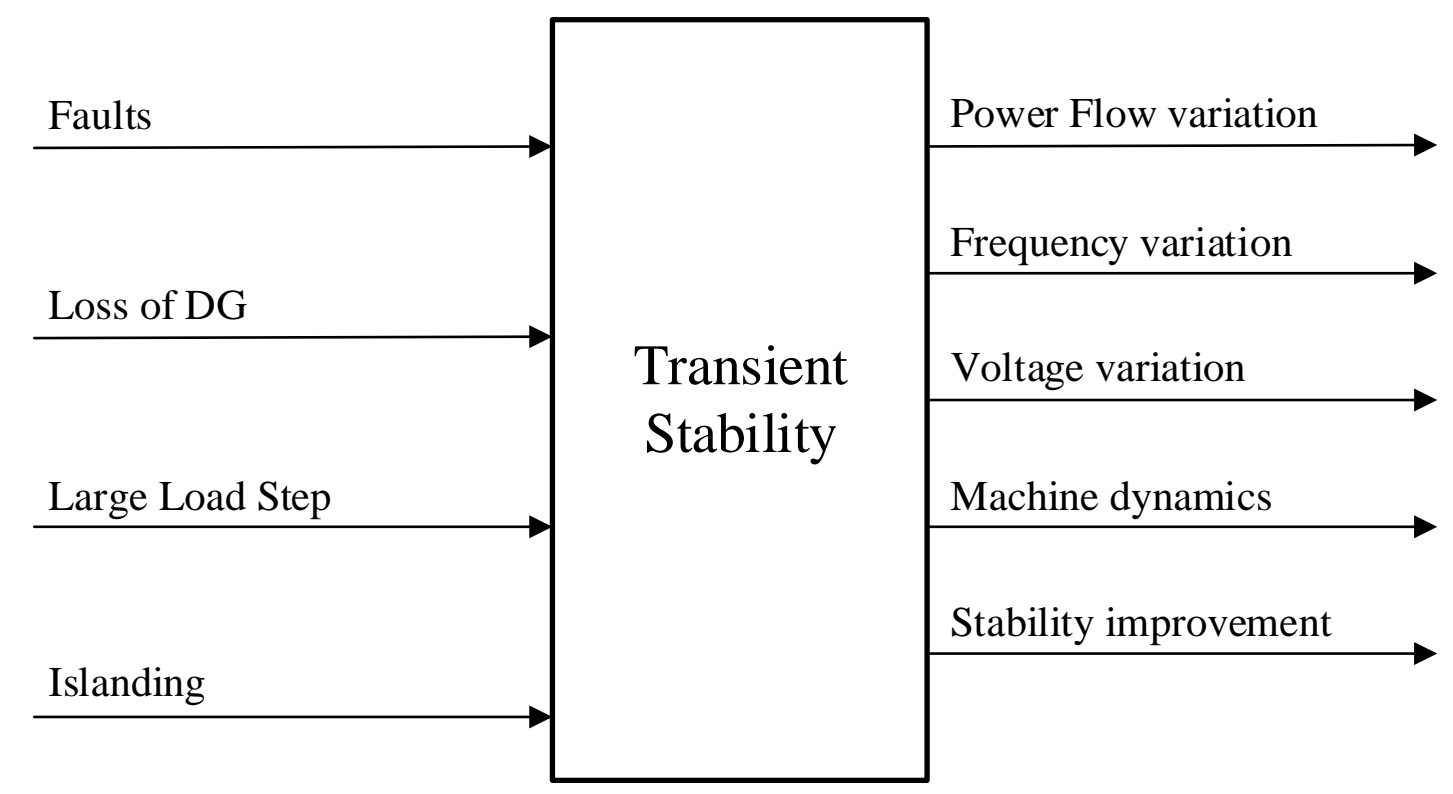

Figure 3-2: Transient Stability Block Diagram, Level 0

The ETAP Transient Stability module will be utilized to investigate the microgrid system dynamic responses and stability limits of the power system before, during, and after system disturbances, characterized as the inputs in Figure 3-2. ET AP Transient Stability will be utilized to investigate system responses including determining machine power angles and speed variations, system electrical frequencies and voltages, real and reactive power flows, determining critical fault clearing times, and testing relay settings. Synchronous machinery will play a crucial role in power system stability as their power (rotor) angles will oscillate and result in power flow oscillations in the microgrid following a disturbance. In order to retain system stability, methods of improving microgrid transient stability will be investigated, generalized from reference [6] in Figure 3-3. Control of battery storage, load shedding methods, protective device settings, and control of power electronics can all be simulated within ETAP software. It is the goal of 
the second phase of this thesis to analyze stability issues within the Cal Poly microgrid and investigate methods of improving transient stability.

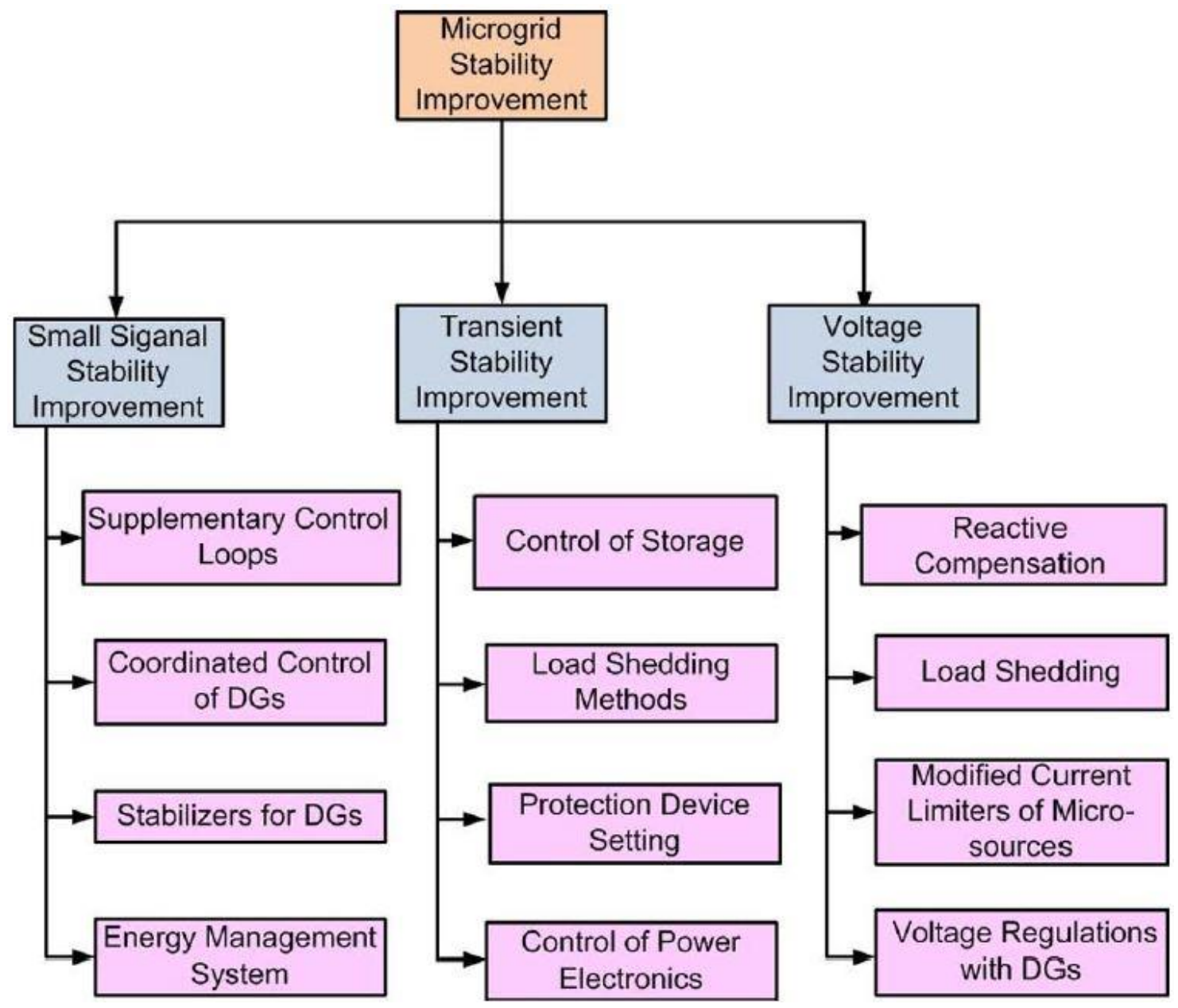

Figure 3-3: Microgrid Stability Improvement 


\section{Chapter 4: Design}

\subsection{Chapter overview}

This chapter develops the framework for the ETAP model of the Cal Poly microgrid accomplishing the goals set out and decomposed in Chapter 3. We begin with the development of the ETAP model with justifications and assumptions needed for system components and their parameters. An overview with examples and modeling of load flow, short circuit, protective device coordination, and transient stability studies in ETAP is developed and outlined in this chapter. The ETAP examples conducted throughout this chapter are not of the Cal Poly microgrid, and instead are performed to provide the reader a background to introductory case studies for power system studies (e.g. protection coordination, transient stability). Simulations, results, and a nalyses for case studies specific to the Cal Poly microgrid will be presented in Chapter 5.

\subsection{ETAP Model}

This section serves to provide preliminary information for all the system components used in the ETAP model, and the parameters that are relevant in the scope of this thesis (e.g. performing load flow, transient stability studies). Device parameters that must be modified for certain case studies will be noted throughout simulations in Chapter

5. Figure 4-1 showcases the one-line diagram created in ETAP modeling the current iteration of the Cal Poly microgrid as of winter quarter of 2018. 


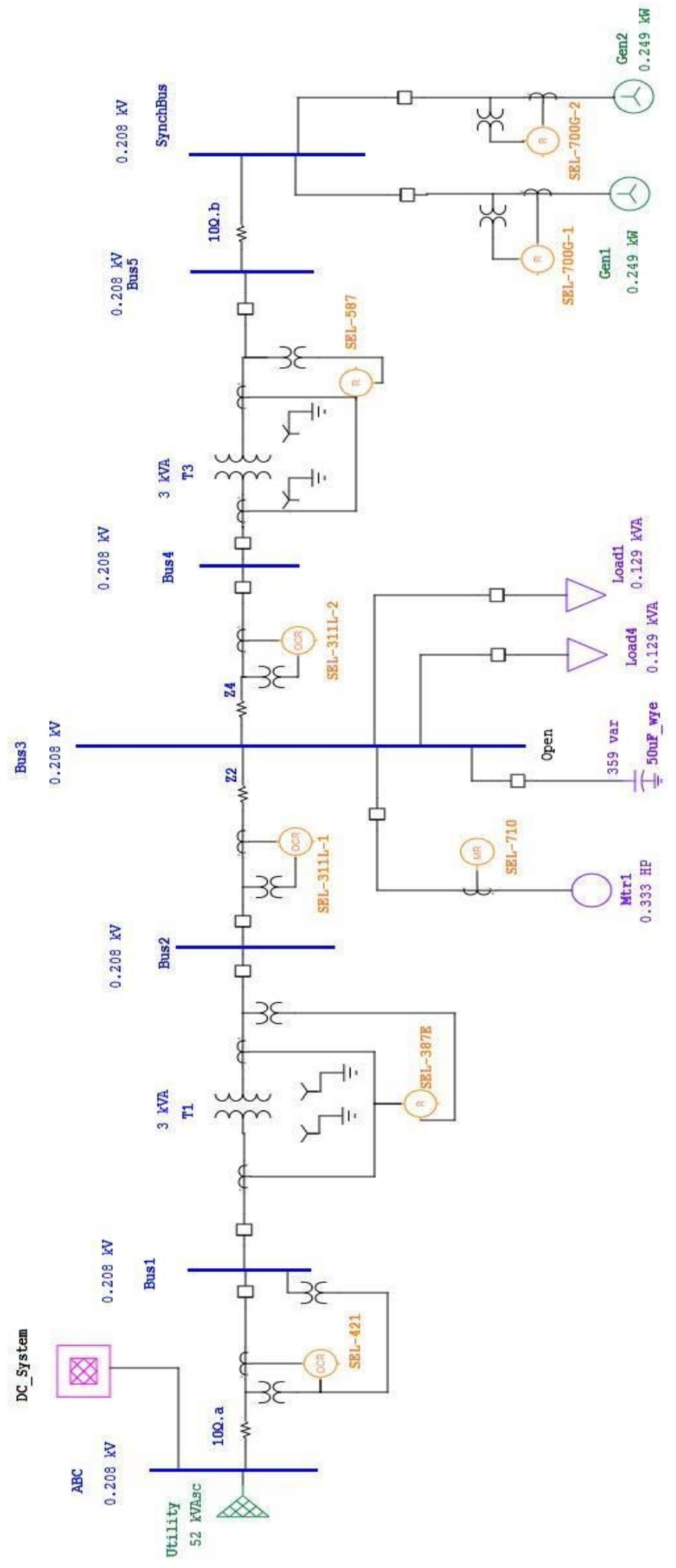

Figure 4-1: ETAP One-Line view 
The ETAP Cal Poly microgrid elements in Figure 4-1 include the power grid, impedances, circuit breakers, power transformers, three-phase induction motor, static loads, circuit breakers, current transformers (CTs), potential transformers (PTs/VTs), and protective relays. Power system elements not shown in Figure 4-1 include future additions such as solar photovoltaics, inverters, and energy storage modules. Generating units are shown in green, electrical loads in purple, and protective relays in orange.

The Power Grid element in ETAP models the utility interconnection with the microgrid. The Cal Poly microgrid utilizes 208V and 240V three-phase AC voltages, modeled as the utility supply voltage throughout this thesis. As such, the Power Grid is rated for $208 \mathrm{~V}$ operating in swing mode. In ETAP load flow studies, an element in swing (slack) mode operation is used to balance power flow (active and reactive), with a voltage magnitude and angle at the terminals remaining at set operating values. The Power Grid in ETAP is modeled with its Thevenin's equivalent, a constant voltage source behind a short-circuit impedance. The Short Circuit page in the Power Grid editor provides information necessary to model the utility grid as a source for studies including Short Circuit and Transient Stability, to be discussed in latter portions of this chapter. Relevant data include line voltage, short-circuit MVA, three phase fault currents, and X/R ratios.

The Impedance elements in ETAP are utilized to model $10 \Omega$ resistors and $45 \mathrm{mH}$ inductors existing in the Cal Poly microgrid. The resistors in the microgrid are utilized for current-limiting purposes for safely testing power system faults. The inductors are utilized to model transmission lines of a power system. Although there exists a detailed Transmission Line and Reactor elements in ETAP, it is unnecessary in the modeling of inductors utilized in the microgrid. 
The Power Transformer element in ETAP models two-winding three single-phase transformers in the Cal Poly microgrid with a 1:1 turns ratio rated at $3 \mathrm{KVA}, 240 \mathrm{~V}$, and z $=2.5 \%$. The transformers were included to more accurately model a complete power system and utilized for protective relaying experimentation by prior Cal Poly students. Two power transformers are modeled connected in wye-wye configurations.

The Induction Machine element in ETAP models the three-phase induction motor. The ETAP element models the Hampden IM-100, a one-third horsepower three-phase, four pole, and squirrel cage motor with a wound stator and a squirrel cage rotor, utilized for loading purposes. Induction motor power and impedance parameters will play a role into short circuit and stability simulations, to be discussed in latter portions of this chapter. Due to resistive losses in the system, voltages applied at the terminals of the induction motor will be less than 208Vac in a laboratory setting. Induction motor parameters will be largely based on laboratory tested ratings rather than nameplate ratings.

The Static Load element in ETAP models two Hampden RLC-100 resistive/reactance loads utilized in the microgrid. The loads are connected in parallel, providing resistive loading controlled by 6 toggle switches (12 total), each one inserting a $2000 \Omega$ resistor in parallel in each leg simultaneously (to a minimum of $167 \Omega$ ). That is, at maximum loading the two three-phase static loads consume a total of $\frac{2 * 3 *\left(120 V_{L N}\right)^{2}}{333 \Omega}=$ 259W at a nominal 208 Vac line-to-line. Due to resistive losses in the system, voltages applied to the static loads will be less than 208 Vac in a laboratory setting. Static load parameters will be largely based on laboratory tested ratings rather than nominal values. 
The Synchronous Generator element in ETAP models two Hampden SM-100-3, three-phase, four pole machines consisting of a wye/delta stator and quadrature rotor having a DC field winding and a damper winding. DC field excitation is controlled by an external variable resistor (rheostat) supplied by $125 \mathrm{~V} \mathrm{DC}$. The rotor of the synchronous generator is driven by a DC machine, Hampden DM-100 providing one-third horsepower at $1800 \mathrm{rpm}$. Synchronous generator modeling is crucial in short circuit and stability studies, and justifications will be provided in the following sections for modeling machine impedances. SEL microprocessor based relays will be utilized to obtain oscillograms of the generator current and voltage characteristics, in which short circuit characteristics can be extracted.

The Relay elements in ETAP models Schweitzer Engineering Laboratory (SEL) microprocessor based protective relays, heavily based on previous work per reference [4]. Models include SEL-387E, SEL-311L, SEL-710, SEL-587, SEL-700G, and SEL-421. A complete analysis of protective device coordination will be conducted in later sections and chapters, detailing zones of protection (e.g. transformer, induction motor), protection schemes utilized (e.g. differential, directional, time-delay overcurrent), and protection device settings. Current transformers (CTs) and potential transformers (VTs/PTs) shown in the ETAP model are utilized to feed SEL relays electrical quantities to determine the status of the microgrid. Due to low nominal and fault currents, the CTs and PTs are included in the one-line diagram to adhere with ETAP modeling standards, and do not exist in the hardware implementation. Therefore, the CTs and PTs throughout the ETAP model have a 1:1 turns ratio. More information can be found in Protection Device Coordination section in 4.5 for a background on protection fundamentals. 
Figure 4-2 showcases a subsystem of the ETAP model of what the future Cal Poly microgrid may consist of. There are currently no renewable energy resources or energy storage systems utilized in the microgrid. Small scale solar photovoltaic generation complete with an inverter to interconnect with the microgrid is a logical addition to the system. ETAP consists of in depth solar photovoltaic and inverter modeling tools to accurately represent Cal Poly's renewable integration with the microgrid. ETAP is also equipped with maximum power point (MPP) tracking control capabilities with its solar inverters to adjust operating points for solar panels to extract maximum power. The SEL751 in Figure 4-2 can provide additional protective capabilities to the system.

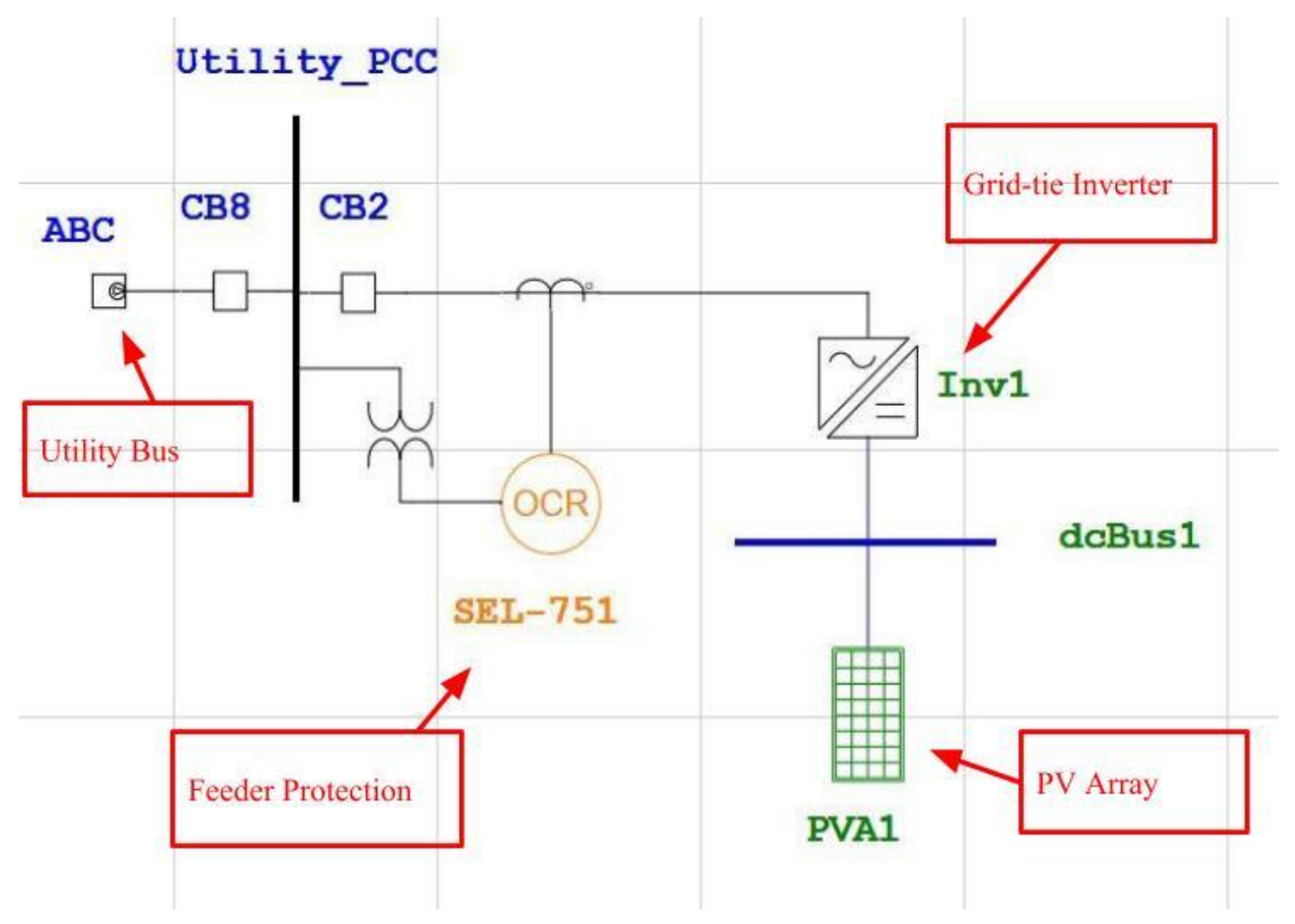

Figure 4-2: ETAP Microgrid PV Subsystem 
As an example, a PV module tentatively chosen for the Cal Poly microgrid modeling purposes is the SUNTECH STP210. Figure 4-3 displays the PV Array editor when double left clicking the PVA1 module in Figure 4-3. Under the PV Panel page, the $\mathrm{P}-\mathrm{V}$ curves display the power-voltage characteristics of a solar module for various levels of solar irradiance, a measure of energy in the form of sunlight. Similarly, the nonlinear IV curves describe the current-voltage characteristics of the solar cells for various levels of irradiance. ETAP has extensive libraries for various power system components, and the curves and parameters shown in Figure 4-3 are populated when selecting the STP210 module from the library. Alternatively, a user can generate these curves individually by creating an ETAP PV Array library file given known equivalent circuit parameters of a solar cell, providing users with tools to accurately model a PV system.

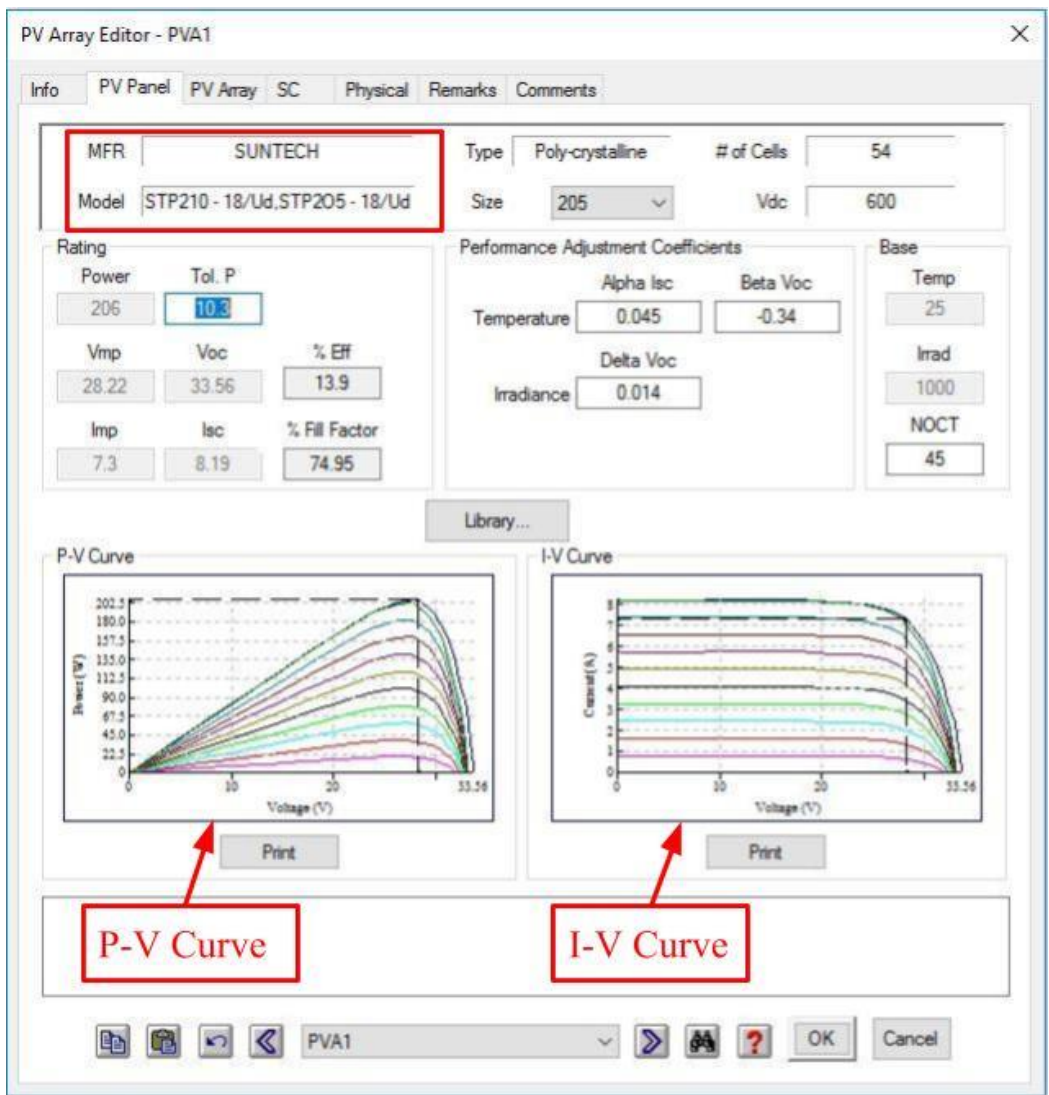




\section{Figure 4-3: PV Array Editor}

The ETAP Inverter will be utilized to convert the DC characteristics from the PV array into the three-phase AC system, modeling the grid-tie inverter. The Inverter Editor is a powerful tool that can control and modify several parameters including converter's efficiency, generation for AC Load Flow calculations, and harmonics of the device. Power quality considerations can be analyzed by harmonics analysis tools in ETAP, and Figure 4-4 displays the Harmonic tab of the grid-tied inverter. Similar to the PV Array Editor in Figure 4-4, the harmonics of a specific device can be chosen from a list of libraries in ETAP or entered given device characteristics. It is the objective that these tools will be useful for the future Cal Poly microgrid students for the investigation of power quality considerations in the system, and the utilization of SEL relays in conjunction with performing proper courses of action. 


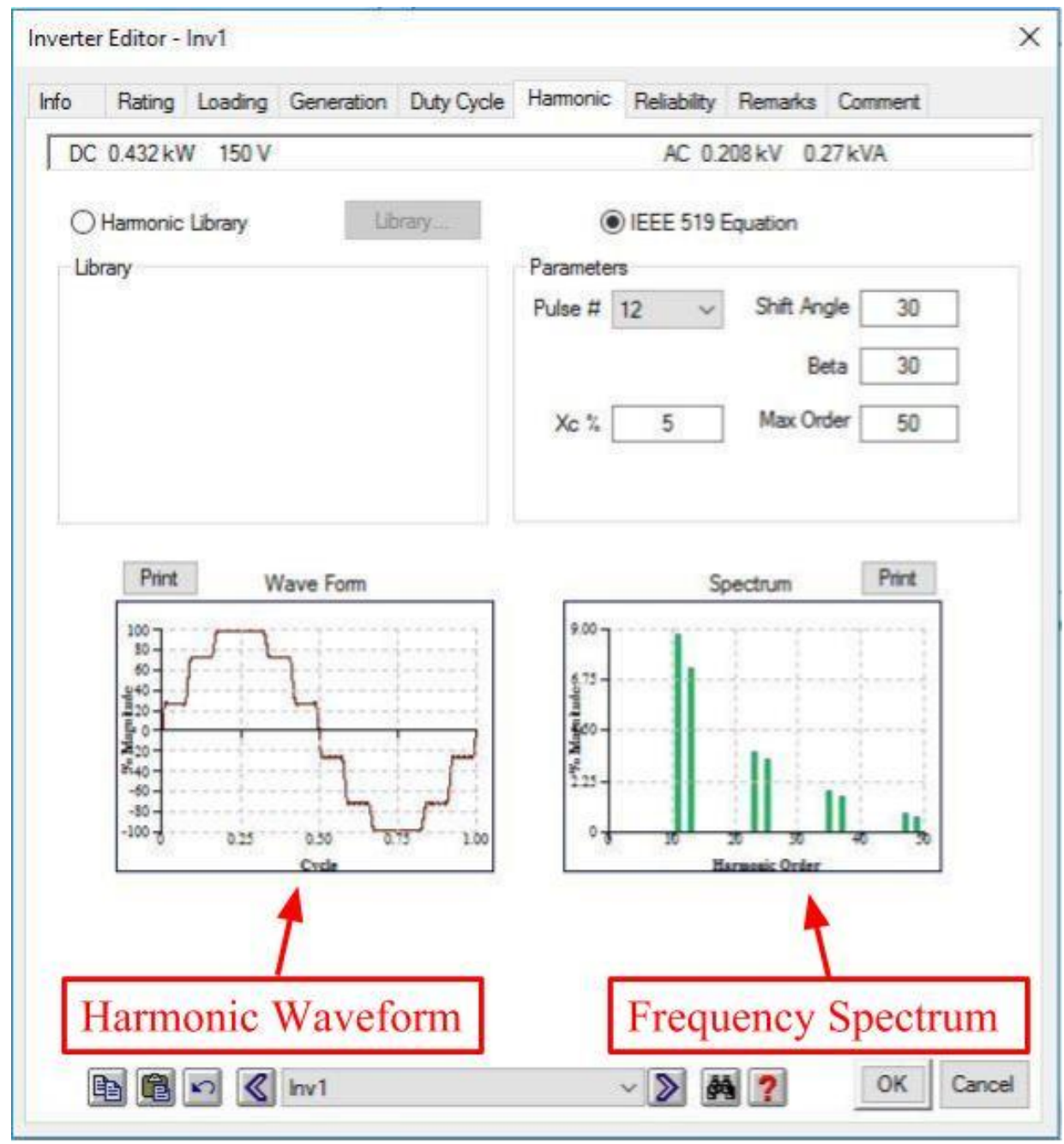

Figure 4-4: Inverter Editor

Additionally, energy storage systems can be appended as additional generation and loading systems. Additional SEL relays can be utilized with solar integration to provide a more dynamic element to the system. That is, SEL relays can continually sense electrical quantities including voltages, currents, and frequencies from a PV subsystem to determine if curtailment or generation of renewable energy is necessary. This can further lead to stability improvement methods, with control of power electronics providing many advantages to the microgrid. Latter chapter will discuss the feasibility and simulations of 
power electronics improvement of microgrid transient stability. Possible load flows, short circuit, and transient stability studies of future microgrids will be conducted following the analysis of the current iteration of the microgrid.

\subsection{Load Flow Modeling}

The main purpose of a load flow is to determine the balanced three-phase steady state operation of the Cal Poly microgrid. Specifically, the solution to the load flow problem will provide us with bus voltages and angles, as well as real and reactive power flow. The load flow study will be performed in ET AP to meet the microgrid requirements of generation adequately supplying the demand (load) and losses, bus voltages close to nominal values, generation operating within active and reactive power limits, and transmission line (inductor) and transformers not overloaded [11]. Equipment operating values against manufacturer's specified maximum capability ratings will be compared when available.

The load flow study will consider several different operation scenarios such as maximum loading, minimum loading, normal loading, grid-connected, and islanded conditions. As an example, consider Figure 4-5 which displays the ET AP Study Case editor for Load Flow Analysis Mode which will be heavily utilized for other modeling simulations as well (short-circuit, transient, protection coordination). 


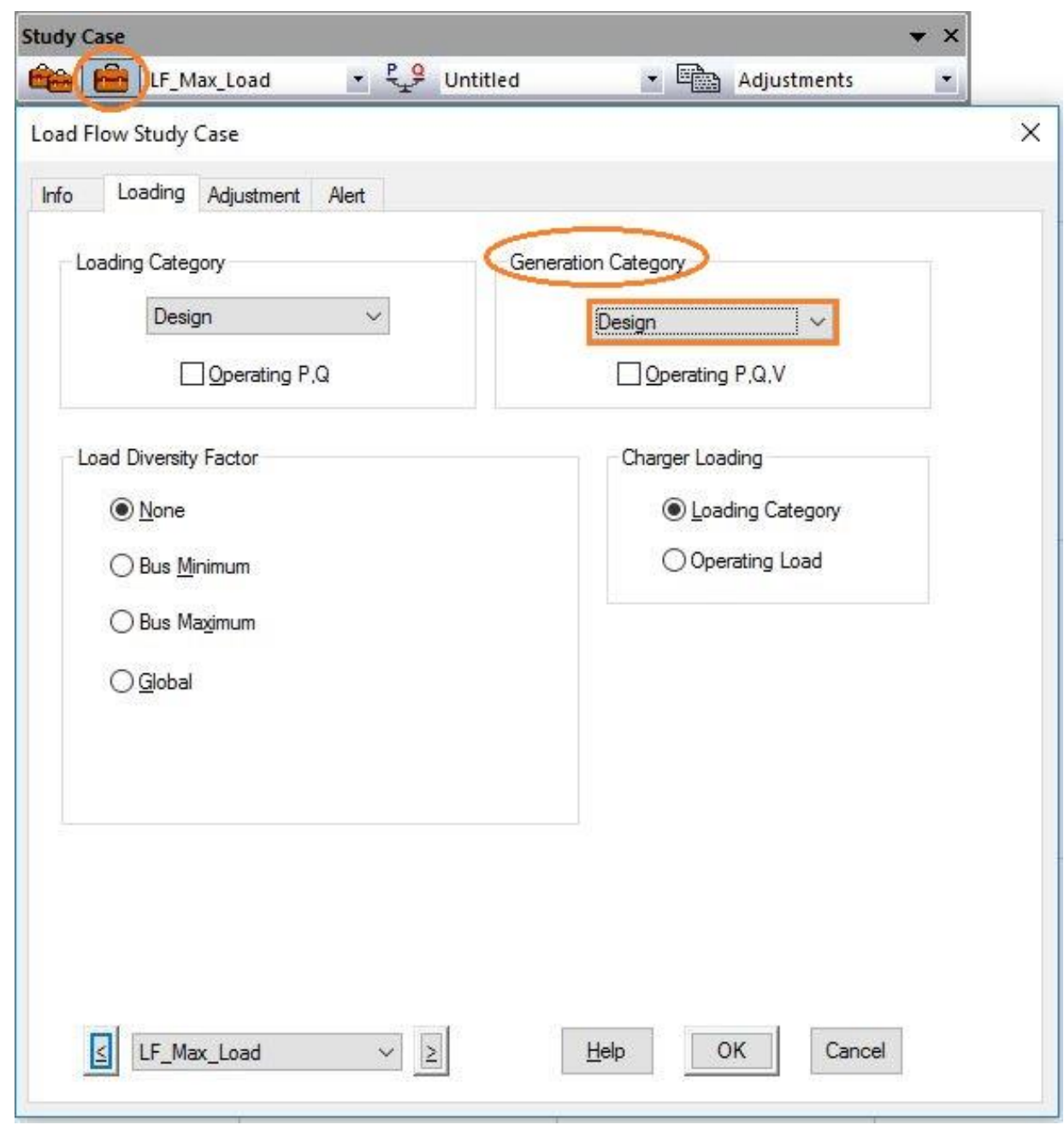

Figure 4-5: Load Flow Study Case Editor

The Loading tab of the Load Flow Study Case editor shows Generation Category operating under Design. This forces the Load Flow study to consider all generating units in ETAP to operate under their Design operating conditions. For example, if we double left click a synchronous generator in the ETAP one-line, we open the Synchronous Generator Editor whose Design category is set to operate at $0.2 \mathrm{~kW}$ and $0.05 \mathrm{kvar}$, illustrated in Figure 4-6. The Synchronous Generator is set to operate under Mvar Control instead of Swing Control in the Info page (not shown), to set fixed active and reactive 
power output of the machines. This will be useful as we can perform accurate case studies for generators outputting specific active and reactive power. Additionally, this is also due to the inherent limitations of the microgrid in which we do not implement generator exciter and governor control, to be further explained in the Transient Stability section. The interested reader can refer to section 4.5.2 for an ETAP example of a load flow leading to protective device coordination.

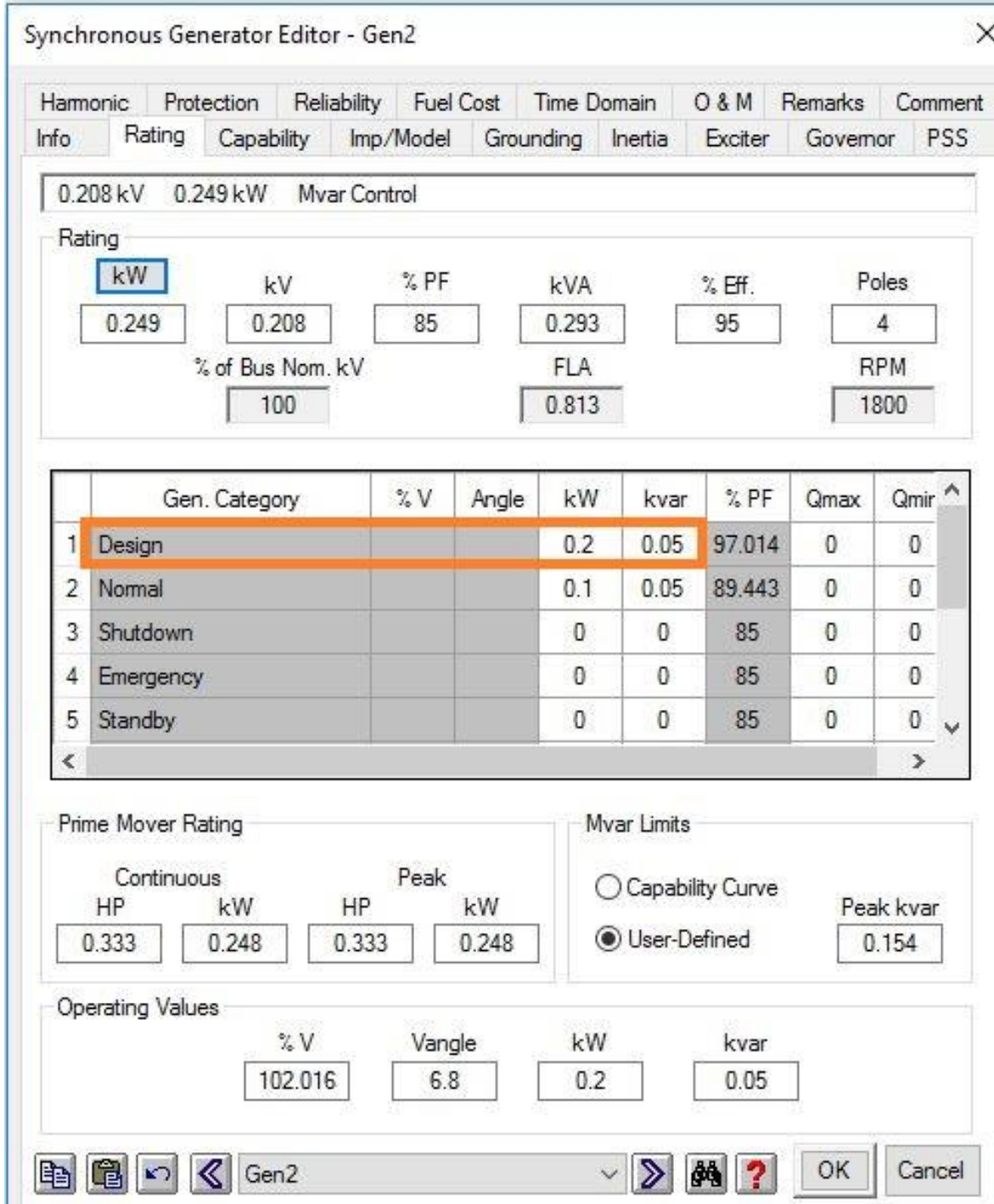

Figure 4-6: Synchronous Generator Editor 
The above procedure will be detailed in depth throughout various Load Flow case studies in Chapter 5, with different loading and generating conditions. Additional load flows will be also conducted on the consideration of future iterations of the microgrid lab including devices such as photovoltaics, inverters, and battery storage. Finally, computer generated analysis reports will be provided to summarize a comparison of power flow results from different operating considerations.

\subsection{Short Circuit Analysis Modeling}

The main purpose of a short circuit study in the context of the Cal Poly microgrid lab is to ultimately determine appropriate ratings and settings for protective relay coordination by analyzing the effect of different faults injected in the system. Short circuit studies enable verification of protective device interrupting capabilities (e.g. circuit breakers), as well as protect equipment from large electromagnetic and mechanical forces due to high fault currents. However, fault currents in the Cal Poly microgrid are deliberately minimized due to safety considerations, and as a result of utilizing smaller rated equipment (e.g. 1/3 ${ }^{\text {rd }}$ horsepower motors and generators). ETAP elements that contribute to a short-circuit fault current include synchronous machines, induction machines, and the power (utility) grid. Additional modifications to the microgrid including inverters and batteries will also contribute to short-circuit currents. 


\subsubsection{Short Circuit Analysis Overview}

Section 4.4.1 serves to provide preliminary information on the fundamentals of short circuit analysis for the interested reader. Additionally, section 4.4.1 can be used as a reference for ETAP simulations in Chapter 5. We begin the overview of short-circuit analysis with an overview of symmetrical components. The method of symmetrical components is of fundamental importance to analyze and simplify an unbalanced power system during the event of a fault (short-circuit) or disturbance, allowing us to convert a three-phase unbalanced system into a set of balanced phasors that we term symmetrical or sequence components. Consider Figure 4-7 which summarizes the resolving of unbalanced voltage phasors into a set of balanced sequence components [8]. The $\alpha$ operator is a complex number whose magnitude is 1 with a phase angle of $120^{\circ}$, and $\alpha^{2}$ has magnitude 1 with phase angle of $240^{\circ} . \mathrm{V}_{0}, \mathrm{~V}_{1}, \mathrm{~V}_{2}$ are the zero, positive, and negative sequence components respectively, which can be further decomposed to individual balanced sequence components (e.g. $\mathrm{V}_{2}$ negative sequence phasor can be decomposed to $\mathrm{V}_{\mathrm{a} 2}, \mathrm{~V}_{\mathrm{b} 2}, \mathrm{~V}_{\mathrm{c} 2}$ ). 


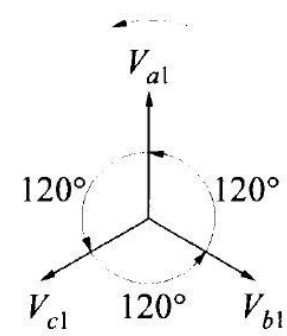

(a) Positive-sequence components

$$
\begin{aligned}
& V_{b \mathrm{1}}=a^{2} V_{a 1} \\
& V_{c 1}=a V_{a \mathrm{1}}
\end{aligned}
$$

(denoted by subscript 1)

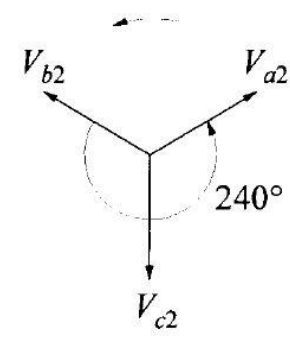

(b) Negative-sequence components

$V_{b 2}=a V_{a 2}$

$V_{c 2}=a^{2} V_{a 2}$

(denoted by subscript 2)

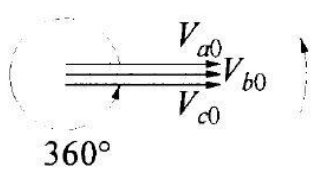

(c) Zero-sequence components

$V_{b 0}=V_{a 0}$ $=V_{c 0}$ (denoted by subscript 0)

Figure 4-7: Symmetrical Components of three balanced phasors [8]

Notice that if we definite matrix operator $\mathrm{A}$ and its inverse $\mathrm{A}$ as

$$
\boldsymbol{A}=\left[\begin{array}{ccc}
1 & 1 & 1 \\
1 & \alpha^{2} & \alpha \\
1 & \alpha & \alpha^{2}
\end{array}\right], \boldsymbol{A}^{-1}=\frac{1}{3}\left[\begin{array}{ccc}
1 & 1 & 1 \\
1 & \alpha & \alpha^{2} \\
1 & \alpha^{2} & \alpha
\end{array}\right]
$$

then one can transform phase values into sequence components and vice versa as shown in equation $4-2$.

$$
\left[\begin{array}{l}
V_{a} \\
V_{b} \\
V_{c}
\end{array}\right]=\boldsymbol{A} \cdot\left[\begin{array}{l}
V a 0 \\
V a 1 \\
V a 2
\end{array}\right],\left[\begin{array}{l}
V a 0 \\
V a 1 \\
V a 2
\end{array}\right]=\boldsymbol{A}^{\mathbf{- 1}} \cdot\left[\begin{array}{l}
V_{a} \\
V_{b} \\
V_{c}
\end{array}\right]
$$

Consider Figure 4-8 which illustrates the decomposition of an unbalanced system with unbalanced voltage phasors as a summation of balanced sequence components [12]. That is, phasor voltage $\mathrm{V}_{\mathrm{a}}$ is the vector or phasor summation of symmetrical components with positive-sequence phasor $\mathrm{V}_{\mathrm{a} 1}$, negative-sequence phasor $\mathrm{V}_{\mathrm{a} 2}$, and zero-sequence phasor $\mathrm{V}_{\mathrm{a} 0}$. Notice that all positive, negative, and zero sequence components are balanced, that is they are equal in magnitude indicated by the length of the vectors and 
offset by $120^{\circ}$ (e.g. positive-sequence components $\mathrm{V}_{\mathrm{a} 1}, \mathrm{~V}_{\mathrm{b} 1}, \mathrm{~V}_{\mathrm{c} 1}$ ). Zero sequence components by definition have no offset.

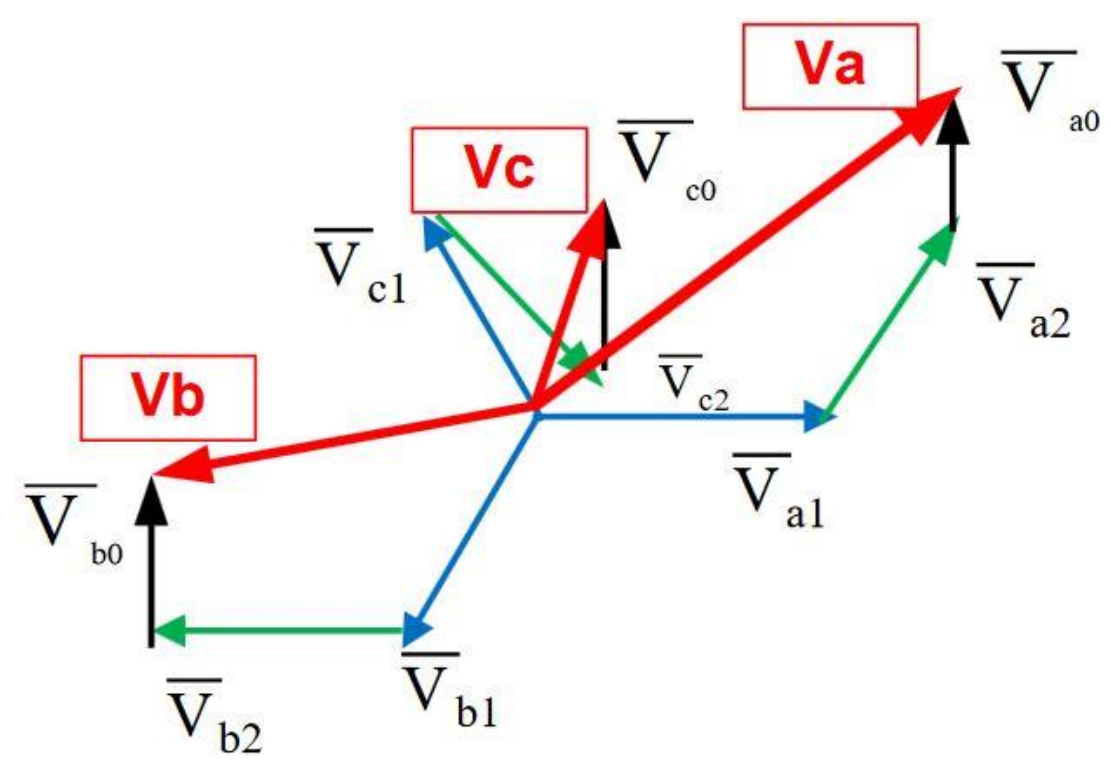

Figure 4-8: Unbalanced voltage phasors, symmetrical components [12]

Several different faults exist in a power system, including line-to-ground, line-toline, line-to-line-to-ground, and three-phase faults. Depending on the type of fault that has occurred, the power system can be decomposed into different sets of symmetrical components and sequence networks for adequate fault analysis. Unbalanced current phasors during the event of a short-circuit fault can also be decomposed into a set of balanced positive, negative, and zero sequence components similar to that of voltage phasors, which is instrumental in the analysis of fault currents. Symmetrical components are fundamental to understand an adequate protection as the protective relays utilized in the Cal Poly microgrid (SEL relays) perform the decomposition shown in Figure 4-8. 
For example, the SEL relays are continually sensing voltage and current phasors, decomposing unbalanced quantities into a set of balanced symmetrical components, and asserting relay trip commands to circuit breakers in the event of a fault. Coordination will be analyzed in detail in further sections - however, ETAP Short-Circuit analysis module will be heavily utilized in conjunction with ETAP Star (protection) module to analyze fault currents, their decompositions into symmetrical components, and adequately implementing protection that accurately models the hardware implementation for SEL relays. It will be imperative for the future Cal Poly microgrid team to understand the method of symmetrical components to adequately implement relay settings, and it is the objective that ETAP Short-Circuit module will help them accomplish this task as the microgrid increases with complexity with added fault contributions from distributed resources (e.g. solar panels, battery storage).

Let us first consider the R-L circuit shown in Figure 4-9, in which the closing of switch SW at time $t=0$ represents a Thevenin equivalent of a three-phase short circuit at the terminals of an unloaded synchronous machine. 

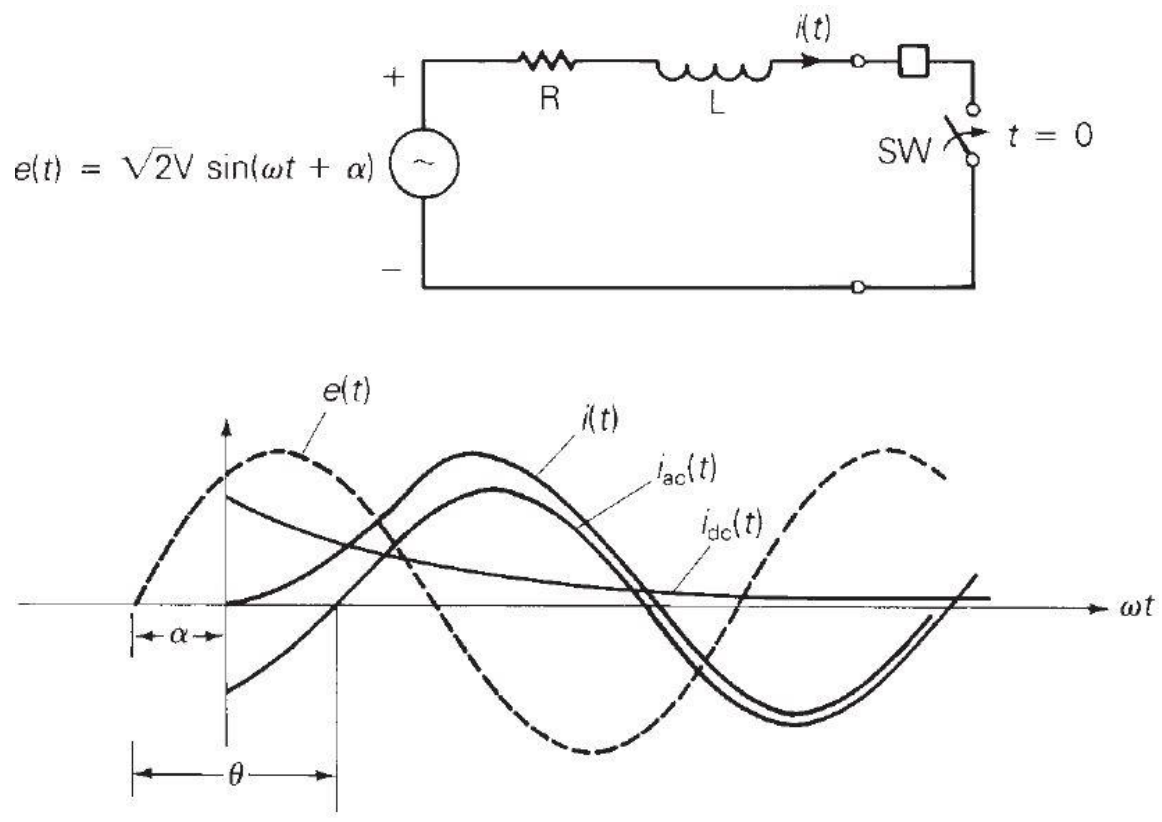

Figure 4-9: R-L circuit short-circuit response [11]

Writing KVL for the circuit in Figure 4-9 results in

$$
\frac{L d i(t)}{d t}+R i(t)=\sqrt{2} V \sin (\omega t+\alpha)
$$

whose solution can be decomposed into a summation of currents $i_{\mathrm{ac}}$ and $i_{\mathrm{dc}}$, summarized in Table 4-1 where time constant $\mathrm{T}=\mathrm{L} / \mathrm{R}=X /(2 \pi f R)$ seconds, angle $\theta=\tan ^{-1}(\mathrm{X} / \mathrm{R})$ degrees, $\mathrm{Z}=\sqrt{R^{2}+X^{2}} \Omega[11]$. 
Table 4-1: Short-circuit current, series R-L circuit [11]

\begin{tabular}{lcc}
\hline Component & $\begin{array}{c}\text { Instantaneous Current } \\
\text { (A) }\end{array}$ & $\begin{array}{c}\text { rms Current } \\
(\mathrm{A})\end{array}$ \\
\hline Symmetrical (ac) & $i_{\mathrm{ac}}(t)=\frac{\sqrt{2} \mathrm{~V}}{\mathrm{Z}} \sin (\omega t+\alpha-\theta)$ & $\mathrm{I}_{\mathrm{ac}}=\frac{\mathrm{V}}{\mathrm{Z}}$ \\
$\mathrm{dc}$ offset & $i_{\mathrm{dc}}(t)=\frac{-\sqrt{2} \mathrm{~V}}{\mathrm{Z}} \sin (\alpha-\theta) e^{-t / \mathrm{T}}$ & \\
Asymmetrical (total) & $i(t)=i_{\mathrm{ac}}(t)+i_{\mathrm{dc}}(t)$ & $\begin{array}{c}\mathrm{I}_{\mathrm{rms}}(t)=\sqrt{\mathrm{I}_{\mathrm{ac}}^{2}+i_{\mathrm{dc}}(t)^{2}} \\
\text { with maximum dc offset: } \\
\end{array}$ \\
& $\mathrm{I}_{\mathrm{rms}}(\tau)=\mathrm{K}(\tau) \mathrm{I}_{\mathrm{ac}}$ \\
\hline
\end{tabular}

Of importance in equipment sizing and relay coordination is the worst case rms asymmetrical fault current, which has a magnitude of $\sqrt{3} I_{\text {ac }}$ and decays to $I_{a c}$ as the dc component of the fault current exponentially decays. It is important to note that this dc offset current is dependent on the time in which the short circuit is initiated, and it is incorrect to assume this dc offset current is a result of stored magnetic energy in inductor L. Additionally, each phase of a three-phase synchronous machine would each have a different dc offset, due to the varying magnitude of induced stator voltage at different times during fault inception. In practical applications, protective devices such as circuit breakers must be able to sustain this worst case scenario fault current without damage.

Let us now consider an oscillogram illustrating the response of one phase to a three phase short circuit on the terminals of an unloaded synchronous generator shown in Figure 4-10 [8]. 


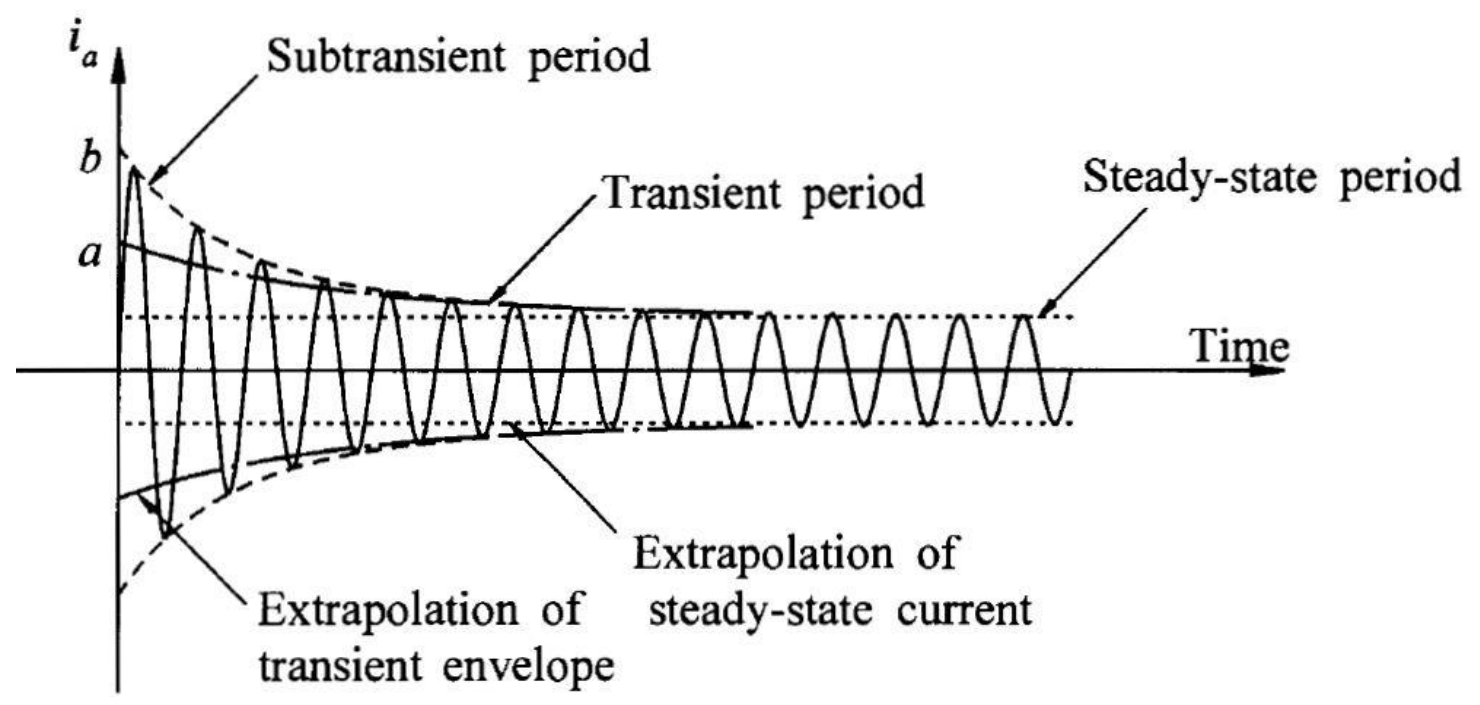

Figure 4-10: Armature short circuit current with dc offset removed

The instantaneous ac fault current can be written as [11]:

$$
\begin{gathered}
i_{a c}(t)=\sqrt{2} E_{g}\left[\left(\frac{1}{X_{d}^{\prime \prime}}-\frac{1}{X_{d}^{\prime}}\right) e^{-t / T_{d}^{\prime \prime}}\right. \\
\left.+\left(\frac{1}{X_{d}^{\prime}}-\frac{1}{X_{d}}\right) e^{-t / T_{d}^{\prime}}+\frac{1}{X_{d}}\right] \sin \left(\omega t+\alpha-\frac{\pi}{2}\right)
\end{gathered}
$$

where $X_{d}^{\prime \prime}$ is the direct axis subtransient reactance, $X_{d}^{\prime}$ is the direct axis transient reactance, $X_{d}$ is the direct axis synchronous reactance, $T_{d}^{\prime \prime}$ is the direct axis short-circuit subtransient time constant, $T_{d}^{\prime}$ is the direct axis short-circuit transient time constant [11]. As we can see from equation 4-4, the fault current on the terminals of a synchronous machine can be modeled in three different stages, characterized by the specific reactance and time since the fault has been initiated. For example, the highest peak fault current exists at time $\mathrm{t}=0$ when equation $4-2$ reduces to $\sqrt{2} \frac{E_{g}}{X_{d}^{\prime \prime}}$ amps, where $E_{\mathrm{g}}$ is the assumed constant pre-fault rms excitation voltage of the synchronous machine, also called the 
voltage behind subtransient reactance. At $t=\infty$, equation 4-2 reduces to a steady state fault current of peak magnitude $\sqrt{2} \frac{E_{g}}{X_{d}}$.

A summary of the instantaneous short-circuit fault current of 4-10 can be found in Table 4-2 [11]. Parameters in Table 4-2 including machine reactances and time constants can be found from analyzing an oscillogram similar to $4-10$, or by obtaining them from manufacturers. Therefore, the Hampden SM-100 3-phase synchronous machine will need to be characterized and modeled with the parameters in Table 4-2 to obtain reliable results in the analysis of short-circuit and transient stability studies. According to Blackburn et al., "For system-protection fault studies, the almost universal practice is to use the subtransient $\left(X_{d}^{\prime \prime}\right)$ for the rotating machinery in the positive-sequence networks. This provides a maximum value of fault current that is useful for high-speed relaying" [12]. In this thesis oscillograms similar to that of Figure 4-10 will be extracted from SEL events to characterize the parameters of a synchronous machine. 
Table 4-2: Short-circuit current, unloaded synchronous machine [11]

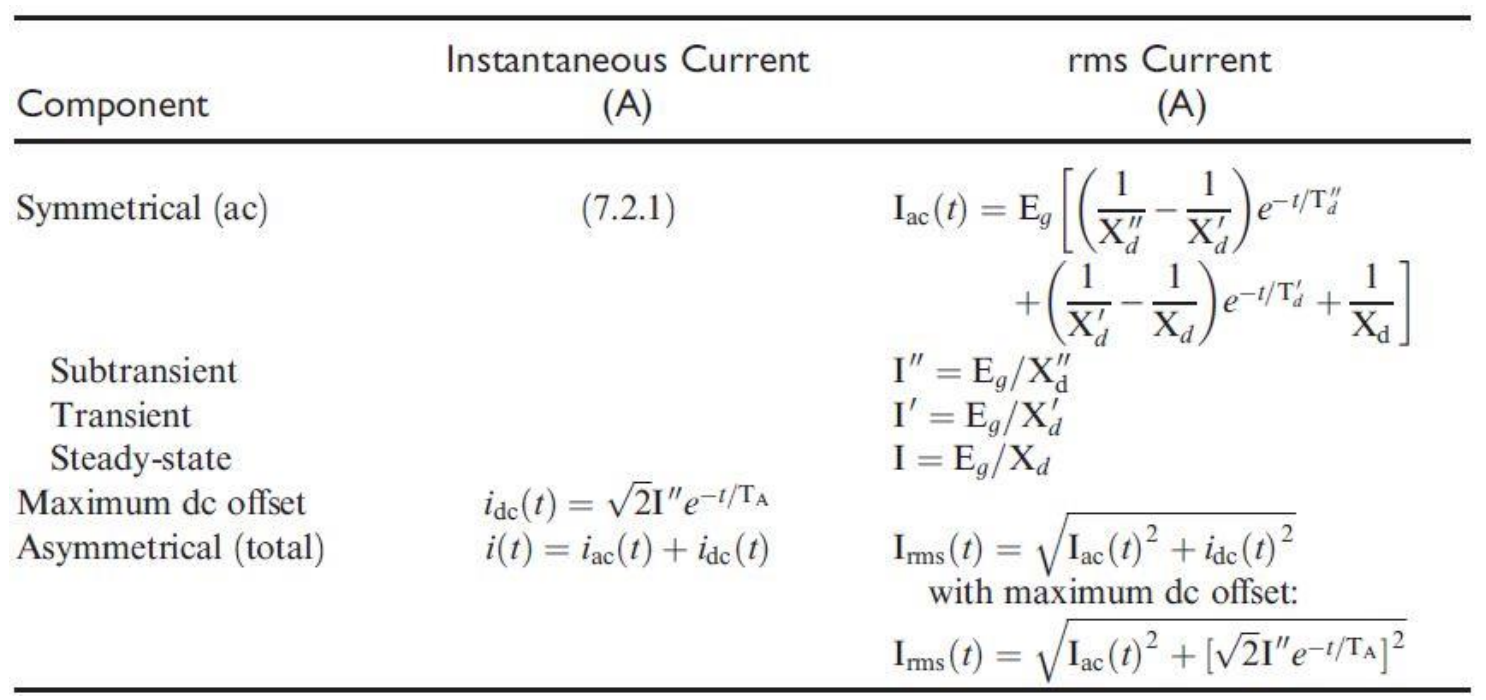

\subsubsection{ETAP Short-Circuit Example}

Figure 4-11 models an approximation to the response of a 3-phase short circuit fault occurring on the terminals of a Hampden 3-phase synchronous machine in ETAP Transient Stability module, whose terminal current oscillogram showcases the short circuit rms current similar to that in Figure 4-11. As we can see, the subtransient period is short-lived and it deteriorates to a transient, which eventually leads to a steady state short circuit component after a couple seconds, with decaying DC offset current not shown. 


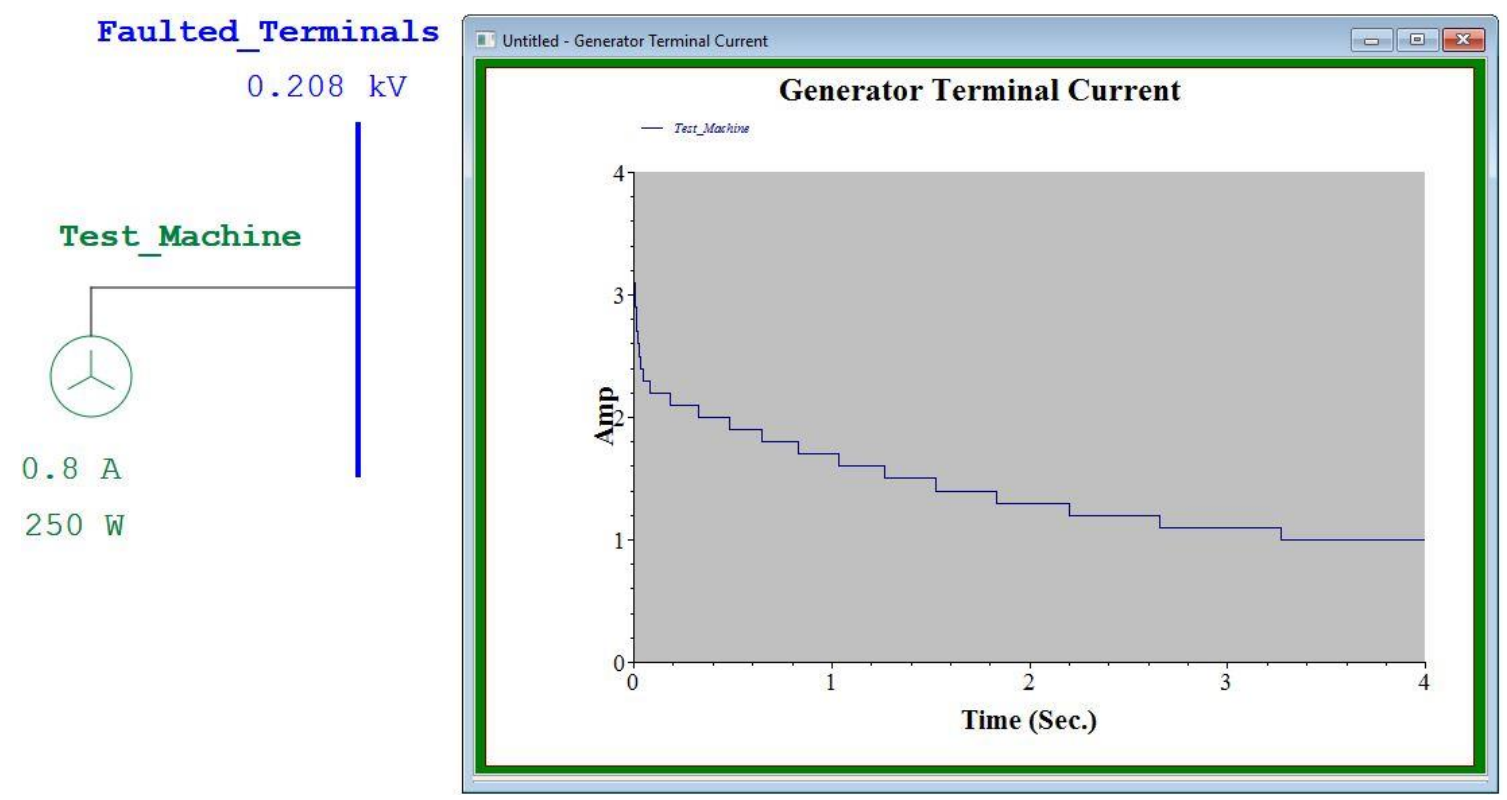

Figure 4-11: Extrapolation of asymmetrical AC fault current

In summary, ETAP Short-Circuit module will be utilized in the context of the Cal Poly microgrid in two parts. First is to determine the symmetrical components associated with different fault currents injected throughout the microgrid. A short circuit study is an essential pre-requisite to adequately implement power system protection. Secondly, short-circuit protection is also necessary to observe and extract the transient behavior of rotating machinery following a fault. It is the objective of this thesis to match ETAP generated oscillograms such as in Figure 4-11 with SEL relay event oscillograms to ensure the accuracy of machine modeling. Once the transient parameters are discovered and modeled accurately, we can begin to perform a transient stability study of the microgrid. 


\subsection{Protective Device Coordination Modeling}

This section on power system protection and device coordination will heavily build upon the work of [4] which laid the framework of the Cal Poly microgrid protection by prior students. As such, all protective relay elements utilized in ETAP will be models of SEL relays implemented in the laboratory. One of the primary goals of this section is not only to demonstrate protective relaying but also provide an intuitive and user-friendly view of protective device coordination. This will be achieved by simulating the injection of various faults throughout the microgrid system and observing the opening and closing of protective devices such as circuit breakers in response. Although reference [4] laid admirable groundwork in the development of the microgrid protection scheme, one area missing from their documentation is an adequate background of symmetrical components and their relation to fault currents. Additionally, the inclusion of Time-Current Curves (TCC) will be useful for the future microgrid team to more easily implement protection as the complexity of the system increases with added system components. It is the objective of this thesis to bridge the gap between symmetrical components calculated in ETAP to its hardware implementation with SEL relays in an intuitive and user-friendly manner for the future Cal Poly microgrid team.

\subsubsection{Protection and Coordination overview}

Section 4.5.1 serves to provide preliminary information on the fundamentals of power system protection and coordination for the interested reader. Additionally, section 4.5.1 can be used as a reference for ETAP simulations in Chapter 5. Power system 
protection can be defined as the "science, skill, and art of applying and setting relays or fuses, or both, to provide maximum sensitivity to faults and undesirable conditions, but to avoid their operation under all permissible or tolerable conditions" [4]. That is, any protection scheme implemented must be able to quickly detect faults or disturbances and initiate appropriate control circuit action accordingly lest risk damaging equipment. Additionally, it is imperative to properly coordinate equipment (e.g. protective relay settings) for reasons including adequate backup protection.

System protection consists of three basic components, including instrument transformers, protective relays, and circuit breakers. System-protection components need to meet the following design criteria including reliability, selectivity, speed, economy, and simplicity, with varying degrees of criteria [11]. Consider instrument transformers shown in Figure 4-12 showing voltage/potential transformers (VTs/PTs) and current transformers (CTs). The purpose of these instrument transformers are to measure electrical quantities and supply them as inputs to protective relays (not shown). Secondary's I' and V' are stepped down to nominal values such as 5 amps and 120Vac line-to-neutral as dictated by the turns ratio of the instrument transformers. As mentioned in section 4.2 the Cal Poly microgrid does not implement instrument transformers as electrical quantities are at a minimum value, and primary currents/voltages are instead directly fed to the SEL relays. 


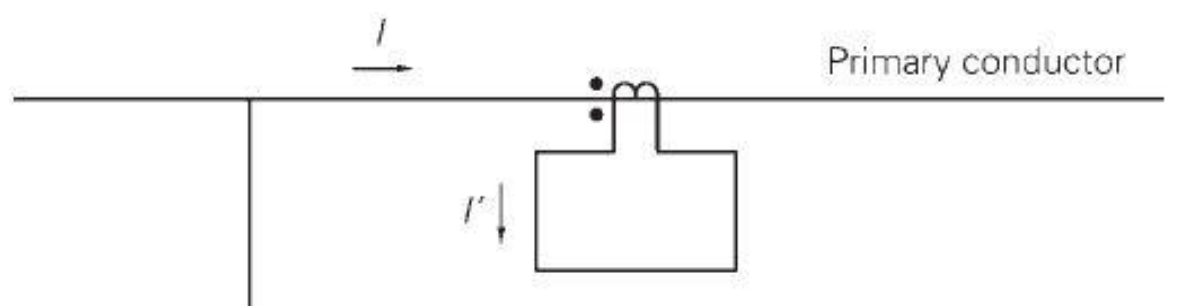

(b) Current transformer (CT)

(a) Voltage transformer (VT)

Figure 4-12: Instrument Transformers (CTs and VTs) [11]

\subsubsection{ETAP Protection and Coordination example}

Consider Figure 4-13 demonstrating implementation of radial protection based on time-delay overcurrent protection [11]. Suppose a fault occurred at point P1. As power flows downstream from generation on the left to the loads towards the right, we would ideally want circuit breakers closest to the fault to open, followed by breakers upstream to the fault. In this case, breaker B3 would be considered primary protection and open, followed by B2 to provide backup protection in the chance B3 fails to operate, and subsequently B1 opening if necessary. If coordinated properly, only load L3 would be out of power if B3 opened and B2 and B1 remain closed for a fault at P1.

Consider a fault instead occurs at point P2. In this case we would want B2 to open, with B1 providing backup protection. In this case, it is unfortunate but necessary that loads L3 and L2 would be out of power. Let us now examine an implementation of this example with ETAP Star, the protection and coordination module. 


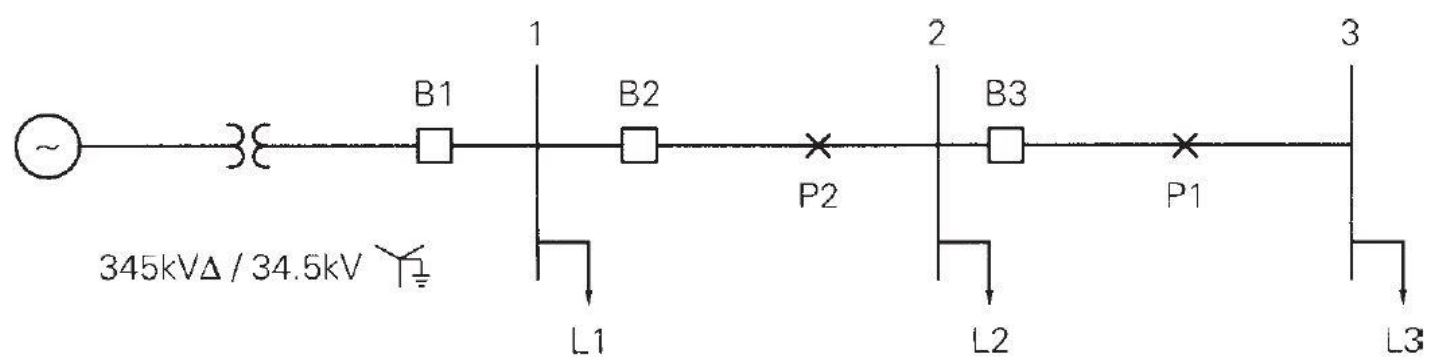

Figure 4-13: Single-line, Radial protection example [11]

Figure 4-14 demonstrates a load flow of the ETAP realization of the radial protection example shown in Figure 4-13. For demonstration purposes, each relay utilizes phase time-delay overcurrent protection (ANSI 51P) function from the SEL-311L microprocessor based protective relays. The relays in this example are set with three basic settings: pickup current or current tap setting, time-dial setting, and characteristics curves. Pickup current is minimum current needed to initiate relay operation. For example, the moment a fault current is transformed by the CT secondary and fed to the relays, the relays determine whether this CT secondary exceeds the pickup current and initiates relay operation. Time-dial settings are utilized to implement intentional time delay prior to relay operation. Relay characteristic curves characterize the curvature of the time curves and are a function of both time delay and pick up currents, defined by equations. In our radial protection example we set our SEL relays with U2 inverse curves. Time delays, pickup current, and curve types will be discussed further in the section from an analysis of a Time-Current-Curve (TCC). 


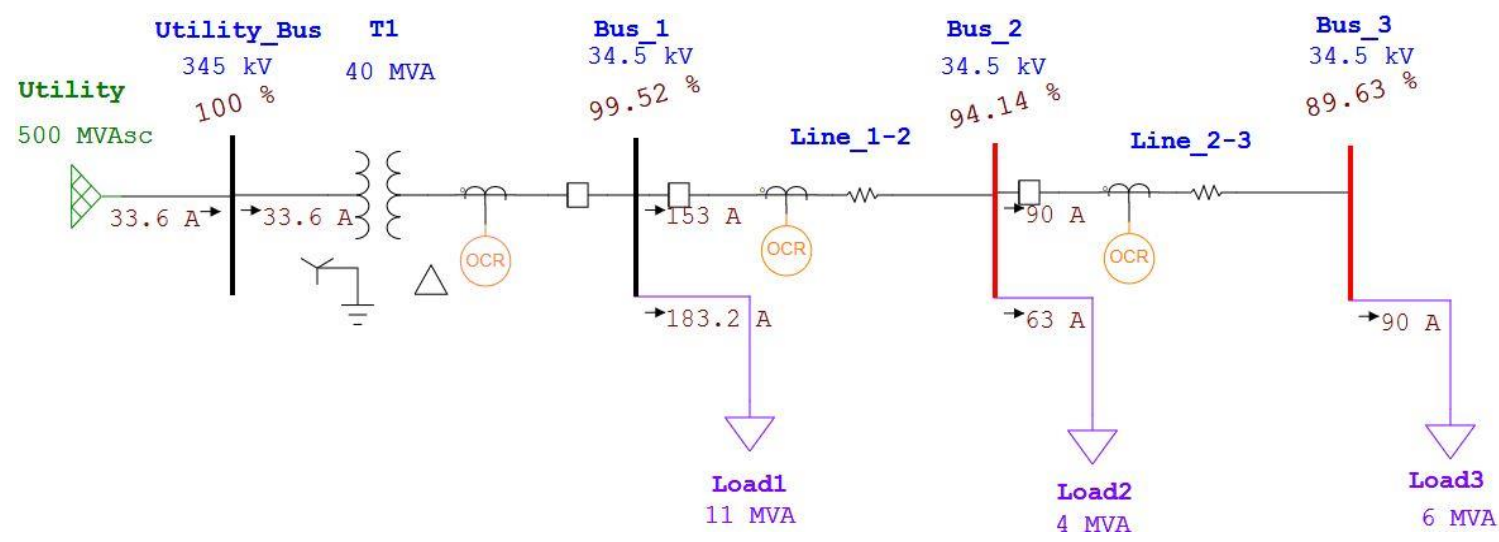

Figure 4-14: ETAP Single-Line, Radial Protection example

Consider Figure 4-15 which demonstrates protective device sequence of operation (SQOP) by faulting Bus 3. ETAP Protection and Coordination module (STAR) enables users to visualize the opening of circuit breakers in response to a short circuit scenario. In this example, a fault initiated in Bus_3 results in a maximum three-phase symmetrical fault current of approximately 1071 amps, resulting in the opening of breakers B3 followed by backup protection of B2 and B1 if necessary. This is indicated with an ' $\mathrm{X}$ ' marked by the breakers opening in sequence shown in Figure 4-15. Although not shown, similar faults on other locations in the power system such as Bus_2 will result in breakers B2 opening followed by B1. Protection coordination can be visualized by the analysis of a TCC generated. 


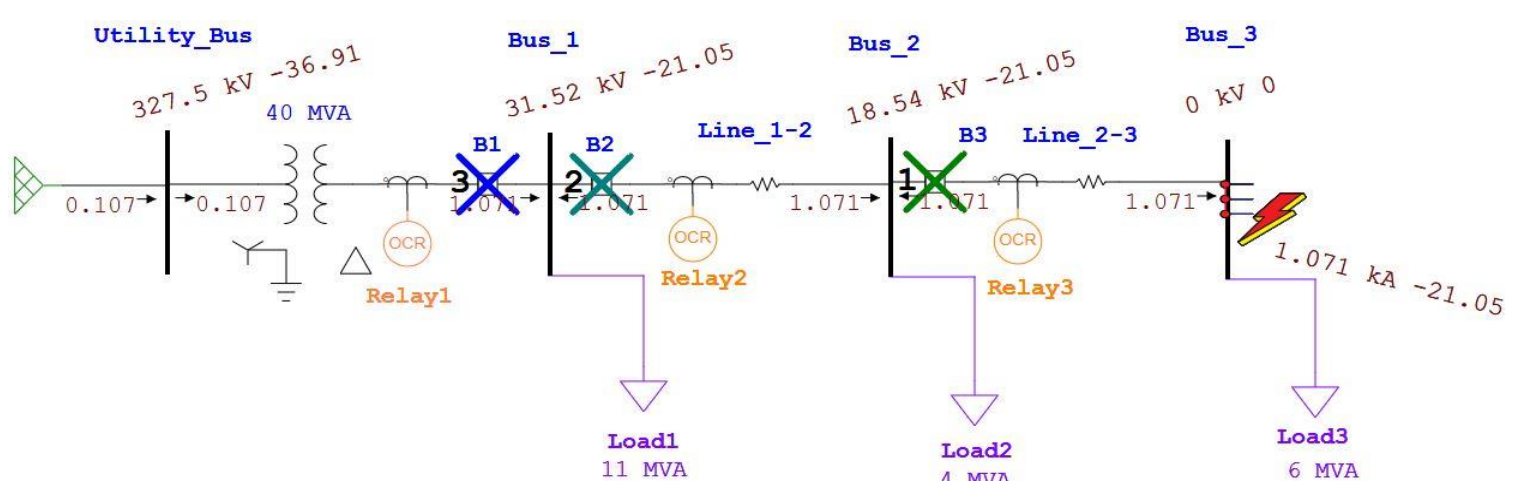

Figure 4-15: Protective Device SQOP

Consider Figure 4-16 which is a Time-Current curve (TCC) showcasing the protective device coordination of the radial protection example shown in Figure 4-15. The TCC represents protective device operating characteristics for a range of overcurrent conditions. For example, for a given line current shown on the $\mathrm{x}$-axis, the intersection with a particular curve provides us information with the time of device operation shown on the y-axis. Consider Relay3 which is responsible for sending trip commands for breaker B3 in Figure 4-15. For a three-phase fault current on Bus_3 resulting in 1071 amps, Relay3 sends trip commands to B 3 in approximately 0.1 seconds (indicative of short time-delay setting), followed by Relay2 sending trip commands to B2 as backup protection approximately 0.516 seconds later (indicative of longer time-delay setting). The time difference shown in Figure 4-16 is necessary for several reasons: time needed for trip signals send to circuit breakers, time for typical circuit breakers to open (e.g. 5 cycles or 0.083 seconds), and extra time necessary for errors and DC offsets $(0.2-0.3$ seconds) resulting from issues such as CT saturation [11]. 


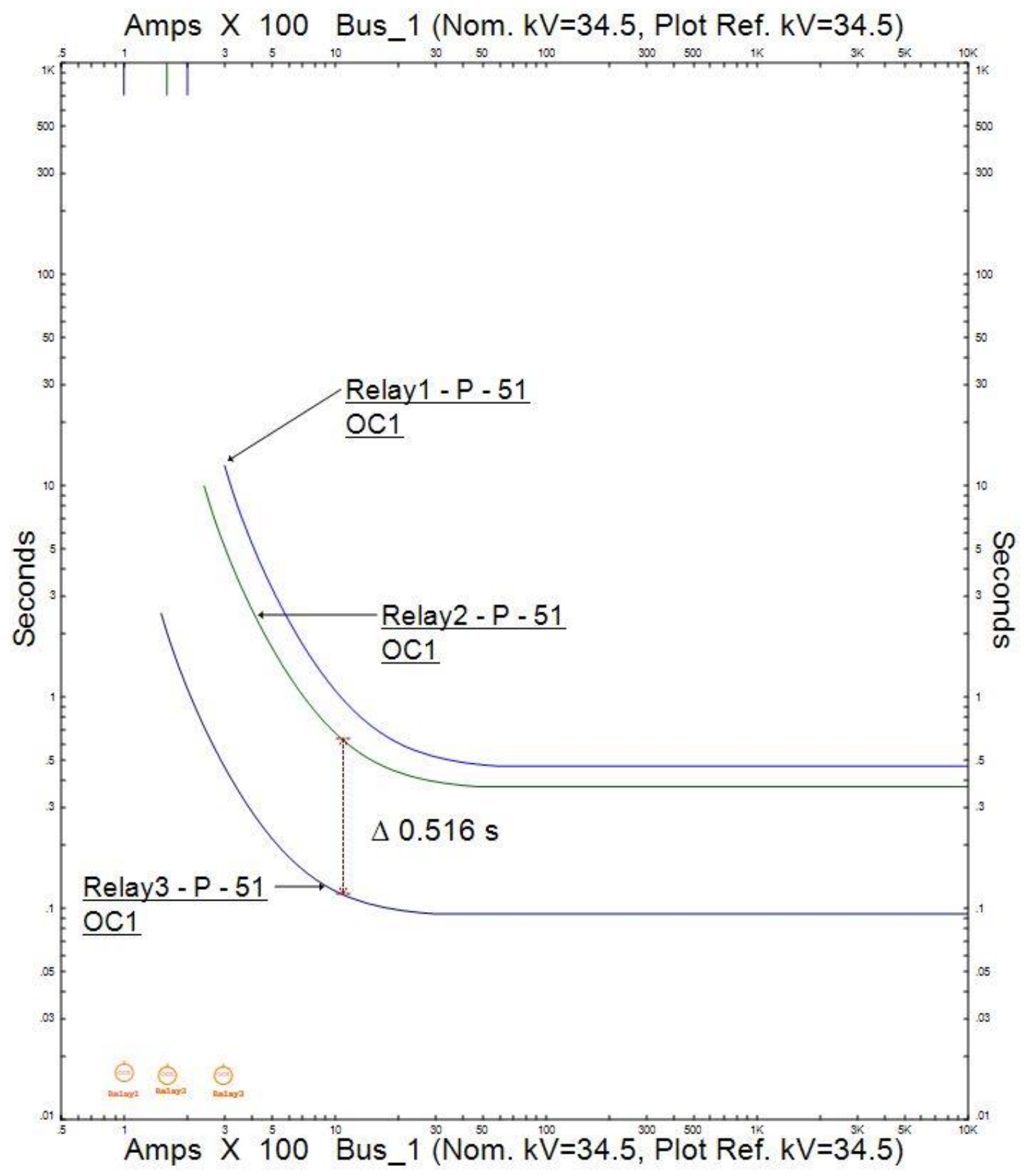

Figure 4-16: TCC, Radial Protection example

Finally, let us modify the single-line diagram in Figure 4-15 to include a secondary source of generation. Let us now observe the bidirectional system in Figure 4 17 in which two sources of generation supply power to loads L1, L2, and L3 [11]. The 
advantage in this configuration is that if properly coordinated, we are able to remove faults occurring along the transmission lines at points $\mathrm{P} 1$ or P2 without the loss of any load. For example, if a fault occurs on points P1, we can open breakers B23 and B32 and power can still be fed from both sides to supply all the loads.

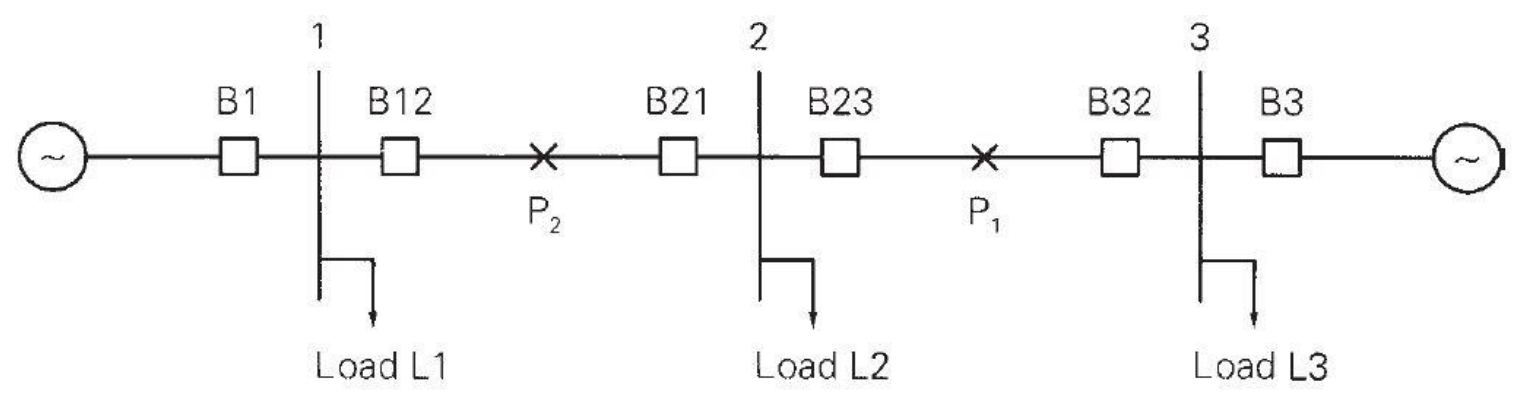

Figure 4-17: Bidirectional System with two sources [11]

However, the disadvantage of this bidirectional system is that we cannot implement simple time-overcurrent protection to coordinate the opening of breakers between relays. For example, time overcurrent is sufficient if we choose B21 as secondary protection if B23 fails to open for a fault at P1. However, consider a fault on point $\mathrm{P} 2$ with the same time overcurrent settings coordinated for a fault at P1. We would want B12 and B21 to open and extinguish the fault at P2 and all loads are still fed power from both sides. However, with the same time overcurrent settings for faults at P1, B23 would open quicker than B21, and we can no longer supply load L2 from generation on the right.

In summary, the current iteration of the Cal Poly microgrid is very similar to that of the bidirectional system is shown in Figure 4-17 in which time overcurrent protection must be supplemented with other types of protection for proper coordination. It is 
impossible for a bidirectional system to implement proper coordination with time overcurrent alone, and thus we will utilize SEL relay capabilities to implement coordination including distance and differential protections. Several case studies for different faults initiated on the microgrid will be conducted, with sequence-of-operation and time current curves illustrated throughout section 4.5.2 provided.

\subsection{Transient Stability modeling}

Load flow, short circuit analysis, and protective device coordination were necessary studies leading up to the implementation of the second phase of this thesis: transient stability analysis in microgrids. Discussed in Chapter 2, transient stability involves the study of a power system and specifically synchronous machine rotor angle response following a disturbance. We begin our study of transient stability with an overview of the transient stability phenomena in classical power systems, implement a transient stability example in ETAP, and justify any assumptions necessary in machine modeling in the context of microgrid transient stability.

\subsubsection{Transient Stability overview}

This section serves to provide preliminary information on the fundamentals of power system transient stability for the interested reader. Additionally, this section can be used as a reference for ETAP simulations in Chapter 5. Consider Figure 4-18 which showcases a mechanical analogy of the transient stability phenomenon in bulk power systems [11]. Each suspending mass can represent a large synchronous machine drawing

or providing electric power, with the strings representing transmission lines holding the 
masses together. At this point the system is at a steady state equilibrium holding the suspended masses together, with constant steady forces exerted on the strings. Let us now consider the moment one of the strings are cut which could represent the loss of a transmission line or sudden loss of a machine. The following moments would involve the remaining masses all experiencing sudden oscillatory fluctuations as forces change, attempting to stabilize to a new steady equilibrium point [11]. This is the transient stability phenomenon in a bulk power system — when a sudden disturbance perturbs steady operating conditions in a power system, will the machines stabilize following the disturbance? Let us now investigate individual machinery themselves and consider their response to sudden disturbances.

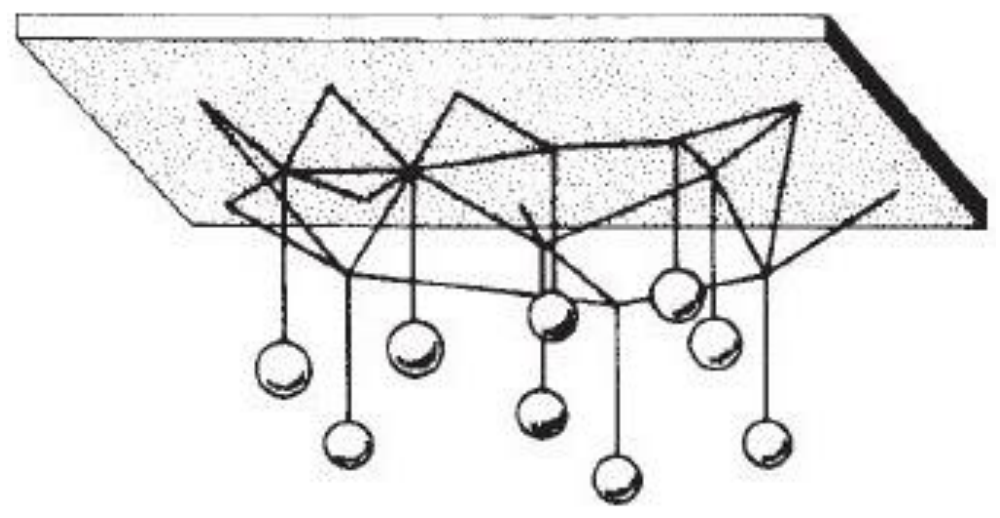

Figure 4-18: Mechanical analogy of transient stability [11]

Consider a magnetic analogy of the transient stability phenomenon manifesting itself from the perspective of synchronous machines themselves. Figure 4-19 displays an analogy of how electrical power is generated in a synchronous generator illustrated through bar magnets [9]. Bar A (rotor field) and bar B (stator field) are fixed on a pivot, and Bar $\mathrm{A}$ is driven to mechanically rotate through external means (not shown) at a 
steady, synchronous speed. In response, Bar B is pushed by the magnetic interaction from Bar A, and it is this mechanism for magnetic fields tending to align themselves which is the source of electromagnetic synchronous torque (and hence the basis of electric power as we will see), expressed as

$$
T_{e}=F_{S} F_{r} \sin \delta
$$

where $F_{s}$ and $F_{r}$ are the peak values of the stator and rotor MMF (magnetomotive force) waves respectively, and torque (rotor) angle $\delta$ is the angle between the two magnetic field axes [9]. The relationship between power output and rotor angle will be seen to be nonlinear in nature and is of utmost importance in the analysis of power system stability studies.

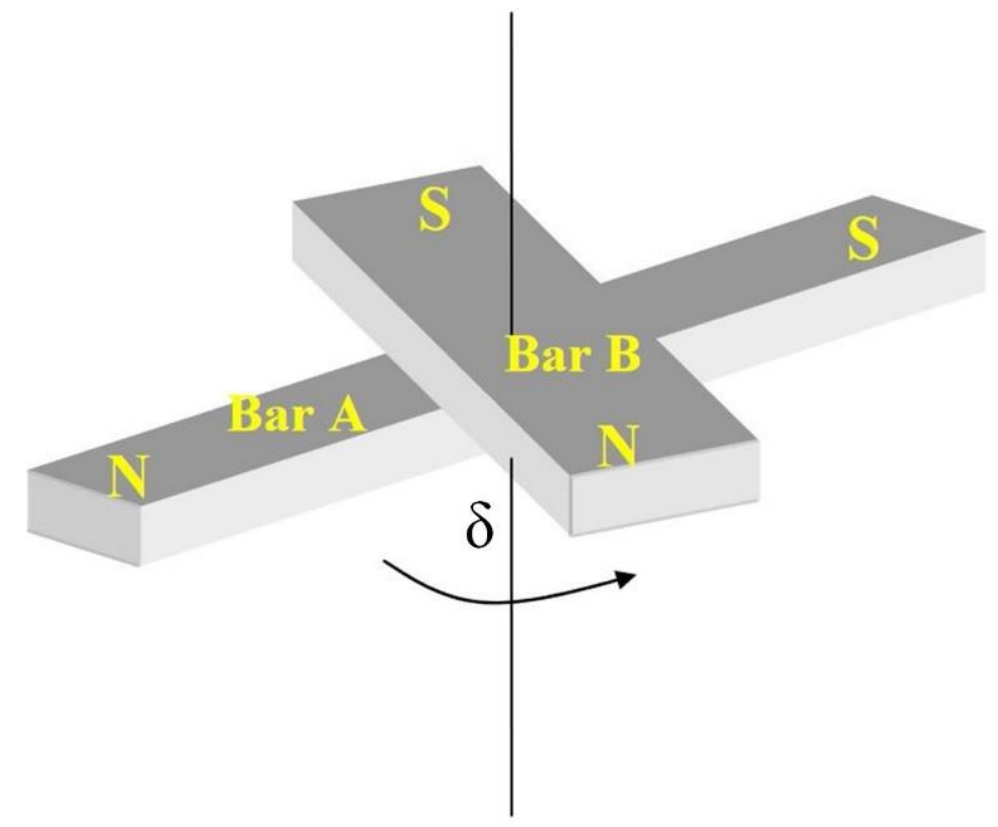

Figure 4-19: Synchronous Generator operation, magnetic bars [9]

The cross section of a three-phase synchronous machine with one pair of field poles is shown in Figure 4-20. The rotating element of the machine (the rotor) is wound 
with a direct current and it produces its rotor magnetic field. The development of this rotor magnetic field is directly analogous to Bar A in Figure 4-19. The stator is wound with three separate windings (a-a', b-b', c-c') distributed evenly $120^{\circ}$ in space to produce voltages distributed $120^{\circ}$ in time. If the machine is open circuited, that is a, b, c terminals of the machine disconnected from a load, there exists no stator current and hence no stator magnetic field to interact with the rotor magnetic field.

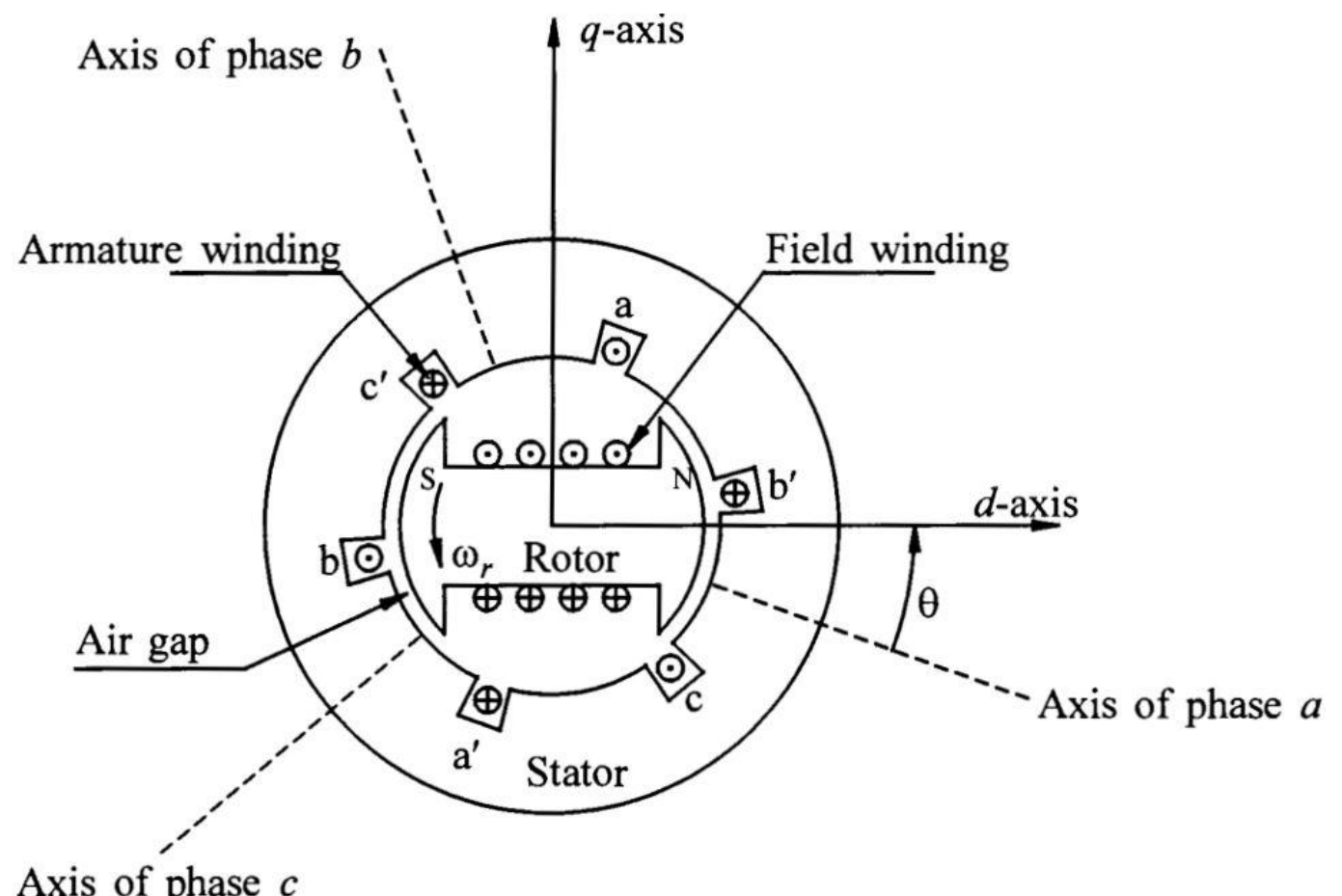

Figure 4-20: Three-phase synchronous machine, schematic [8]

However, if the machine is operating as a loaded synchronous generator, armature (stator) currents will flow from $\mathrm{a}, \mathrm{b}$, $\mathrm{c}$ windings which produce their own magnetic fields in response. There exists a total of four sources of magnetic fields within the synchronous machine: a rotor field and three stator fields as the machine is loaded. The cumulative 
effects of stator magnetic fields are directly analogous to Bar B in Figure 4-19. That is, balanced three-phase currents in the armature windings result in a single rotating stator magnetic field from the perspective of the rotor in the air-gap rotating at synchronous speed. Therefore, a production of steady electric torque is developed if the stator and rotor fields rotate at the same speed, conceptualized as Bar A and Bar B rotating synchronously. When there is variation of these magnetic fields, whether by speed or magnitude (e.g. fault on generator terminals, increase in loading conditions), the resultant variations in flux linkages throughout the machine will invariable affect rotor angle $\delta$, which is the essence of the transient stability phenomena.

\subsubsection{ETAP Transient Stability Example}

Let us now investigate an elementary example of transient stability in ETAP, which will serve as an introduction to stability simulations for the Cal Poly microgrid in Chapter 5. Figure 4-21 represents a system in which a generator is supplying power to an infinite bus represented as the power grid through two transmission lines [8]. Bus HT is suddenly disturbed with a three-phase bolted fault following a steady state scenario. 


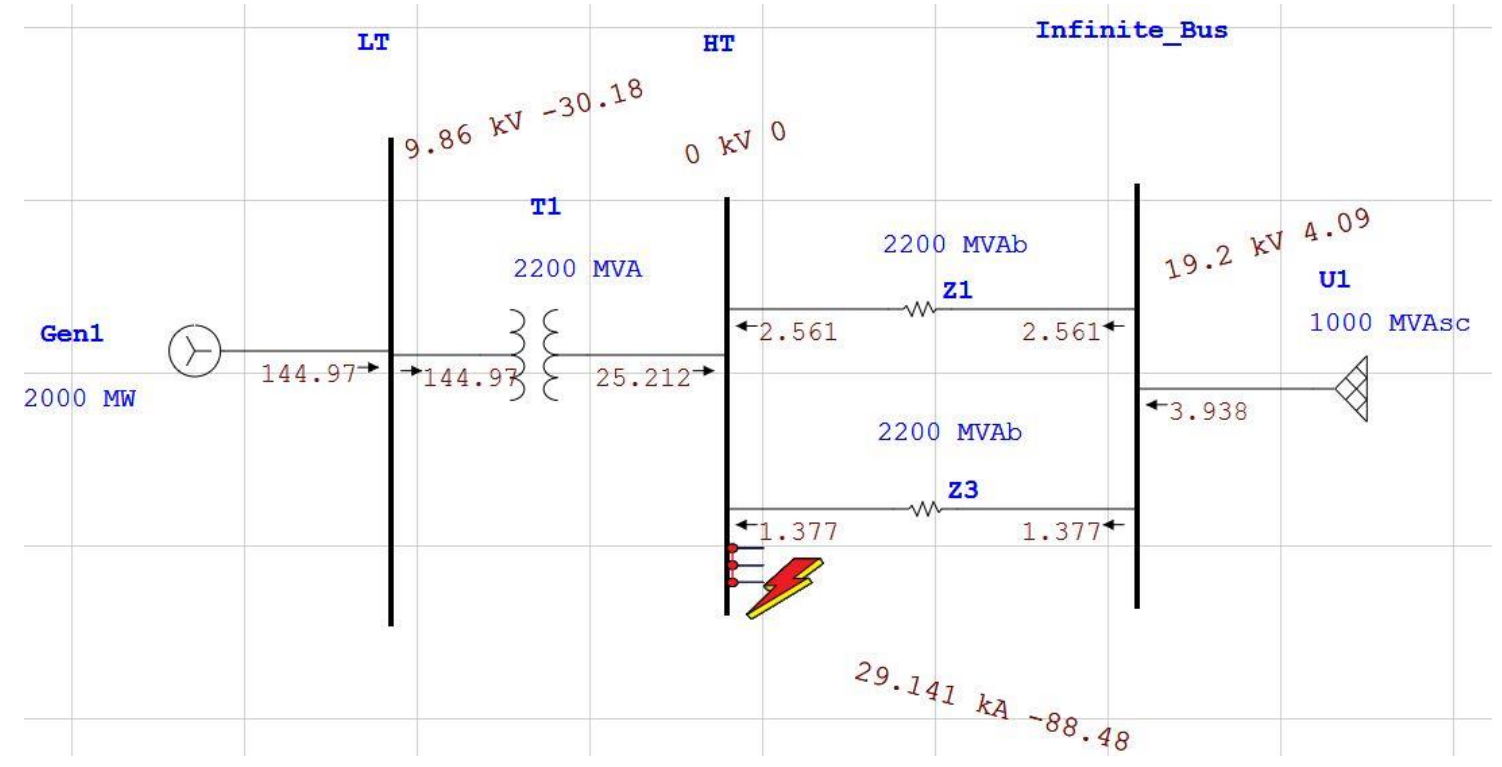

Figure 4-21: ETAP implementation of faulted bus

Figure 4-22 displays a plot of the rotor angle response of the generator with respect to time following the faulted scenario. In this ETAP example the power grid represents an infinite bus and is modeled as the swing bus with a reference angle of $0^{\circ}$. We assume the input mechanical power driving the generator is constant throughout this study. Prior to time $t=1$ seconds, the system is assumed to be at a pre-fault steady state with the generator supplying power to the infinite bus. At time $\mathrm{t}=1$ second the three-phase fault is applied on bus HT, and in response the generator experiences a variation from its initial internal rotor angle $\delta$ of about $92^{\circ}$. Due to inertial effects, the rotor angle cannot change instantaneously, but increases from its initial value as mechanical power is greater than electrical power supplied. At time $t=1.05$ seconds, the fault is cleared, but the rotor angle does not settle to a steady state value immediately. The oscillatory nature of the rotor angle response is due to a constant acceleration and deceleration of the rotor as it stores and releases kinetic energy, attempting to reach a steady state operating point at a 
new fixed rotor angle in which mechanical power input is matched with electrical power output.

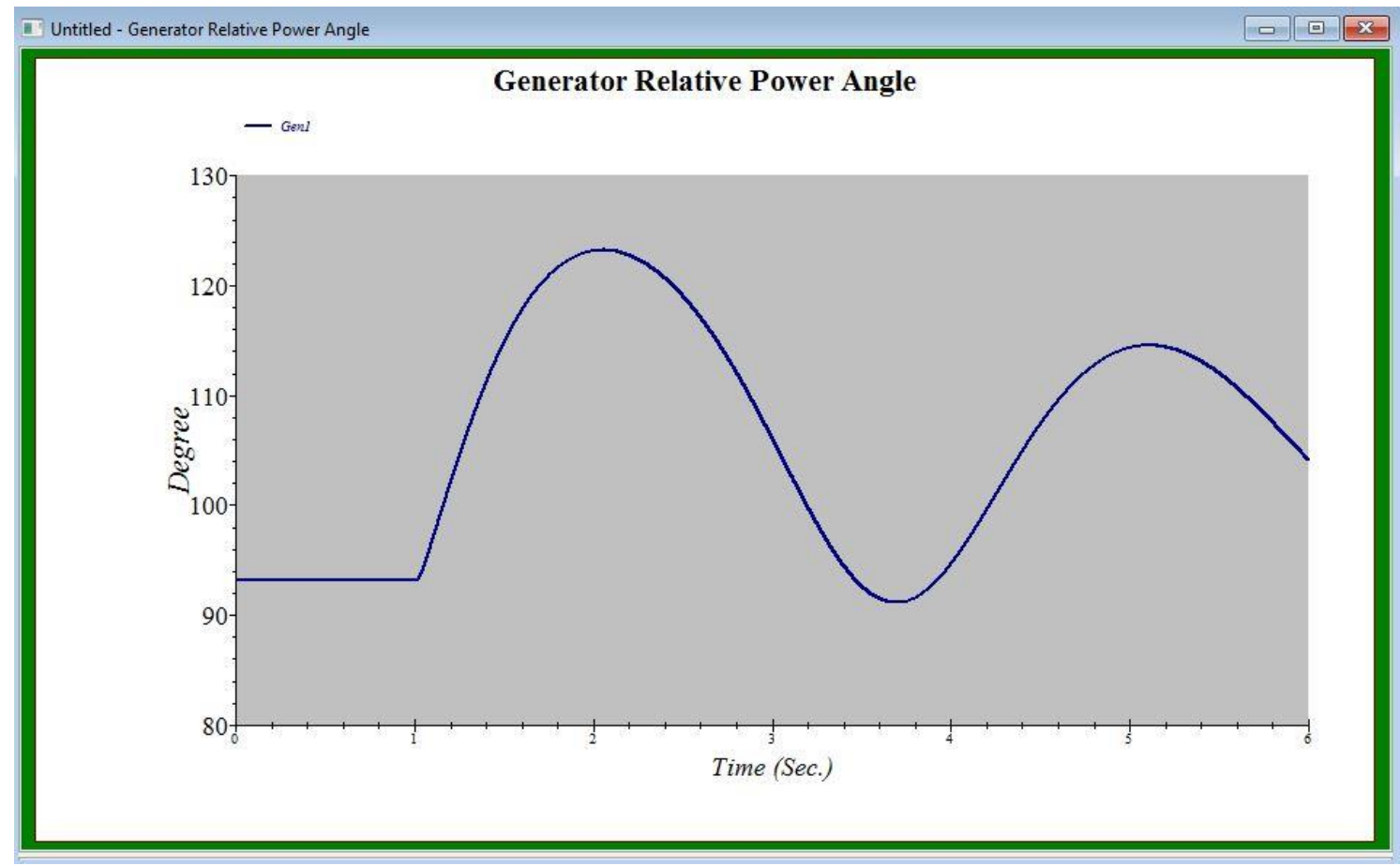

Figure 4-22: Rotor angle response, fault cleared in 0.05 seconds

Consider Figure 4-23 which represents the variation in generator electrical power with respect to time during the disturbance. As the generator is initially delivering power prior to time $\mathrm{t}=1$ second at the steady state operating condition, its electrical power drops nearly to 0 as the fault is initiated. The non-zero electrical power demonstrates resistive losses in the system, and in a purely reactive system there would be no power delivered to the infinite bus during this scenario for a fault at HT. As the fault is cleared at $\mathrm{t}=0.05$ seconds, electrical power delivered still manifests itself in an oscillatory manner as the rotor angle varies. 


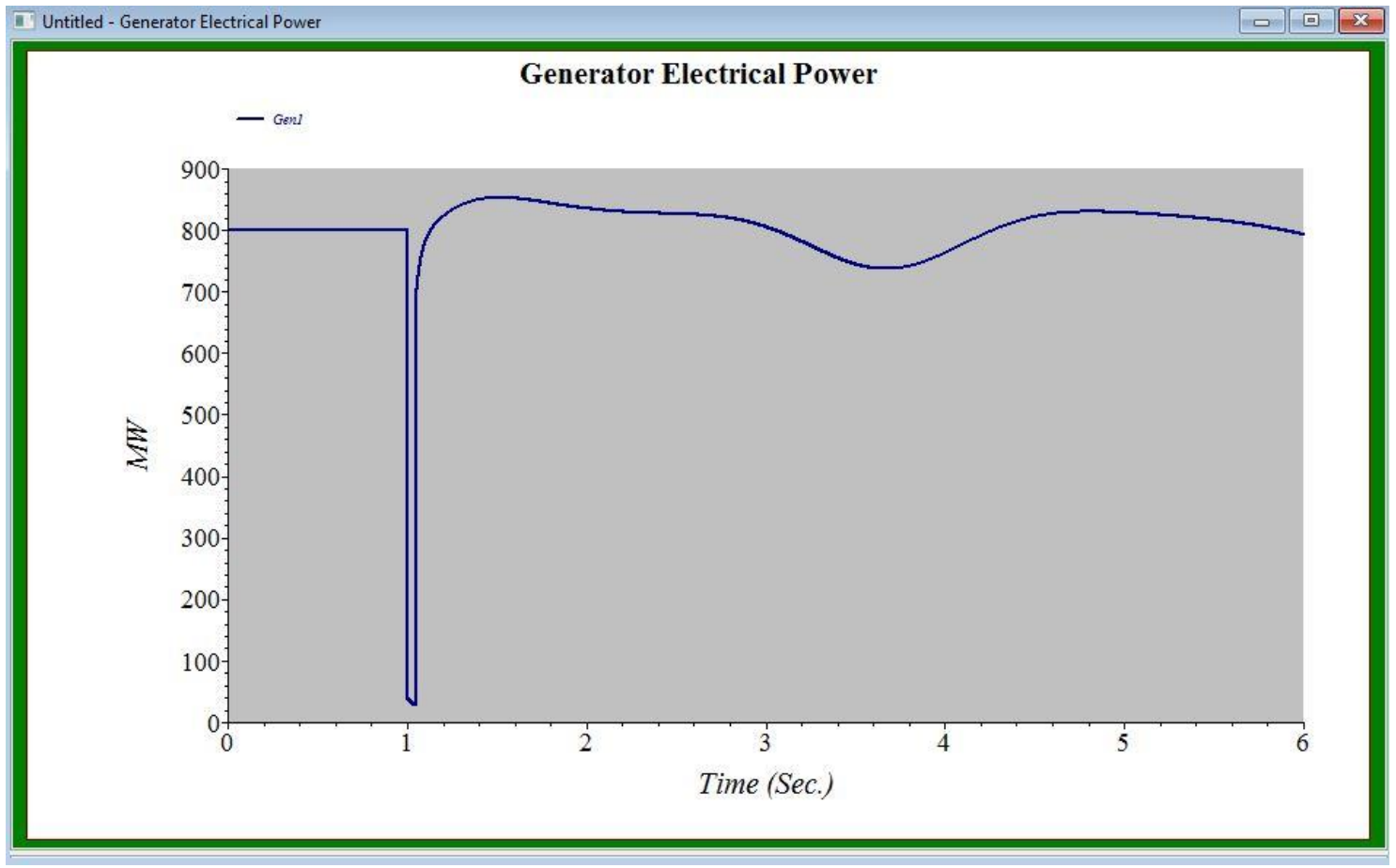

Figure 4-23: Electrical power output, fault cleared in 0.05 seconds

Consider the AC power-angle equation which relates the electrical power delivered from sending and receiving end voltages, which will help provide insight into the plots shown.

$$
P_{e}=\frac{V_{s} V_{r} \sin \delta}{\mathrm{X}}
$$

Equation 4-6 can be generalized for transient case as well if we assume voltages during the faulted scenario remain constant. In this scenario the sending end voltage $\mathrm{V}_{\mathrm{s}}$ could represent the terminal voltage of the generator, $V_{\mathrm{r}}$ represents the faulted bus (or infinite bus prior to fault) with a reference angle of $0^{\circ}$, and $\mathrm{X}$ is the equivalent reactance between the two buses. It is important to remember the phase angle of the sending end voltage $\delta$ is physically dependent on the internal angular displacement of the rotor driven by a prime 
mover as previously discussed. Electrical power delivered is highly dependent on the electrical angles between the voltages, which in turn varies in response as internal rotor angle of the machine varies during transients. This can be observed as variations in electrical power after time $\mathrm{T}=1.05$ in seconds in Figure 4-20 as rotor angle $\delta$ varies in Figure 4-19. Let us now consider the effect of the same scenario with a different fault clearing time.

Consider Figure 4-24 which represents the clearing of fault on bus HT in 0.07 seconds, at time $\mathrm{t}=1.07$ seconds. The system is once again assumed at a pre-fault steady state prior to time $t=1$ seconds with a constant mechanical power input throughout the time of study. However, although the fault from bus HT is cleared, the machine internal rotor angle cannot stabilize to a new steady operating point, and there is not enough decelerating energy available for the rotor mass to retain synchronism with the stator. Instead, the rotor accelerates further into instability seen as the rotor power angle exceeds $180^{\circ}$. At this point the machine is unable to stabilize and there is nothing that can be done but to disconnect the generator from the power system and restart to synchronize with the grid. Furthermore, this study helps us determine the critical fault clearing time, which would exist within the vicinity of 0.05-0.07 seconds. This critical time can be thought of as on the borderline between stability and instability, and an important consideration for implementing adequate protection in fault clearing times. 


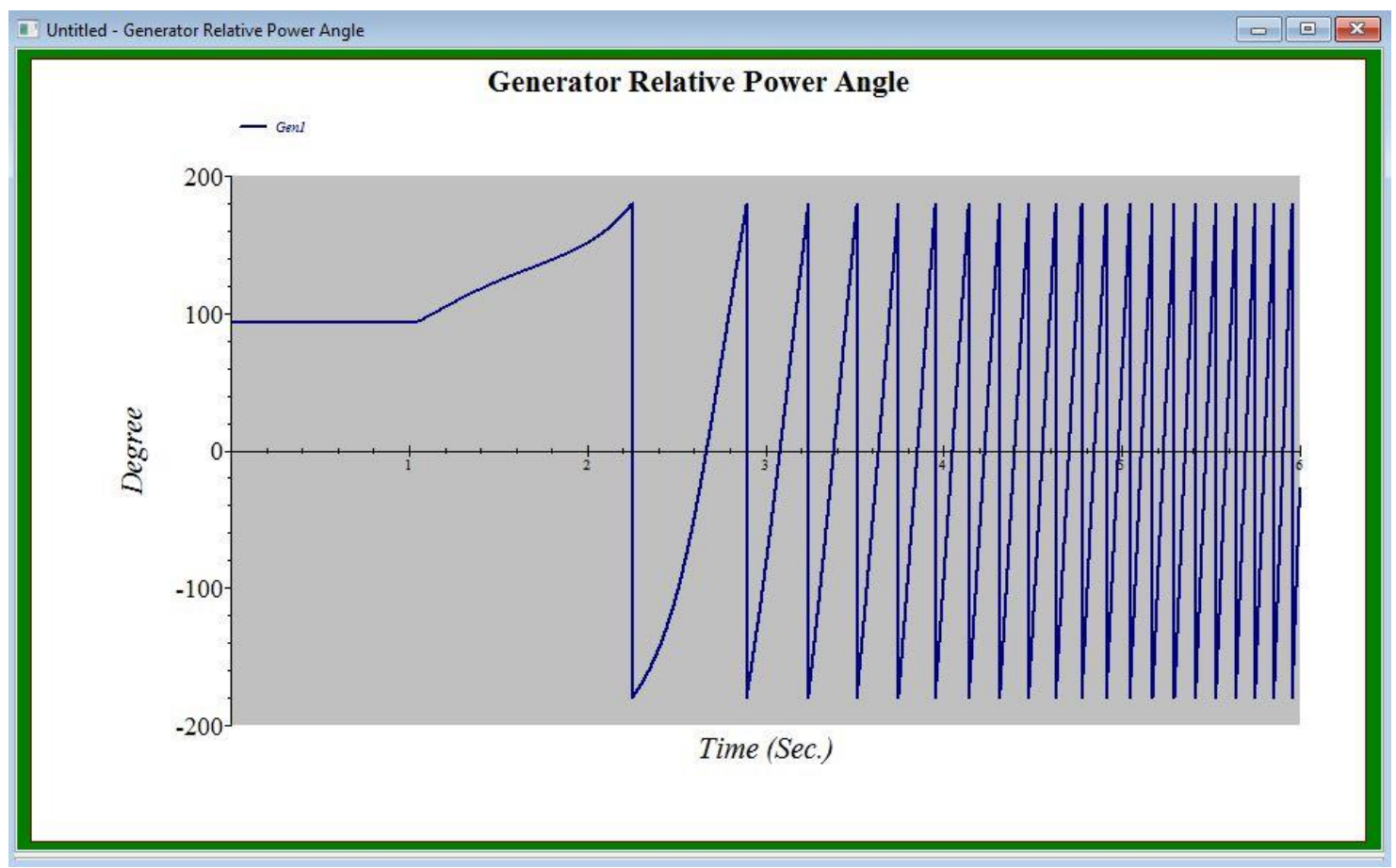

Figure 4-24: Unstable rotor angle response, fault cleared in 0.07 seconds

The prior information and examples can be further understood by studying the governing equation of motion for synchronous machines. Consider a three-phase synchronous generator driven by a prime mover, whose equation of motion is dictated by

$$
J \frac{d^{2} \theta}{d t^{2}}=T_{m}-T_{e}=T_{a}
$$

where $\mathrm{J}$ is the total moment of inertia of the rotor mass (generator and turbine) in $\mathrm{kg}-\mathrm{m}^{2}$, $\mathrm{T}_{\mathrm{m}}$ is the mechanical torque supplied by the prime mover in $\mathrm{N}-\mathrm{m}, \mathrm{T}_{\mathrm{e}}$ is the electrical torque output of the generator in $\mathrm{N}-\mathrm{m}$, and $\theta$ is the angular position of the rotor with respect to a stationary reference frame [11]. More conveniently, consider the equation of motion in an alternative form

$$
\frac{2 H}{\omega_{0}} \frac{d^{2} \delta}{d t^{2}}=P_{m}-P_{e}=P_{a}
$$


where $\mathrm{P}_{\mathrm{m}}$ is the mechanical power input in $\mathrm{pu}, \mathrm{H}$ is the inertia constant in $\mathrm{MW} \cdot \mathrm{s} / \mathrm{MVA}, \delta$ is the rotor angle in electrical radians, $t$ is time in seconds, $\omega_{0}$ is the synchronous speed in electrical radians per second, $\mathrm{P}_{\mathrm{e}}=\mathrm{P}_{\max } \cdot \sin \delta$ where $\mathrm{P}_{\max }$ is the maximum electrical power output in $\mathrm{pu}, \mathrm{P}_{\mathrm{m}}$ is mechanical power input in pu, and $\mathrm{P}_{\mathrm{a}}$ is the net acceleration in pu [8]. Notice that at a steady state synchronous condition, mechanical power input $\mathrm{P}_{\mathrm{m}}$ by the prime mover is matched with electrical demand or power output $\mathrm{P}_{\mathrm{e}}$, and hence net acceleration of the rotor is zero. It is only when there exists a mismatch between mechanical power driving the generators and the electrical power output that the rotor begins to deviate from its synchronous condition and stability may be compromised, as covered in previous ETAP examples. Swing equation 4-6 will be heavily utilized throughout the transient stability study of the Cal Poly microgrid to explain phenomena experienced by loss of generation, large step loads, islanding, and electrical faults.

In summary, we investigated an elementary study of transient stability through the event of a fault. Throughout Chapter 5 several case studies will be conducted on microgrid transients including loss of generation, large load steps, islanding, and electrical faults. Through conducting these case studies, it is the objective of this thesis to determine methods to implement improvement of microgrid transients through the goals outlined in Chapter 3. 


\section{Chapter 5: Simulations and System Validation}

\subsection{General overview}

This chapter entails the load flow, short-circuit, protection coordination, and transient stability analysis of the Cal Poly microgrid through ETAP software. Simulation validations will be made with hardware implementation wherever possible. Several case studies per load flow, short-circuit, protection coordination, and transient stability are conducted. The interested reader can refer to Chapter 4 for a background on load flow, short-circuit, protection coordination, and transient stability in the context of the Cal Poly microgrid. Figures 5-1 to 5-4 display the hardware and ETAP implementations of the microgrid system, separated between two different sections. 


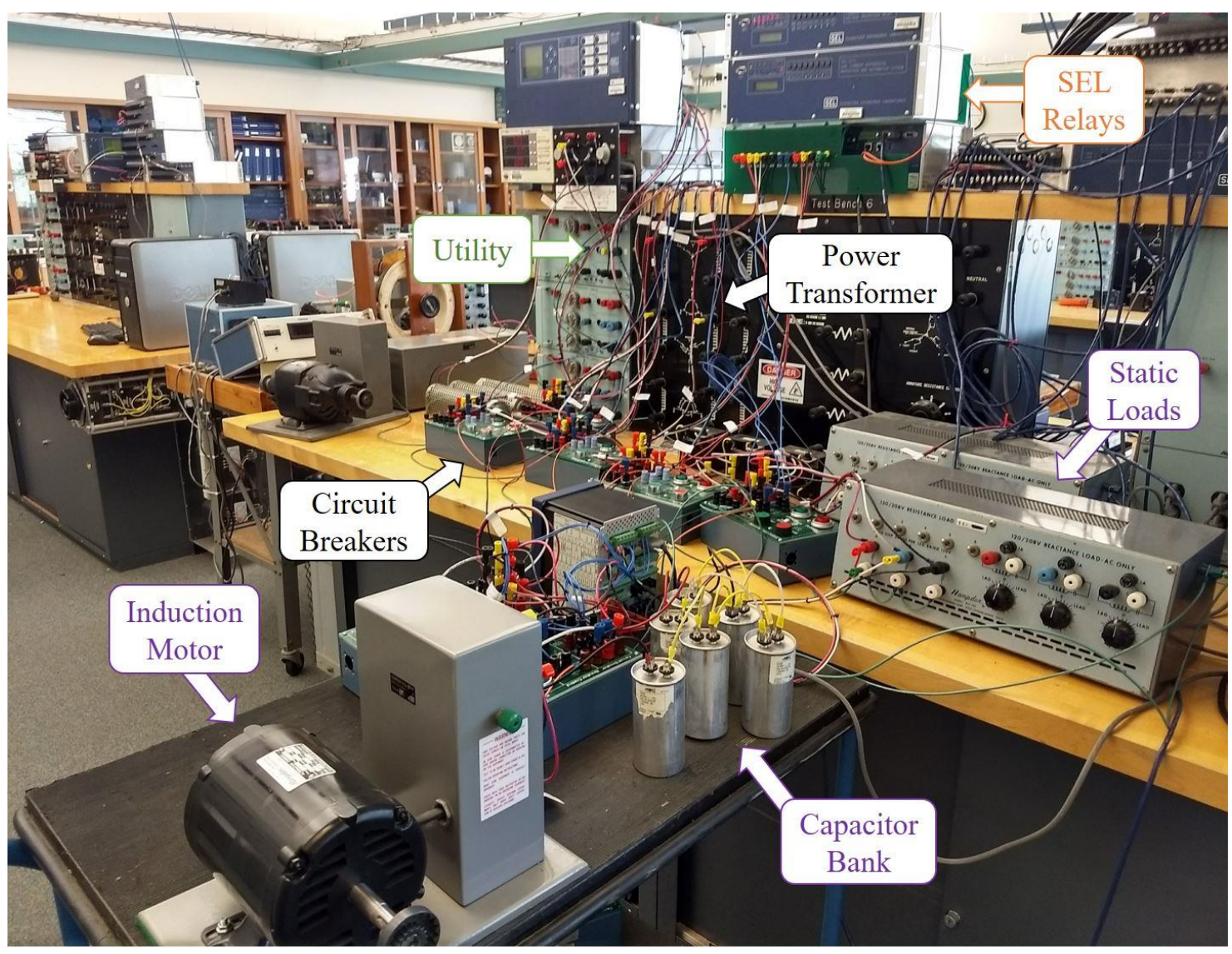

Figure 5-1: Utility to Bus 3, laboratory setup

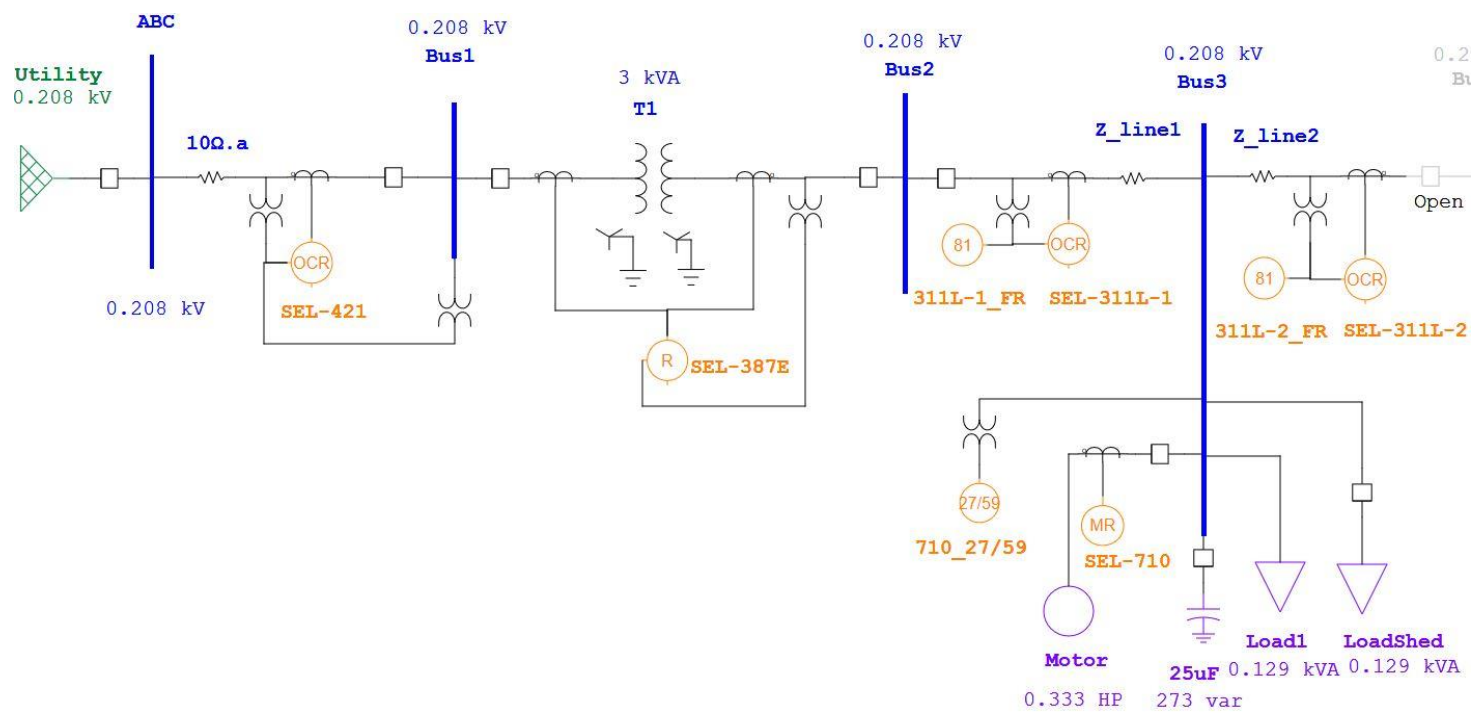

Figure 5-2: Utility to Bus 3, ETAP one line diagram 


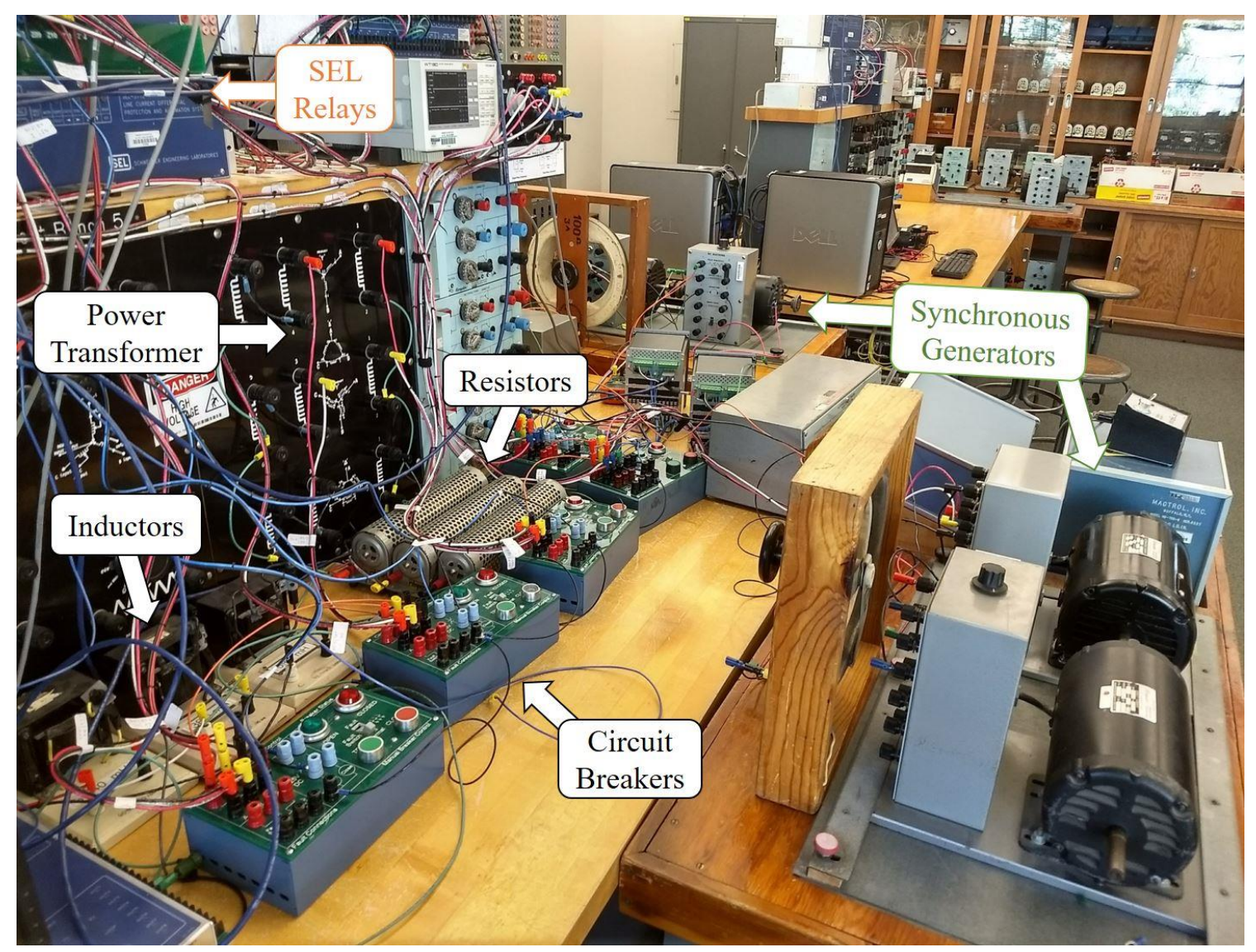

Figure 5-3: Generators to Bus 3, laboratory setup

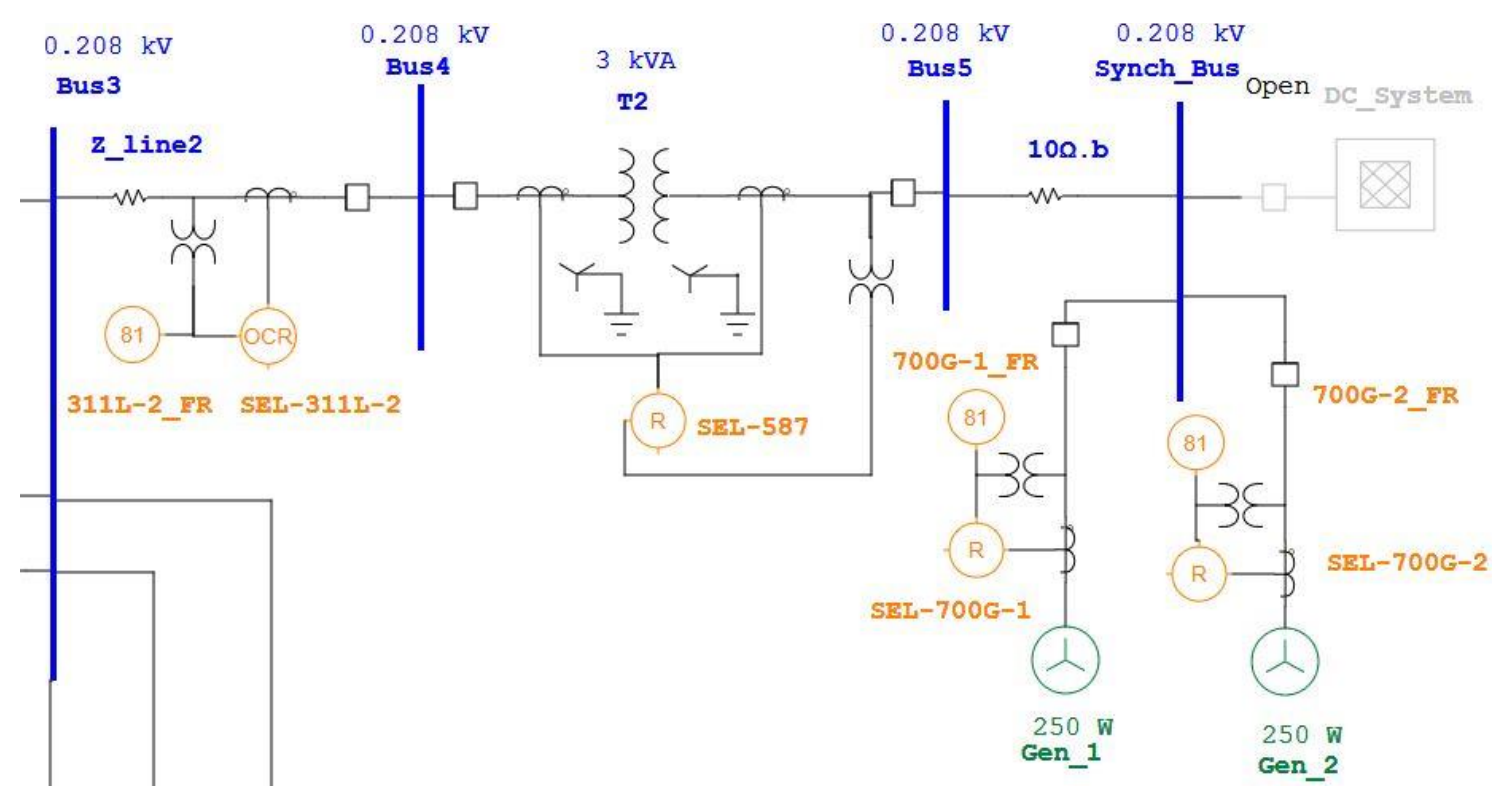

Figure 5-4: Generators to Bus 3, ETAP one line diagram 


\subsection{Load Flow Analysis}

Reference [4] states that "the operating characteristics of the laboratory bench power transformers presented certain difficulties in this project. Due to their construction, the transformers consistently operate in saturation.” Magnetization current observed in the hardware implementation of the microgrid also results in greater reactive power, lower power factor, and overall more losses throughout the system. Energizing the transformers in the laboratory resulted in an observed magnetizing current of about 150mA each. Protective elements including instrument transformers and relays are hidden in the analysis of load flow studies.

\subsubsection{Case I: Bidirectional System, No Motor and Capacitors}

Table 5-1 displays laboratory measured data of the microgrid to gather load flows throughout the system, provided from another graduate student working on the Microgrid lab project per reference [14]. In this scenario the excitation voltage and the output power of the generator is manually adjusted by setting the speed of the prime mover (DC motor). Each synchronous generator is operating at 100W, 12Var, supplying a total of 200W and 24Var. 
Table 5-1: System synchronized, no motor, no capacitors [14]

\begin{tabular}{|c|c|c|c|c|c|c|}
\hline Location & $\begin{array}{c}\text { Real } \\
\text { Power } \\
{[\mathrm{W}]}\end{array}$ & $\begin{array}{c}\text { Current } \\
{[\mathrm{A}]}\end{array}$ & $\begin{array}{c}\text { Voltage } \\
{[\mathrm{V}]}\end{array}$ & $\begin{array}{c}\text { Reactive } \\
\text { Power } \\
{[\mathrm{VAR}]}\end{array}$ & $\begin{array}{c}\text { Apparent } \\
\text { Power } \\
{[\mathrm{VA}]}\end{array}$ & $\begin{array}{c}\text { Power } \\
\text { Factor }\end{array}$ \\
\hline Generator & 200 & .563 & 208 & 24 & 235 & .857 \\
\hline Utility & 133.8 & .369 & 207.6 & 54.6 & 152.6 & .739 \\
\hline Motor & 0 & 0 & 194 & 0 & 0 & 1 \\
\hline
\end{tabular}

Figure 5-5 provides a load flow comparison of a one-line depicting the apparent power (VA) and amps (A) flowing throughout the system. All sources of generation are selected to operate in swing mode. The utility supplies the power flowing from Bus 2 to Bus 3, and the generators supply the power flowing from Bus 4 to Bus 3. De-energized elements are grayed out (motor and capacitor).

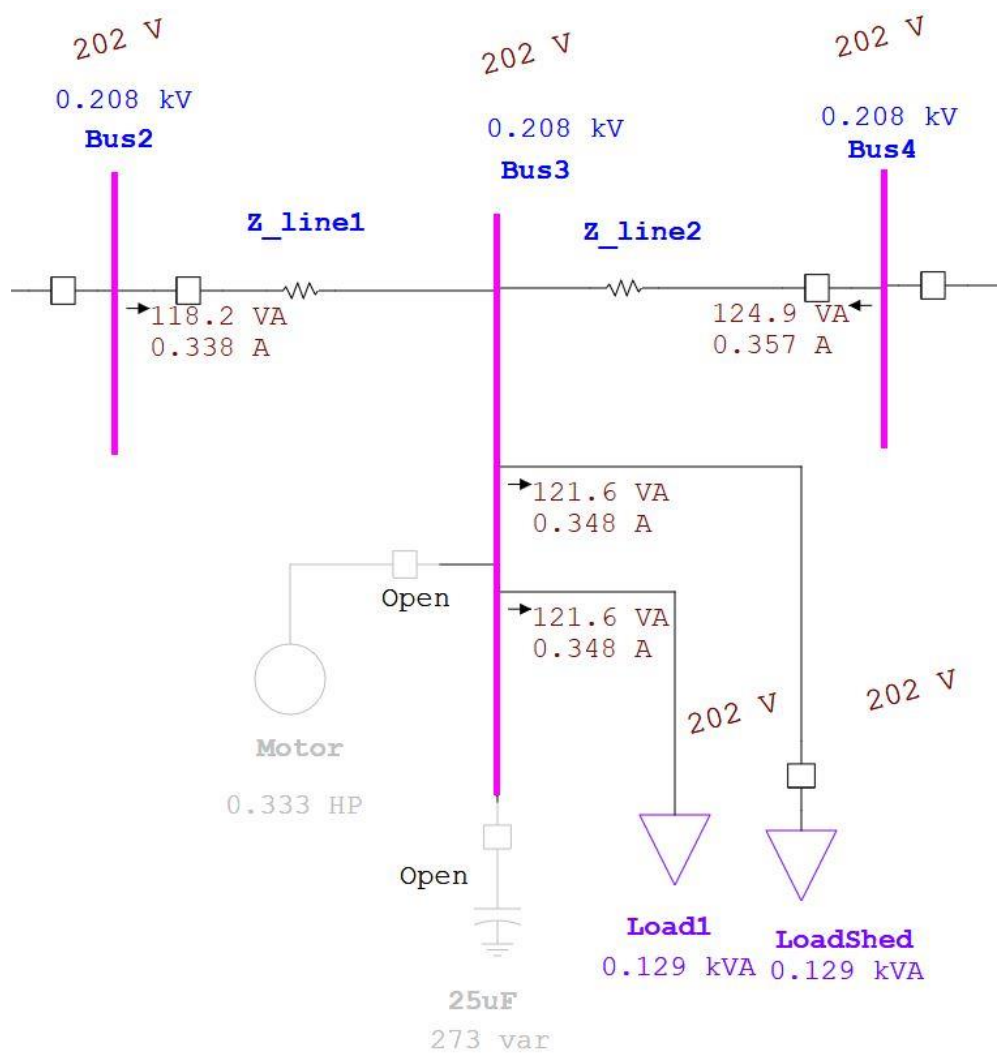

Figure 5-5: Load Flow, no motor and capacitors 
In Figure 5-5, the total current supplied to the static loads at Bus 3 is $0.696 \mathrm{~A}$. However, laboratory tested data in Table 5-1 suggests total current from utility and the generators supply about 0.932 A. The discrepancies between the two data can be attributed to transformer magnetizing current and saturation, both of which are not modeled in ETAP.

Consider Figure 5-6 in which the synchronous generators are instead operated in Mvar mode, where the user can enter specific values of active and reactive power generation from the rating page of the synchronous generator models. The utility is still selected as swing mode, supplying the remaining power and balancing load flow in the system. We can observe that the power flowing from Bus 4 to Bus 3 from the generators closely matches that of Table 5-1 of $200 \mathrm{~W}$ and 24 Var. However, we have compromised the remaining power flowing from the utility in this configuration. This is the inherent limitation of ETAP load flow modeling of non-ideal components largely due to the transformers drawing additional current throughout the system. Therefore, even if the generators are modified to supply specific fixed amounts of reactive and active power, the ETAP model will not accurately represent the hardware representation of the system, and there will be less total power flowing in the system when compared to laboratory data. 


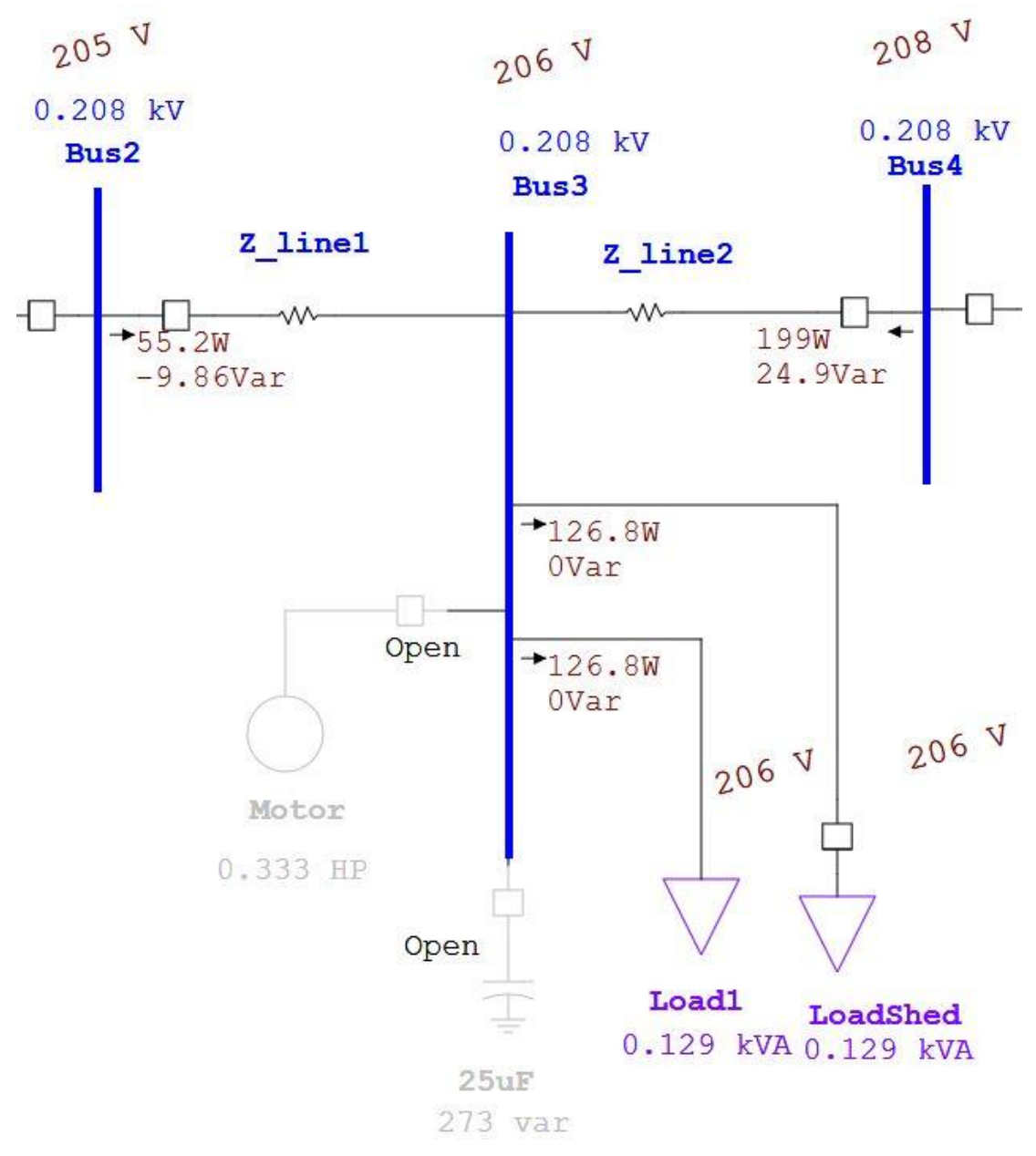

Figure 5-6: Load Flow, no motor and capacitors, MVAR mode

\subsubsection{Case II: Bidirectional System, motor and capacitors}

Table 5-2 displays laboratory data on load flow parameters throughout the system with the motor per reference [14]. The power factor throughout the system is inherently low due to motor operating conditions: there is no applied external torque, i.e. the motor is operating under no load conditions. Additionally, load flow study cases and all other future studies will consist of the induction motor operating at $0 \%$ (no load) conditions when energized, at the specific power factor and currents shown in Table 5-2. 
Table 5-2: System Synchronized, with motor, no capacitors [14]

\begin{tabular}{|c|c|c|c|c|c|c|}
\hline Location & $\begin{array}{c}\text { Real } \\
\text { Power } \\
{[\mathrm{W}]}\end{array}$ & $\begin{array}{c}\text { Current } \\
{[\mathrm{A}]}\end{array}$ & $\begin{array}{c}\text { Voltage } \\
{[\mathrm{V}]}\end{array}$ & $\begin{array}{c}\text { Reactive } \\
\text { Power } \\
{[\text { VAR] }}\end{array}$ & $\begin{array}{c}\text { Apparent } \\
\text { Power } \\
{[\mathrm{VA}]}\end{array}$ & $\begin{array}{c}\text { Power } \\
\text { Factor }\end{array}$ \\
\hline Generator & 200 & .814 & 208 & 214 & 337 & .593 \\
\hline Utility & 161 & .774 & 205.7 & 226 & 318 & .502 \\
\hline Motor & 65.7 & 1.06 & 173.2 & 308.3 & 315.2 & .208 \\
\hline
\end{tabular}

The motor modified nameplate characteristics can be seen in Figure 5-7 in ETAP. The microgrid does not apply external load to the motor, and hence only considers the case when the motor is turned off or drawing power at no load conditions, with effects of inrush current negated. The loading column in Figure 5-7 is by default $100 \%$ for full load conditions, but it is instead modified to $0 \%$ to more accurately model the system. Hence, by design the motor is operating in no load conditions. This thesis does not consider motor dynamic studies, which could be a future project on its own. 


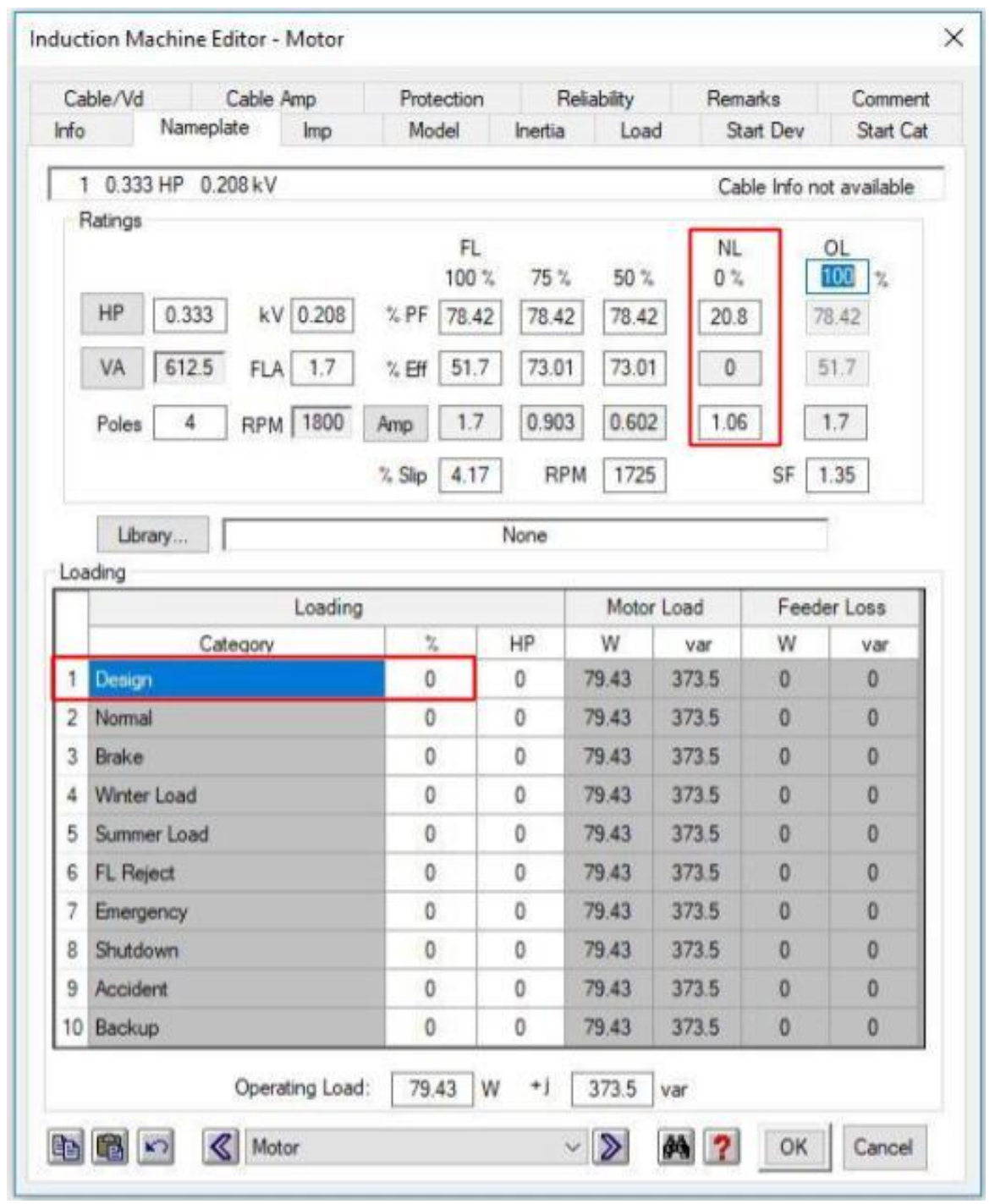

Figure 5-7: ETAP Induction Motor loading conditions

Figure 5-8 displays the load flow with all generations as swing buses for purposes of simulation. Power flow between Bus 4 and Bus 3 from the generators and between Bus 2 and Bus 3 from the utility results in a smaller current than that shown in Table 5-2. This is again due to the inherent limitation of limited reactive power flow in the system as mentioned in Case 1 of load flow analysis. As a result, Bus 3 voltage is higher than that 
indicated in Table 5-2 compared to the laboratory observation of the induction motor terminal voltage at $173 \mathrm{~V}$.

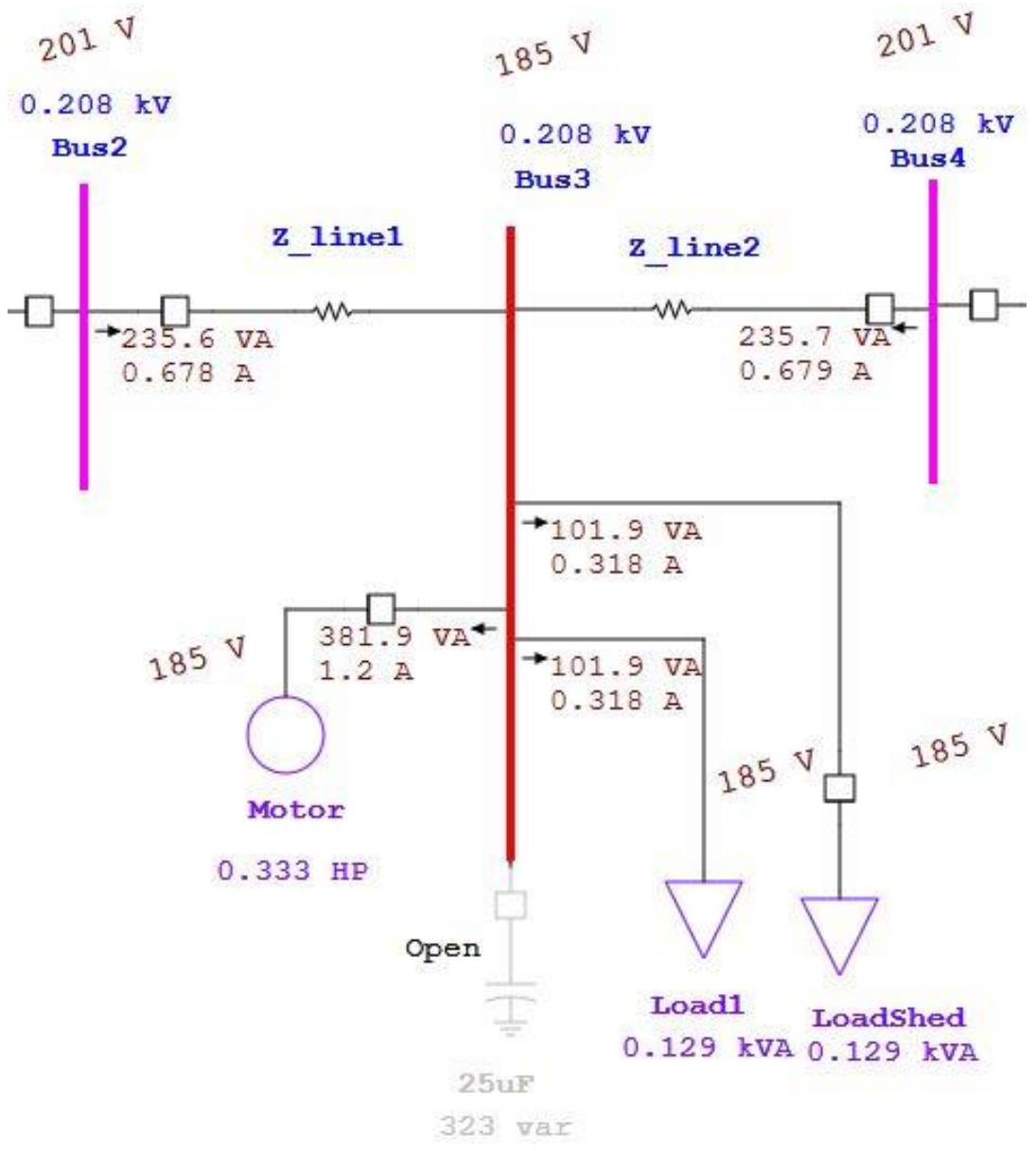

Figure 5-8: Load Flow, motor energized, no capacitor

Table 5-3 per reference [14] showcases microgrid system data with the motor and capacitor both turned on. Compared with Table 5-2, apparent power and currents supplied from the utility and generators are reduced as a result of power factor correction. 
Table 5-3: System Synchronized, with motor and capacitors [14]

\begin{tabular}{|c|c|c|c|c|c|c|}
\hline Location & $\begin{array}{c}\text { Real } \\
\text { Power } \\
{[\mathrm{W}]}\end{array}$ & $\begin{array}{c}\text { Current } \\
{[\mathrm{A}]}\end{array}$ & Voltage [V] & $\begin{array}{c}\text { Reactive } \\
\text { Power } \\
{[\text { VAR] }}\end{array}$ & $\begin{array}{c}\text { Apparent } \\
\text { Power } \\
{[\mathrm{VA}]}\end{array}$ & $\begin{array}{c}\text { Power } \\
\text { Factor }\end{array}$ \\
\hline Generator & 200 & .6 & 208 & 130 & 250 & .799 \\
\hline Utility & 184.9 & .562 & 206.4 & 58.5 & 232.5 & .797 \\
\hline Motor & 76.9 & .268 & 187 & 40 & 87 & .88 \\
\hline
\end{tabular}

Next we apply a wye-connected capacitor bank of $25 \mu \mathrm{F}$ each energized at $185 \mathrm{~V}$ line-to-line supplying a total of 323 Var at the motor bus, shown in Figure 5-9. Bus voltages are increased by providing reactive power support to the system. Additionally, the lowering of apparent power and current is seen from Bus 2 to Bus 3 and Bus 4 to Bus 3, which are the apparent power and current flow from the utility and generators, respectively. 


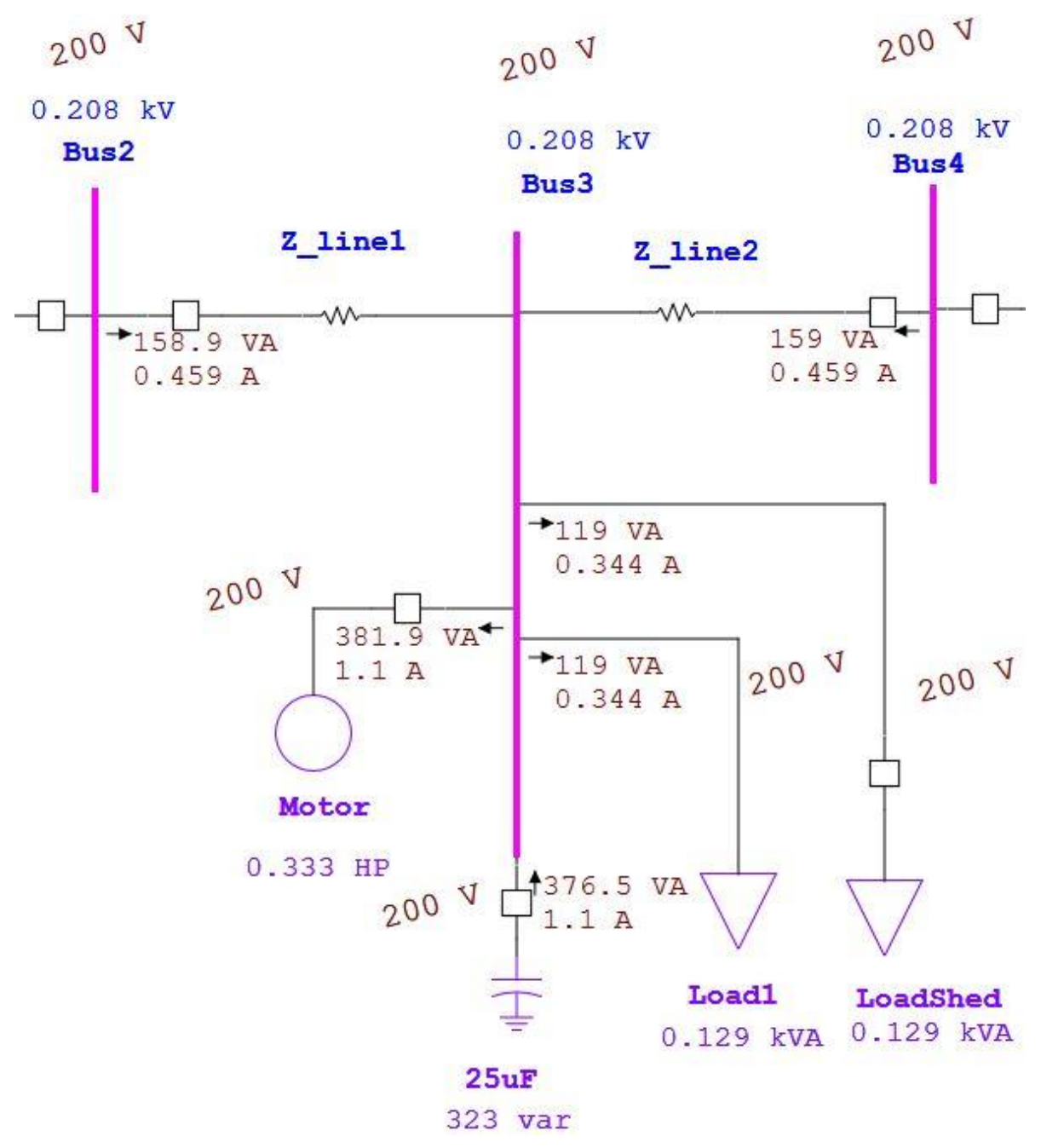

Figure 5-9: Load Flow, motor and capacitors

\subsubsection{Case III: DC Load Flow}

Case III of Load Flow analysis considers some of the capabilities and possibilities of running DC load flow simulations. There is currently no supplementary PV generation in the microgrid. The future microgrid lab will utilize BP SX 150S Solar Panels rated at $150 \mathrm{~W}$, open circuit voltage of $43.5 \mathrm{~V}$, short circuit current of $4.75 \mathrm{~A}$, maximum power point operating voltage at $34.5 \mathrm{~V}$, and maximum power point current of $4.35 \mathrm{~A}$. The inverter to connect to the AC system will be the APsystems 1000W YC-1000 3-phase 
microverter, whose datasheet can be found per reference [15]. For purposes of simulations, the Photowatt PV1400 will be used as a model in ETAP for conduction DC Load Flow, rated at $150 \mathrm{~W}$, maximum power point operating voltage at $33.69 \mathrm{~V}$, and maximum power point current of $4.45 \mathrm{~A}$, which closely model the BP SX 150S.

Solar panel ratings are provided based on standard test conditions and several conditions such as solar irradiation, module temperature, angle with respect to the sun, etc. For purposes of simulations we utilize standard test conditions of 25 degrees Celsius, and set an irradiance of $200 \mathrm{~W} / \mathrm{m}^{2}$ for four PV1400 panels, with a DC load flow shown in Figure 5-10.

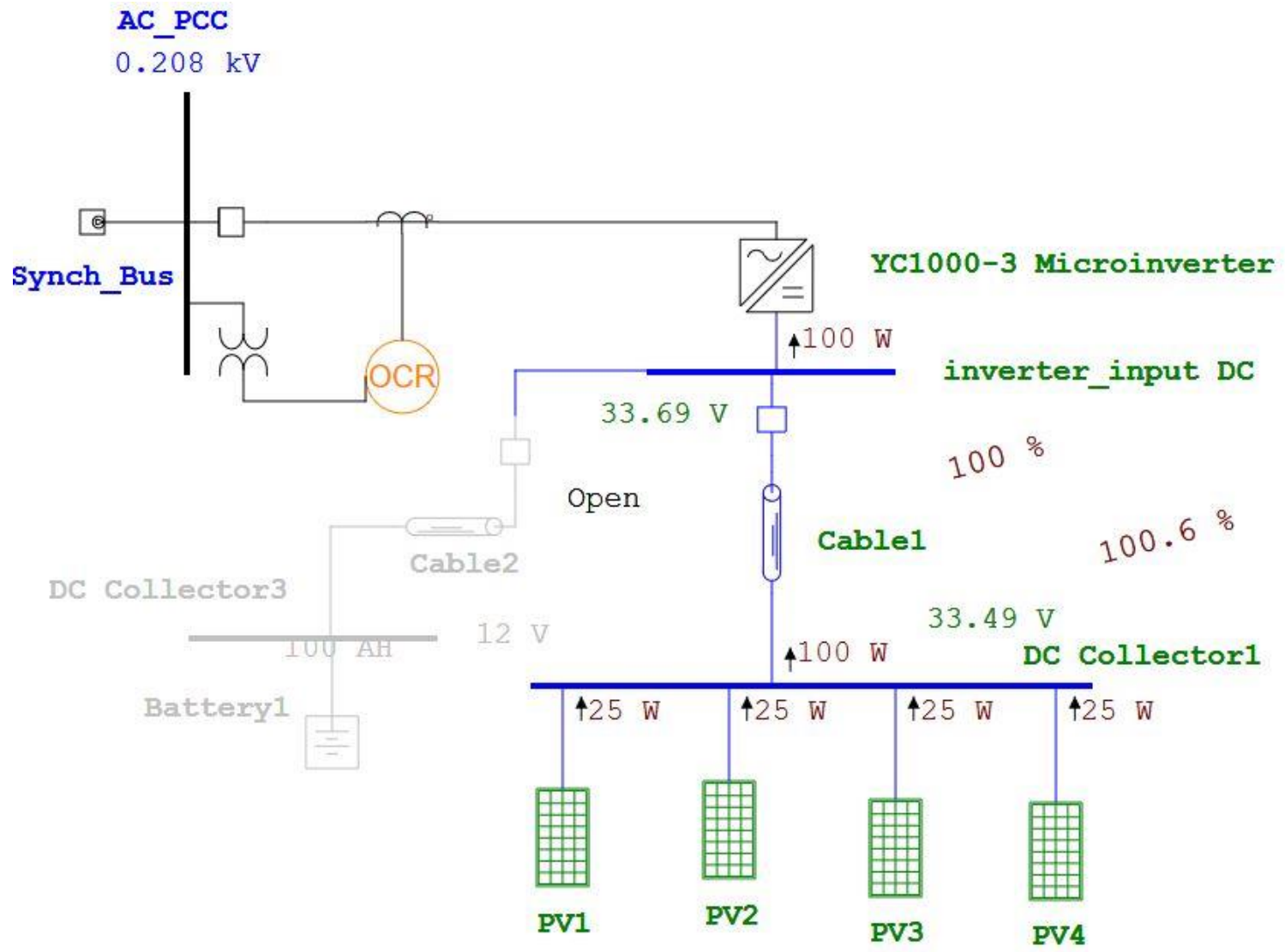

Figure 5-10: DC Load Flow, DC System 
The inverter can be operated as MVAR controlled AC operation mode, similar to that of the synchronous generators. With a $95 \%$ efficiency, we can specify the AC output to be $95 \mathrm{~W}$, or any specific fixed amount of the input DC power from the solar panels. Cable impedance is neglected for purposes of simulation, but can be entered if losses are needed. This shows the capabilities of the DC load flow: we can investigate different PV generating parameters and determine output $\mathrm{AC}$ power and supply known power to the microgrid accordingly. Figure 5-11 displays an AC Load Flow taking into account the DC power supplied by the panels. The generators are heavily relieved from the active power demanded from the system, supplemented from solar generation. The synchronous generators instead provide mostly reactive support to the system. The generators and utility are operating in swing mode, while the inverter is operating in MVAR with fixed output of $95 \mathrm{~W}$. The motor is turned on, with the capacitor off. The DC_system subsystem block in Figure 5-11 contains the DC system depicted in Figure 5-10.

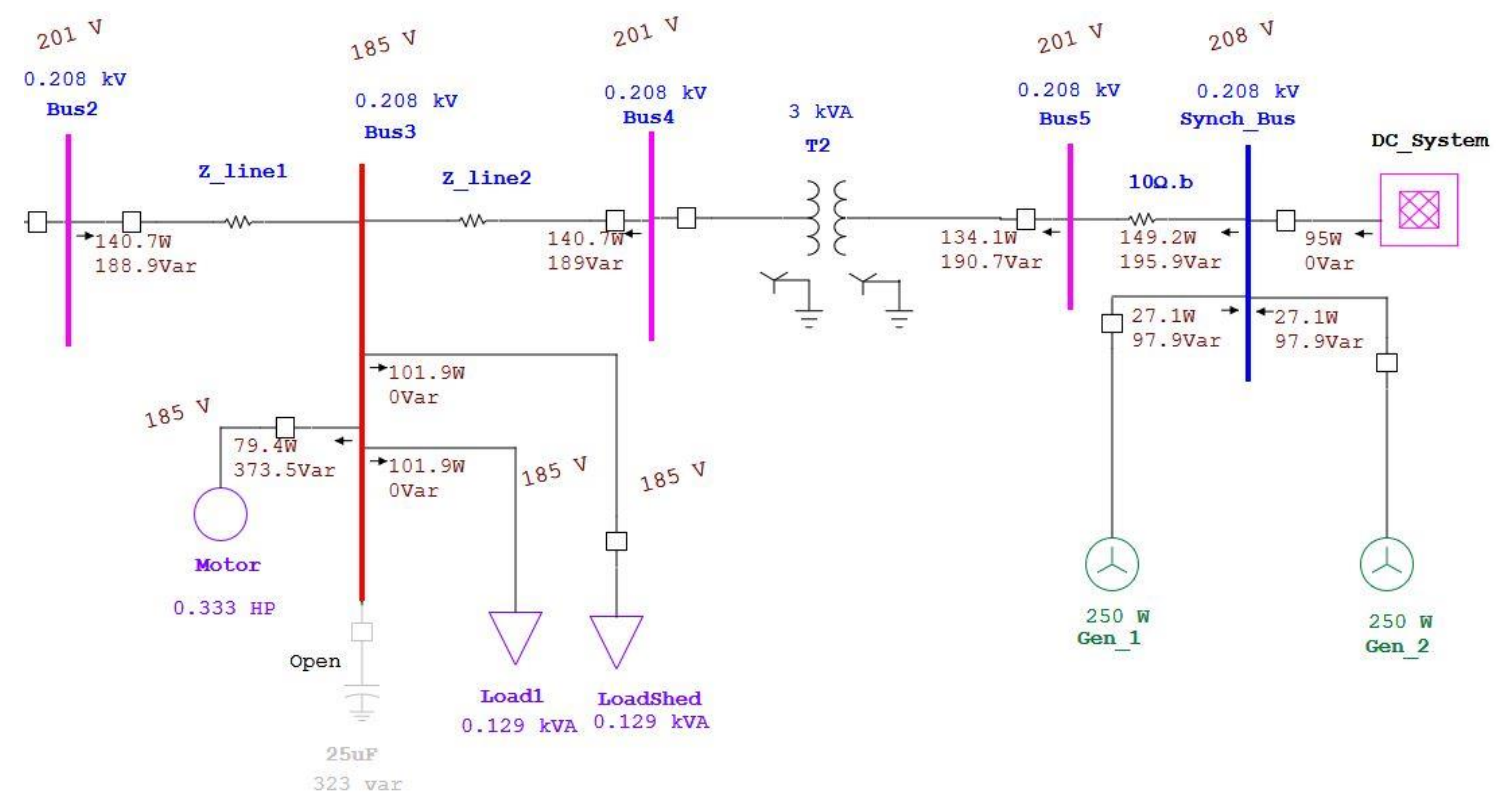

Figure 5-11: AC Load Flow, PV generation 


\subsubsection{Load Flow Summary}

Cases I-III of Load Flow analysis considered different variations of the bidirectional microgrid system. In all cases, total power supplied from generation is lower than the hardware implementation of the microgrid. This is due to inherent limitations of the Load Flow analysis module which does not consider the effects of transformer magnetizing current and saturation. Case III also considered the DC Load Flow in which PV panels were utilized to supplement active power in the system. The future microgrid can vary the amount of panels based on power demand, and utilize the generator(s) for reactive power support.

\subsection{Short Circuit Analysis}

Short circuit analysis will be utilized to determine the contribution of fault currents from synchronous generators. Per reference [4], the prior microgrid utilized the utility to supply all the power in the system. Hence, fault contributions from both sides of the microgrid will essentially be equivalent, with the same relay settings to be discussed in Section 5.4. Known fault current contribution from the synchronous generators will be necessary to implement protection and coordination in the current iteration of the microgrid.

\subsubsection{Short Circuit System Validation}

Figure 5-12 displays the hardware implementation to extract relevant machine parameters in the event of a short circuit. SEL-421 is utilized in extracting the fault 
current from the system. The synchronous generator is originally unloaded, driven by a DC motor for the prime mover and field excitation by a rheostat producing rated voltage (208 Vac) and rated speed (1800 rpm). A three-phase fault is suddenly applied on the terminals of the machine.

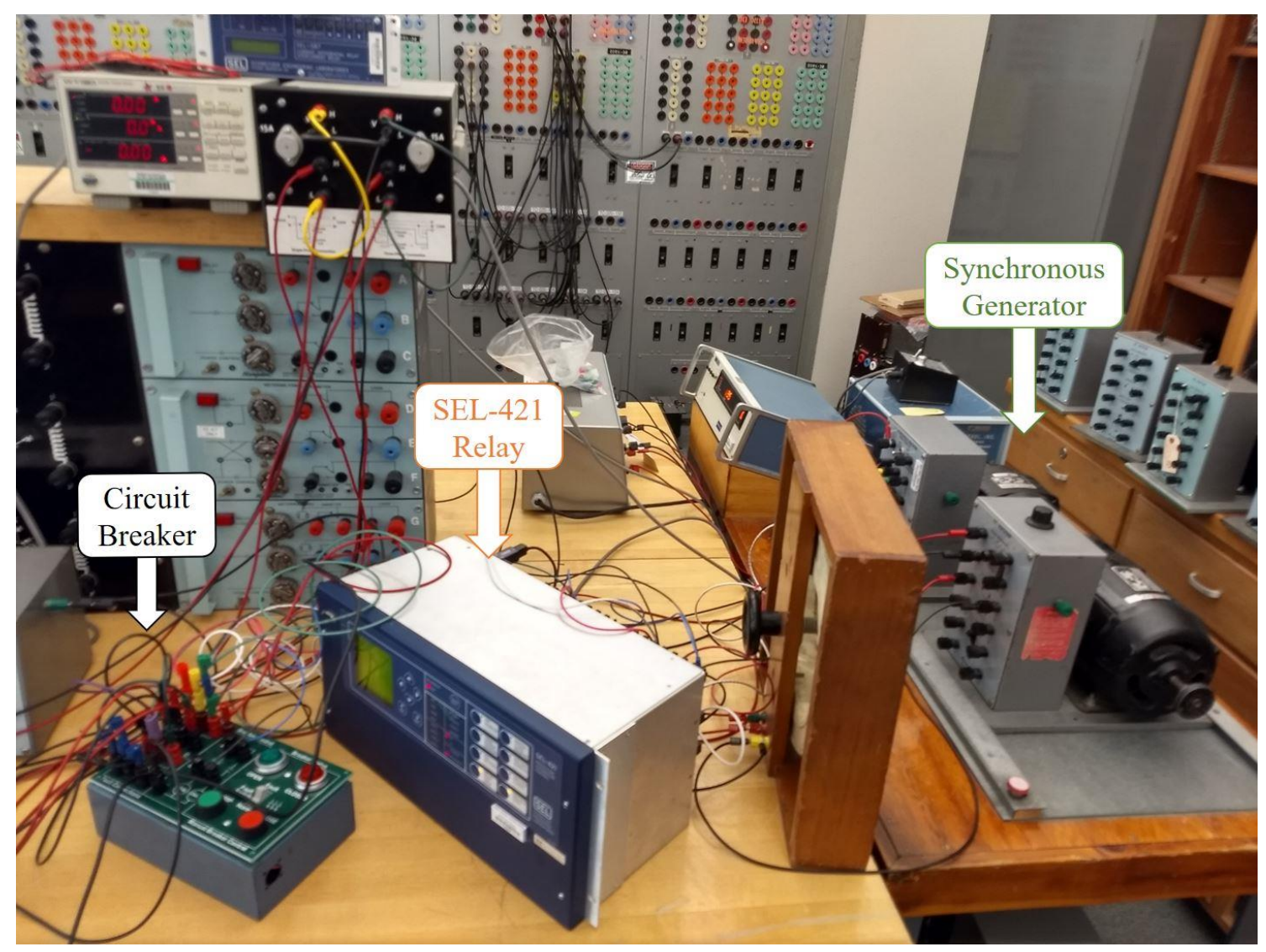

Figure 5-12: Three-phase short circuit test, synchronous generator

Figure 5-13 displays the ETAP implementation demonstrating a three-phase short circuit to an unloaded synchronous generator. The value displayed as 0.002 represents minimum ( 30 cycle) short circuit current $\mathrm{A}_{\mathrm{rms}}$ from the generator, after the asymmetrical 
component has decayed. Refer to Chapter 4 on a discussion of asymmetrical short circuit current.

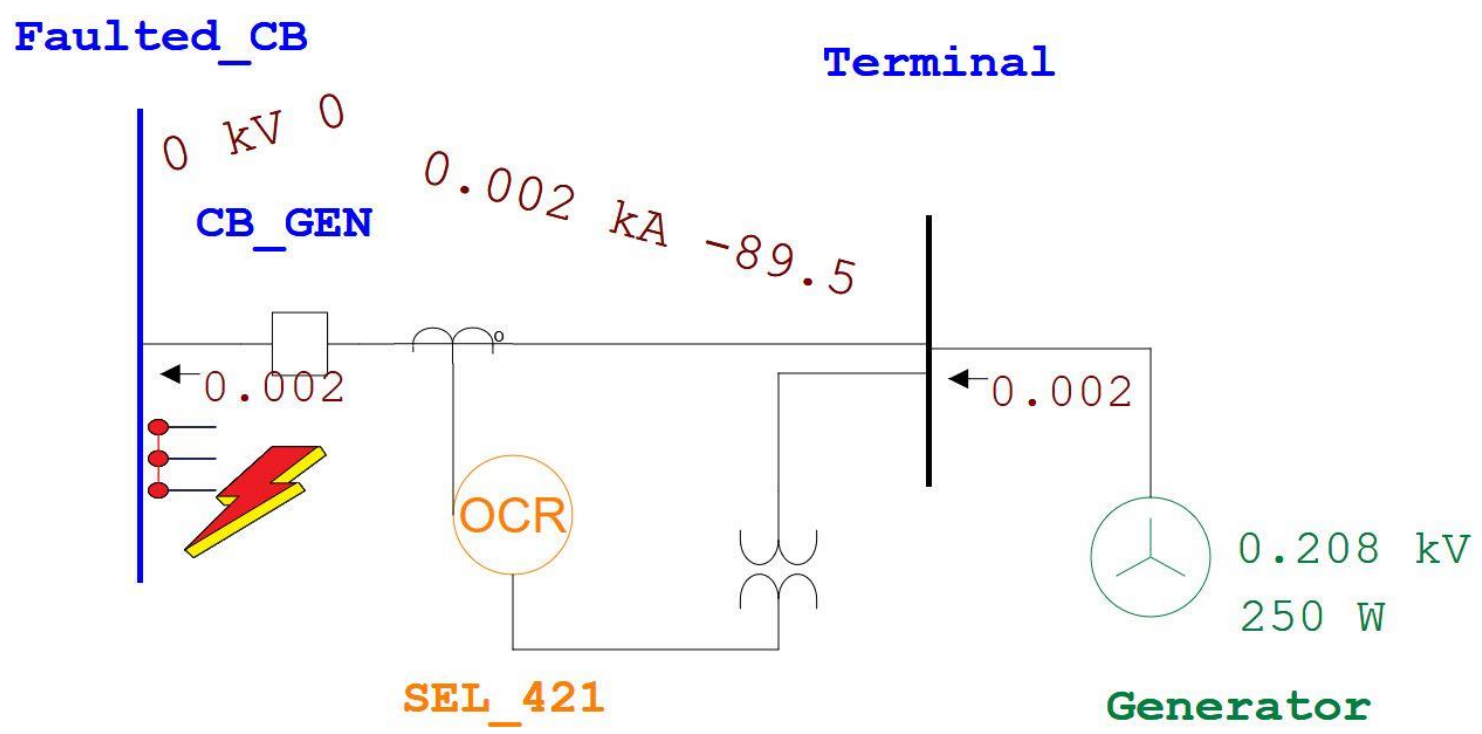

Figure 5-13: ETAP, three-phase short circuit test, synchronous generator

Figure 5-14 displays an oscillogram from an SEL-421 event report showcasing the generator response to a three-phase short circuit. The peak asymmetrical current is approximately 10.6 A, corresponding to a $7.5 \mathrm{~A}_{\mathrm{rms}}$ current. The asymmetrical (dc) component quickly dies down in less than a cycle and reaches a steady-state peak current of approximately $2.1 \mathrm{~A}$ or $1.5 \mathrm{~A}_{\text {rms. }}$. 


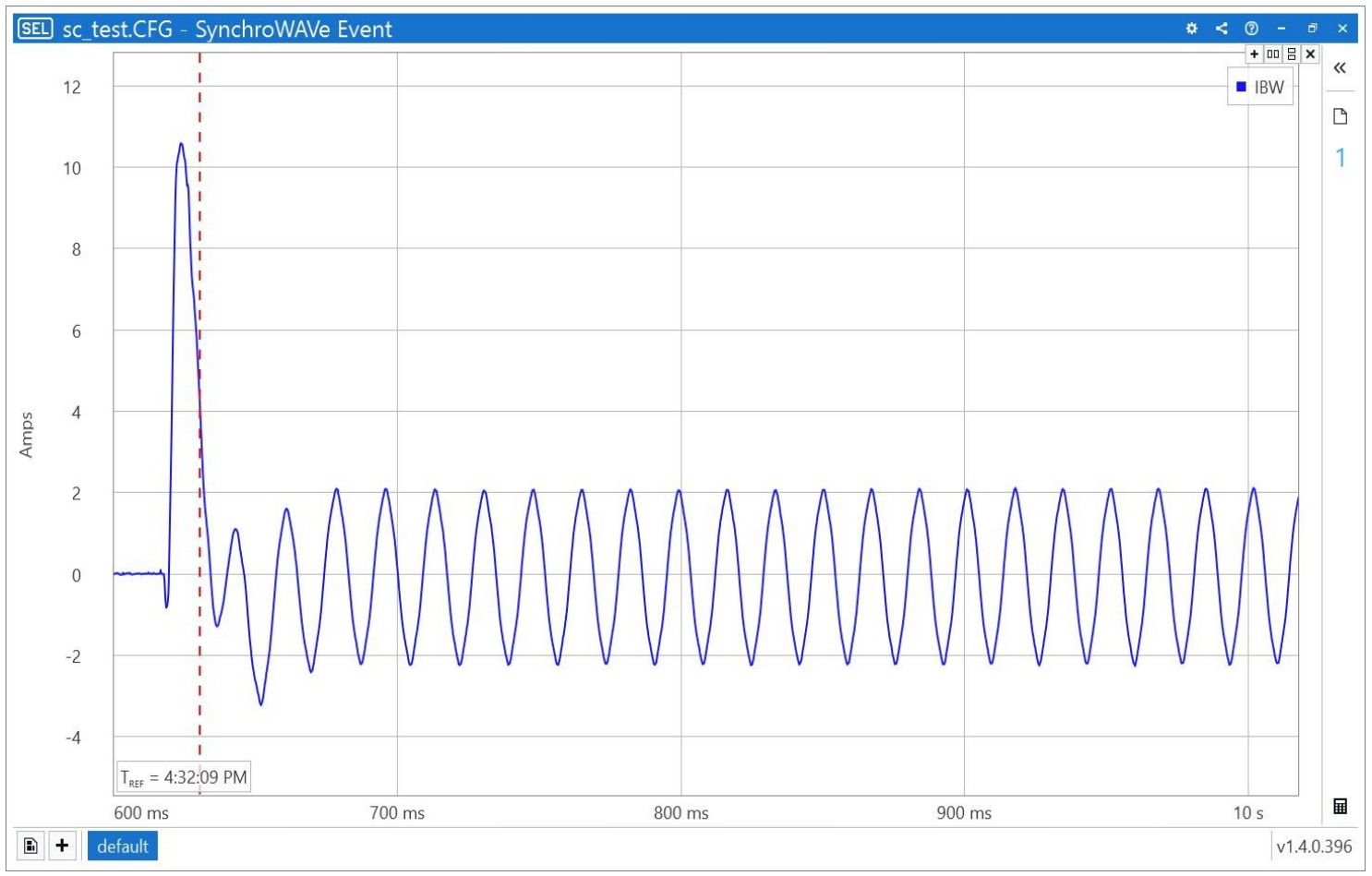

Figure 5-14: SEL Oscillogram, three-phase short circuit, synchronous generator

Figure 5-15 illustrates a plot utilizing ETAP transient stability module of a sudden three-phase short circuit data, showcasing the envelope of the asymmetrical current. The current in Figure 5-15 is provided in rms values, which is consistent with the hardware test of approximately $7 \mathrm{~A}_{\text {rms }}$ asymmetrical peak and $1.5 \mathrm{~A}_{\text {rms }}$ steady state short circuit. As will be seen in Section 5.4 this steady short circuit current will be utilized in the coordination of fault protection. 


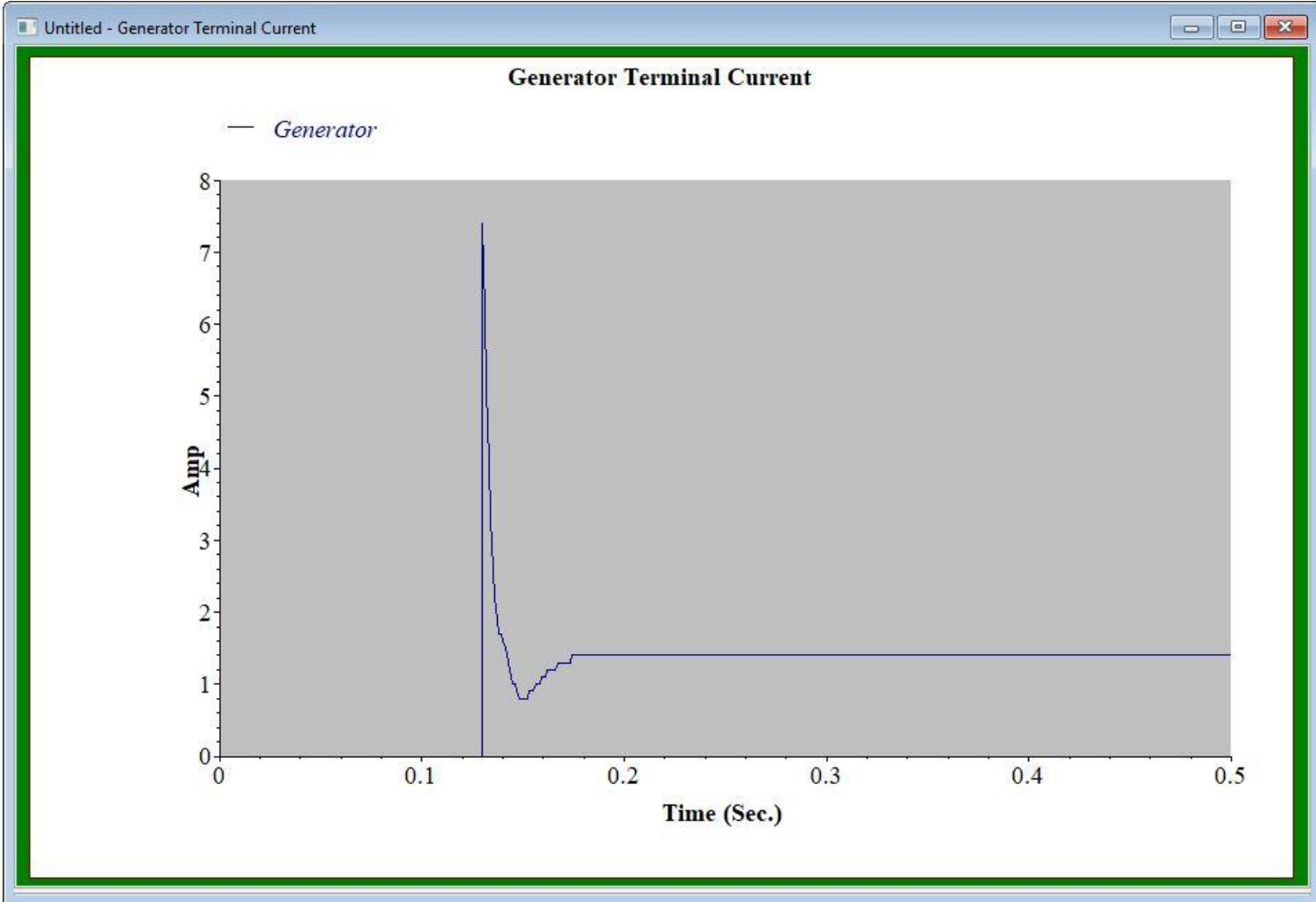

Figure 5-15: Generator short circuit terminal current, three-phase fault

ETAP Short Circuit module allows the short circuit studies performed in different timeframes, e.g. $1 / 2$ cycle, $1 \frac{1}{2}$ to 4 cycle, and 30 cycle networks. The $1 / 2$ cycle considers the network in which maximum fault currents are supplied to the system. For example, consider Figure 5-16, which displays an ETAP short circuit study at Synch_Bus. The maximum fault current is approximately $18 \mathrm{~A}_{\mathrm{rms}}$, where the two synchronous generators supply approximately $7 \mathrm{~A}_{\mathrm{rms}}$ momentarily. This is consistent with our transient stability simulation of Figure 5-15. 


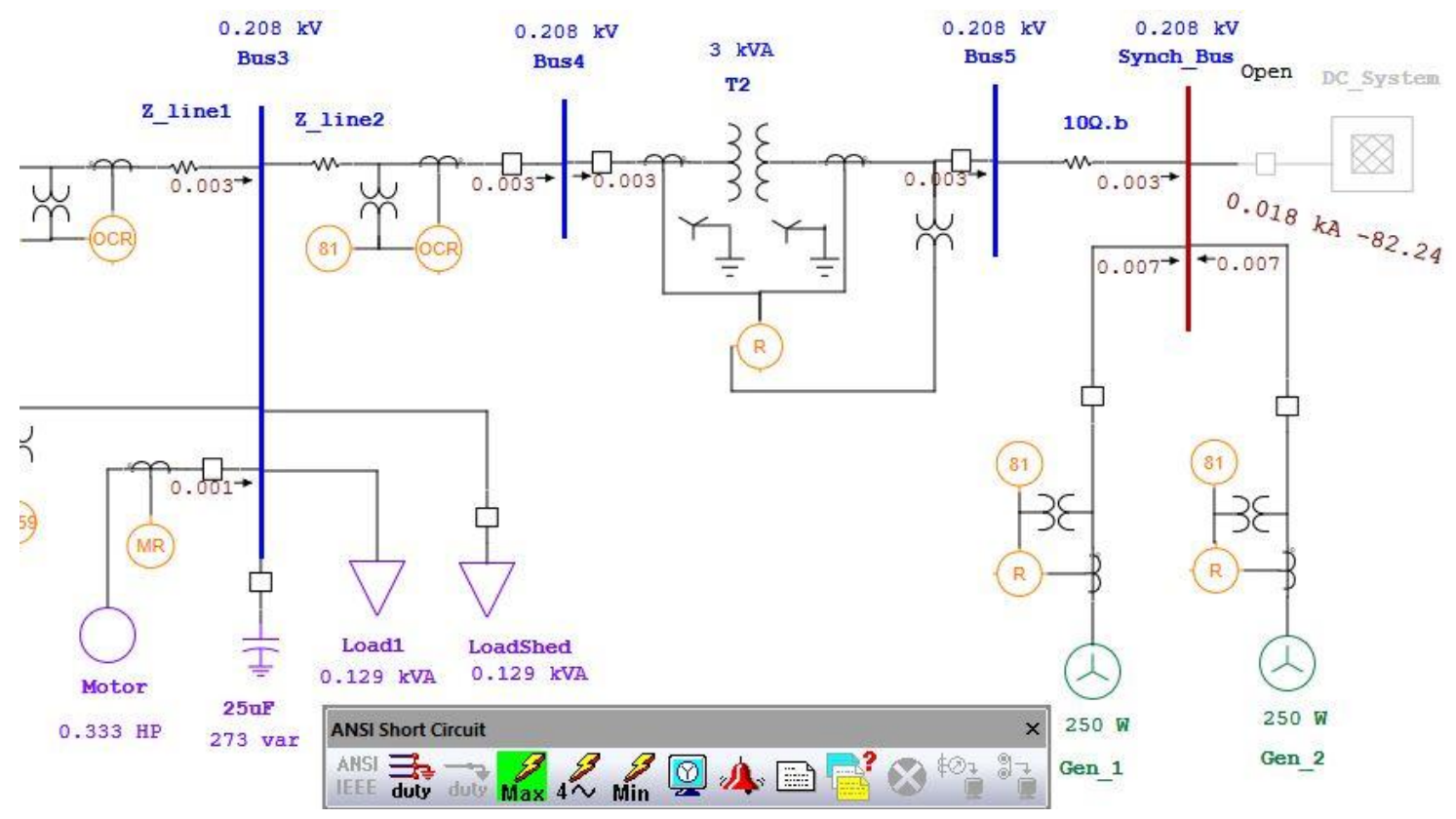

Figure 5-16: Maximum 3-phase SC (1/2 cycle) on generator terminals

Consider Figure 5-17 where the maximum fault current has been decreased from the generators. The fault at Synch_Bus has a minimum fault current of approximately $0.006 \mathrm{kA}_{\mathrm{rms}}$ or $6 \mathrm{~A}_{\mathrm{rms}}$, much lower than maximum simulated of $18 \mathrm{~A}_{\mathrm{rms}}$. This is the steady state asymmetrical short circuit current after the subtransient and transient portions has decayed. 


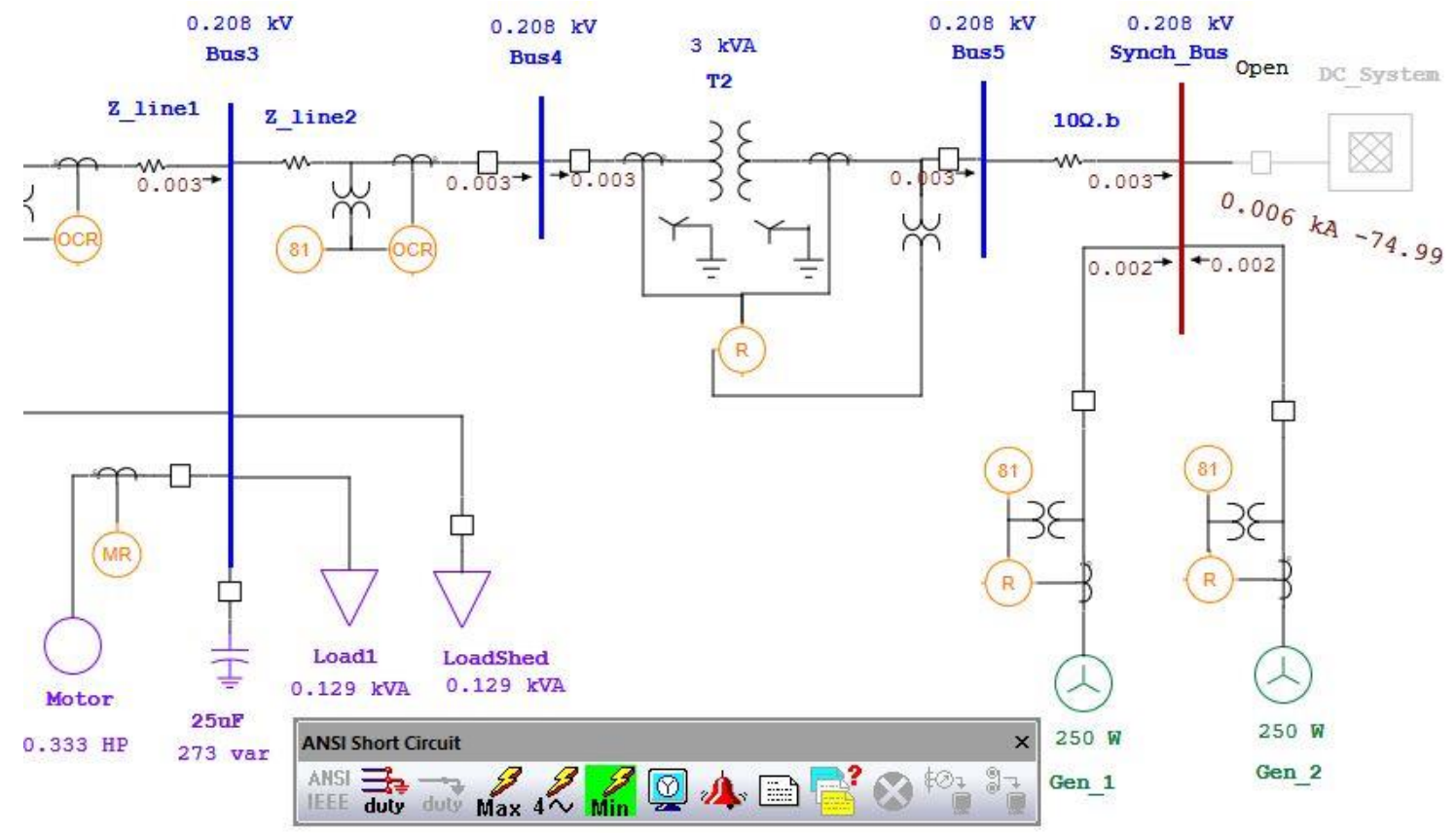

Figure 5-17: Minimum 3-phase SC (30 cycle) on generator terminals

Consider Figure 5-18 which displays the minimum 3-phase short circuit current at Bus 3. This is the fault current that will be heavily utilized throughout the protection and coordination section of the thesis. Hardware testing resulted in relays carrying current from Bus 4 to Bus 3 to not trip for maximum asymmetrical fault currents from the generators. 


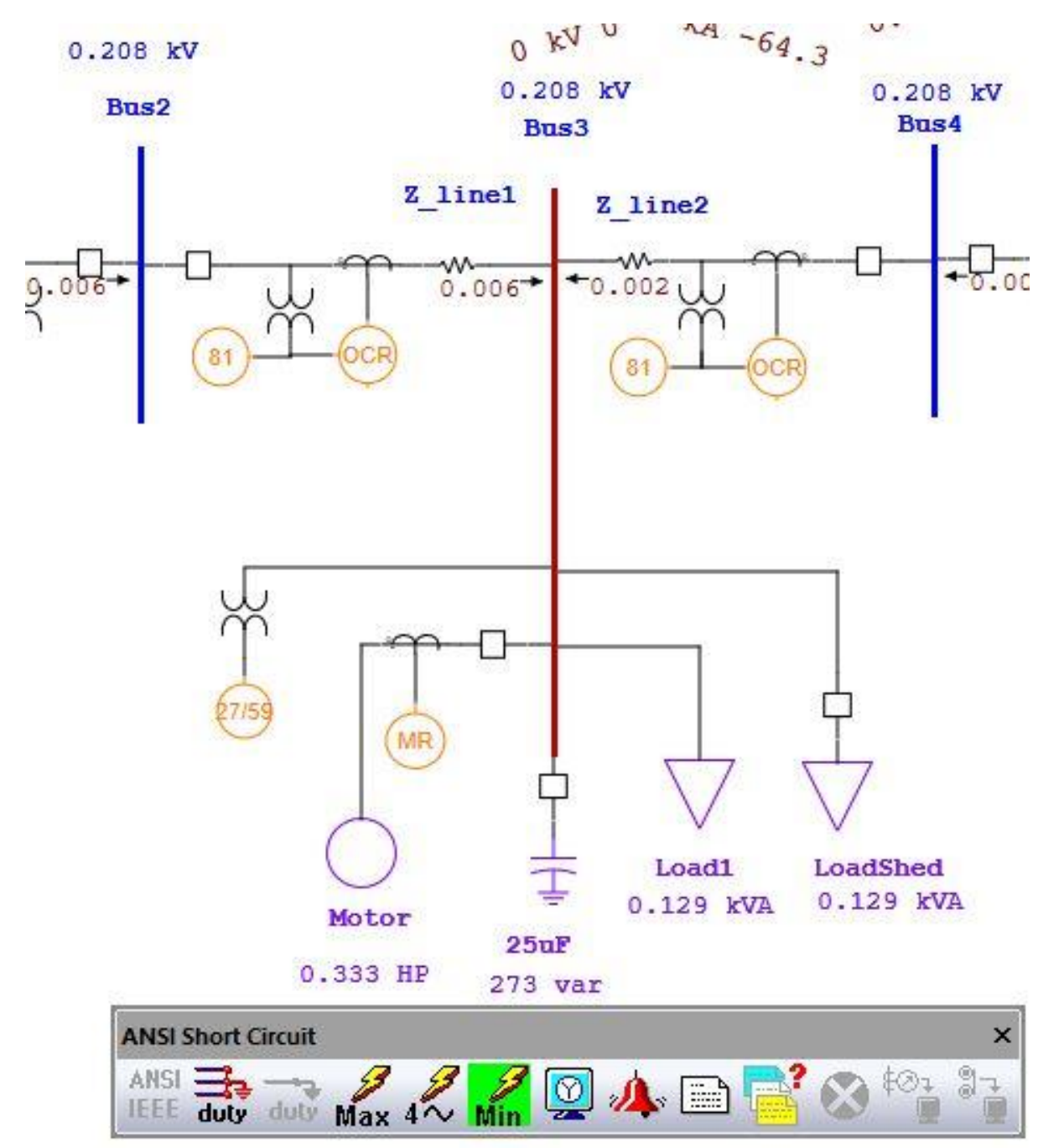

Figure 5-18: Minimum 3-phase SC (30 cycle) on Bus3

Figure 5-19 provides short circuit data for a line-to-line-to-ground fault at Bus 3.

The first row provides the total fault current at Bus 3 due to all sources of generation. The second row provides short circuit data from Bus 2 to Bus 3, namely the short circuit contribution from the utility. For example, sequence current I1 of $4 \mathrm{~A}_{\mathrm{rms}}, \mathrm{I} 2$ of $3 \mathrm{~A}_{\mathrm{rms}}$, and $\mathrm{I} 0$ of $2 \mathrm{~A}_{\mathrm{rms}}$ are the positive, negative, and zero sequence currents from the utility, respectively, due to a double line-to-ground fault at Bus 3. The third row provides short circuit data from Bus 4 to Bus 3, namely the short circuit contribution from the 
generators. A complete tabulation of necessary short-circuit date can be found in the appendix.

\section{Line-To-Line-To-Ground Fault}

\begin{tabular}{|c|c|c|c|c|c|c|c|c|}
\hline \multicolumn{6}{|c|}{ Current at From Bus (kA) } & & & \\
\hline \multicolumn{2}{|c|}{ Ia } & \multicolumn{2}{|c|}{$\mathrm{Ib}$} & \multicolumn{2}{|c|}{ Ic } & \multicolumn{3}{|c|}{ Sequence Current (kA) } \\
\hline Mag. & Ang. & Mag. & Ang. & Mag. & Ang. & I1 & $\mathrm{I} 2$ & I0 \\
\hline 0.000 & 0.0 & 0.008 & -180.0 & 0.008 & 51.3 & 0.005 & 0.003 & 0.002 \\
\hline 0.001 & -50.9 & 0.005 & -169.7 & 0.006 & 50.1 & 0.004 & 0.002 & 0.001 \\
\hline 0.001 & 129.1 & 0.003 & 161.6 & 0.003 & 53.9 & 0.001 & 0.001 & 0.002 \\
\hline
\end{tabular}

Figure 5-19: Double-Line-to-Ground Fault Bus 3, short circuit report

\subsubsection{Short Circuit Summary}

Short circuit analysis was utilized primarily as a precursor to the protection and coordination analysis. Maximum and minimum fault current contribution case studies were conducted, and the advantage of ETAP allows us to fault any bus with any kind of fault to obtain short circuit data. ETAP provides us to the tools to now be able to coordinate for faults at any bus by dissecting the positive, negative, and zero sequence component from the short circuit reports and adjusting relay settings as necessary. In particular, we are concerned with faults applied at Bus 3, the load bus, since we will coordinate our protective relays based on faults primarily the motor terminals as will be presented in Section 5.4. 


\subsection{Protection and Coordination Analysis}

We begin our ETAP protection and coordination analysis by considering several case studies. Case I considers the prior microgrid setup conducted in 2017, and analyzes an ET AP model with the hardware realization of the system. The following cases then study the current iteration of the microgrid with added synchronous generators and relays.

\subsubsection{Case I: Protection System Validation}

Case I considers the ET AP model of the previous microgrid and compares its protection coordination results with the hardware implementation of the microgrid for purposes of system validation and accuracy. Figure 5-20 models and displays a portion of the bidirectional system of the previous iteration of the microgrid. The bus is fully loaded with the induction motor and static loads drawing power. A double line-to-ground fault is suddenly applied on the terminals of the induction motor at Bus 3. Figure 5-20 displays the sequence-of-operation (SQOP) utilizing ETAP's STAR protection module, indicating the order of operation in which circuit breakers trip due to a fault applied at Bus 3. An ' $\mathrm{X}$ ' next to a number on the circuit breaker shows the tripping of circuit breakers in order due to a line-to-line-to-ground fault. Notice that this adheres to coordination criteria: circuit breakers closest to the fault trip, followed by circuit breakers upstream to the fault. Generation consists of the utility at 240 Vac to the left and right of the one-line, not shown in Figure 5-20. 


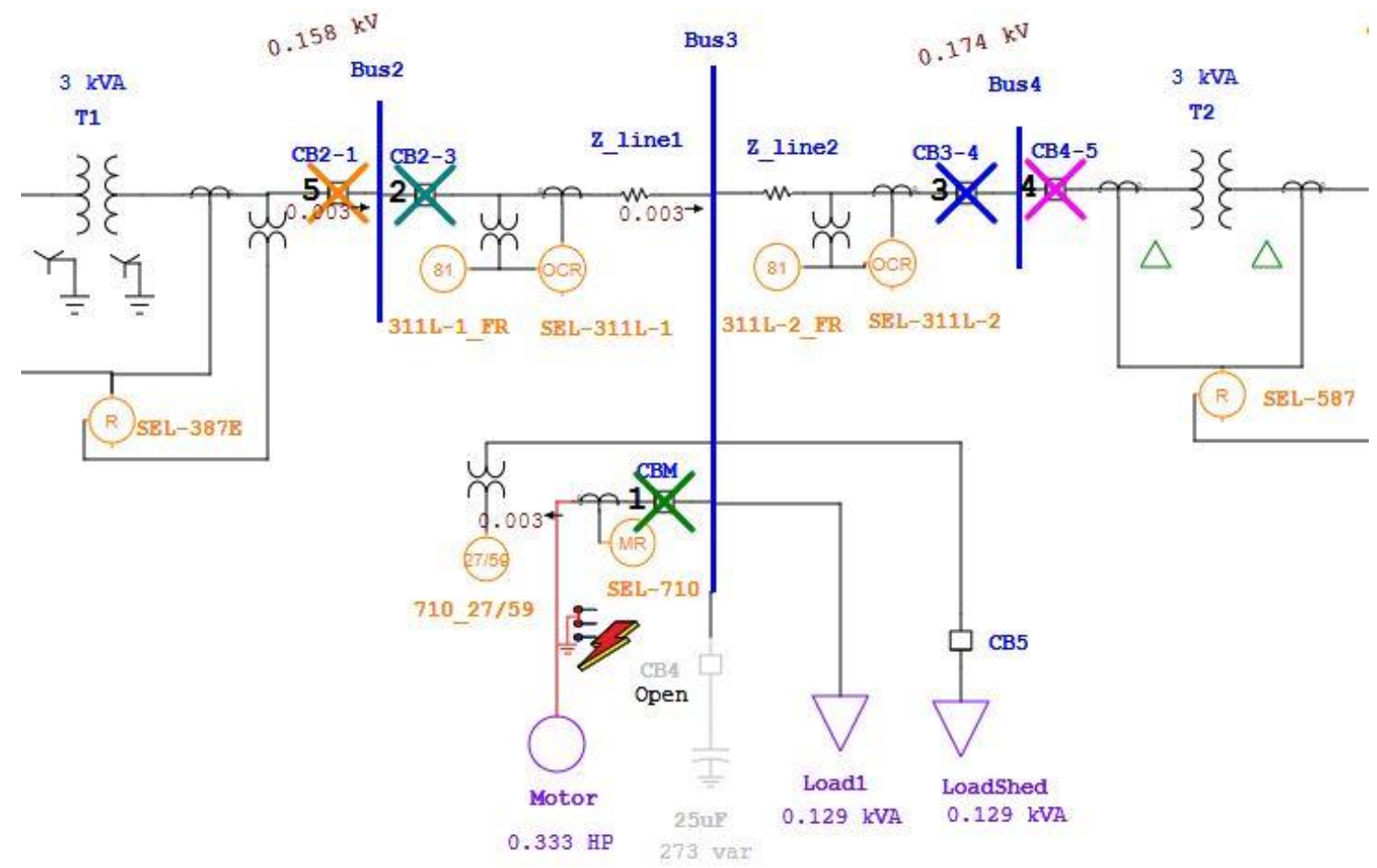

Figure 5-20: SQOP, Double Line-to-Ground Fault, prior microgrid

Figure 5-21 displays the SQOP viewer, showcasing a more analytical view of the tripping of circuit breakers. The time (in ms) column indicates the moment at which certain protective elements have asserted different commands, T1 (ms) indicates the operating time of the device, and the condition column indicates the reasoning behind the operation of protective elements. For example, at time $85.2 \mathrm{~ms}$ SEL-311L-1's negative inverse overcurrent (51Q) element asserts trip signals to circuit breaker CB2-3. At time $119 \mathrm{~ms}, \mathrm{CB} 2-3$ opens the line within two cycles $(\mathrm{T} 1=33.3 \mathrm{~ms})$, providing secondary protection for a double line-to-ground fault at the induction motor in case primary protection from SEL-710 misoperates or fails. 


\begin{tabular}{|c|c|c|c|c|c|c|}
\hline \multicolumn{6}{|c|}{ II Sequence-of-Operation Events - Output Report: Bidirectional System Tripping for DLG Fault } & X \\
\hline \multicolumn{7}{|c|}{ Line-to-Line-to-Ground (Symmetrical) fault on connector between Motor \& CT15. Adjacent bus: Bus 3} \\
\hline \multicolumn{4}{|c|}{ Data Rev: Base } & \multicolumn{2}{|c|}{ Config: Normal Date: $04-06-2018$} & \\
\hline Time $(\mathrm{ms})$ & ID & If $(\mathrm{kA})$ & T1 (ms) & $\mathrm{T} 2$ (ms) & Condition & \\
\hline 0.0 & SEL-710 & 0.011 & 0.0 & & Overload Phase - Instantaneous & \\
\hline 33.3 & CBM & & 33.3 & & Tripped by SEL-710 0verload Phase - Instantane... & \\
\hline 85.2 & SEL-311L-1 & 0.008 & 85.2 & & Negative Sequence $-0 \mathrm{C1} \cdot 51$ & \\
\hline 85.2 & SEL-311L-2 & 0.008 & 85.2 & & Negative Sequence - 0C1 - 51 & \\
\hline 112 & SEL-587 & 0.008 & 112 & & Negative Sequence - 0C1 - 51 & \\
\hline 112 & SEL-387E & 0.008 & 112 & & Negative Sequence - 0C1 - 51 & \\
\hline 119 & $\mathrm{CB} 2-3$ & & 33.3 & & Tripped by SEL-311L-1 Negative Sequence - 0C... & \\
\hline 119 & CB3-4 & & 33.3 & & Tripped by SEL-311L-2 Negative Sequence - 0C... & \\
\hline 145 & CB $4-5$ & & 33.3 & & Tripped by SEL-587 Negative Sequence - 0C1 - 51 & \\
\hline 145 & $\mathrm{CB} 2-1$ & & 33.3 & & Tripped by SEL-387E Negative Sequence - 0C1 ... & \\
\hline
\end{tabular}

Figure 5-21: SQOP Report, Double Line-to-Ground, prior microgrid

Consider Table 5-4 which is tabulated per reference [4] of the previous microgrid configuration indicating the system tripping time for the same fault in Figure 5-20. The ETAP model showcases a very accurate tripping time compared to the previous microgrid. For example, SEL-587 trips at time $109 \mathrm{~ms}$ in Table 5-4, compared to $112 \mathrm{~ms}$ in Figure 5-21. Imbalances in tripping times shown in Table 5-4 could be attributed to slight imbalances in the microgrid, differences in pre-fault voltages, and system impedances, but ultimately the ETAP model indicates a very accurate response to the system for the double line-to-ground fault. 
Table 5-4: Bidrectional System Tripping for a Double-Line-to-Ground Fault [4]

\begin{tabular}{|c|c|c|c|}
\hline $\begin{array}{r}\text { TIME } \\
\text { DELTA } \\
(\text { mSEC) }\end{array}$ & $\begin{array}{c}\text { SEL RELAY } \\
\text { DEVICE }\end{array}$ & $\begin{array}{c}\text { ASSERTED } \\
\text { ELEMENTS }\end{array}$ & COMMENT \\
\hline 7 & 710 & TRIP & Instantaneous Trip \\
\hline 80 & 311L - LINE 2 & 51QT, TRIP & Timeout and Trip \\
\hline 84 & 311L - LINE 1 & 51QT, TRIP & Timeout and Trip \\
\hline 109 & 587 & $51 \mathrm{Q} 2 \mathrm{~T}$, TRIP & Timeout and Trip \\
\hline 114 & $387 \mathrm{E}$ & 51Q2T, TRIP & Timeout and Trip \\
\hline
\end{tabular}

Table 5-5 provides settings for both the hardware implementation as well as settings implemented in ETAP for negative-sequence time overcurrent protection (and motor protection) for the prior iteration of the microgrid. In particular, the negative sequence elements are identical for both hardware and software implementations for system validation. 
Table 5-5: Negative sequence time overcurrent settings, prior microgrid

\begin{tabular}{|c|c|c|c|c|c|c|}
\hline \multirow{2}{*}{ Relay ID } & \multirow{2}{*}{$\begin{array}{l}\text { Device } \\
\text { Function }\end{array}$} & \multirow{2}{*}{$\begin{array}{c}\text { Trip } \\
\text { Element }\end{array}$} & \multirow{2}{*}{ Curve } & \multicolumn{3}{|c|}{$\begin{array}{c}\text { OCR }(50,51), \text { OLR }(49, \\
\text { Acc. })\end{array}$} \\
\hline & & & & $\begin{array}{l}\text { Pickup } \\
\text { (A) }\end{array}$ & $\begin{array}{c}\text { Prim. } \\
\text { Amps } \\
\text { (A) }\end{array}$ & $\begin{array}{c}\text { Time } \\
\text { Dial } \\
\text { Setting } \\
\end{array}$ \\
\hline SEL-387E & Overcurrent & $\begin{array}{l}\text { Negative } \\
\text { Sequence }\end{array}$ & $\begin{array}{l}\text { U1- U.S. } \\
\text { Moderately } \\
\text { Inverse }\end{array}$ & 0.500 & 0.500 & 0.550 \\
\hline SEL-710 & Overload & $\begin{array}{l}\text { Overload } \\
\text { Phase }\end{array}$ & & 2.280 & 2.00 & \\
\hline SEL-311L-1 & Overcurrent & $\begin{array}{l}\text { Negative } \\
\text { Sequence }\end{array}$ & $\begin{array}{l}\text { U1 - U.S. } \\
\text { Moderately } \\
\text { Inverse }\end{array}$ & 0.250 & 0.250 & 0.500 \\
\hline SEL-311L-2 & Overcurrent & $\begin{array}{l}\text { Negative } \\
\text { Sequence }\end{array}$ & $\begin{array}{l}\text { U1 - U.S. } \\
\text { Moderately } \\
\text { Inverse }\end{array}$ & 0.250 & 0.250 & 0.500 \\
\hline SEL-587 & Overcurrent & $\begin{array}{l}\text { Negative } \\
\text { Sequence }\end{array}$ & $\begin{array}{l}\text { U1 - U.S. } \\
\text { Moderately } \\
\text { Inverse }\end{array}$ & 0.500 & 0.500 & 0.550 \\
\hline
\end{tabular}

Figure 5-22 demonstrates a time-current curve (TCC) of a line-to-line-to-ground fault at the terminals of the induction motor, as indicated in Figure 5-20. The vertical dashed red arrow indicates a normalized fault current of 1 per unit, corresponding to 10.8 $\mathrm{A}_{\mathrm{rms}}$ fault current. The time difference shown in blue of 0.0269 seconds $(26.9 \mathrm{~ms})$ is indicative of the delay between upstream relays. SEL-710's instantaneous phase overcurrent protection first detects and trips the nearby circuit breaker on the motor terminals. This is observed by SEL-710's instantaneous vertical overcurrent curve having a pickup setting less than the fault current to the right. The overlapping pair of negative sequence time overcurrent curves for SEL-311L-1 and SEL-311L-2, as well as SEL-587 and SEL-387E are due to identical relay settings tabulated in Table 5-5. 
Figure 5-22 illustrates an example of the following design criteria for system protection outline in Chapter 4: reliability, selectivity, speed, economy, and simplicity [11]. Glover suggests that "Precise determine of relay operating times is complicated by several factors, including CT error, dc offset component of fault current, and relay overtravel. Therefore, typical coordination time intervals from 0.2 to 0.5 seconds are selected to account for these factors in most practical applications" [11]. The time difference of $26.9 \mathrm{~ms}$ in Figure 5-22 can be argued to be too low of a coordination time interval between secondary and tertiary protection in the prior iteration of the microgrid. Circuit breakers in the Cal Poly microgrid clear the fault within $33 \mathrm{~ms}$ (two cycles), therefore this protection scheme can be improved by allowing a greater time delay added to both SEL-311's as well as SEL-587 and SEL-387E negative sequence settings. Although this protection scheme was verified in the prior implementation of the microgrid, the time margin between relay operating times may be susceptible for false tripping, and illustrates the compromise of relay selectivity in favor of relay speed. 


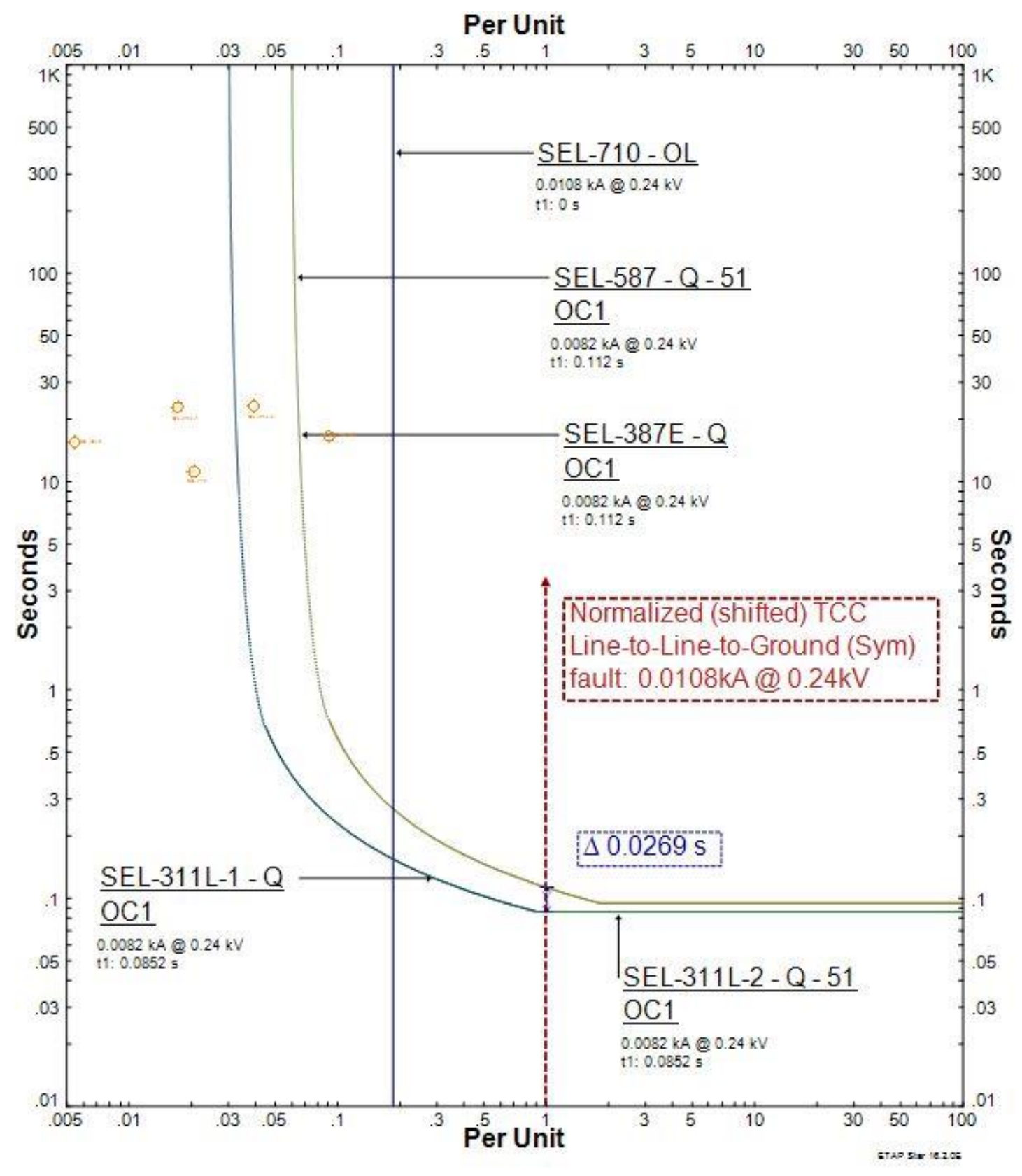

Figure 5-22: TCC Bidirectional Relay Coordination, prior microgrid

Figure 5-23 shows a modified protection scheme for a double line-to-ground fault at the terminals of the induction motor for the prior microgrid. Greater selectivity is achieved by implementing adequate time delay between secondary and tertiary protection. Time difference $\mathrm{t} 1$ of 0.334 seconds is the time margin for SEL-311L-1 and 
SEL-387E negative sequence time overcurrent curves. Similarly, time difference t 2 of 0.333 seconds is the time margin for SEL-311L-2 and SEL-587. This provides a standardized relay coordination time of 0.3 seconds added with two cycle circuit breaker clearing times of 0.033 seconds at $60 \mathrm{~Hz}$.

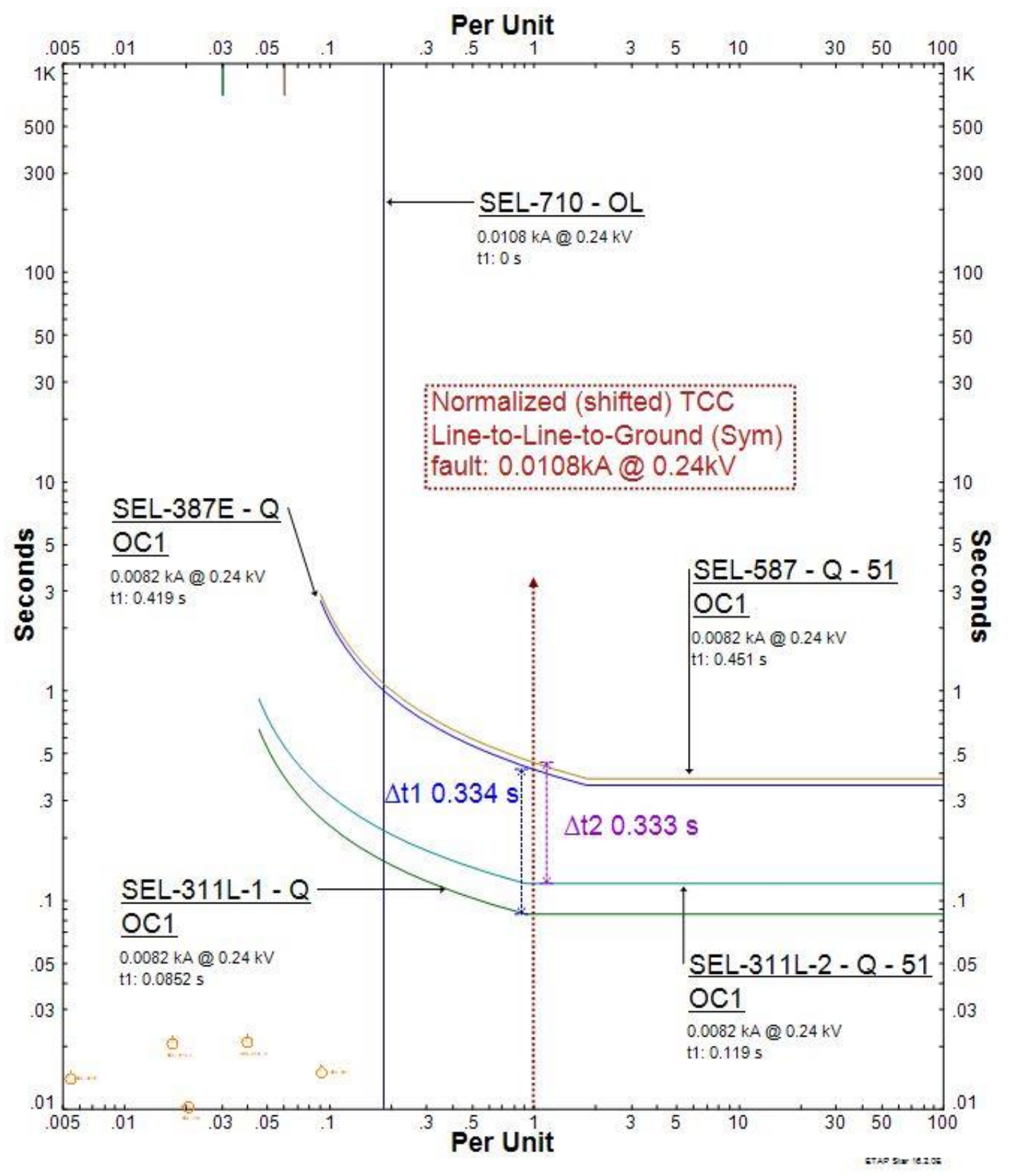

Figure 5-23: TCC Modified Bidirectional Relay Coordination, prior microgrid 
Table 5-6 provides settings implemented in ETAP for negative-sequence time overcurrent protection for the modified prior iteration of the bidirectional system illustrated in Figure 5-23. Comparisons can be made with Table 5-5 to observe the variations in time delay. For example, SEL-311L-2 was modified from a time delay of 0.5 to 0.7 and SEL-587 from 0.55 to 2.220 for purposes of illustrating a modified protection scheme with added selectivity instead of speed.

Table 5-6: Negative sequence time overcurrent settings, modified prior microgrid

\begin{tabular}{|c|c|c|c|c|c|c|}
\hline \multirow[b]{2}{*}{ Relay ID } & \multirow[b]{2}{*}{$\begin{array}{l}\text { Device } \\
\text { Function }\end{array}$} & \multirow[b]{2}{*}{$\begin{array}{c}\text { Trip } \\
\text { Element }\end{array}$} & \multirow[b]{2}{*}{ Curve } & \multicolumn{3}{|c|}{$\begin{array}{c}\text { OCR }(50,51), \text { OLR }(49, \\
\text { Acc. })\end{array}$} \\
\hline & & & & $\begin{array}{l}\text { Pickup } \\
\text { (A) }\end{array}$ & $\begin{array}{l}\text { Prim. } \\
\text { Amps } \\
\text { (A) }\end{array}$ & $\begin{array}{l}\text { Time } \\
\text { Dial } \\
\text { Setting }\end{array}$ \\
\hline SEL-710 & Overload & $\begin{array}{l}\text { Overload } \\
\text { Phase }\end{array}$ & & 2.280 & 2.00 & \\
\hline SEL-311L-1 & Overcurrent & $\begin{array}{l}\text { Negative } \\
\text { Sequence }\end{array}$ & $\begin{array}{c}\text { U1 - U.S. } \\
\text { Moderately Inverse }\end{array}$ & 0.250 & 0.250 & 0.500 \\
\hline SEL-311L-2 & Overcurrent & $\begin{array}{l}\text { Negative } \\
\text { Sequence }\end{array}$ & $\begin{array}{c}\text { U1 - U.S. } \\
\text { Moderately Inverse }\end{array}$ & 0.250 & 0.250 & 0.700 \\
\hline SEL-387E & Overcurrent & $\begin{array}{l}\text { Negative } \\
\text { Sequence }\end{array}$ & $\begin{array}{l}\text { U1- U.S. Moderately } \\
\text { Inverse }\end{array}$ & 0.500 & 0.500 & 2.060 \\
\hline SEL-587 & Overcurrent & $\begin{array}{l}\text { Negative } \\
\text { Sequence }\end{array}$ & $\begin{array}{c}\text { U1 - U.S. } \\
\text { Moderately Inverse }\end{array}$ & 0.500 & 0.500 & 2.220 \\
\hline
\end{tabular}

Figure 5-24 displays the SQOP viewer for the modified protection scheme. In this scenario relay trip signals are slower than the prior microgrid, with added selectivity gained. Ultimately, protection is not an exact science and there is no ideal right answer in 
incorporating relay settings - there are tradeoffs that must be taken into account. For example, we will investigate the detriment of having slower relay fault clearing speeds in transient stability case I.

\begin{tabular}{|c|c|c|c|c|c|c|}
\hline \multicolumn{7}{|c|}{ III Sequence-of-Operation Events - Output Report: DLG Fault improved selectivity $\quad \times$} \\
\hline \multicolumn{7}{|c|}{ Line-to-Line-to-Ground (Symmetrical) fault on connector between Motor \& CT15. Adjacent bus: Bus 3} \\
\hline \multicolumn{4}{|c|}{ Data Rev:: Base } & Config: Normal & Date: $04-07-2018$ & \\
\hline Time (ms) & ID & If $[\mathrm{kA}]$ & $\mathrm{T} 1$ (ms) & $\mathrm{T} 2$ (ms) & Condition & \\
\hline 0.0 & SEL-710 & 0.011 & 0.0 & & Overload Phase - Instantaneous & \\
\hline 33.3 & $\mathrm{CBM}$ & & 33.3 & & Tripped by SEL-710 0verload Phase - Instantane... & \\
\hline 85.2 & SEL-311L-1 & 0.008 & 85.2 & & Negative Sequence - 0C1 - 51 & \\
\hline 119 & $\mathrm{CB} 2 \cdot 3$ & & 33.3 & & Tripped by SEL-311L-1 Negative Sequence - OC... & \\
\hline 119 & SEL-311L-2 & 0.008 & 119 & & Negative Sequence - $0 \mathrm{C1} \cdot 51$ & \\
\hline 153 & $\mathrm{CB} 3-4$ & & 33.3 & & Tripped by SEL-311L-2 Negative Sequence - OC... & \\
\hline 419 & SEL-387E & 0.008 & 419 & & Negative Sequence - $0 \mathrm{C1} \cdot 51$ & \\
\hline 451 & SEL-587 & 0.008 & 451 & & Negative Sequence - $0 \mathrm{C1} \cdot 51$ & \\
\hline 452 & $\mathrm{CB} 2-1$ & & 33.3 & & Tripped by SEL-387E Negative Sequence - 0C1 ... & \\
\hline 484 & CB4-5 & & 33.3 & & Tripped by SEL-587 Negative Sequence - 0C1 - 51 & \\
\hline
\end{tabular}

Figure 5-24: SQOP viewer, DLG fault improved selectivity

Consider Figure 5-25 displaying an SEL oscillogram per reference [4] showcasing differential protection of the prior microgrid. In this illustration, "the restrained differential element (87R) on the SEL-387E asserts approximately 2 cycles after fault inception, whereupon the relay trips its circuit breakers on Bus 1 and Bus 2 to clear the fault" [4]. 


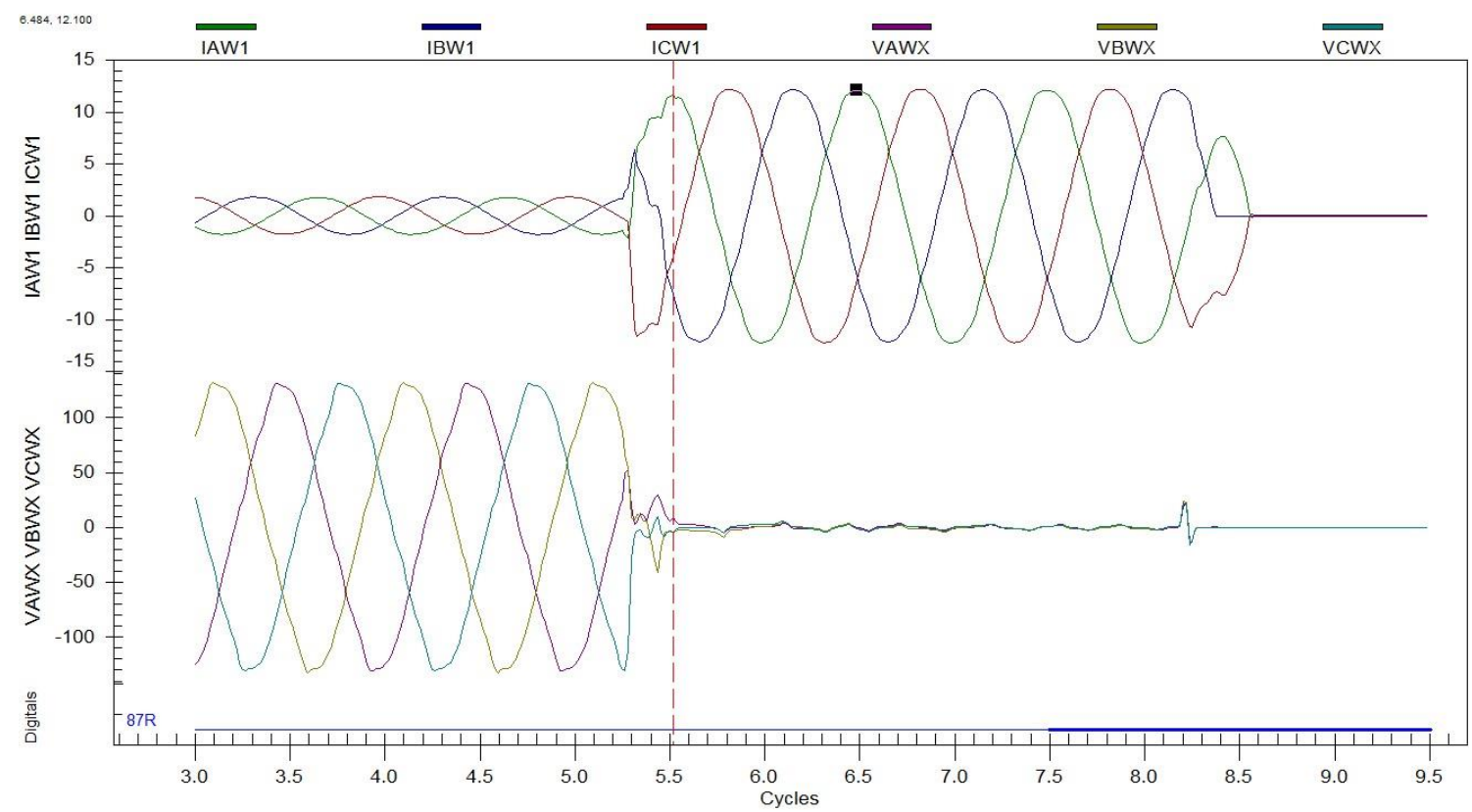

Figure 5-25: SEL-387E Three-Phase Fault, Bus 1, Phases A, B, C [4]

Let us now consider a different type of protection other than overcurrent: differential protection. Figure 5-26 illustrates differential protection modeled in ETAP for that of Figure 5-25. Notice that $0.012 \mathrm{kA}_{\text {rms }}$ or $12 \mathrm{~A}_{\mathrm{rms}}$ flows from Bus 1 towards Bus 2 contributed from the utility on the left. This is consistent with Figure 5-25, where the oscillogram showcases a $12 \mathrm{~A}_{\text {rms }}$ peak. It is important to notice that the peak values shown in Figure 5-25 is the rms value of the current waveform, consistent with the rms current of $12 \mathrm{~A}_{\mathrm{rms}}$ shown in Figure 5-26. 


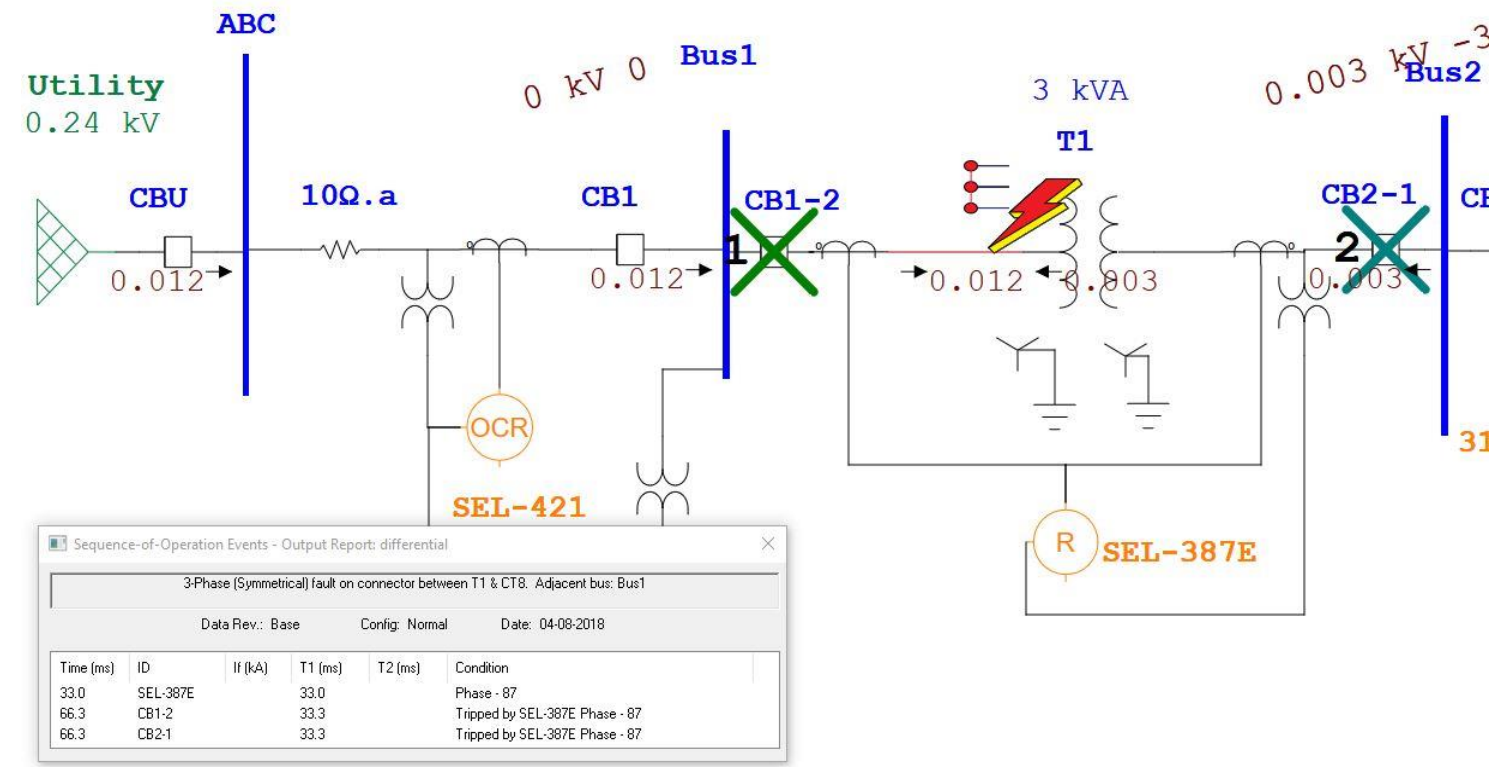

Figure 5-26: ETAP, differential protection

In summary, Case I illustrated the ETAP system validation of the prior iteration of the microgrid through considering the coordination of a double line-to-ground fault at the terminals of the induction motor. TCCs were generated to illustrate the coordination between devices, protective device settings were tabulated, and modifications were made to illustrate the improvement of selectivity over speed in coordination of relays. We now turn to the current iteration of the microgrid by lowering system voltages and adding synchronous generators.

\subsubsection{Case II: Three-Phase Fault}

The complete settings utilized in the protection of three-phase, double-line-toground, line-to-line, and single-line-to-ground faults can be found in Appendix E. We begin our study of protection coordination of the current iteration of the microgrid by applying a three-phase fault on the terminals of the induction motor at Bus 3. If 
coordinated correctly, the protective devices closest to the fault should open first followed by breakers upstream to the fault. The symmetrical components of a balanced three-phase fault result in only positive sequence components, and therefore phase overcurrent protection is utilized for this case. SEL-710 first clears the fault utilizing phase instantaneous overcurrent protection (ANSI 50P). Secondary protection is implemented utilizing phase time-overcurrent protection (51PT) for SEL311L-1 and SEL311L-2. Tertiary protection is implemented utilizing 51PT settings for SEL-387E and SEL-587. Figure 5-27 displays the sequence-of-events (SQOP) of circuit breakers tripping in order indicated by a number beside an ' $\mathrm{X}$ ' for a three phase fault on the terminals of the induction motor.

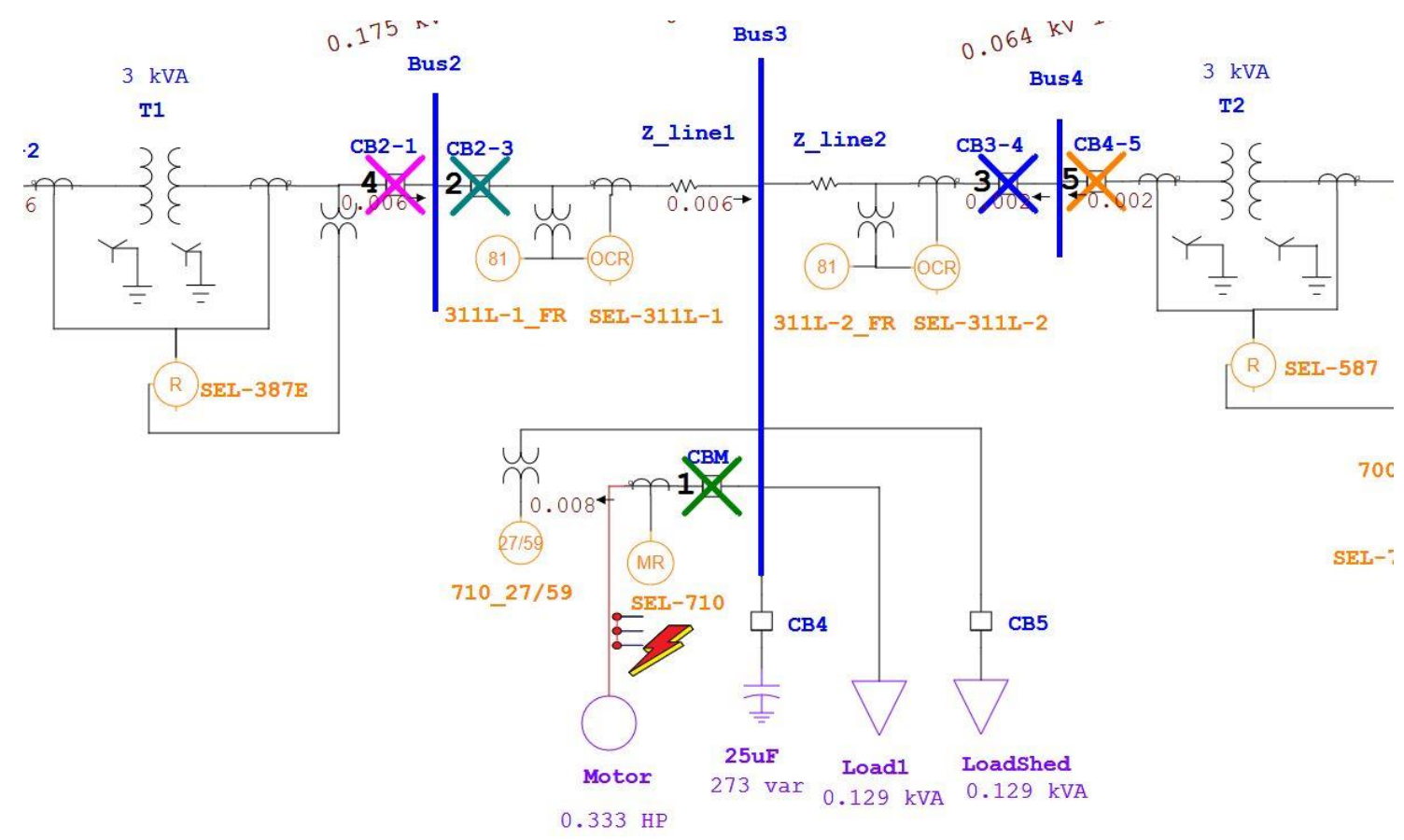

Figure 5-27: SQOP, Three-Phase Fault, Motor Terminals 
The opening of circuit breakers can be investigated more analytically through ETAP's sequence-of-operation (SQOP) event viewer, shown in Figure 5-28. At time $t=0$ sec, a three-phase fault is applied onto the terminals of the induction motor. SEL-710's instantaneous overcurrent protection detects and opens the nearest circuit breaker, CBM. Breaker CBM operates in $33.3 \mathrm{~ms}$, clearing the fault in two cycles.

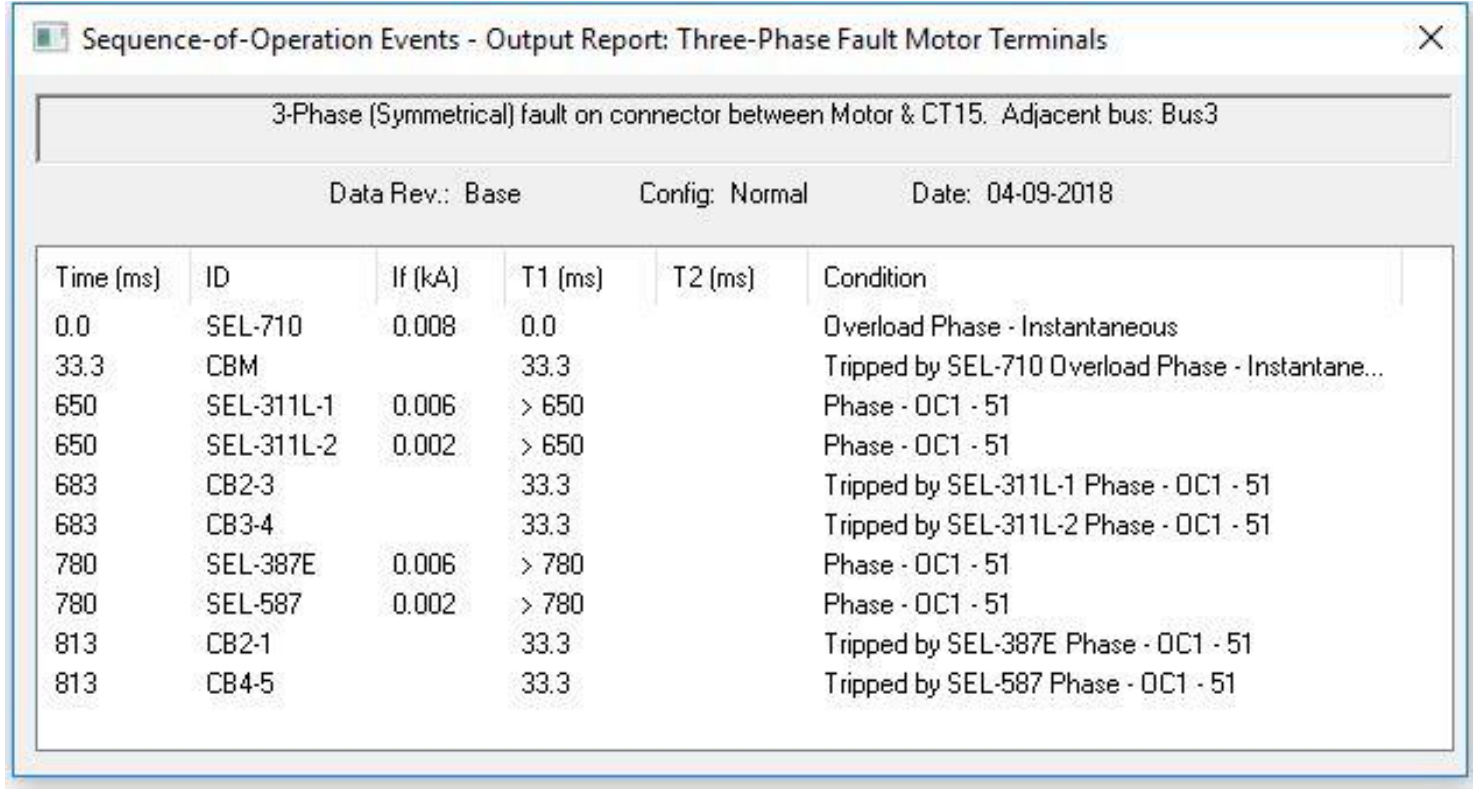

Figure 5-28: SQOP Events, three-phase fault motor terminals

Consider Figure 5-29 which illustrates a time-current curve (TCC) of a threephase fault injected on the terminals of the induction motor. The vertical red dashed arrows indicate the approximate contribution to the fault currents from both the utility and the synchronous generators. Notice that phase time-inverse overcurrent $(51 \mathrm{P})$ curves for both SEL-311L-2 and SEL-587 are shifted towards the left. This is necessary and indicative of lower pickup settings for the aforementioned relays due to being in a path with smaller fault currents from the generators. However, SEL-387E and SEL-311L 51P 
curves are shifted towards the right, due to higher pickup settings a result of being on the path sustaining fault current from the utility.

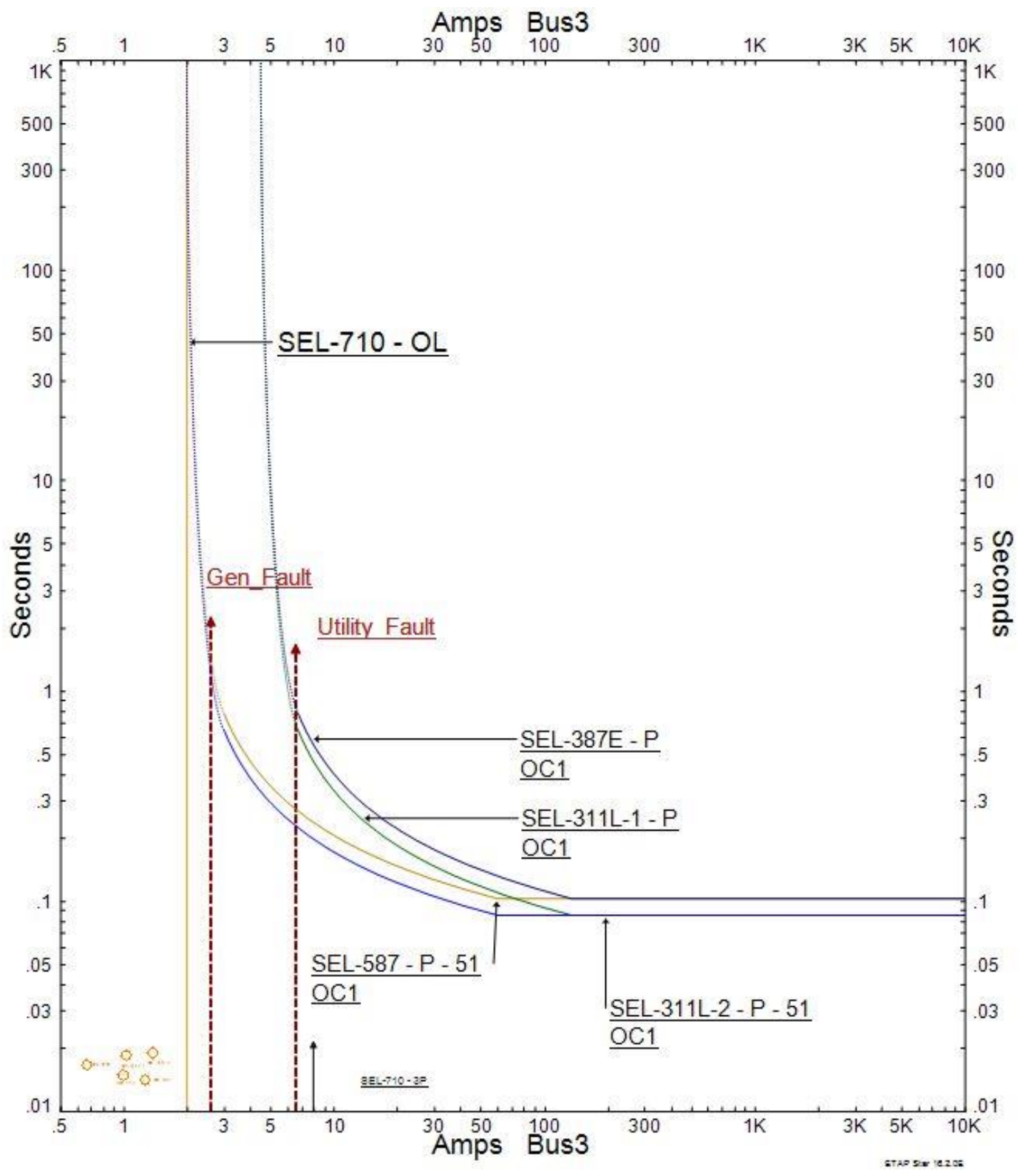

Figure 5-29: Three-Phase Fault, Motor Terminals, TCC 


\subsubsection{Case III: Single-Line-to-Ground}

A single-line-to-ground fault is applied on the terminals of the motor.

Decomposition of the fault current results in positive, negative, and zero sequence components. SEL-710 first clears the fault utilizing definite-time residual overcurrent element (50G). SEL-311L-1 and SEL-311L-2 utilize inverse-time negative sequence elements (51Q) providing secondary backup protection. Similarly, SEL-587 and SEL387E utilize 51Q to provide tertiary backup protection. Figure 5-30 displays the sequence-of-events (SQOP) of circuit breakers tripping in order indicated by a number beside an ' $\mathrm{X}$ ' for a single-line-to-ground fault on the terminals of the induction motor. Additionally, currents shown in Figure 5-30 display the 3Io ground fault current. This case proves to be the anomaly between all the different short circuit tests, with higher single-line-to-ground fault current in the system. Generator grounding schemes could contribute to the higher sustained fault current, and can be modified in ETAP to more accurately model a smaller ground fault current as observed in laboratory. However, tripping still adheres to coordination criteria. Figure 5-31 provides the SQOP events for the operation of protective devices. 


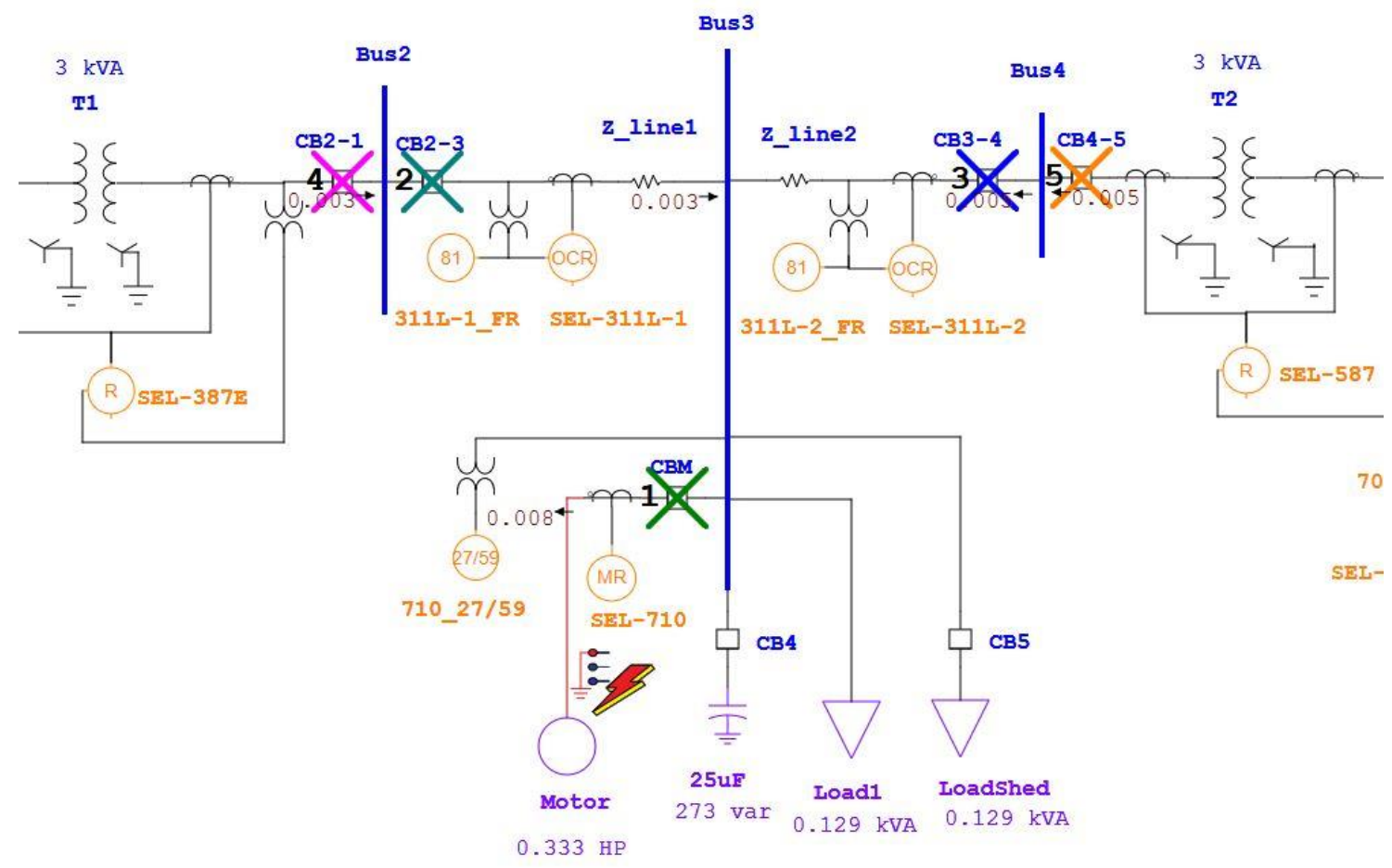

Figure 5-30: SQOP, SLG, Motor Terminals

\begin{tabular}{|c|c|c|c|c|c|}
\hline \multicolumn{6}{|c|}{ III Sequence-of-Operation Events - Output Report: Single Line-to-Ground Induction Motor } \\
\hline \multicolumn{6}{|c|}{ Line-to-Ground (Symmetrical) fault on connector between Motor \& CT15. Adjacent bus: Bus 3} \\
\hline \multicolumn{4}{|c|}{ Data Rev: Base } & Config: Normal & Date: $04-09-2018$ \\
\hline Time $[\mathrm{ms}]$ & ID & If $[\mathrm{kA}]$ & $\mathrm{T} 1$ (ms) & $\mathrm{T} 2$ (ms) & Condition \\
\hline 100 & SEL-710 & 0.008 & 100 & & Overload Ground \\
\hline 101 & SEL-311L-1 & 0.005 & 101 & & Negative Sequence - 0C1 - 51 \\
\hline 118 & SEL-311L-2 & 0.003 & 118 & & Negative Sequence $\cdot 0 \mathrm{C} 1 \cdot 51$ \\
\hline 133 & CBM & & 33.3 & & Tripped by SEL-710 0verload Ground \\
\hline 134 & $\mathrm{CB} 2-3$ & & 33.3 & & Tripped by SEL-311L-1 Negative Sequence - 0C1 - 51 \\
\hline 145 & SEL-387E & 0.005 & 145 & & Negative Sequence - $0 \mathrm{C1} \cdot 51$ \\
\hline 151 & $\mathrm{CB} 3-4$ & & 33.3 & & Tripped by SEL-311L-2 Negative Sequence - 0C1 - 51 \\
\hline 178 & $\mathrm{CB} 2-1$ & & 33.3 & & Tripped by SEL-387E Negative Sequence - 0C1 - 51 \\
\hline 180 & SEL-587 & 0.003 & 180 & & Negative Sequence - $0 \mathrm{C1} \cdot 51$ \\
\hline 213 & $\mathrm{CB} 4-5$ & & 33.3 & & Tripped by SEL-587 Negative Sequence - 0C1 - 51 \\
\hline \multicolumn{6}{|l|}{$<$} \\
\hline
\end{tabular}

Figure 5-31: SQOP Events, SLG, Motor Terminals 


\subsubsection{Case IV: Line-to-Line Fault}

A line-to-line fault is applied on the terminals of the motor. Decomposition of the fault current results in positive and negative sequence components. SEL-710 first clears the fault utilizing instantaneous phase-time overcurrent elements (50P). SEL-311L-1 and SEL-311L-2 utilize inverse-time negative sequence elements (51Q) providing secondary backup protection. Similarly, SEL-587 and SEL-387E utilize 51Q to provide tertiary backup protection. Figure 5-32 displays the sequence-of-events (SQOP) of circuit breakers tripping in order indicated by a number beside an ' $\mathrm{X}$ ' for a single-line-to-ground fault on the terminals of the induction motor. Additionally, currents shown in Figure 5-32 displays positive, negative, and sequence components in amps, respectively. Figure 5-33 provides the SQOP events for the operating of protective devices.

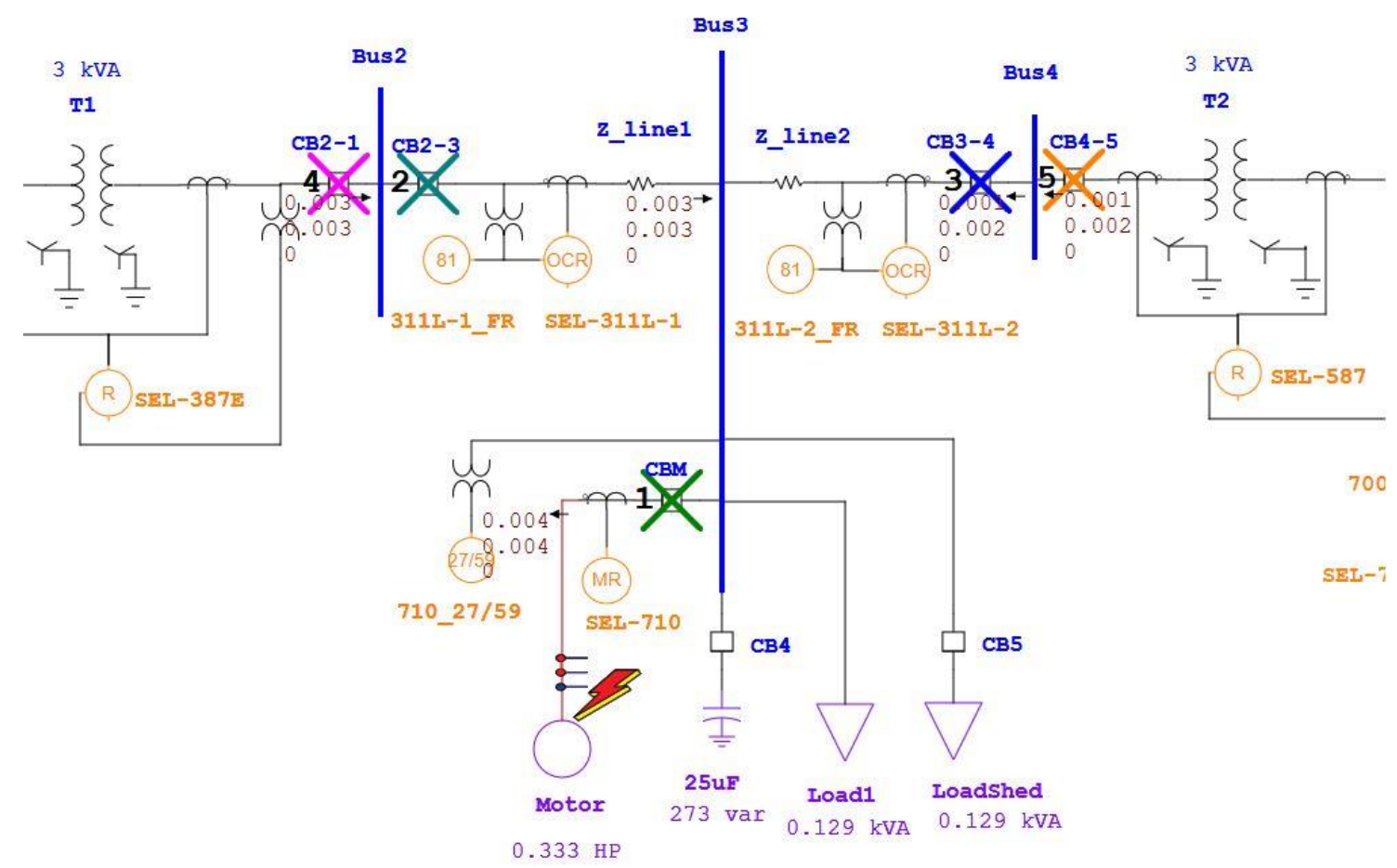

Figure 5-32: SQOP, Line-to-Line Fault, Motor Terminals 


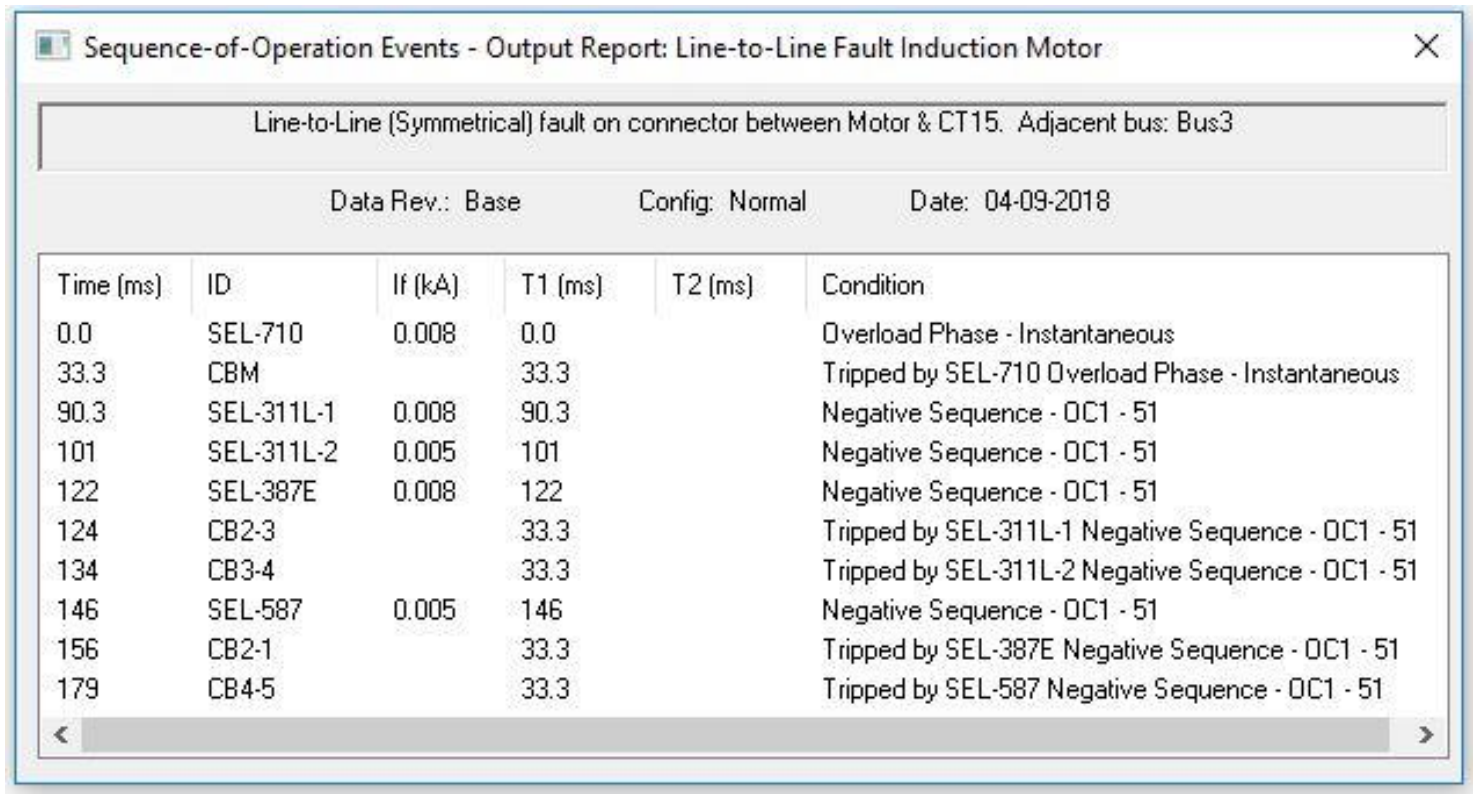

Figure 5-33: SQOP Events, Line-to-Line Fault, Motor Terminals

\subsubsection{Case V: Line-to-Line-to-Ground Fault}

A line-to-line fault is applied on the terminals of the motor. Decomposition of the fault current results in positive, negative, and zero sequence components. SEL-710 first clears the fault utilizing instantaneous phase-time overcurrent elements (50P). SEL-311L1 and SEL-311L-2 utilize inverse-time negative sequence elements (51Q) providing secondary backup protection. Similarly, SEL-587 and SEL-387E utilize 51Q to provide tertiary backup protection. Figure 5-34 displays the sequence-of-events (SQOP) of circuit breakers tripping in order indicated by a number beside an ' $\mathrm{X}$ ' for a single-line-to-ground fault on the terminals of the induction motor. Additionally, currents shown in Figure 5-34 displays positive, negative, and sequence components in amps, respectively. Figure 5-35 provides the SQOP events for the operating of protective devices. 


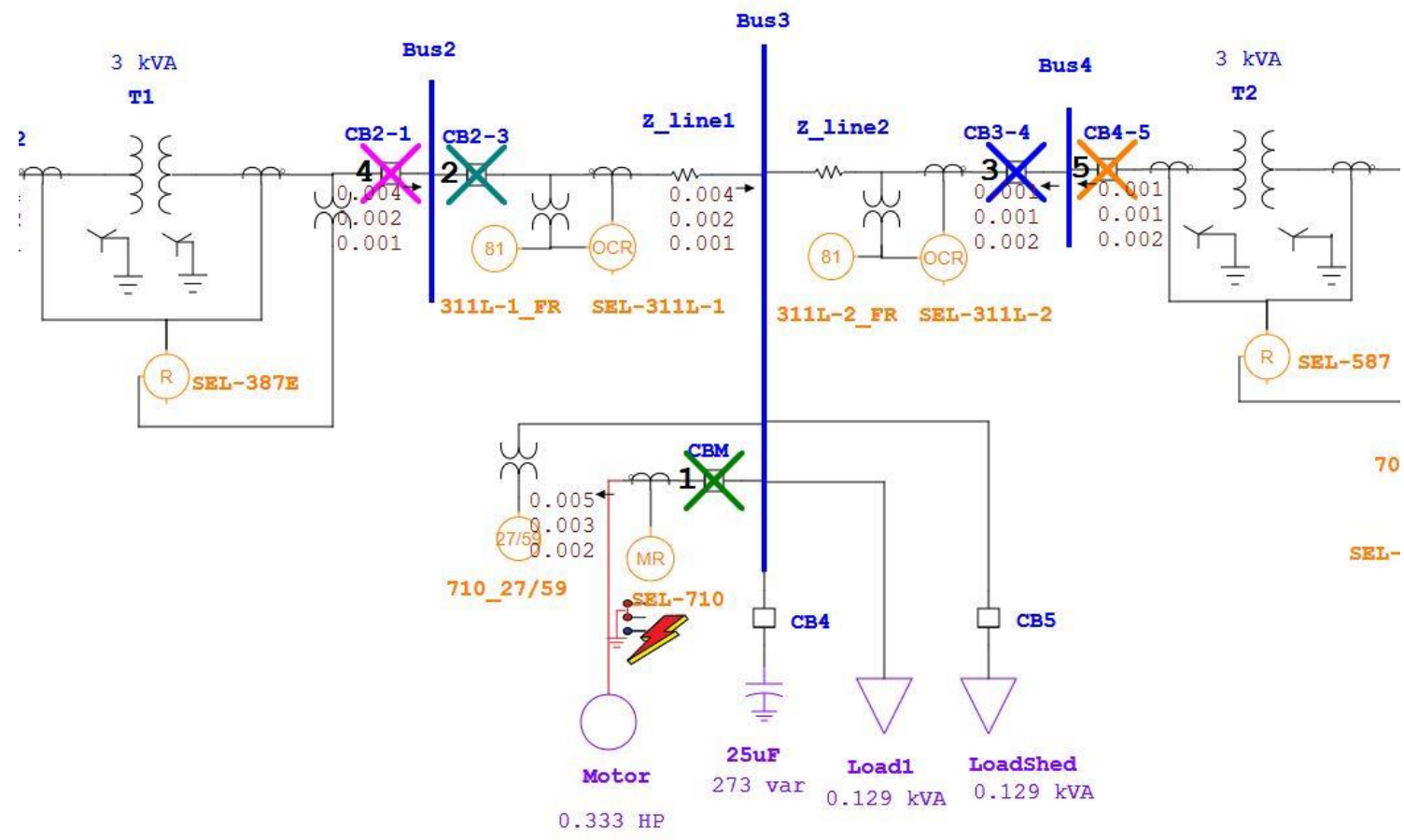

Figure 5-34: SQOP, Double Line-to-Ground, Motor Terminals

\begin{tabular}{|c|c|c|c|c|c|}
\hline \multicolumn{6}{|c|}{ Line-to-Line-to-Ground (Symmetrical) fault on connector between Motor \& CT15. Adjacent bus: Bus 3} \\
\hline \multicolumn{4}{|c|}{ Data Rev: Base } & \multirow{2}{*}{$\begin{array}{l}\text { Config: N } \\
\text { T2 (ms) }\end{array}$} & Date: $04-09-2018$ \\
\hline Time $[\mathrm{ms}]$ & ID & If $(k A)$ & $\mathrm{T} 1$ (ms) & & Condition \\
\hline 0.0 & SEL-710 & 0.008 & 0.0 & & Overload Phase -Instantaneous \\
\hline 33.3 & CBM & & 33.3 & & Tripped by SEL- 710 0verload Phase - Instantaneous \\
\hline 97.1 & SEL-311L-1 & 0.006 & 97.1 & & Negative Sequence - $0 \mathrm{C1}-51$ \\
\hline 113 & SEL-311L-2 & 0.004 & 113 & & Negative Sequence - 0C1- 51 \\
\hline 130 & $\mathrm{CB} 2-3$ & & 33.3 & & Tripped by SEL-311L-1 Negative Sequence - 0C1 - 51 \\
\hline 138 & SEL-387E & 0.006 & 138 & & Negative Sequence - $0 \mathrm{C1}-51$ \\
\hline 147 & CB3-4 & & 33.3 & & Tripped by SEL-311L-2 Negative Sequence - 0C1 - 51 \\
\hline 170 & SEL-587 & 0.004 & 170 & & Negative Sequence $-0 C 1 \cdot 51$ \\
\hline 171 & $\mathrm{CB} 2-1$ & & 33.3 & & Tripped by SEL-387E Negative Sequence - 0C1 - 51 \\
\hline 203 & CB $4-5$ & & 33.3 & & Tripped by SEL-587 Negative Sequence - 0C1 - 51 \\
\hline
\end{tabular}

Figure 5-35: SQOP Events, Double Line-to-Ground, Motor Terminals 


\subsubsection{Case VI: Three-Phase Fault, SEL-421}

The SEL-421 is utilized in the microgrid for synchronization purposes with the utility. Additionally, the SEL-421 will be utilized for overcurrent protection. Figure 5-36 shows a one-line of a three-phase fault applied at Bus 2. The microgrid is energized from utility only, two static loads are energized, and overcurrent protection from SEL-387E and SEL-311L-1 is bypassed in the hardware test as well as in ETAP. The three-phase fault at Bus 2 is detected from SEL-421 at time $\mathrm{t}=397 \mathrm{~ms}$ from the SQOP in ETAP, and asserts trip commands to circuit breaker $\mathrm{CB} 1$ at time $\mathrm{t}=430 \mathrm{~ms}$.

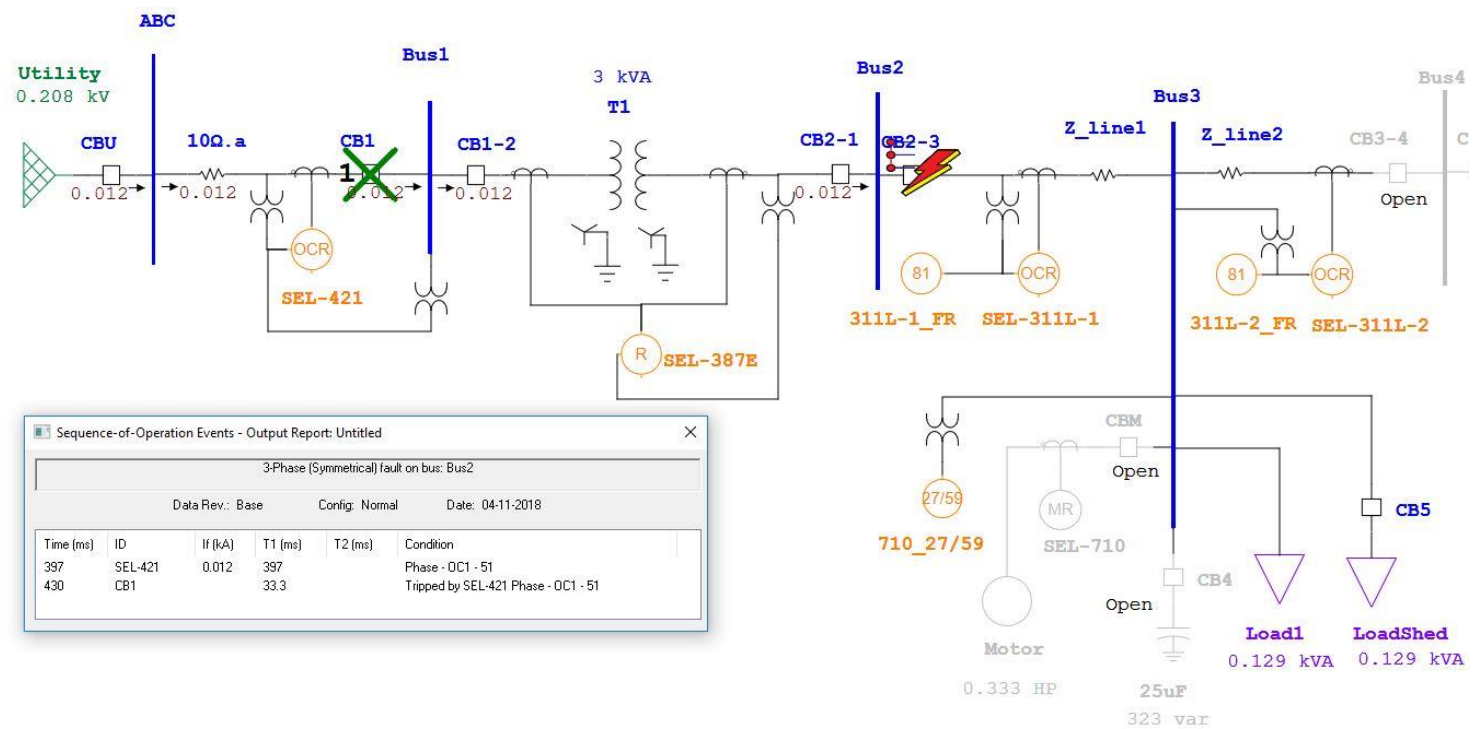

Figure 5-36: SEL-421 test, three-phase fault Bus 2

Figure 5-37 displays event data tested in lab from the SEL-421 for a current senior design project student per reference [16], equivalent to the system configuration displayed in the one-line in Figure 5-36. The event data suggests a pickup time of approximately $458 \mathrm{~ms}$, which is greater than the pickup time of $397 \mathrm{~ms}$ from ETAP. 
SEL-421 event data suggests a slightly lower three-phase fault current of approximately $10.5 \mathrm{~A}_{\mathrm{rms}}\left(15 \mathrm{~A}_{\text {peak }}\right)$, with respect to nearly $12 \mathrm{~A}_{\mathrm{rms}}$ observed in ETAP. Variations in three-phase fault current can be attributed to greater impedances and lower pre-fault voltages observed in the laboratory test. SEL-421 phase time overcurrent settings utilize a U1 - Moderately inverse curve type with a pickup setting of $4.5 \mathrm{~A}$ and time dial setting of 0.7 .

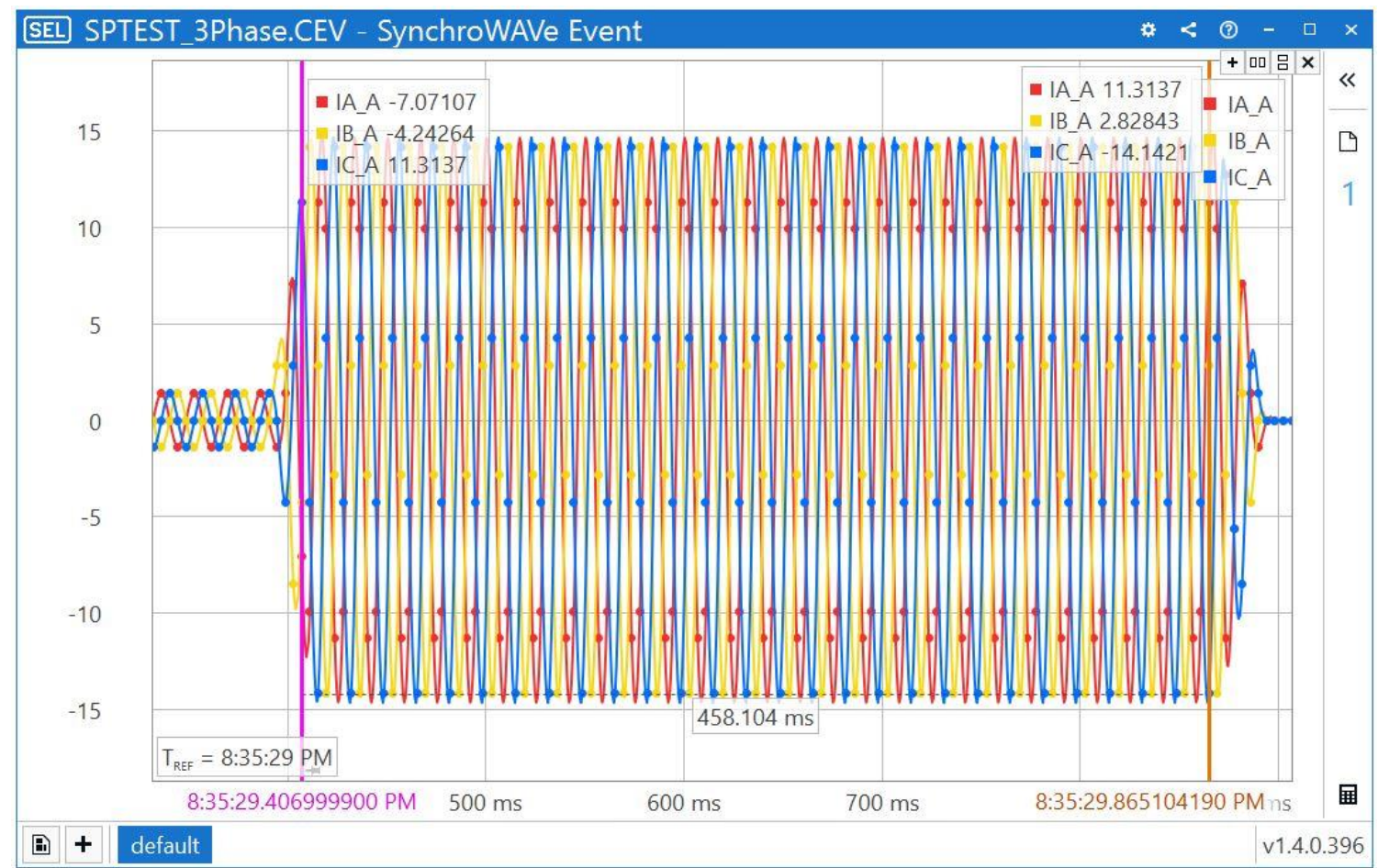

Figure 5-37: SEL-421 three-phase SC test, Bus 2

\subsubsection{Protection and Coordination Summary}

ETAP was successfully used to implement the testing of protection and coordination for both the prior and current iterations of the microgrid. Relay settings implemented in the section as well as shown in appendix B are settings that are both 
implemented in the laboratory as well as in ETAP, indicating a successful replication of relay coordination. Protection and coordination analysis allows users to evaluate different fault currents flowing throughout the system and implement protection as needed. Although protection and coordination were primarily conducted on Bus 3, one can choose to fault a separate bus as shown in Case I and implement protection as necessary, such as Bus 2 in Case VI. Additional protection schemes such as directional and distance can be complemented in conjunction of overcurrent protection to protect every section of the microgrid. For example, the SEL-311L has capabilities of directional overcurrent protection (ANSI 67) to detect faults flowing opposite to the assumed nominal direction of current flow. The example studied in Case VI can be extended to include the bidirectional system with synchronous generators. SEL-311L-1 can implement directional protection in both laboratory as well as ETAP to coordinate for faults at Bus 2. Of special concern is the relatively low fault current contributed from the synchronous generators, which will become an issue if the microgrid becomes more heavily loaded; thus, becoming susceptible to false trips on nominal loading conditions.

\subsection{Transient Stability Analysis}

Transient stability analysis will be conducted primarily to observe the response of synchronous generators. These simulations mainly are theoretically based, and not tested in laboratory. Hence the purpose of this section is to provide insights for the future microgrid team of transient stability issues that may occur and possible improvements throughout the cases. Interested readers may refer to Chapter 4 for a review on an elementary study of power system transient stability. 


\subsubsection{Case I: Faults}

The study of protection and coordination will be extended to observe the response of synchronous generators to faults. There are inherent limitations of transient stability studies that result in difficulties obtaining accurate results. From the swing equation discussed in Chapter 4, the rotational inertia constant of a machine $\mathrm{H}$ will largely determine if generators retain stability. Per reference [8], Kundur provides typical values of $\mathrm{H}$, given in per unit MW.s per MVA shown in Table 5-7.

Table 5-7. Typical values of $H$, thermal and hydraulic generating units [8]

\begin{tabular}{|c|c|}
\hline Type of generating unit & $\begin{array}{c}\text { Per Unit Inertia Constant, } \mathrm{H} \\
\text { (MW.s/MVA) }\end{array}$ \\
\hline $\begin{array}{c}\text { Thermal unit } \\
\text { (a) } 3600 \mathrm{r} / \mathrm{min} \text { (2-pole) }\end{array}$ & $\begin{array}{c}2 \text { to } 6.0 \\
\text { (b) } 1800 \mathrm{r} / \mathrm{min} \text { (4-pole) }\end{array}$ \\
\hline Hydraulic unit & 2.0 to 10.0 \\
\hline
\end{tabular}

Kundur also provides another way of interpreting machine inertia constant $\mathrm{H}$ by defining " $\mathrm{T}_{\mathrm{M}}$ as the time required for rated torque to accelerate the rotor from standstill to rated speed" [8], resulting in equation 5-1 describing:

$$
T_{M}=2 H \quad[\mathrm{~s}]
$$

where " $\mathrm{T}_{M}$ is called the mechanical starting time" [8]. For example, for an $1800 \mathrm{r} / \mathrm{min}$ (4pole) thermal unit of $\mathrm{H}=4.0 \mathrm{MW} \cdot \mathrm{s} / \mathrm{MVA}$, mechanical starting time would be 8 seconds per equation 5-1.

However, the issue resulted from inherently very low rotational inertia presents in synchronous machinery used in the microgrid. ETAP is originally designed for industrial 
scale power systems and larger utility level systems. Recall that the three-phase generators utilized in the Cal Poly microgrid are rated at $208 \mathrm{~V}$ at $250 \mathrm{~W}$, and laboratory testing resulted in very low observable mechanical starting times, less than one second. In transient stability studies conducted in ETAP, machine inertia is a necessary constant used in evaluating the swing equation and determining parameters such as the rate of change of rotor angles. For purposes of simulation, theoretical machine inertias $\mathrm{H}=1$ and $\mathrm{H}=0.1 \mathrm{MW} \cdot \mathrm{s} / \mathrm{MVA}$ are considered corresponding to mechanical starting times of 2 and 0.2 seconds respectively and observe the effect of rotor angle variations. Figure 5-38 showcases a one-line diagram of the example, with one generator (Gen_2) and the DC system de-energized. Gen_1 is initially supplying 0.3 A pre-fault, and a three-phase fault is suddenly applied to Bus 3 at time $t=1$ seconds. The fault is cleared 6 cycles $(0.1$ seconds at $60 \mathrm{~Hz}$ ) later at time $\mathrm{t}=1.1$ seconds.

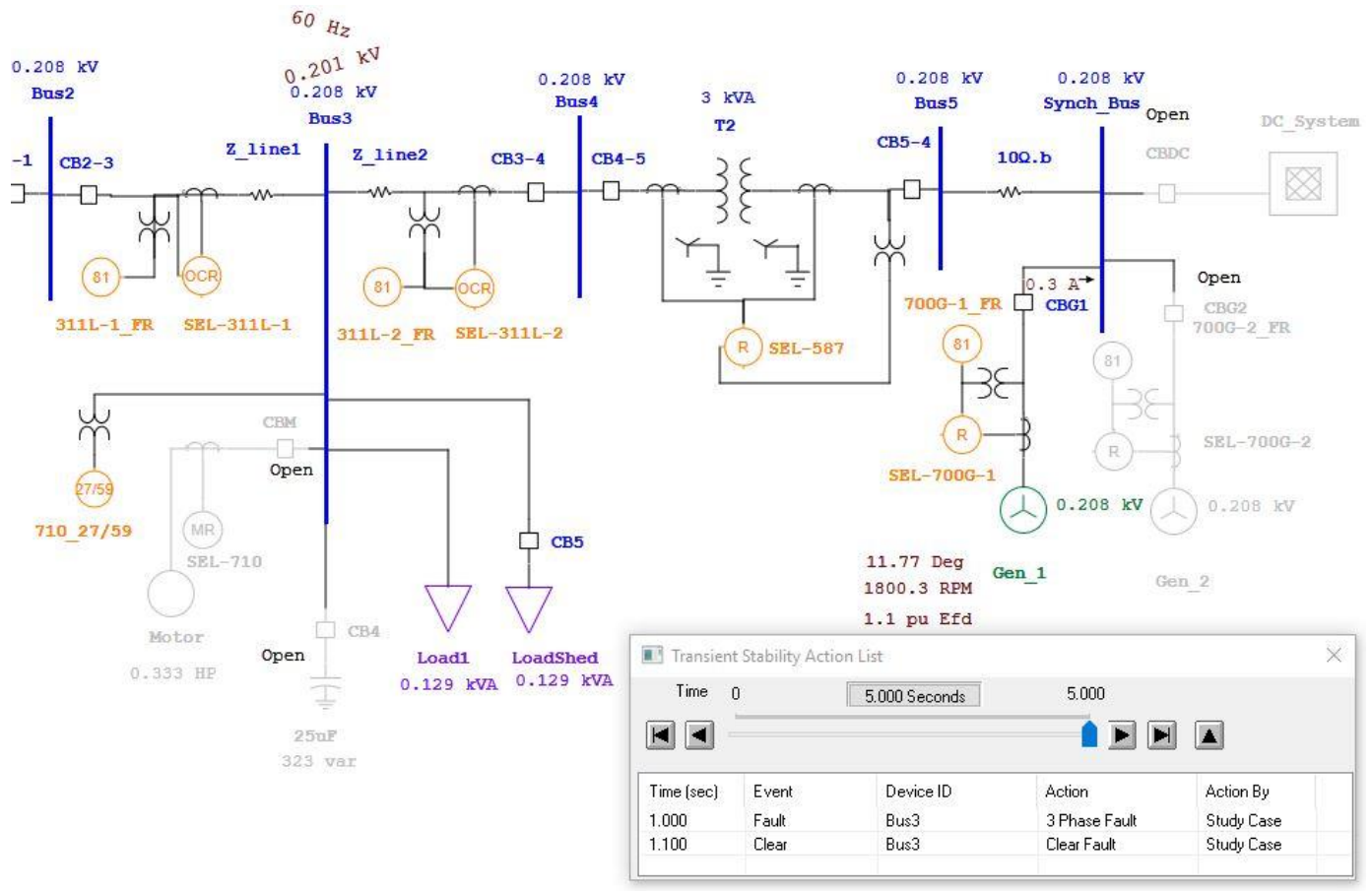

Figure 5-38: Transient Stability, three-phase fault Bus 3 


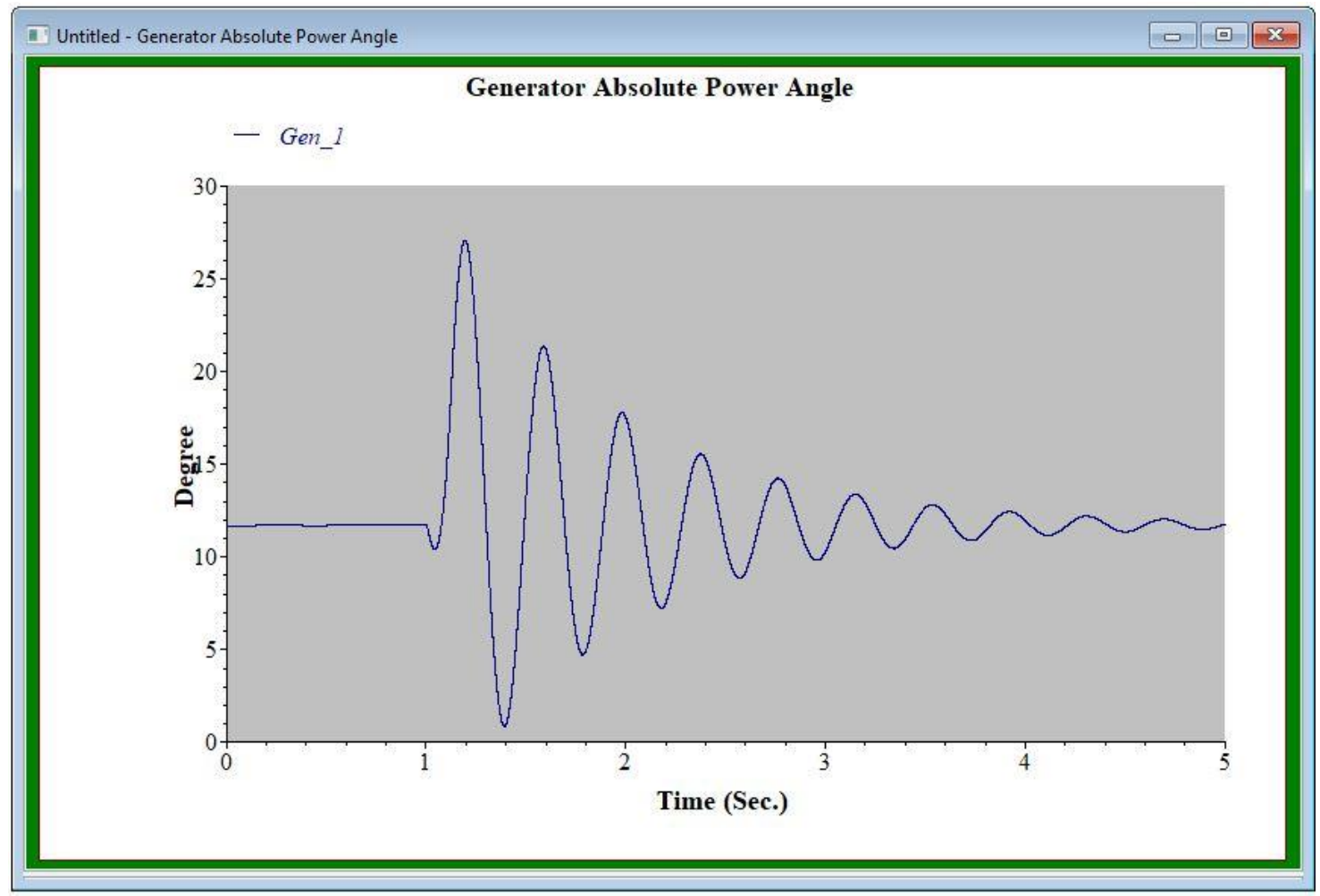

Figure 5-39: Rotor angle response, $\mathrm{H}=1 \mathrm{MW} \cdot \mathrm{s} / \mathrm{MVA}, 6$ cycle clear

Figure 5-39 displays the rotor angle response of the generator with respect to the applied and clearing of the fault for a machine inertia constant $\mathrm{H}$ of $1.0 \mathrm{MW} \cdot \mathrm{s} / \mathrm{MVA}$. The generator internal rotor angle is approximately 12 degrees, shooting to a maximum of about 27 degrees as the fault is initiated, and decays to a new operating angle after the fault has cleared. Notice that although the fault is cleared 6 cycles later at time $t=1.1$ seconds, the machine cannot stabilize instantaneously to a constant rotor angle as the rotor accelerates and decelerates from $1800 \mathrm{rpm}$, observed as oscillations in the rotor angle. 


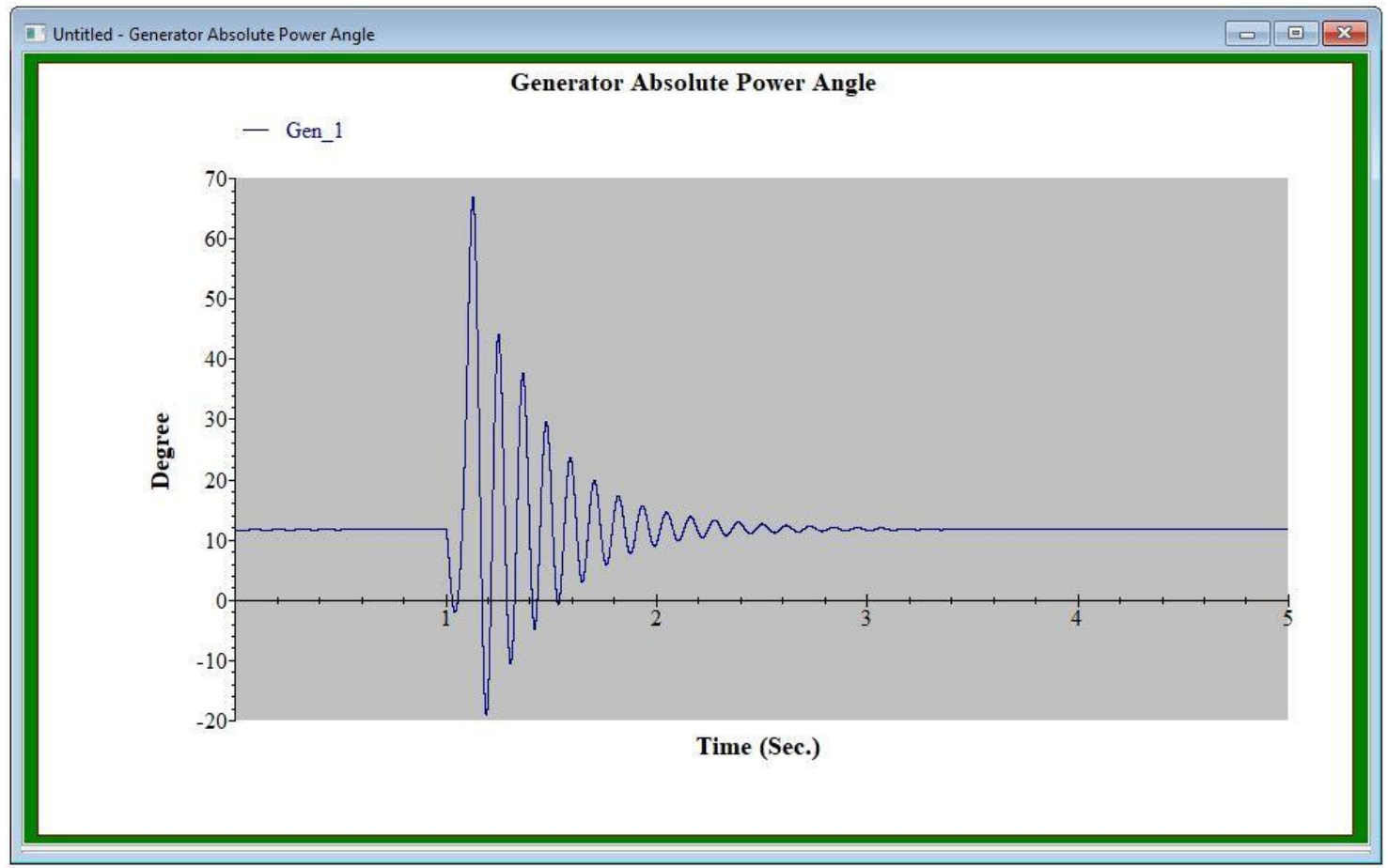

Figure 5-40: Rotor angle response, $\mathrm{H}=0.1 \mathrm{MW} \cdot \mathrm{s} / \mathrm{MVA}, 6$ cycle clear

Let us consider a more extreme machine inertia constant of $0.1 \mathrm{MW} \cdot \mathrm{s} / \mathrm{MVA}$, where Figure 5-40 displays the corresponding rotor angle response to the same scenario in which a fault is applied at Bus 3 at time $\mathrm{t}=1$ seconds, and cleared 6 cycles later at time $\mathrm{t}=1.1$ seconds. Compared with Figure 5-39, notice the drastic effect in the reduction in machine inertia: the generator experiences a peak rotor angle nearing 70 degrees as the rotor has less rotational inertia, resulting in an increased rate of change of rotor angle.

Let us now instead consider the case in which we improve transient stability of a machine by implementing faster fault clearing time, reducing the fault duration from 6 cycles to 3 cycles. A three phase fault is still applied on Bus 3 at time $t=1$ seconds, followed by the clearing of the fault in time $t=1.05$ seconds $(3$ cycles at $60 \mathrm{~Hz})$. Figure 
5-41 displays the faster clearing of the fault at time $\mathrm{t}=1.05$ seconds, with a much lower peak rotor angle when compared to Figure 5-40.

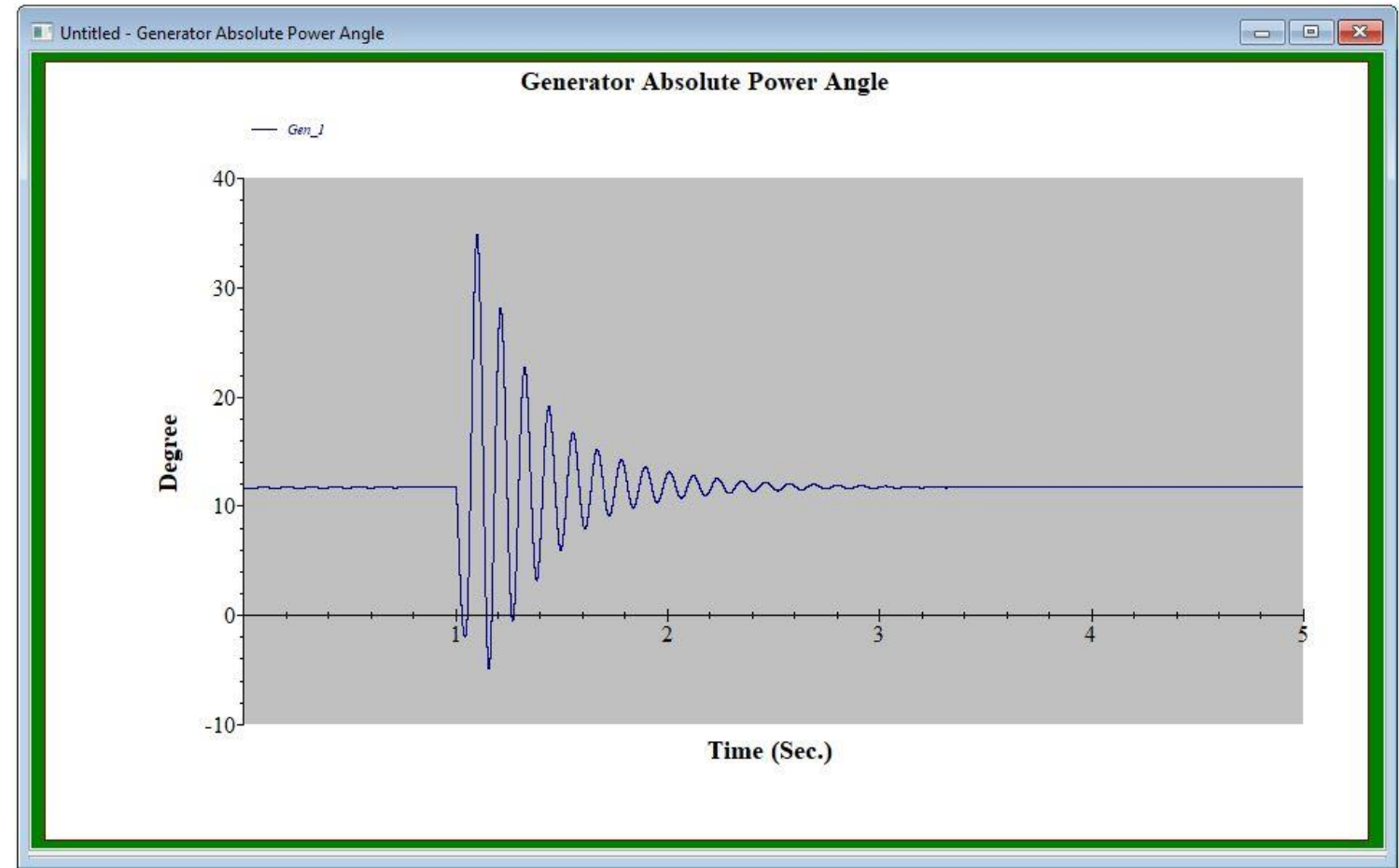

Figure 5-41: Rotor angle response, $\mathrm{H}=0.1 \mathrm{MW} \cdot \mathrm{s} / \mathrm{MVA}, 3$ cycle clear

Figure 5-42 displays the terminal current response for the scenario shown in

Figure 5-41. Notice the asymmetrical short circuit current decaying to a steady state value quickly. This is similar to the expected response of the generator terminal current considered in Section 5.3. However, the peak asymmetrical current reaches about 3.5 $\mathrm{A}_{\mathrm{rms}}$ instead of over $7 \mathrm{~A}_{\mathrm{rms}}$ as tested and simulated in Section 5.3. This is largely due to the fault not initiated on the terminals of the generator but instead applied further downstream at Bus 3, with added impedance seen from the generator terminals. 


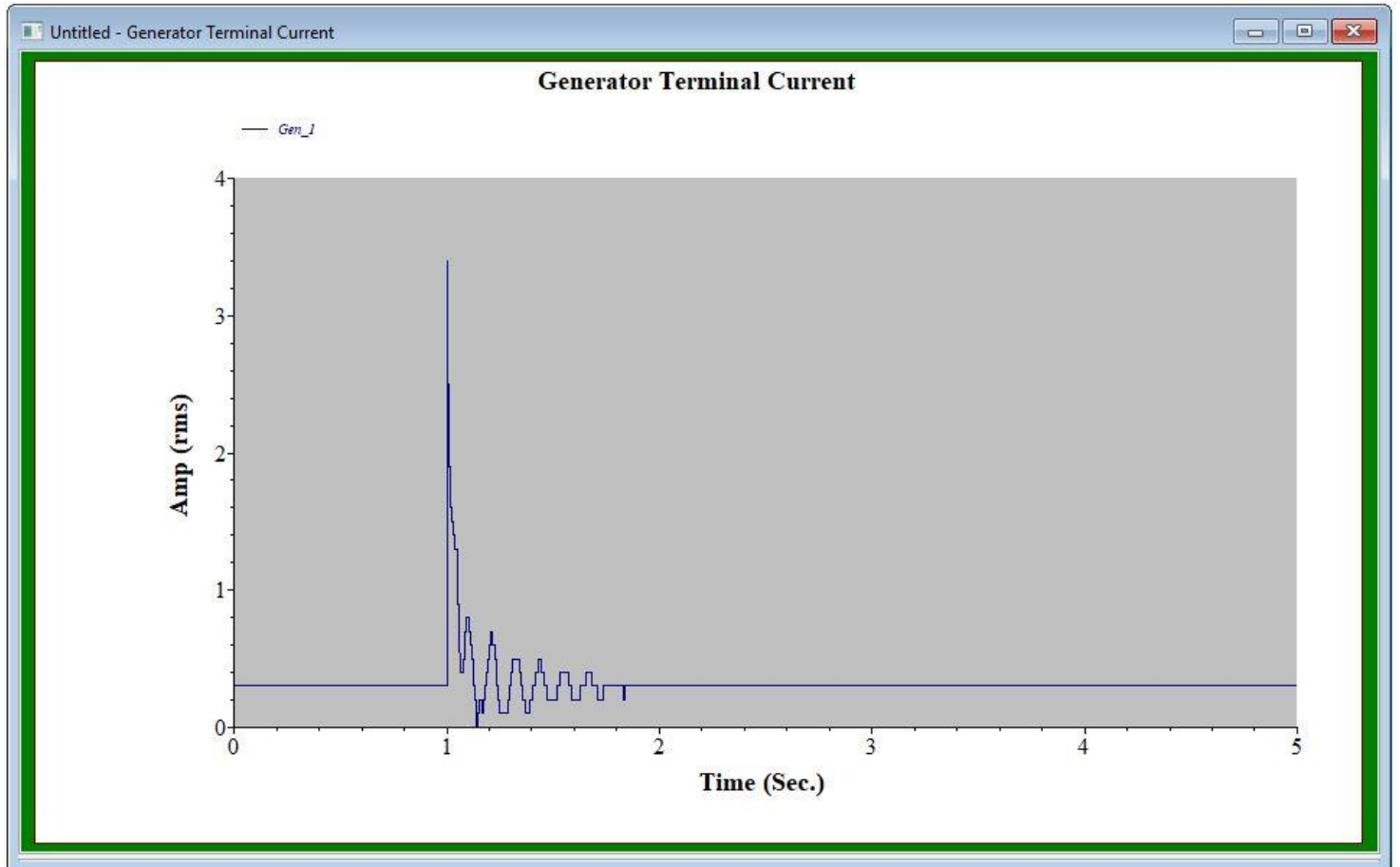

Figure 5-42: Generator terminal current response, $\mathrm{H}=0.1 \mathrm{MW} \cdot \mathrm{s} / \mathrm{MVA}, 3$ cycle clear

Lastly, Figure 5-43 displays the generator speed response due to a three-phase fault applied at Bus 3 and cleared within 3 cycles with an inertia constant $\mathrm{H}$ of 1.0 MW.s/MVA. Notice the generator operating at steady state $1800 \mathrm{rpm}$ prior to the fault at time $t=1$ seconds as expected. Once the fault is initiated, electrical power output decreases, and hence the rotor accelerates greater than $1800 \mathrm{rpm}$. As the fault is cleared at time $\mathrm{t}=1.05$ seconds, the rotor speed still oscillates between $1800 \mathrm{rpm}$, constantly supplying or absorbing kinetic energy as the generator attempts to stabilize back to 1800 rpm. 


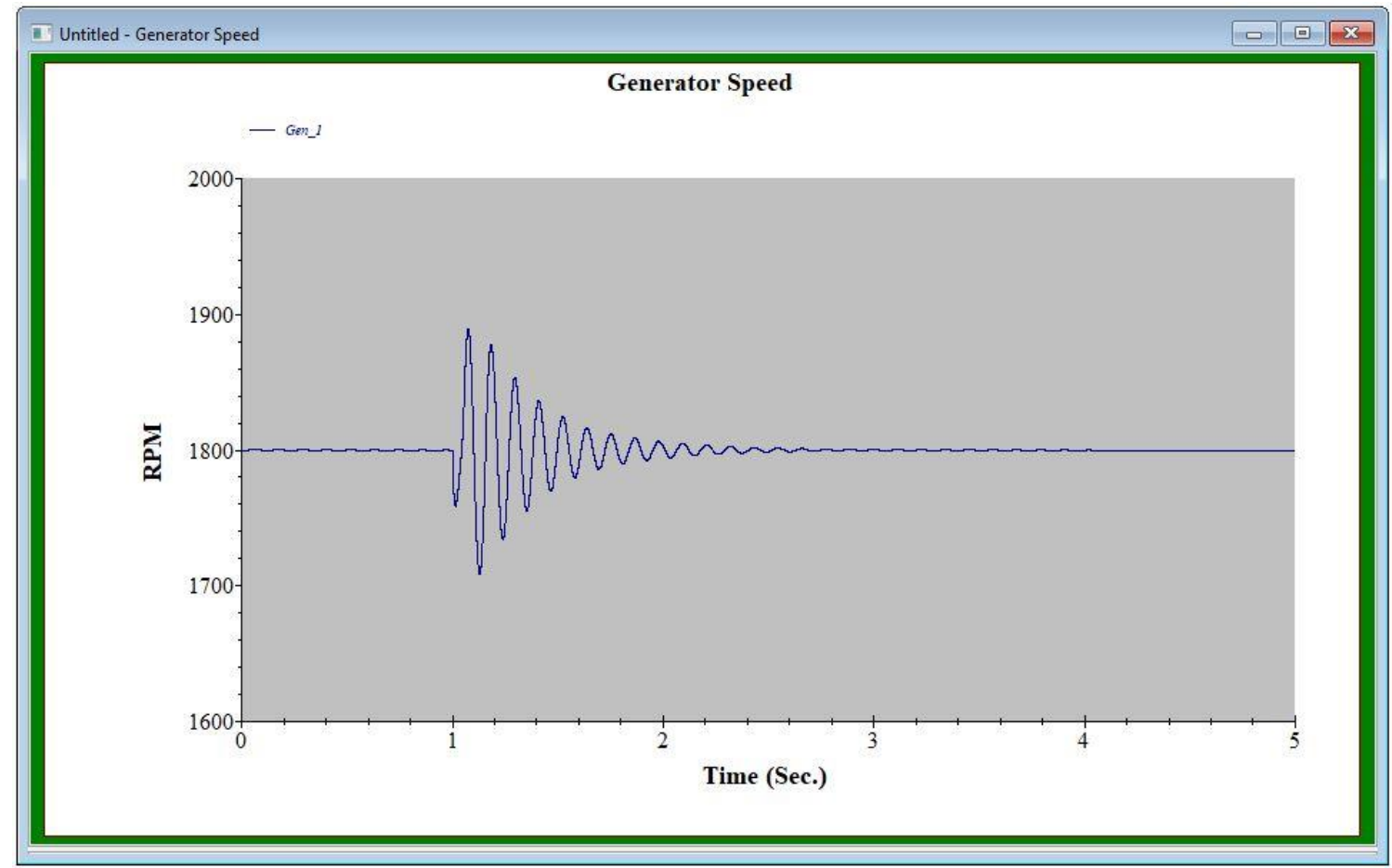

Figure 5-43: Generator speed response, $\mathrm{H}=0.1 \mathrm{MW} \cdot \mathrm{s} / \mathrm{MVA}, 3$ cycle clear

Case 1 of transient stability studied the effect of applying and clearing three-phase faults in the microgrid with variations in machine inertia and fault clearing time. Increasing generator inertia decreased the rate of change of the rotor angle and consequently the effect of supplying and absorbing kinetic energy, consistent with the swing equation. Increasing fault time (longer fault clearing time) was observed to increase rotor acceleration, increase rotor angle deviation from steady state, and overall greater kinetic energy exchange. Generator response characteristics is additionally dependent on factors such as where the fault has been initiated and the rotor loading conditions prior to fault. That is, increasing loading increases initial rotor angle of the generator, resulting in a smaller margin of fault clearing time before reaching instability. Case I can be extended to future senior design projects or master's thesis, in studying 
purely the effect of generator response due to different faulted scenarios. Lastly, Case I reiterates the importance of inertia: increasing the amount of generation from sources other than generators reduces system overall inertia and compromises stability. There is no rotational inertia associated with photovoltaics or battery storage systems, which could adversely affect stability of the system.

\subsubsection{Case II: Islanding}

This case investigates the generator response to islanding from utility utilizing the transient stability analysis module in ETAP. We consider the microgrid in a state in which power feeds two static loads, and suddenly islanded at time $t=1.0$ seconds. We consider only the utility and one generator as sources of generation. The generators are assumed to have an inertia constant $\mathrm{H}$ of $1.0 \mathrm{MW} \cdot \mathrm{s} / \mathrm{MVA}$. Per swing equation of 4-8, electrical demand is suddenly increased, and a deceleration of machines should be observed. Figure 5-44 shows the speed response of the generator. 


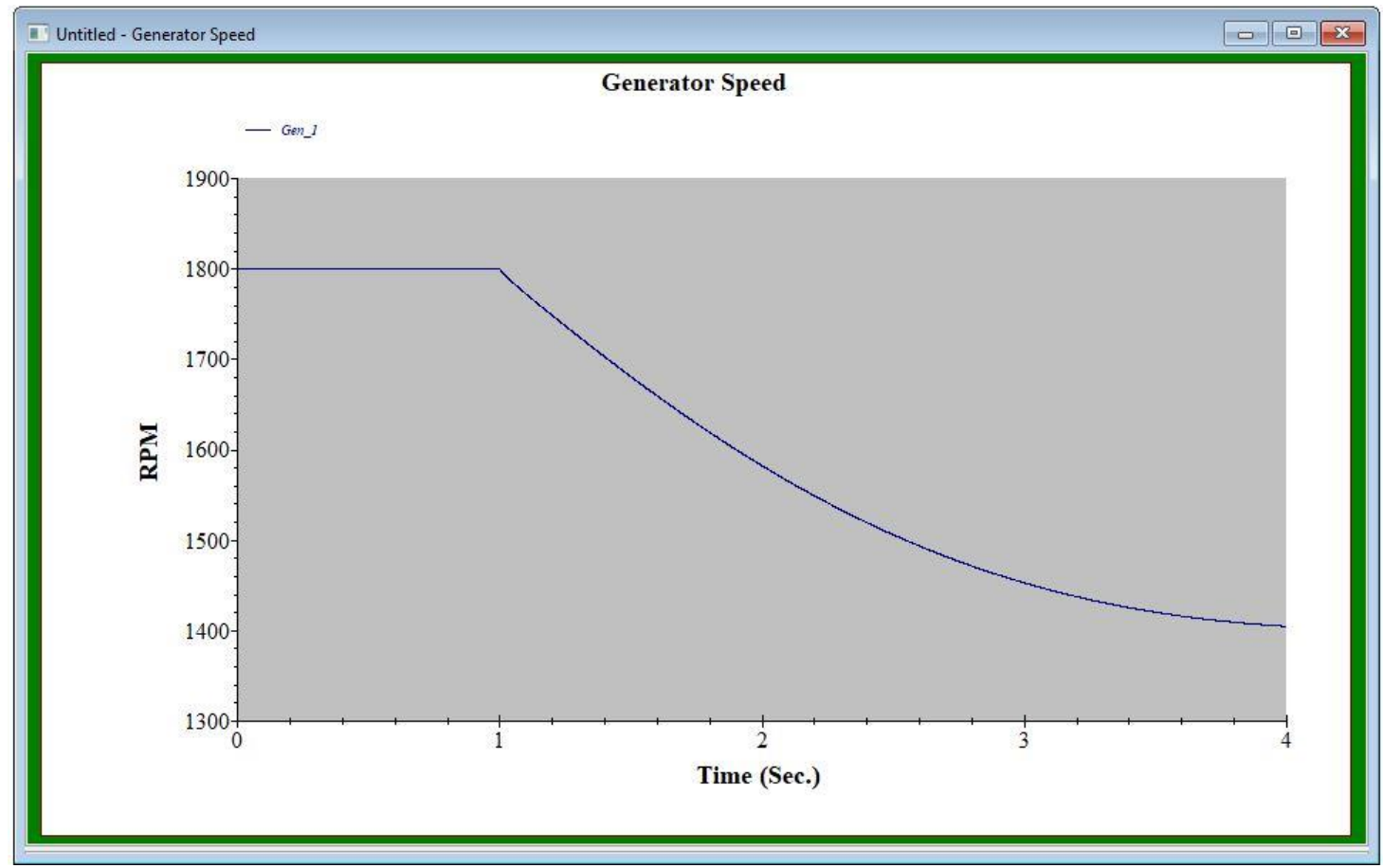

Figure 5-44: Generator speed, islanded and no load shed

We now utilize the frequency element from the SEL-311L-2 (81) to monitor the frequency of Bus 3. When observed to be less than a certain percentage of nominal frequency $(60 \mathrm{~Hz})$, the SEL-311L-2 sends trip signals to the circuit breaker in front of a static load to decrease electrical demand from the system. Conceptually, this is similar to how load shedding is currently implement in the microgrid. However, hardware testing considers both the motor and capacitor to be on. For this simulation we keep the motor and capacitor de-energized. Generator inertia is simulated at $\mathrm{H}=1 \mathrm{MW} \cdot \mathrm{s} / \mathrm{MVA}$ corresponding to a mechanical starting time of 2 seconds. SEL $311-\mathrm{L}-2$ frequency relay is set to assert trip signals the CB5 in front of LoadShed static load at $98 \%$ bus frequency or $58.8 \mathrm{~Hz}$ after a delay of 0.1 seconds. Figure 5-45 showcases the transient event of islanding from utility at time $t=1$ seconds, with a total simulation time of 4 seconds and a static load being shed. 


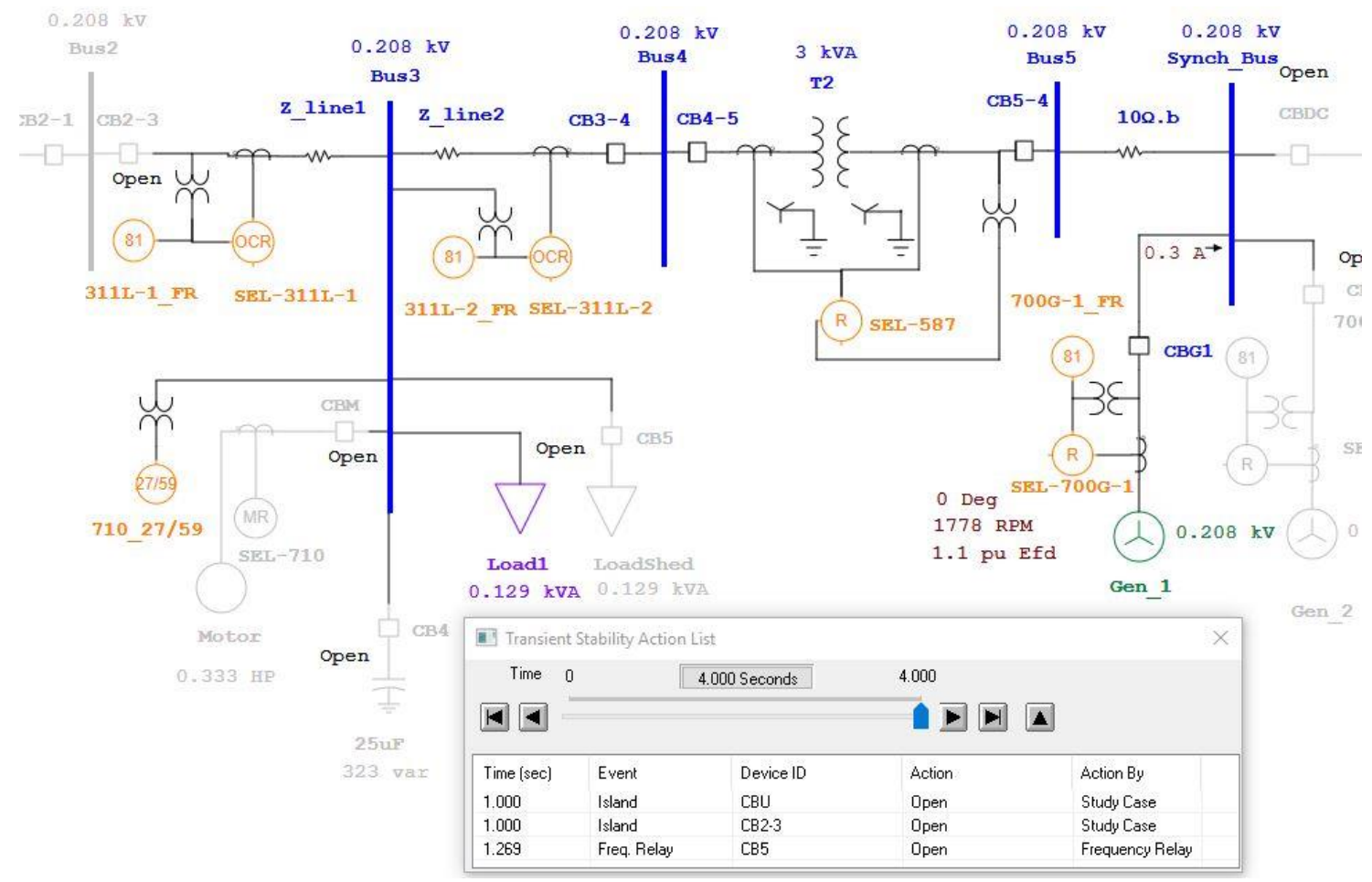

Figure 5-45: Islanded, Load Shed

Figure 5-46 shows the frequency in percent nominal (60\%) at Bus 3 after the microgrid has been islanded at time $\mathrm{t}=1$ seconds. As the frequency drops below $98 \%$ $(58.8 \mathrm{~Hz})$, the relay asserts trip signals to shed load 0.1 seconds later at time $\mathrm{t}=1.269$ seconds. In response, the frequency begins to increase as generator speed increases. 


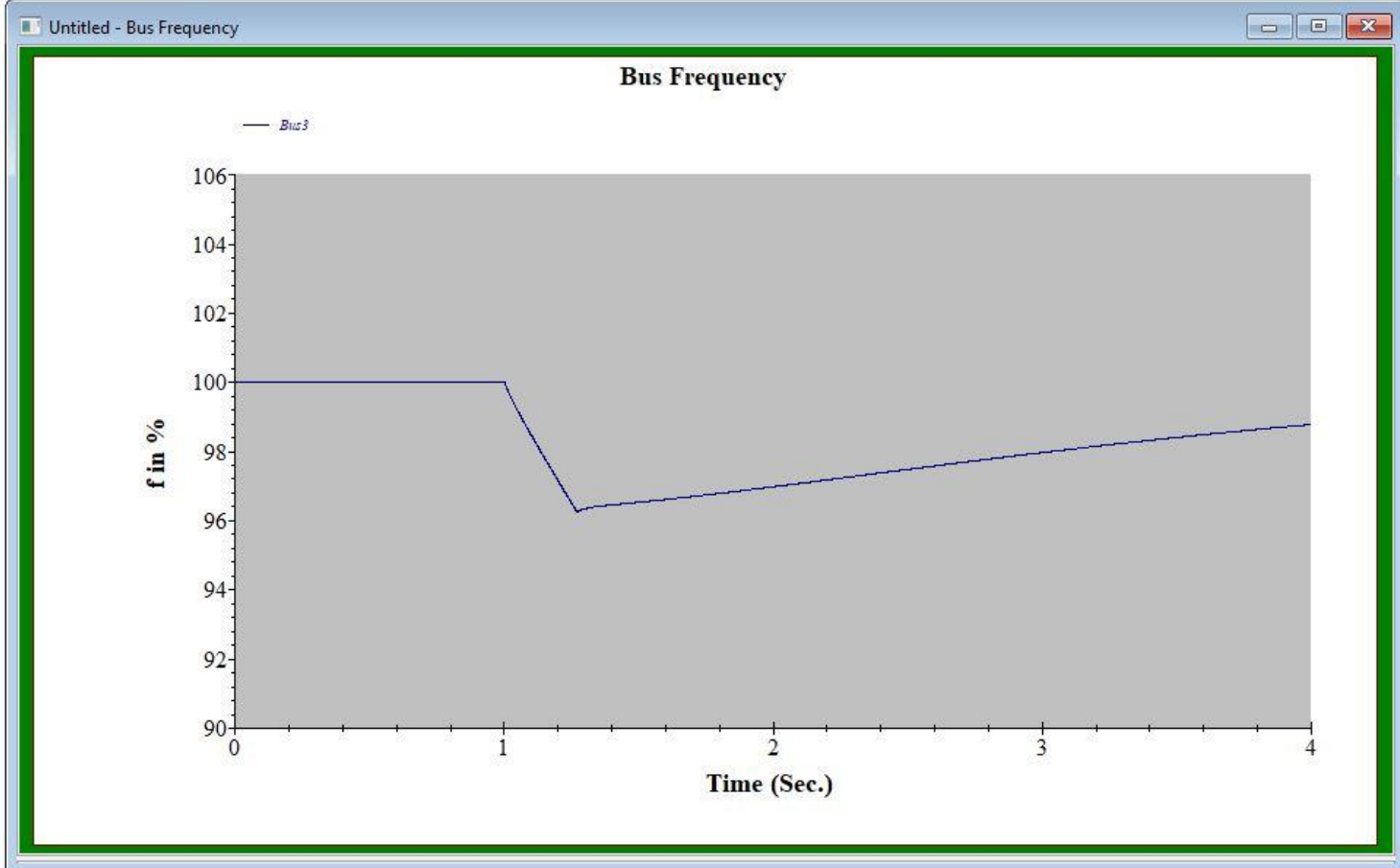

Figure 5-46: Bus 3 frequency, islanding load shed

Figure 5-47 displays the generator speed response as load is shed from the islanding event. Compared to Figure 5-44, the generator speed increases due to the lowering of electrical demand. However, the generator does not return to nominal operating speed (1800 rpm). Generator rpm can be improved with faster load shedding times, increased system inertia, or supplemented generation. 


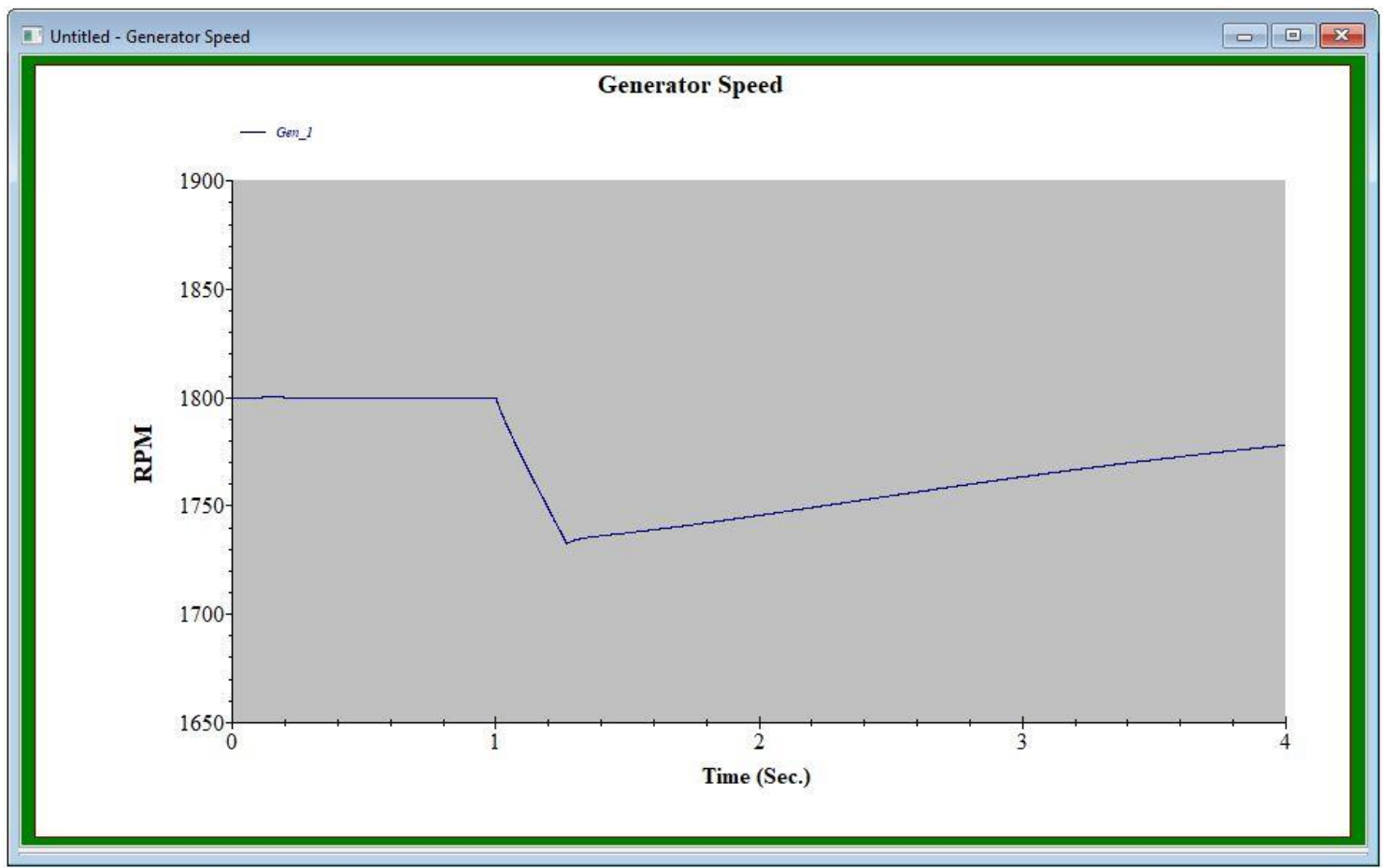

Figure 5-47: Generator speed, islanded and load shed

\subsubsection{Case III: Loss of DG}

We now observe the effect of loss of distributed generation, in the case of one or both of the synchronous generators. The microgrid is initially islanded from the system, with both generators operating in swing with an inertia constant $\mathrm{H}$ of $1.0 \mathrm{MW} \cdot \mathrm{s} / \mathrm{MVA}$. The motor and capacitors are turned off, and Gen_2 is suddenly de-energized by opening the breaker on its terminals at time $\mathrm{t}=1.0$ seconds. Figure 5-48 displays the speed response of Gen_1 for loss of the other generator (Gen_2). Notice the severity in the speed drop. This is the inherent limitation of the synchronous generators utilized in the current microgrid. Since there is no excitation or governor control, frequencies cannot be stabilized unless by external control mechanisms. 


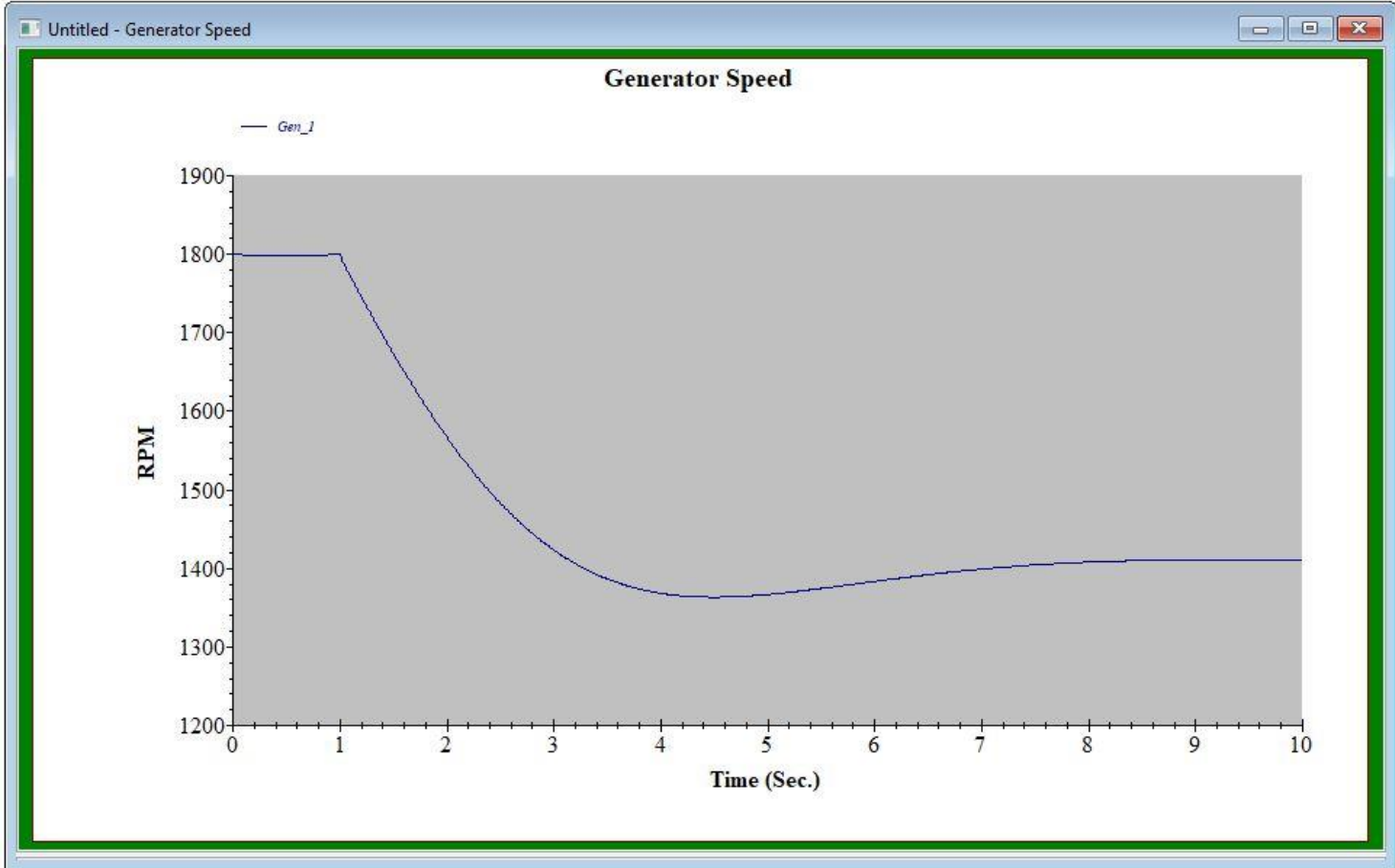

Figure 5-48: Generator speed response, loss of DG

Figure 5-49 shows the generator governor tab with sample data available for a ST1 Single-Reheat Steam-Turbine governor-turbine system. The objective is purely to showcase the application of a governor control system thereby providing insight for methods in improving transient stability in the microgrid. 


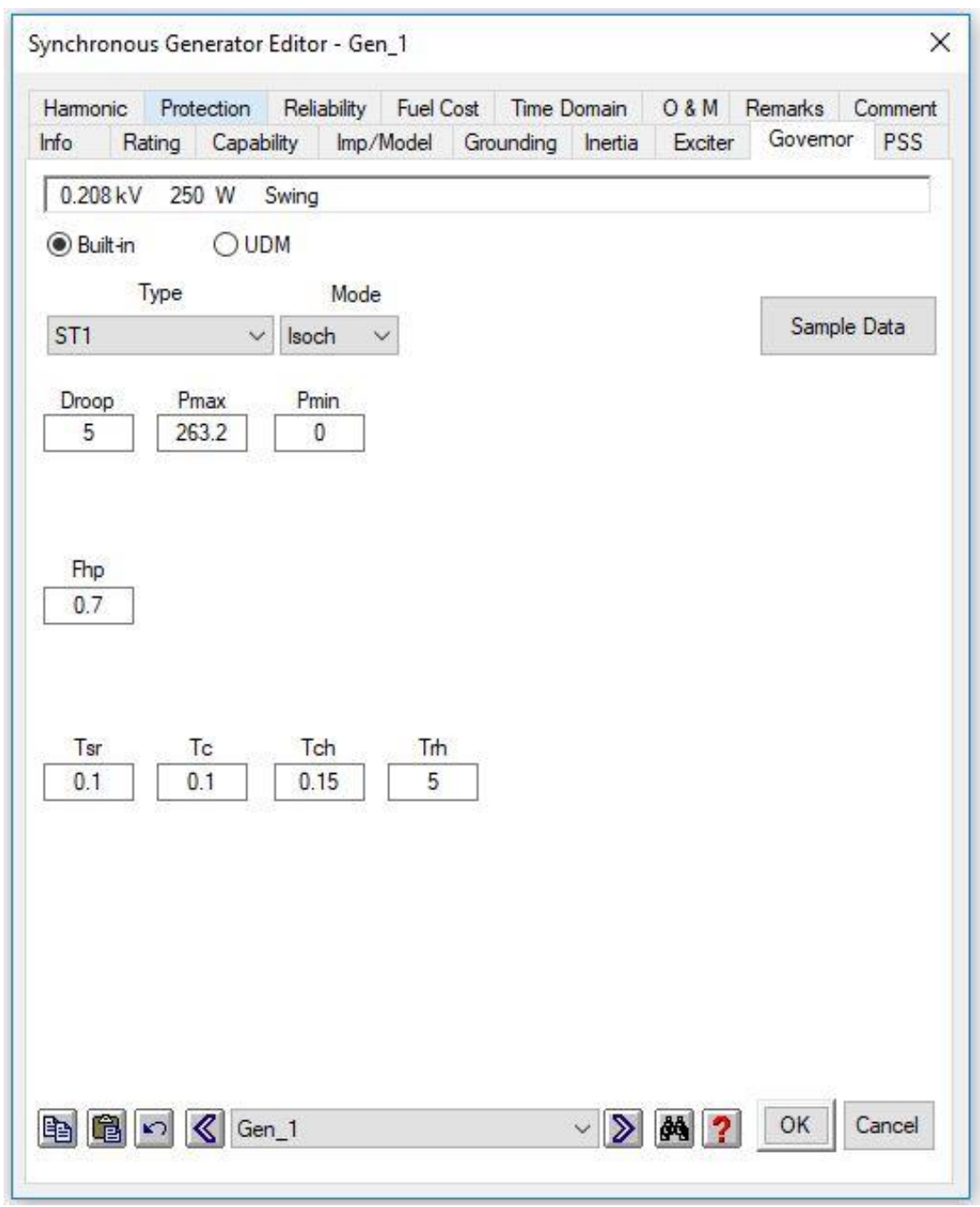

Figure 5-49: ST1 Governor sample data

Table 5-8 consists of parameter definitions for the data shown in Figure 5-49, taken from ETAP Help 16.0. Recall that the prime mover utilized in the hardware implementation of the microgrid is a DC motor, and hence will not have several parameters listen in Table 5-8. Nonetheless, these constants are utilized for demonstrating generator response with governor control. 
Table 5-8: Single-Reheat Steam-Turbine (ST1) parameters and definitions [10]

\begin{tabular}{|c|c|c|}
\hline Parameter & Definition & Unit \\
\hline Mode & Droop or Isoch & $\%$ \\
\hline Droop & Steady-state speed droop & p.u. \\
\hline Fhp & $\begin{array}{c}\text { (Shaft capacity ahead of reheater)/(Total shaft } \\
\text { capacity ) }\end{array}$ & MW \\
\hline Pmax & Maximum shaft power & MW \\
\hline Pmin & Minimum shaft power & seconds \\
\hline Tc & Control Amplifier (servomotor) time constant & seconds \\
\hline Tch & Steam time constant & seconds \\
\hline Tdrp & Load sensor time constant & seconds \\
\hline Tsr & Speed relay time constant & . \\
\hline
\end{tabular}

The effect of loss of DG and the speed response of the remaining energized generator will be observed next. Figure 5-50 displays the speed response of the generator utilizing the governor control to adjust the speed. This showcases the advantages of implementing a control scheme to stabilize system frequencies during disturbances. Several considerations have to take into account into designing a control scheme for governor control, including the inherently low time constants and low inertia associated with the synchronous generators utilized in the microgrid. 


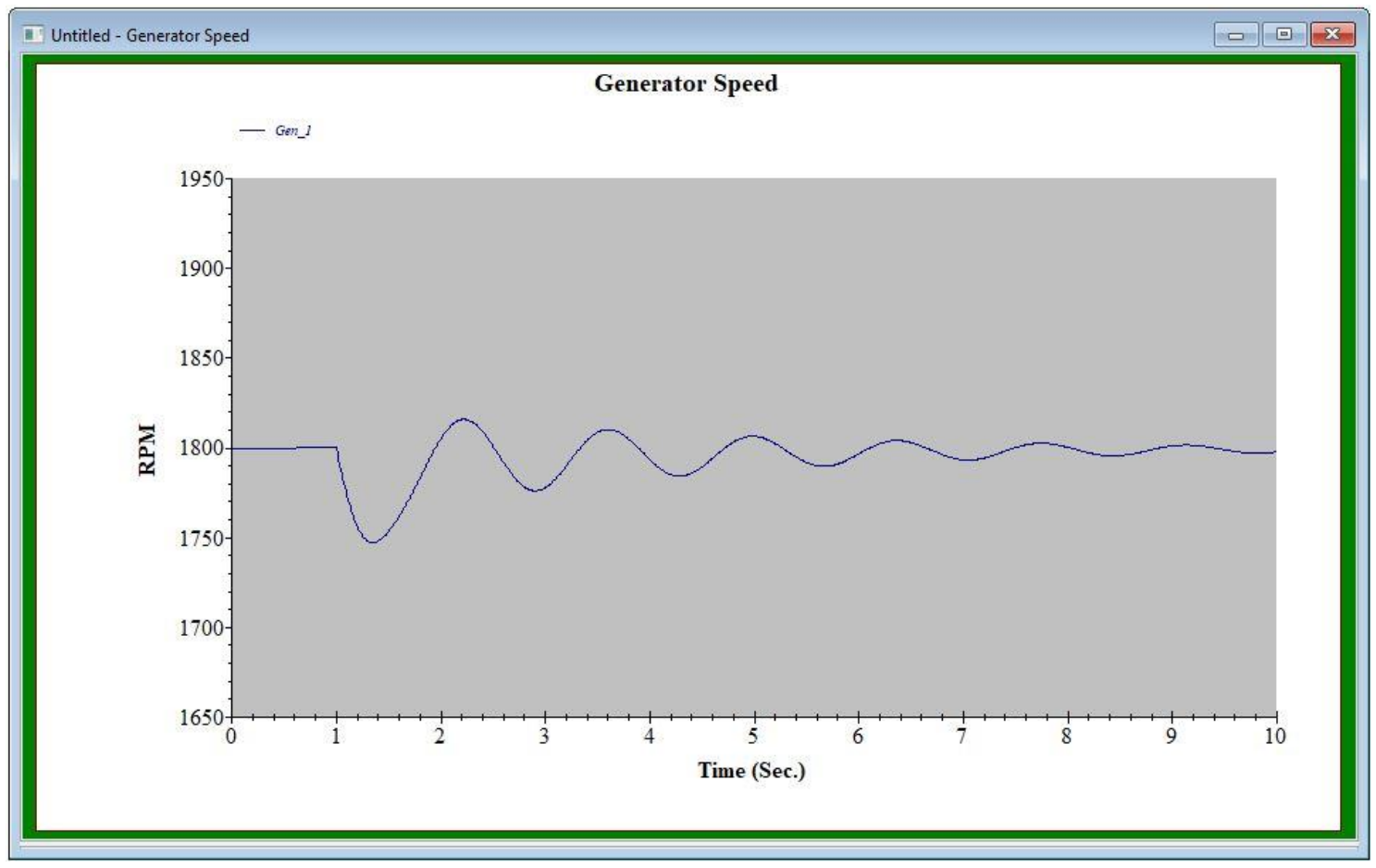

Figure 5-50: Generator speed response, governor control

The simulation shown in Figure 5-50 is similar to that of trying to manually adjust the speed of the DC motor driving the synchronous generator in the lab. Hence, another possible senior design or master's thesis can investigate the implementation of a control method to adjust mechanical input to the generators. During transient scenarios in the hardware implementation of the microgrid, there is no feedback control mechanism currently present. That is, field excitation and mechanical speed are assumed to be constant during all transient events. Another possible improvement of the microgrid transients could be to implement excitation control, which is beyond the scope of this thesis. 


\subsubsection{Case IV: Large Load Step}

The effect of applying a large load is simulated by first considering the microgrid system islanded with one of the static loads supplied from one of the synchronous generators. One of the loads are energized by means of closing a circuit breaker at its terminals. Machine inertia constant is simulated to be $1.0 \mathrm{MW} \cdot \mathrm{s} / \mathrm{MVA}$. The resulting frequency of the synchronous generator terminals is shown in Figure 5-51.

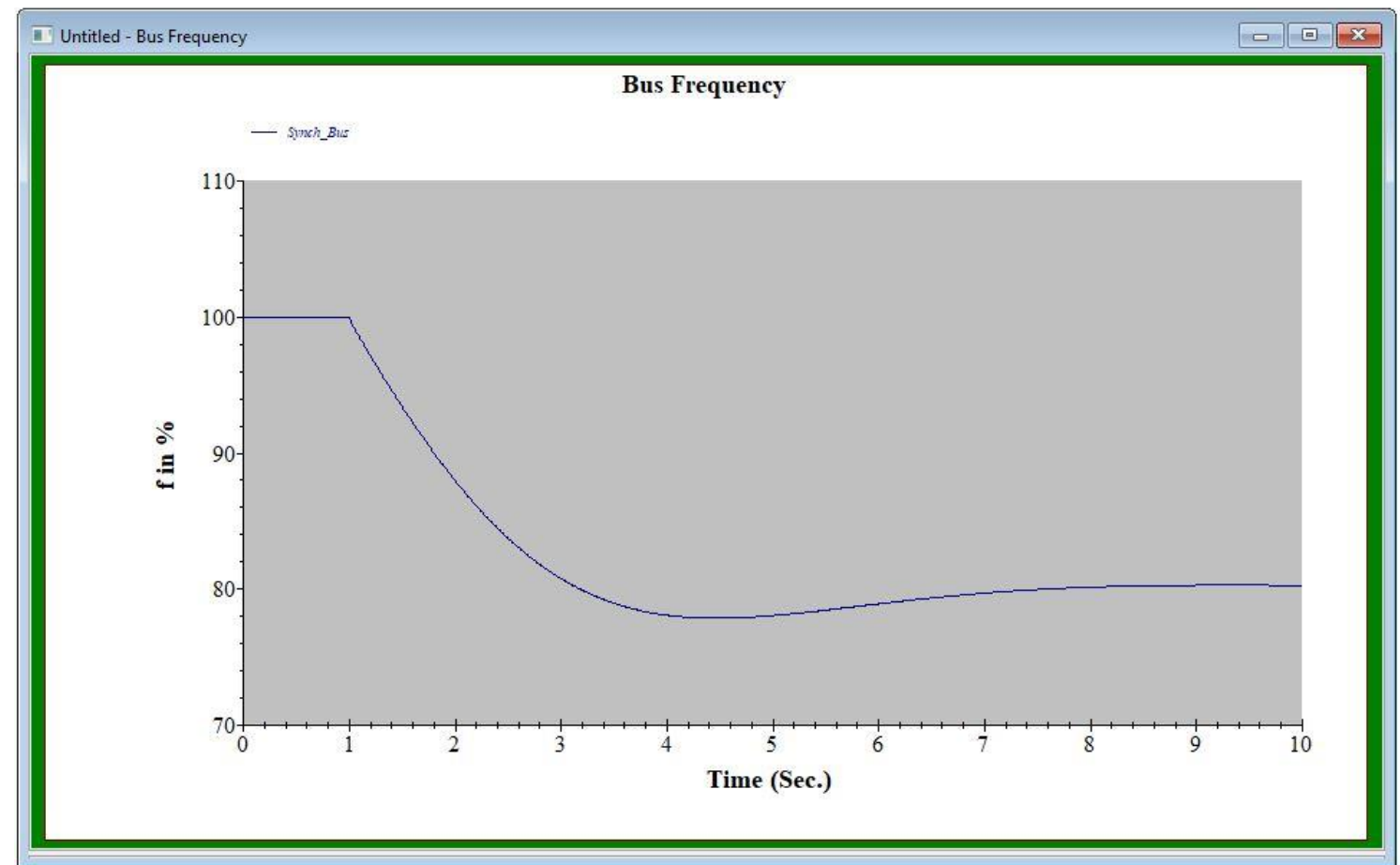

Figure 5-51: Large Load Step, generator frequency

Frequency collapses as the synchronous generator fails to supply enough mechanical power to meet the increased electrical demands from the static load. This example showcases the necessity of added supplemental generation in the form of photovoltaics or battery storage. The synchronous generator is equipped with frequency 
relays monitors the terminal frequency. One possible improvement is to enable supplementary generation from the DC system when detecting under-frequency conditions. The SEL700G relays for the synchronous generators have frequency monitoring capabilities, which can be utilized to monitor the decrease in generator terminal frequencies and send trip commands to nearby supplementary generation to turn on. This case study does not consider grid-connected mode, as the utility will be able to supply the necessary demands.

\subsubsection{Transient Stability Summary}

Several case studies were conducted on the transient stability section to analyze and investigate possible transient stability improvement methods. The application of the swing equation was investigated in Case I with deviations of machine's rotor angle with respect to faults. The biggest issue encountered in transient stability studies was the uncertainty in exact system inertia in the form of rotating machinery. As synchronous machineries utilized in the microgrid have inherently low machine inertia as well as low time constants associated with asymmetrical short circuit current, it is difficult to model machines in ETAP precisely. ETAP can plot mechanical and electrical power outputs on the scale of MW and MW mechanical-however, generators are rated at 250W.

Additionally, several case studies did not investigate the effect of motor dynamics, in that the induction motor was assumed to be de-energized throughout our study. Future work may characterize and explore the effect of loading the induction motor. However, the microgrid cannot sustain ramping the induction motor with the synchronous generator alone, and will need to be supplemented with alternative sources of generation. Case III 
investigated the possibility of implementing control schemes such as governor or excitation control to improve transient stability in the microgrid. It will be important to consider the very low time constants associated with machine currents and low rotational inertia in implementing such a design. Lastly, there are several relay elements available in the microgrid that closely monitor parameters such as frequencies and over/under voltage conditions. These can be utilized to help turn on/off elements including supplementary generation such as that from the DC subsystem. 


\section{Chapter 6: Conclusion}

Advancements in renewable energy technologies along with their decreasing costs and renewable energy mandates are shifting the power industry away from the centralized generation model and instead incorporate distributed energy resources close to end users to meet the electrical demands of the customer. The modern microgrid has capabilities of operating in both islanded and grid-connected modes to help supplement the transfer of energy. This thesis aims to develop the foundation of an ETAP model of the system and test its performance of the current development iteration of the Cal Poly microgrid lab. Several case studies and system validations comparing the ETAP model with the Cal Poly microgrid were conducted in Chapter 5, showcasing the powerful analysis tools ETAP can offer. Successful replication of both short circuit and protection coordination studies were validated for both the hardware and ETAP implementations of the microgrid. Specifically, identical relay protection settings were implemented in both SEL microprocessor based relays as well as its equivalent model in ETAP. Additionally, the appendix includes an ETAP protection tutorial created to aid future power system students. This thesis therefore may serve to help supplement reference [4] and assist in the preparation of students entering the power industry.

\subsection{Difficulties Encountered}

Load flow and transient stability studies were the most difficult studies to accurately model the Cal Poly microgrid due to several considerations: non-ideal low rated equipment, low time constants associated with dampening of transients, and low 
system inertia, discussed throughout Chapter 5. Magnetizing current and transformer saturation could not be modeled in ETAP load flow analysis, resulting in less current flowing throughout the system and higher overall bus voltages. ET AP is originally designed to model industrial scale and larger power systems, whereas the rotating machineries in the Cal Poly's microgrid lab are rated at one-third horse power with very low rotational inertia. Future students must take these considerations into account if they wish to utilize ETAP in the modeling of transient stability or other dynamic studies such as motor acceleration.

ETAP is also incapable of modeling the entire functionality of the SEL relays offered from SEL microprocessor based relays. Per reference [4], the prior microgrid demonstrated SEL-311L's permissive trip and mho distance protection, which are not available in the Cal Poly version of ETAP 16.2. However, coordination was still implemented primarily utilizing time overcurrent protection and demonstrated throughout Chapter 5.

\subsection{Recommended Future Work}

Per reference [4], the Cal Poly San Luis Obispo’s electrical engineering department proposed the "Advanced Power Systems Initiatives to better prepare its students for entering the power industry." Since ETAP is a widely used software in the power industry, it will be beneficial for power students to learn ETAP and conduct projects using ETAP. The Appendix includes a custom step-by-step tutorial of protection and coordination studies conducted through ETAP. Possible future senior design projects or master's theses may focus on the ETAP development of SEL based laboratory 
experiments created by the author of [4] to include simulations of the laboratory experiments. Additionally, several functionalities of SEL relays are not currently utilized, which can be incorporated in both the hardware and ETAP implementations of the microgrid for future senior design and master's theses. Overcurrent protection is not implemented for the synchronous generator relays SEL700G. Directional protection is available for both SEL-311L and SEL-421, but not currently implemented within the microgrid. Frequency relays from SEL-421 can also be utilized to monitor transient events and assert commands as necessary.

Several work may be done on the DC subsystem, which can be improved and analyzed in more detail for the future microgrid. The addition of battery storage will heavily relieve the energy demands of the system when operating in islanded conditions. The two synchronous generators cannot adequately supply all the loads without substantial decreases in generator speeds, system frequencies, and bus voltages in islanded mode. Photovoltaics and energy storage systems will greatly relieve power demands from the generators. Power quality analysis can be performed with the harmonic analysis mode in ETAP to investigate the distortions of inverter current waveforms. ETAP also has capabilities of DC short circuit analysis. DC protection and coordination can be conducted throughout ETAP and tested with the future microgrid, similar to AC protection implemented in this thesis.

Lastly, in the hardware implementation of the microgrid there exists no feedback control to adjust the field current or speed of the prime mover for the synchronous generator. Control schemes may be investigated in detail in ETAP for excitation and governor control. However, future students will need to take into consideration the very 
low time constants and inertia associated with the rotating machinery, which may prove difficult to model accurately. 


\section{REFERENCES}

[1] “The Utility View Of Microgrids," Utility Dive. 2014.

[2] A. Majzoobi and A. Khodaei, "Application of microgrids in providing ancillary services to the utility grid," Energy, vol. 123, pp. 555-563, Mar. 2017.

[3] P. Denholm, M. O'Connell, G. Brinkman, and J. Jorgenson, "Overgeneration from Solar Energy in California: A Field Guide to the Duck Chart," National Renewable Energy Laboratory, Golden, CO, 2015.

[4] K. Pretzer, "Protective Relaying Student Laboratory," Master's Thesis, Dept. Elect. Eng., California Polytechnic State Univ., San Luis Obispo, 2017.

[5] P. Kundur et al., "Definition and classification of power system stability IEEE/CIGRE joint task force on stability terms and definitions," in IEEE Transactions on Power Systems, vol. 19, no. 3, pp. 1387-1401, Aug. 2004.

[6] R. Majumder, "Some Aspects of Stability in Microgrids," in IEEE Transactions on Power Systems, vol. 28, no. 3, pp. 3243-3252, Aug. 2013.

[7] R. Singh and M. Kirar, "Transient stability analysis and improvement in microgrid," 2016 International Conference on Electrical Power and Energy Systems (ICEPES), Bhopal, 2016, pp. 239-245.

[8] P. Kundur, N. J. Nalu, and M. G. Lauby. Power System Stability and Control. New York: McGraw-Hill, 1994. Print.

[9] J. McCalley. EE 554. Class Lecture, Topic: "Preliminary Fundamentals." College of Engineering, Iowa State University, Ames, Iowa, Spring 2009.

[10] ETAP 14.1 User Guide. Operation Technology, Inc. 
[11] J. D. Glover, T.J. Overbye, and M.S. Sarma, Power system analysis and design, $5^{\text {th }}$ ed. Stamford, CT: Cengage Learning, 2012. Print.

[12] A. Shaban, and A. Nafisi. EE 518. Class Lecture, Topic: "Symmetrical Components." College of Electrical Engineering, California Polytechnic State University, San Luis Obispo, San Luis Obispo, California, Spring 2017.

[13] J. L. Blackburn and T. J. Domin, Protective Relaying: Principles and Applications, $3^{\text {rd }}$ ed. FL: CRC Press, 2006. Print.

[14] C. Osborn, “Microgrid Laboratory,” Master’s Thesis, Dept. Elect. Eng., California Polytechnic State Univ., San Luis Obispo, In Progress.

[15] APsystems YC1000-3 Microinverter Datasheet, APsystems, Seattle, WA, June 13, 2017. Available: http://usa.apsystems.com/wpcontent/uploads/2017/07/APsystems-YC1000-Datasheet-7.20.17.pdf

[16] Yang, Woo-Sik “Microgrid Laboratory," Senior Design Project, Dept. Elect. Eng., California Polytechnic State Univ., San Luis Obispo, In Progress.

[17] A. Shaban, EE 518. Class Lecture, Topic: "ETAP Student Manual." College of Electrical Engineering, California Polytechnic State University, San Luis Obispo, San Luis Obispo, California, Spring 2017. 


\section{APPENDICES}

\section{Appendix A: ETAP Protection Tutorial}

\section{INTRODUCTION}

The following documentation has been created to assist power students familiarize themselves with ETAP and protective relaying principles. Working through the following example is similar to that assigned in EE 407 and EE 518. Consider Figure A1 which illustrates a one-line of a $34.5-\mathrm{kV}$ radial system per reference [1], example 10.4. The audience is intended to have gone through the example prior to its implementation in ETAP. Select current tap settings (TSs), and time-dial settings (TDSs) to protect the system from any fault. Assume three Westinghouse CO-8 relays for each breaker, with a 0.3 second coordination time interval. Assume 5 cycle breaker operating time. Assume 34.5-kV nominal line-to-line voltages at each bus for nominal operation. Tables 1 and 2 provide necessary data in the implementation of the problem in ETAP. Figure A2 provides a CO-8 time-delay overcurrent relay characteristics.

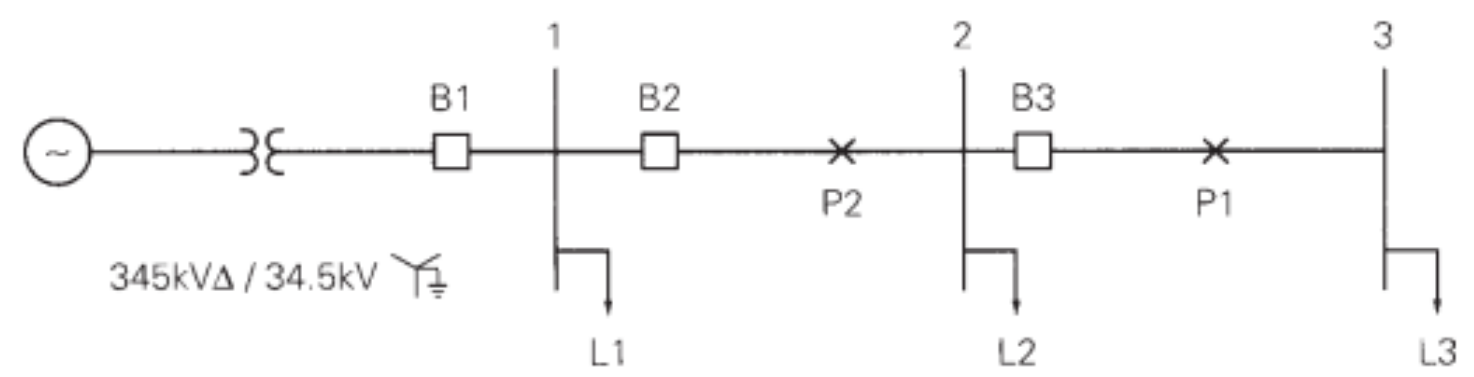

Figure A1: Radial System [11] 
Table A1: Loading and Max Fault data [11]

\begin{tabular}{|c|c|c|c|}
\hline BUS & S MVA & Lagging PF & Max 3-phase bolted fault current (A) \\
\hline 1 & 11.0 & 0.95 & 2000 \\
\hline 2 & 4.0 & 0.95 & 1000 \\
\hline 3 & 6.0 & 0.95 & \\
\hline
\end{tabular}

Table A2: Breaker Operating time and CT Ratio [11]

\begin{tabular}{|c|c|c|c|}
\hline Breaker & Breaker Operating Time & CT Ratio & Relay \\
\hline CB1 & 5 cycles & $400: 5$ & CO-8 \\
\hline CB2 & 5 cycles & $200: 5$ & CO-8 \\
\hline CB3 & 5 cycles & $200: 5$ & CO-8 \\
\hline
\end{tabular}




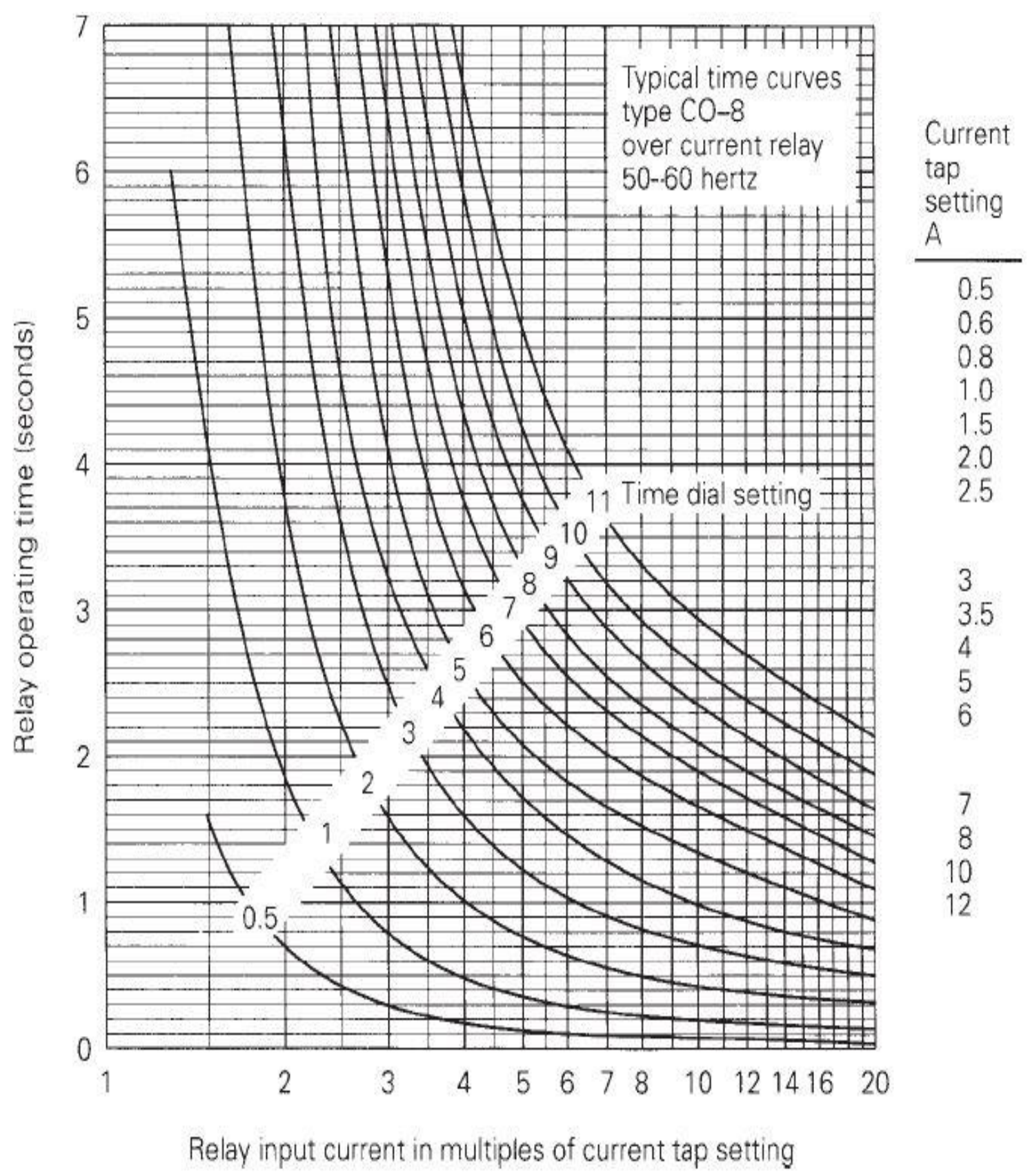

Figure A2: $\mathrm{CO}-8$ time-delay overcurrent relay characteristics [11] 


\section{SOLUTION}

Table A3: TS and TDS settings

\begin{tabular}{|c|c|c|c|}
\hline Breaker & Relay & Current Tap Setting (A) & Time Dial Setting \\
\hline CB1 & CO-8 & 5 & 3 \\
\hline CB2 & CO-8 & 5 & 2 \\
\hline CB3 & CO-8 & 3 & $1 / 2$ \\
\hline
\end{tabular}

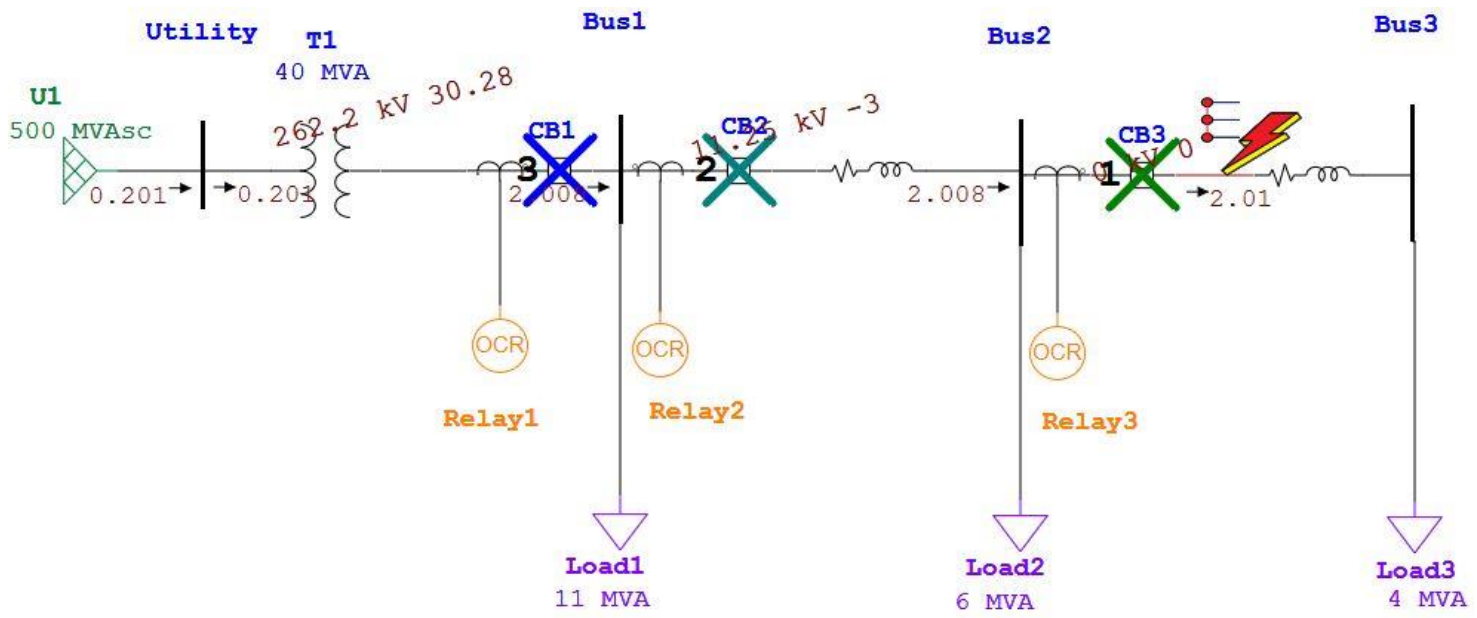

Figure A3: Max 3 phase fault for breaker CB3, Bus2 


\begin{tabular}{|c|c|c|c|c|c|c|}
\hline \multicolumn{6}{|c|}{ [1] Sequence-of-Operation Events - Output Report: Untitled } & $\times$ \\
\hline \multicolumn{7}{|c|}{ 3-Phase (Symmetrical) fault on connector between CB3 \& Line5. A.djacent bus: Bus2 } \\
\hline \multicolumn{4}{|c|}{ Data Rev: Base } & \multicolumn{2}{|c|}{ Config: Normal Date: 03-19-2018 } & \\
\hline Time $(\mathrm{ms})$ & ID & If $(\mathrm{kA})$ & $\mathrm{T} 1$ (ms) & $\mathrm{T} 2$ (ms) & Condition & \\
\hline 69.6 & Relay3 & 2.008 & 69.6 & & Phase - 0C1 - 51 & \\
\hline 153 & $\mathrm{CB} 3$ & & 83.3 & & Tripped by Relay3 Phase - 0C1 - 51 & \\
\hline 451 & Relay2 & 2.008 & 451 & & Phase - 0C1 - 51 & \\
\hline 534 & $\mathrm{CB} 2$ & & 83.3 & & Tripped by Relay2 Phase - 0C1 - 51 & \\
\hline 1180 & Relay1 & 2.008 & 1180 & & Phase-0C1- 51 & \\
\hline 1263 & CB1 & & 83.3 & & Tripped by Relay 1 Phase - 0C1 - 51 & \\
\hline
\end{tabular}

Figure A4: Sequence-of-Operation for Figure A3 


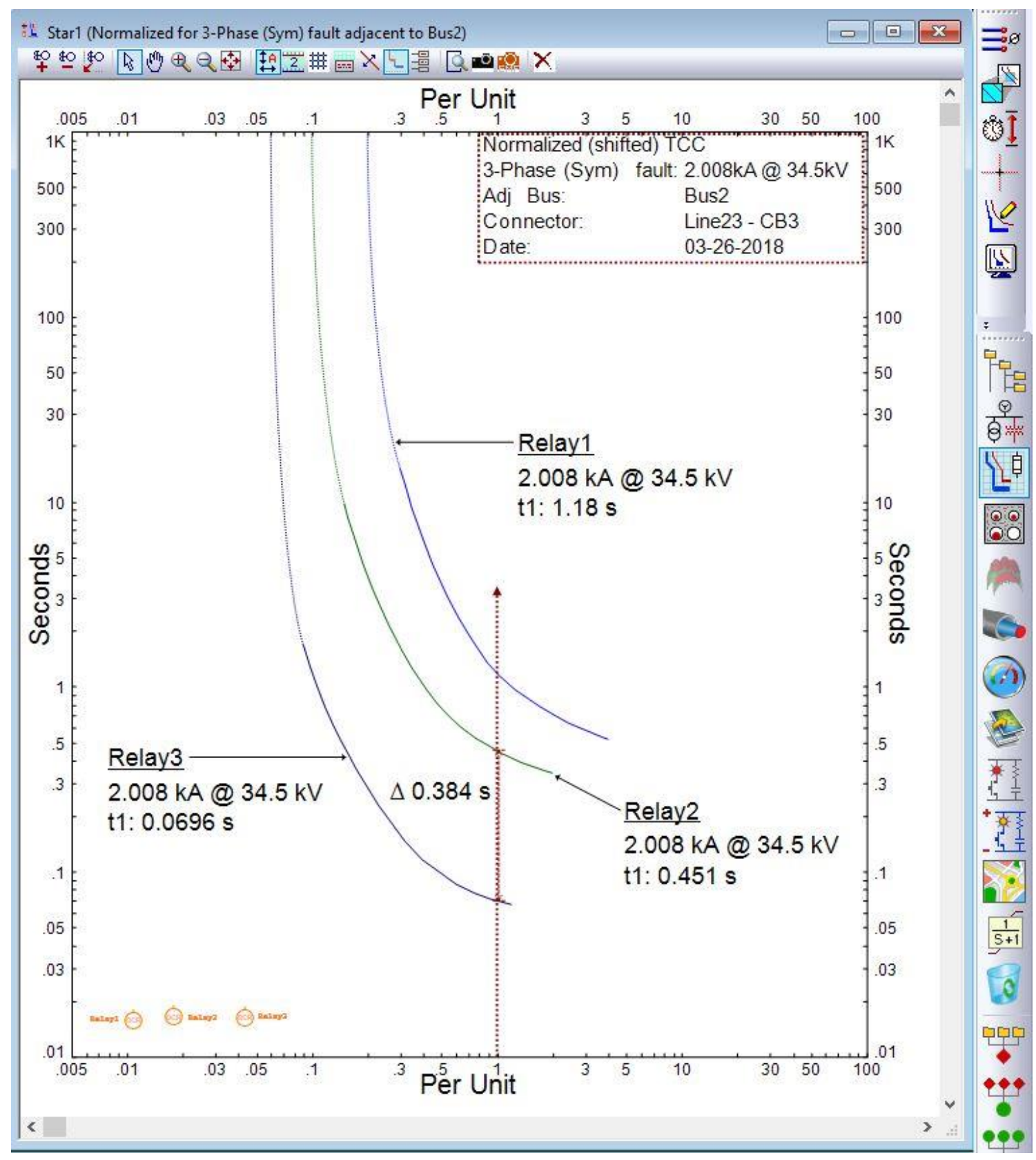

Figure A5: TCC for 3 phase fault Bus 2 


\section{Part 1: Setting up ETAP One-Line}

Open ETAP 16.2.0 and create a new project from File > New Project. Enter a name for the new project, e.g. "protection" and press OK shown in Figure A6.

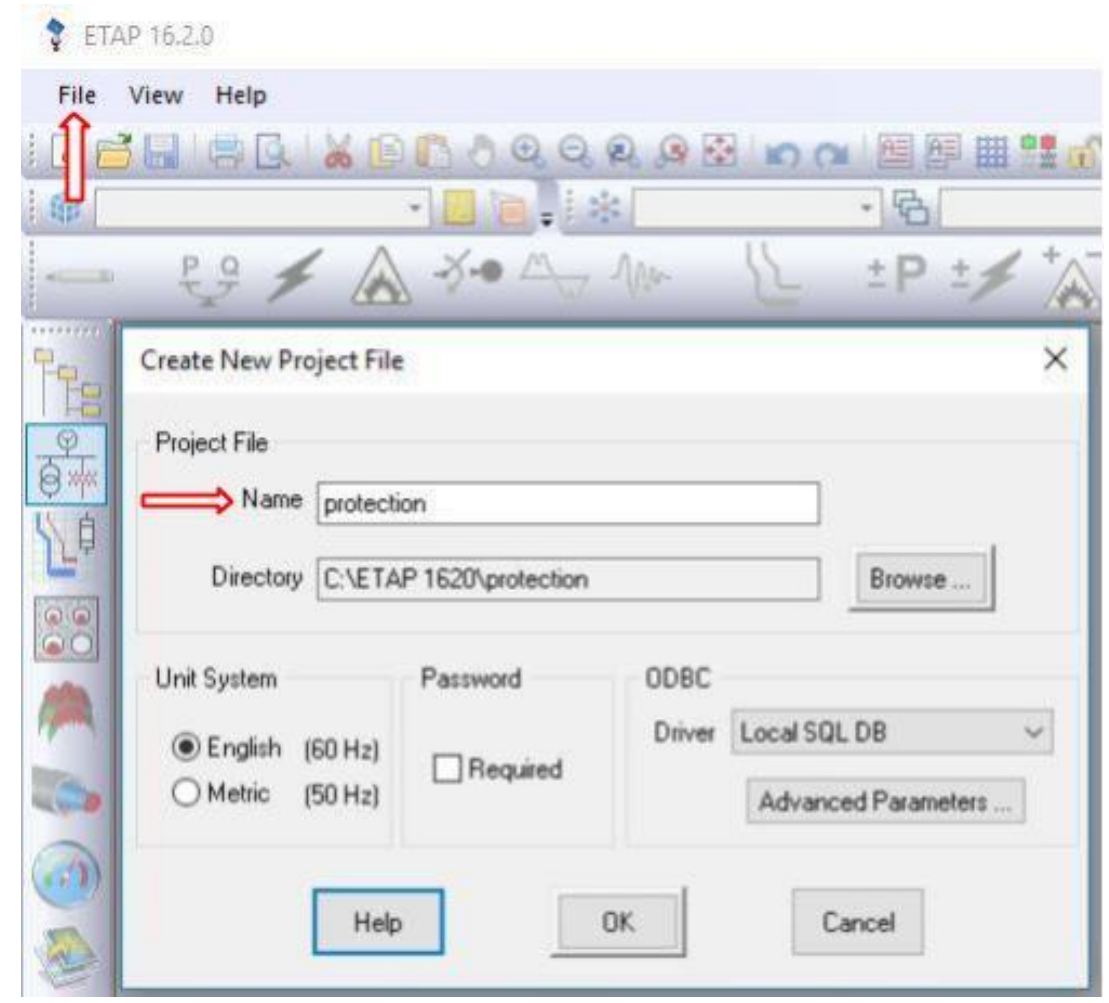

Figure A6: ETAP, New Project

When prompted for user information, default values are acceptable and Access level permissions should all be selected to provide the user with the highest level of access and press $\mathbf{O K}$. At this point, you should see an empty one-line diagram in which we will create our radial power system.

Create four buses by left clicking an AC Bus ( $\stackrel{\text { Bus }}{-}$ ) from the AC Edit toolbar and placing them on the empty one-line diagram. ETAP automatically labels the buses as "Bus1", "Bus2", etc. Double left click any bus on the one-line diagram to open up the 
Bus Editor which has several tabs available to the user to vary bus parameters. Select the Info tab if not already selected, and change the Nominal $\mathbf{k V}$ for Bus1 to $34.5 \mathrm{kV}$ and hit OK. Repeat the process for Bus2 and Bus3. Hit Ctrl+z at anytime on the one-line diagram to revert any misoperation.

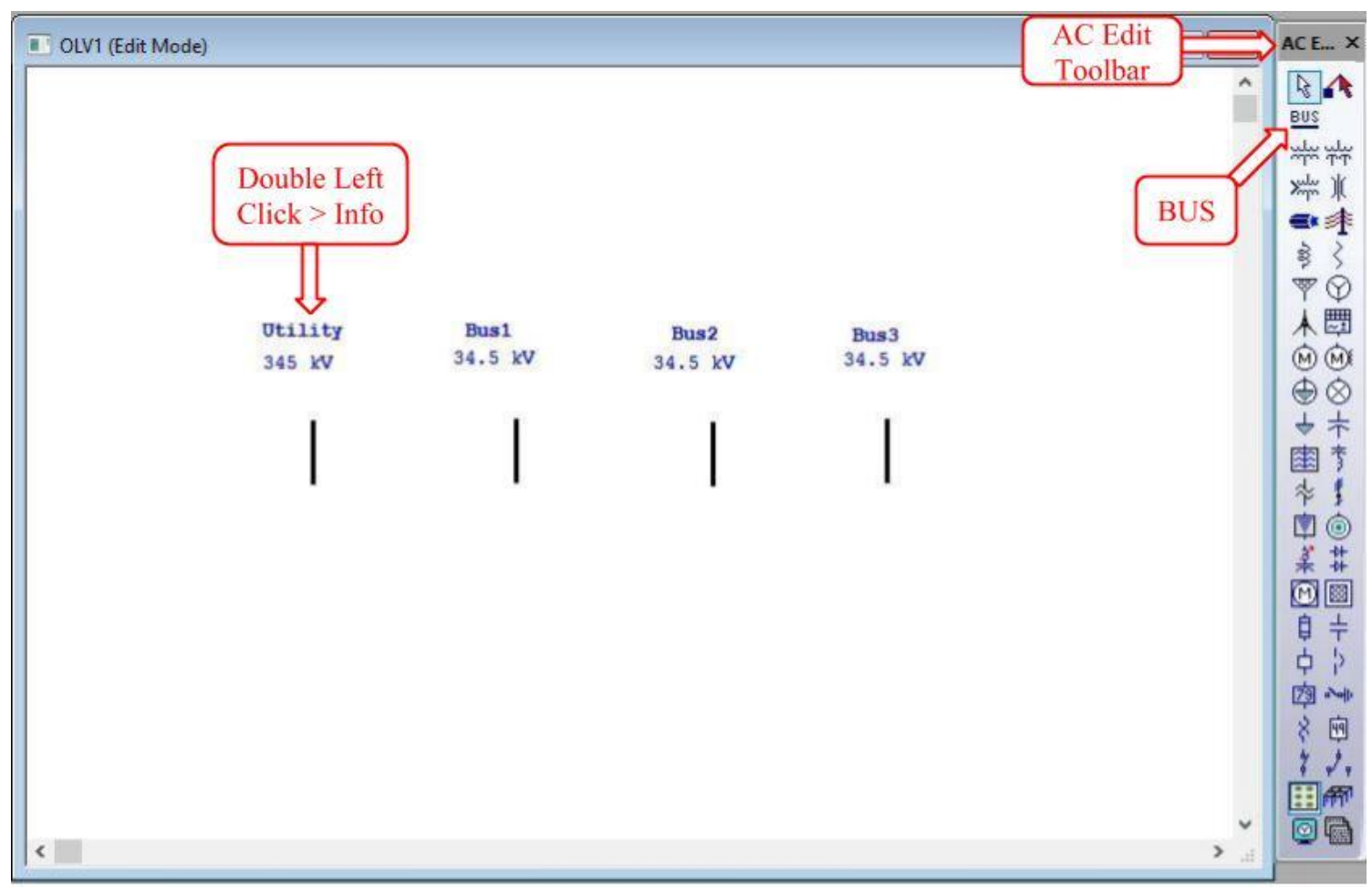

Figure A7: ETAP, Placing AC Bus, one-line

Double left click Bus4, select Info tab and edit its name under ID to "Utility" and change the Nominal $\mathbf{k V}$ to $345 \mathrm{kV}$ and hit OK. Right click any bus on the one-line and click Rotate $>90$ to reorient the buses. At this point you should arrange your components on the one-line diagram such that it resembles Figure A7. Feel free to move around Bus labels on the one-line diagram by left click, hold, and dragging. Figure A8 shows the Bus Editor for the Utility bus. 


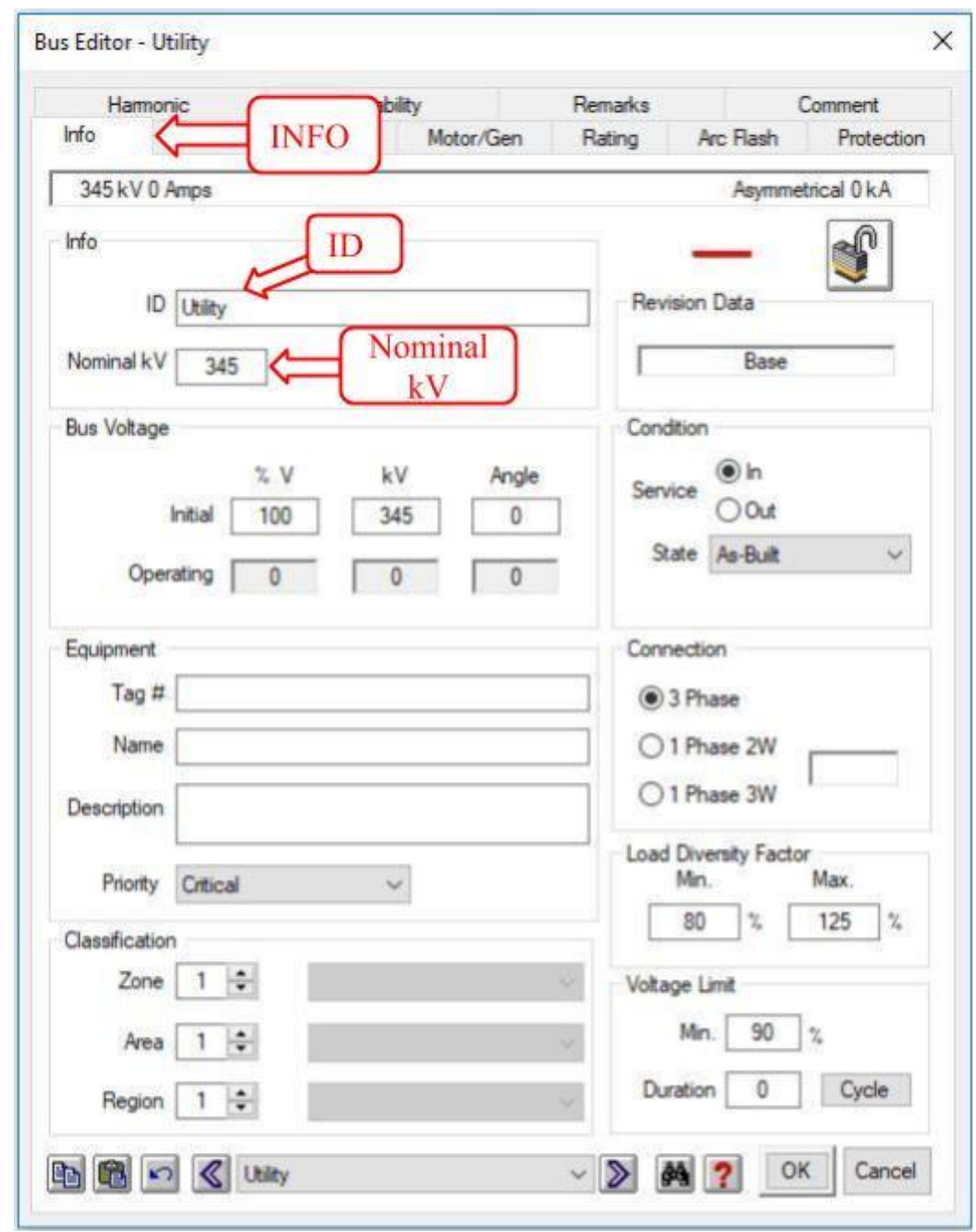

Figure A8: ETAP, Bus Editor

We will now add the 2-Winding Transformer. Click the 2-Winding Transformer from the AC Edit Toolbar. Place the transformer between the Utility Bus and Bus1 on the one-line. Double click the transformer T1 to open up the 2-Winding Transformer Editor. Click the Info tab if not already selected, and select Utility from the drop down box for the 'Prim.' winding and select Bus1 from the drop down box for the 'Sec.' winding. Select the Rating tab and enter $\mathbf{4 0}$ under the Rated MVA field. Select the 
Impedance tab and select Typical $\mathbf{Z} \& \mathbf{X} / \mathbf{R}$. We have selected typical impedance values for this transformer for purposes of simulation. Click OK. You may need to right click the transformer on the one-line, and select Rotate $>\mathbf{- 9 0}$ for convenient placing. Figure A9 displays the entering of transformer parameters and its placement on the one-line.

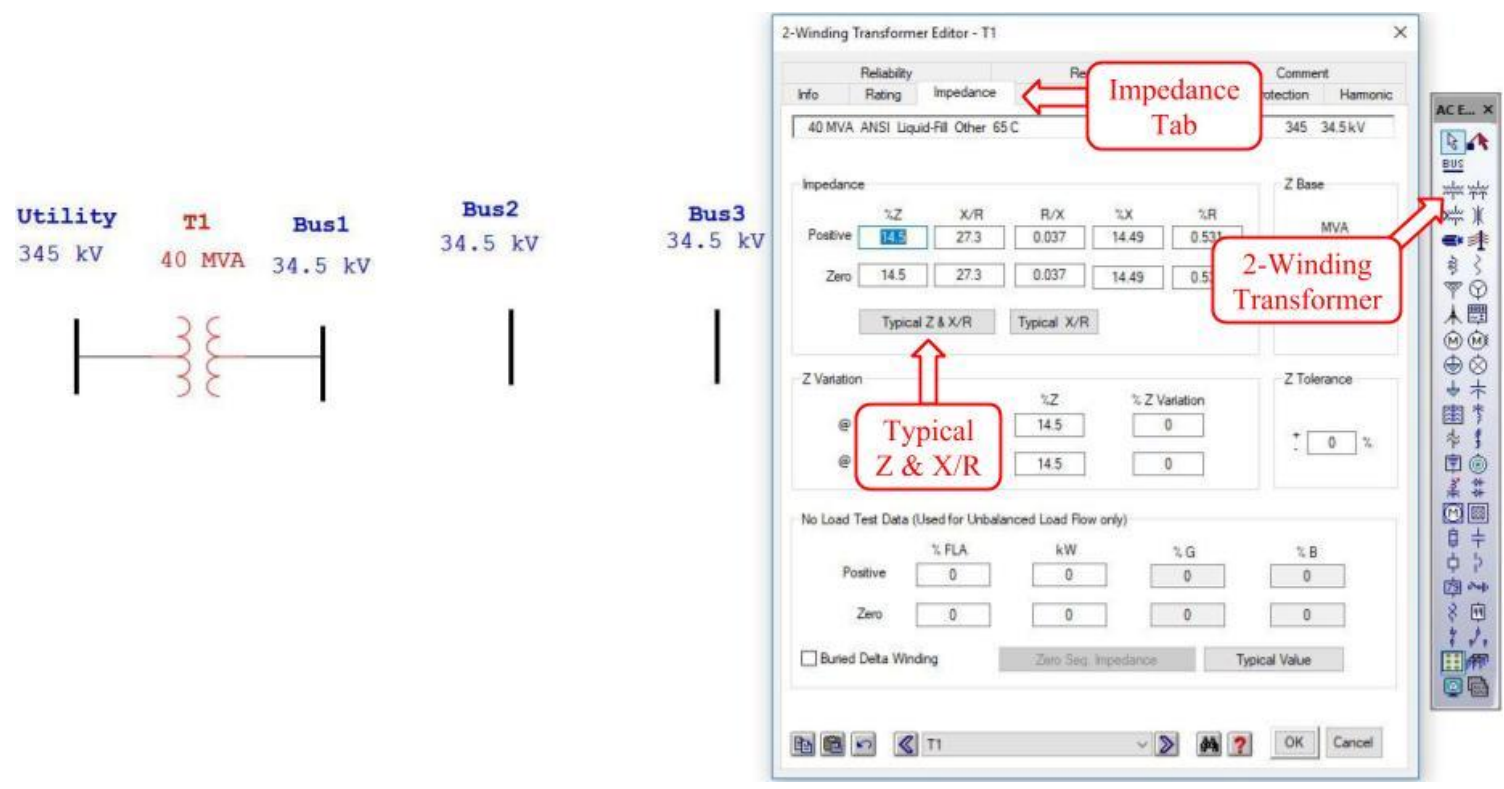

Figure A9: ETAP, Transformer Editor, one-line

We will now add the Power Grid. Click the Power Grid from AC Edit Toolbar.

Place the power grid to the left of the Utility Bus on the one-line. Double click the power grid U1 to open up the Power Grid Editor. Click the Info tab if not already selected, and select Utility from the drop down box for the Bus. Select the Short Circuit tab and enter 500 under the MVAsc 3-Phase SC Rating field. Enter 10 under the X/R field. We have selected typical short circuit contributions from the power grid for purposes of simulation. Click OK. Figure A10 displays the entering of power grid parameters and its placement on the one-line. 


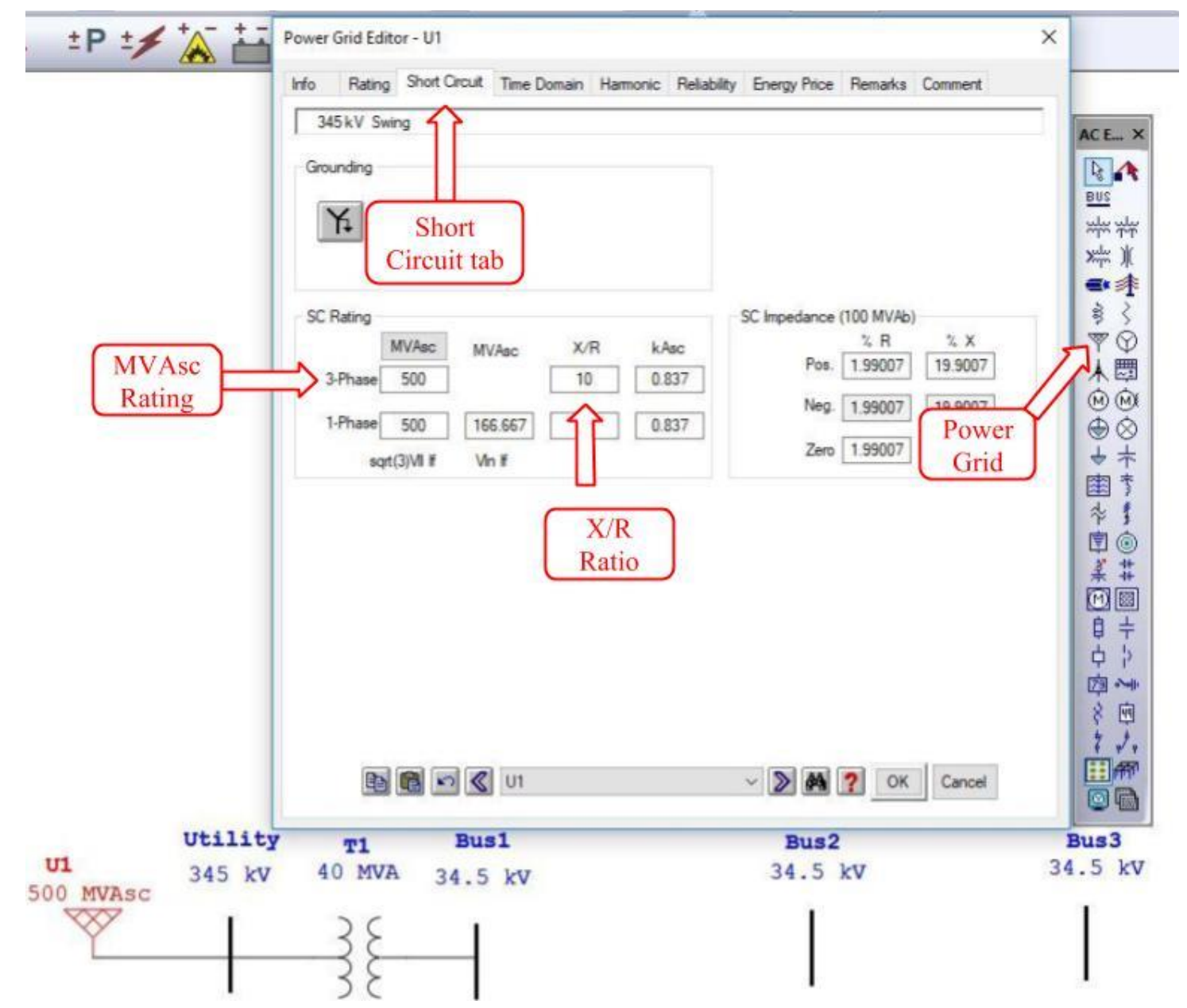

Figure A10: ETAP, Power Grid Editor, one-line

We will now add two transmission lines. The complete realization of a transmission line requires several considerations to model. The interested reader may refer to reference [2] for a more detailed understanding of transmission line parameterization. Click the Transmission Line from the AC Edit Toolbar. Place the transmission line between Bus1 and Bus2. Double click the transmission line to open up the Transmission Line Editor. Click the Info tab if not already selected, enter Line12 under ID. Select Bus1 from the drop down box 'From'. Select Bus2 from the drop down 
box 'To'. Enter 6 miles under the length. Click the Parameter tab and select Conductor Lib... to open up the Library Quick Pick - Transmission Line. Select

EPRI/M.LAYER under Source Name. Scroll down and select Curlew under Size. Click OK to close the Library Quick Pick window. Click Configuration in the Transmission Line Editor and enter $\mathbf{2 5} \mathrm{ft}$ for $\mathrm{AB}, \mathbf{2 5} \mathrm{ft}$ for $\mathrm{BC}$, and $\mathbf{5 0 f t}$ for $\mathrm{CA}$ under Spacing. Enter $\mathbf{3 0} \mathrm{ft}$ under Height. Check the box for Transposed under Conductors. Enter 45.7 under Separation. Enter 2 under Conductors/phase. Hit OK.

Add another transmission line between Bus 2 and Bus3 and repeat the process noting slight variations. Double click the new transmission line to open up the Transmission Line Editor. Click the Info tab if not already selected, enter Line23 under ID. Select Bus2 from the drop down box 'From'. Select Bus3 from the drop down box 'To'. Enter 18 miles under the length. Click the Parameter tab and select Conductor Lib... to open up the Library Quick Pick - Transmission Line. Select EPRI/M.LAYER under Source Name. Scroll down and select Mallard under Size. Click OK to close the Library Quick Pick window. Click Configuration in the Transmission Line Editor and enter $\mathbf{2 5} \mathrm{ft}$ for $\mathrm{AB}, \mathbf{2 5} \mathrm{ft}$ for $\mathrm{BC}$, and $\mathbf{5 0} \mathrm{ft}$ for $\mathrm{CA}$ under Spacing. Enter 30ft under Height. Check the box for Transposed under Conductors. Enter 45.7 under Separation. Enter 2 under Conductors/phase. Hit OK. You may need to reorient transmission lines on the one-line by right clicking them and selecting Rotate > 90. Figure A11 illustrates the entering of sample transmission line parameters for Line23. Figure A12 displays the transmission lines onto the one-line diagram. 


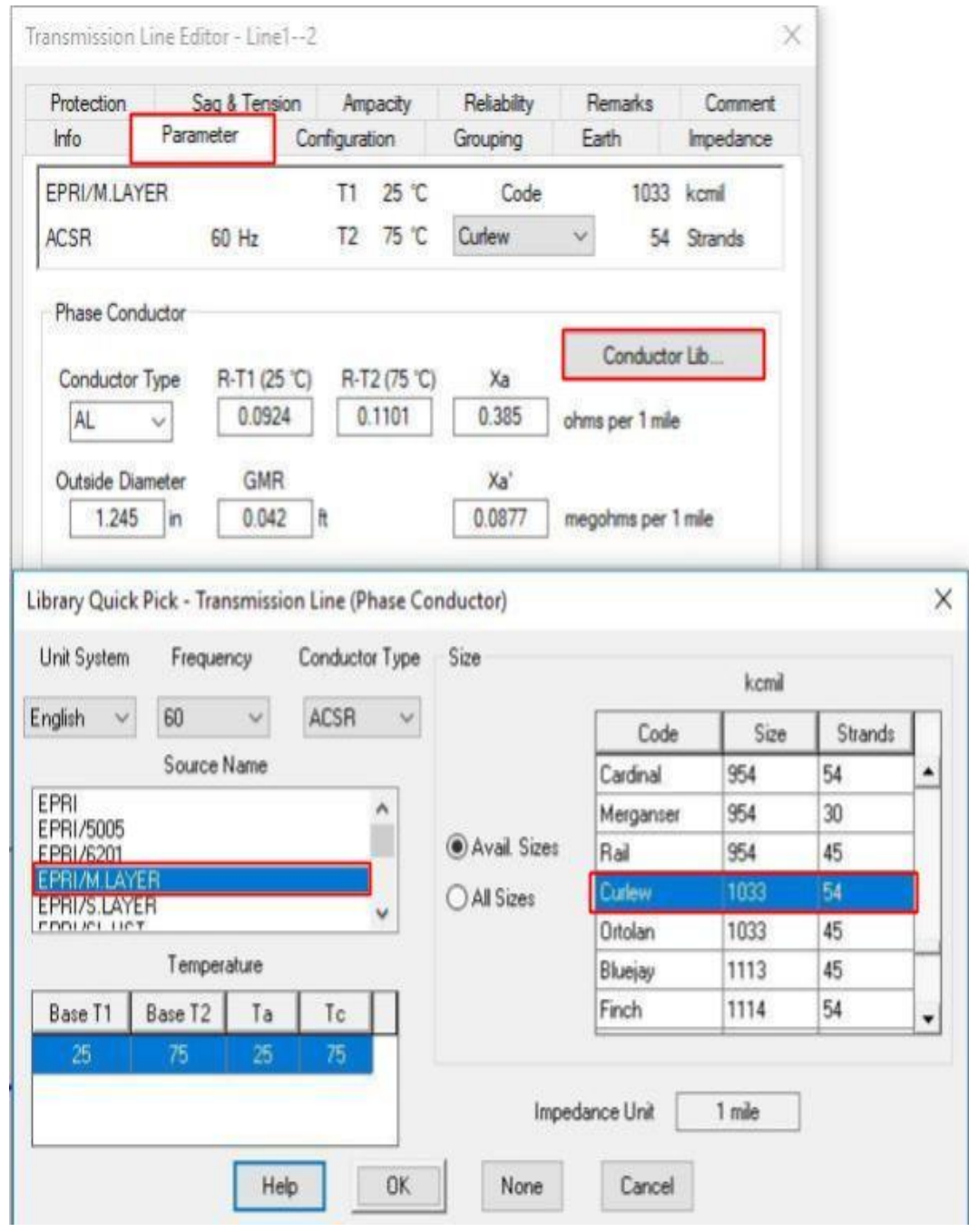

Figure A11: ETAP, Transmission Line Editor 


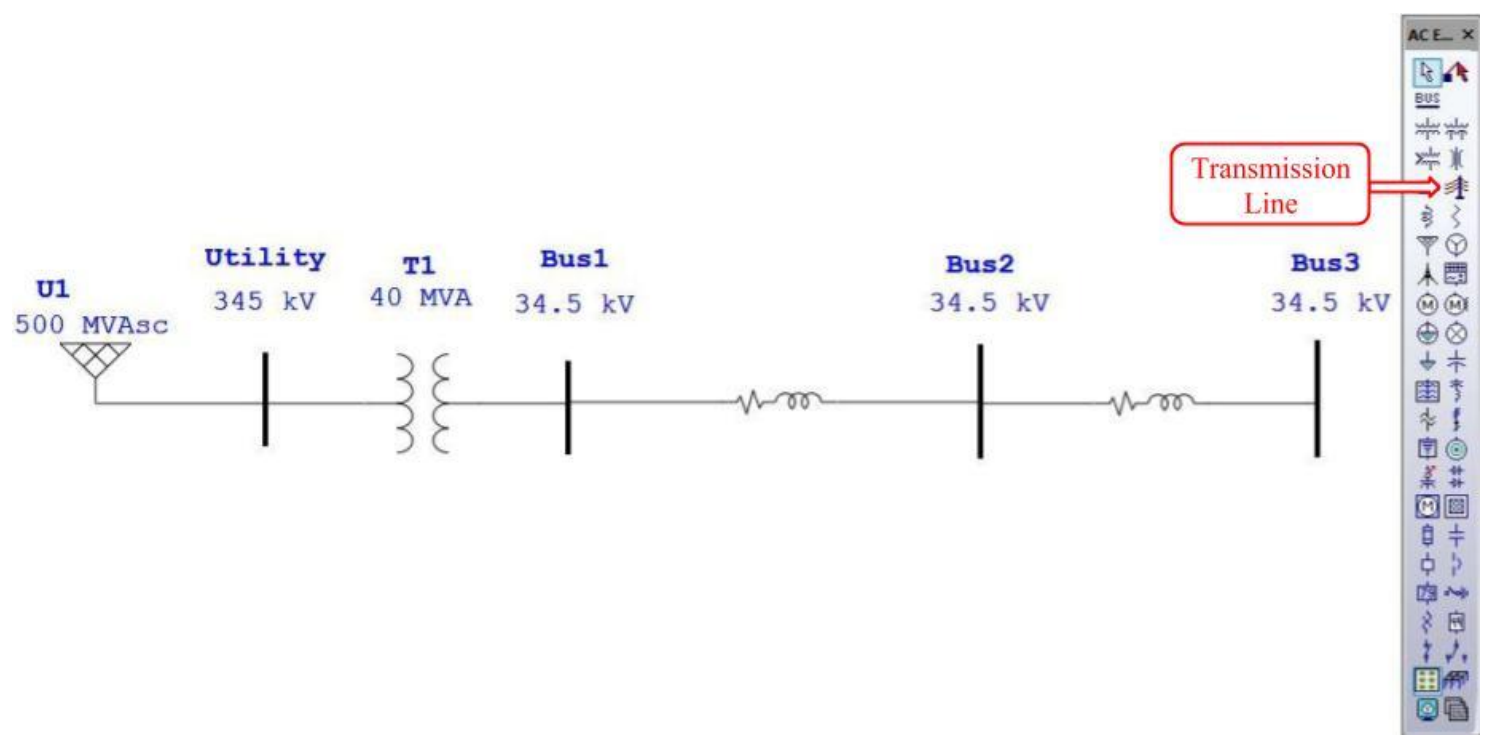

Figure A12: ETAP, Transmission Lines, one-line

We will now add static loads to our one-line. Click the Static Load from the AC Edit Toolbar. Place three static loads, Load1, Load2, and Load3 below Bus1, Bus2, and Bus3, respectively. Double click Load1 from the one-line and click the Info tab if not already selected and select Bus1 from the drop down box 'Bus'. Click the Loading tab and enter 11 MVA and $95 \%$ PF. Hit OK. Double click Load2 from the one-line and click the Info tab if not already selected and select Bus2 from the drop down box 'Bus'. Click the Loading tab and enter 4 MVA and $95 \%$ PF. Hit OK. Double click Load3 from the one-line and click the Info tab if not already selected and select Bus3 from the drop down box 'Bus'. Click the Loading tab and enter 6 MVA and $95 \%$ PF. Hit OK. 


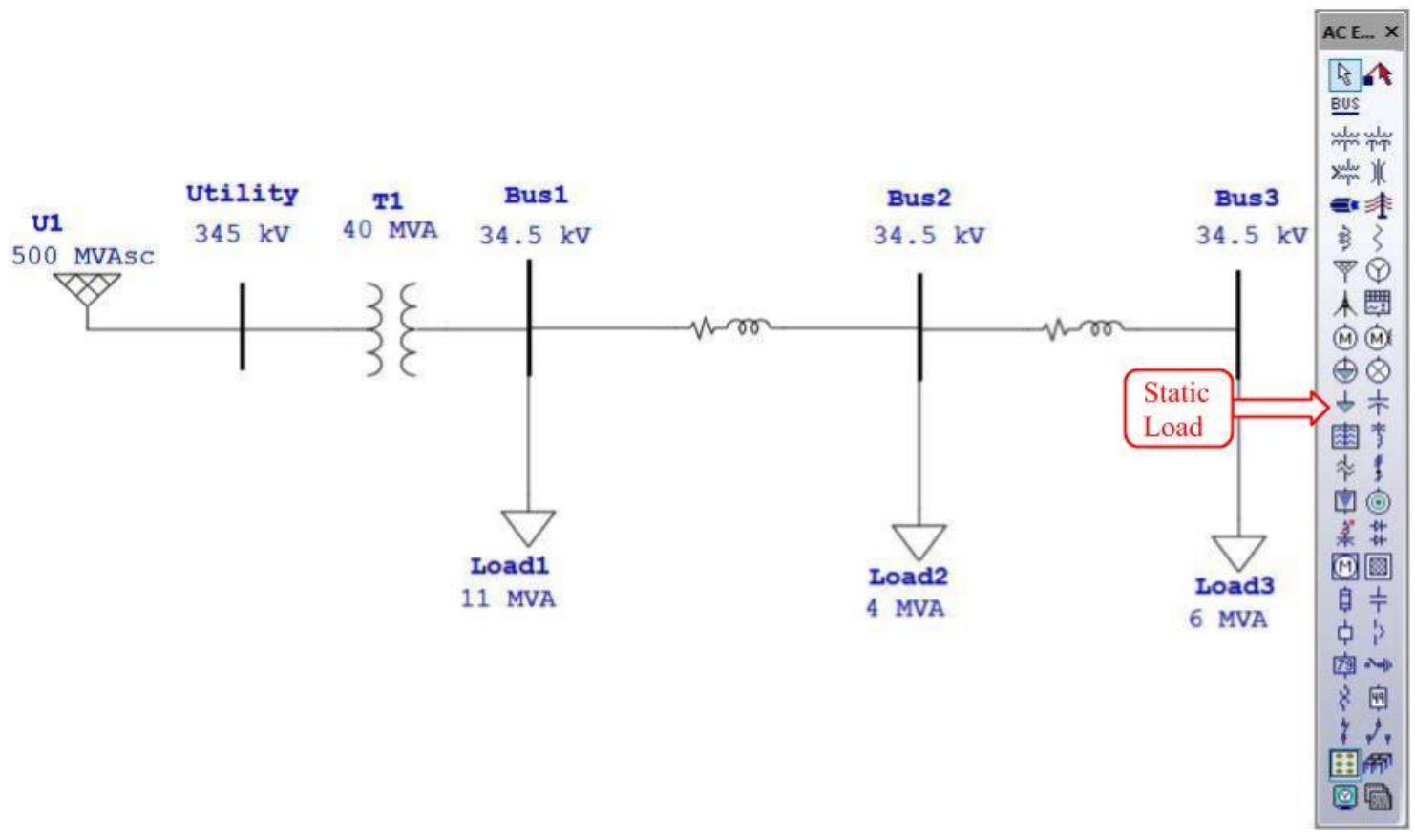

Figure A13: ETAP, Static Loads 


\section{Part 2: ETAP Protection and Coordination settings}

We will now modify the prior one-line to add protective elements including the current transformer, high voltage circuit breaker, and protective relay to create the figures shown in the solutions section above. Break the connection between transformer T1 and Bus1 on the one-line by clicking the connector between the circuit elements and pressing Delete. Alternatively, Right Click > Cut to remove the connection. While holding Ctrl, click transformer T1, Utility bus, and U1 power grid, and release Ctrl, ensuring the selected elements are highlighted in red. Click and drag the highlighted elements towards to left to allocate more empty space between $\mathrm{T} 1$ and Bus1 on the one-line.

We will now add the Current Transformer (CT) and High Voltage Circuit Breaker (HVCB) to our one-line. Select Current Transformer (CT) from the Instrumentation Toolbar and place the CT between T1 and Bus1. Select Display Options from the AC Edit Toolbar, select the AC tab if not already selected, and check the boxes next to PT \& CT under ID and Rating, and hit OK. This will identify and display the CT names and ratings on the one-line. Select High Voltage Circuit Breaker (HVCB) and place the HVCB between the CT and Bus1. Rotate both the CT and HVCB so they are horizontally aligned by Right Click > Rotate 90. Connect the left end of the CT to transformer T1 by clicking and holding on the pink box which appears when you point over the end of the $\mathrm{CT}$ element. Connect the right end of the CT to left end of HVCB CB1. Connect the right end of CB1 with Bus1. Figure A14 illustrates the addition of a CT and CB onto the oneline. 


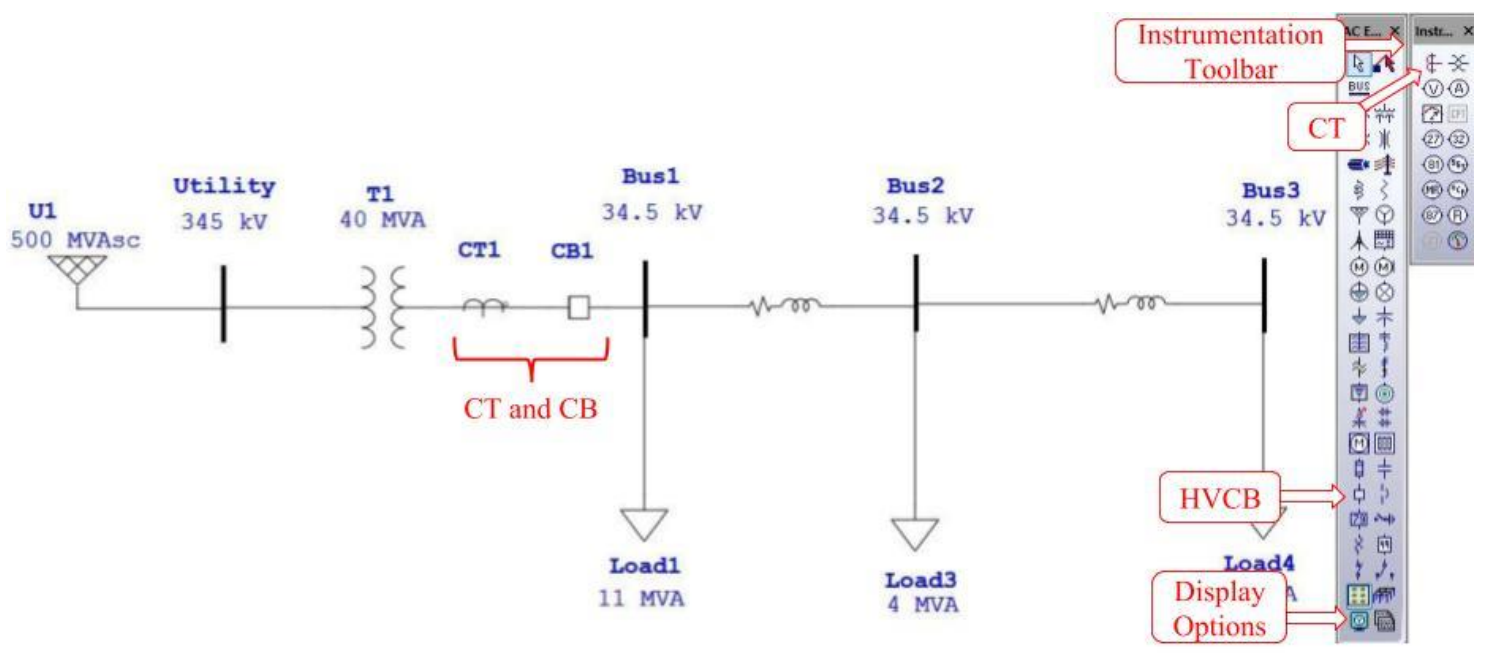

Figure A14: ETAP, CT and CB

We will now repeat the process by adding two more sets of CTs and CBs next to Bus1 and Bus 2, respectively. Delete the segment between Bus1 and transmission line Line12. Add a CT and HVCB between Bus1 and Line12, rotate the protective elements as needed, and relocate other circuit elements as necessary. Delete the segment between Bus2 and Line23. Add a CT and HVCB between Bus2 and Line23, rotate the protective elements as needed, and relocate other circuit elements as necessary. Figure A15 displays the one-line with all circuit transformers and circuit breakers added to the system. 


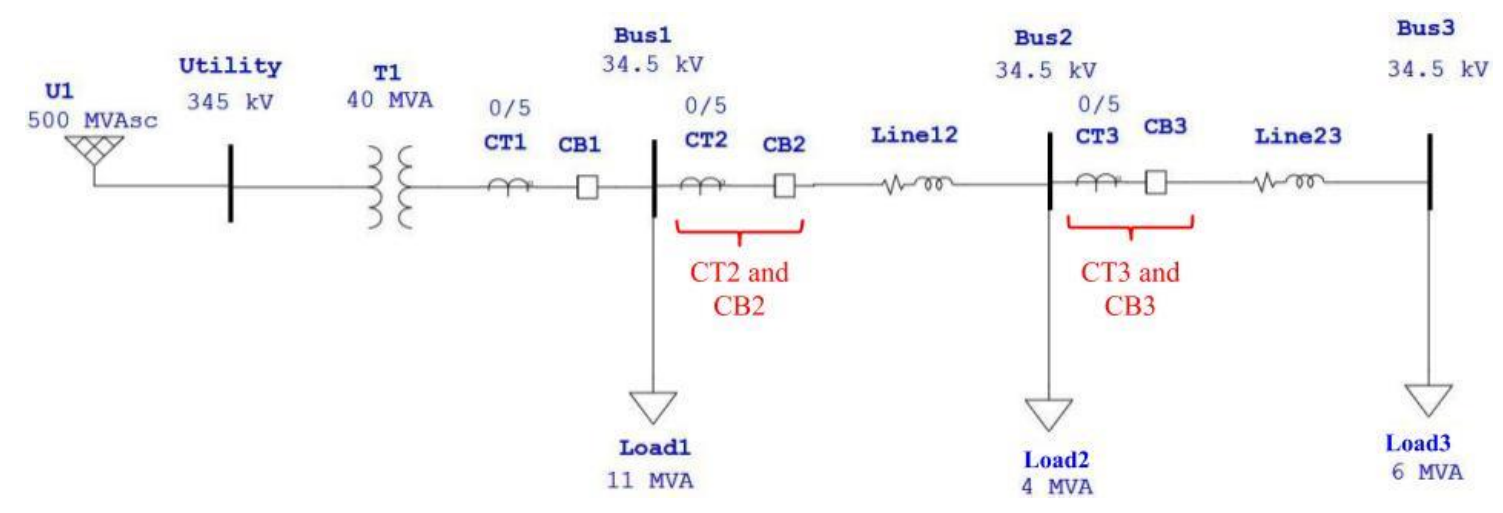

Figure A15: ETAP, complete CTs and CBs

We will now add time-inverse overcurrent relays to our system. Select

Overcurrent Relay from the Instrumentation Toolbar and place it on the one-line.

Connect the Relay1 to CT1, located between T1 and CB1. Similarly, add two additional relays, Relay 2 and Relay 3, and connect them to CT2 and CT3, respectively. At this point we have completed adding every element in our radial power system. Figure A16 shows the complete radial power system model.

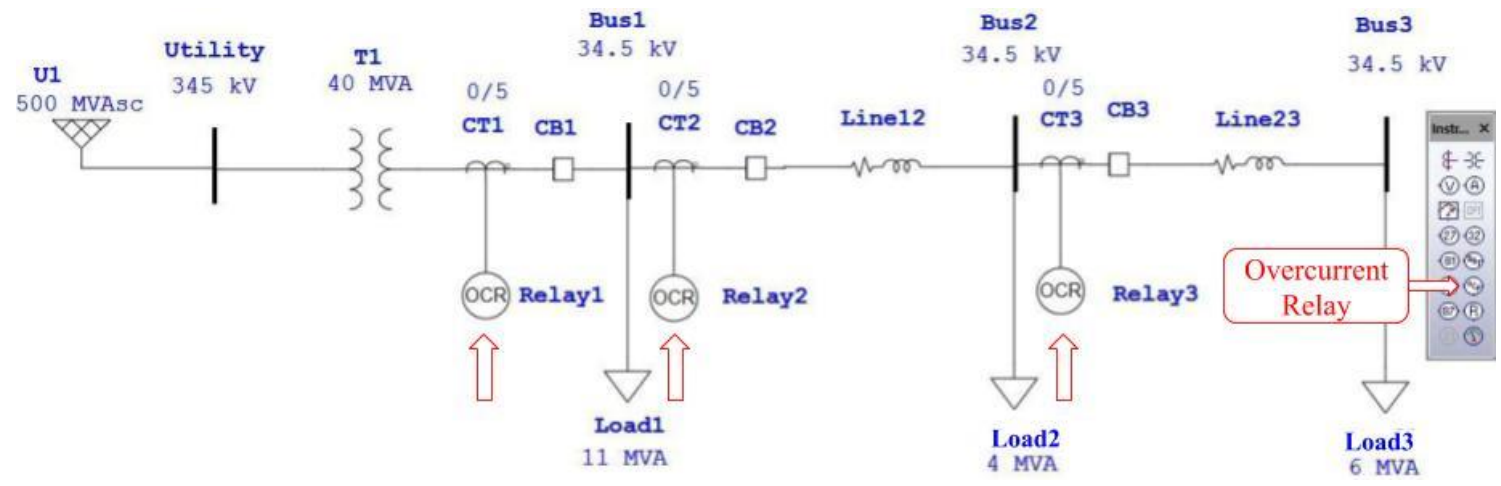

Figure A16: ETAP, Overcurrent Relays 


\section{Part 3: Device coordination settings}

We will now implement all the necessary settings to coordinate our protective relays and circuit breakers to protect the radial system in Figure A16 from three-phase faults. Let us first set our current transformer ratios. Double click CT1 on the one-line to open the Current Transformer (CT) Editor and select the Rating page. Enter 400 A for Primary under Ratio, and 5 A Secondary, leave all other settings as default values, and hit OK. We are neglecting the effect of CT saturation for the purposes of simulation and hence not entering CT burden values. Similarly, double click CT2 on the one-line and select the Rating page. Enter 200 A for Primary under Ratio, 5 A Secondary, and hit OK. Double click CT3 on the one-line and select the Rating page. Enter 200 A for Primary under Ratio, 5 A Secondary, and hit OK. We have now successfully assigned proper CT ratios to step down fault currents to nominal values to be fed to our relays. Figure A17 displays an example of setting CT primary and secondary settings for CT2. 


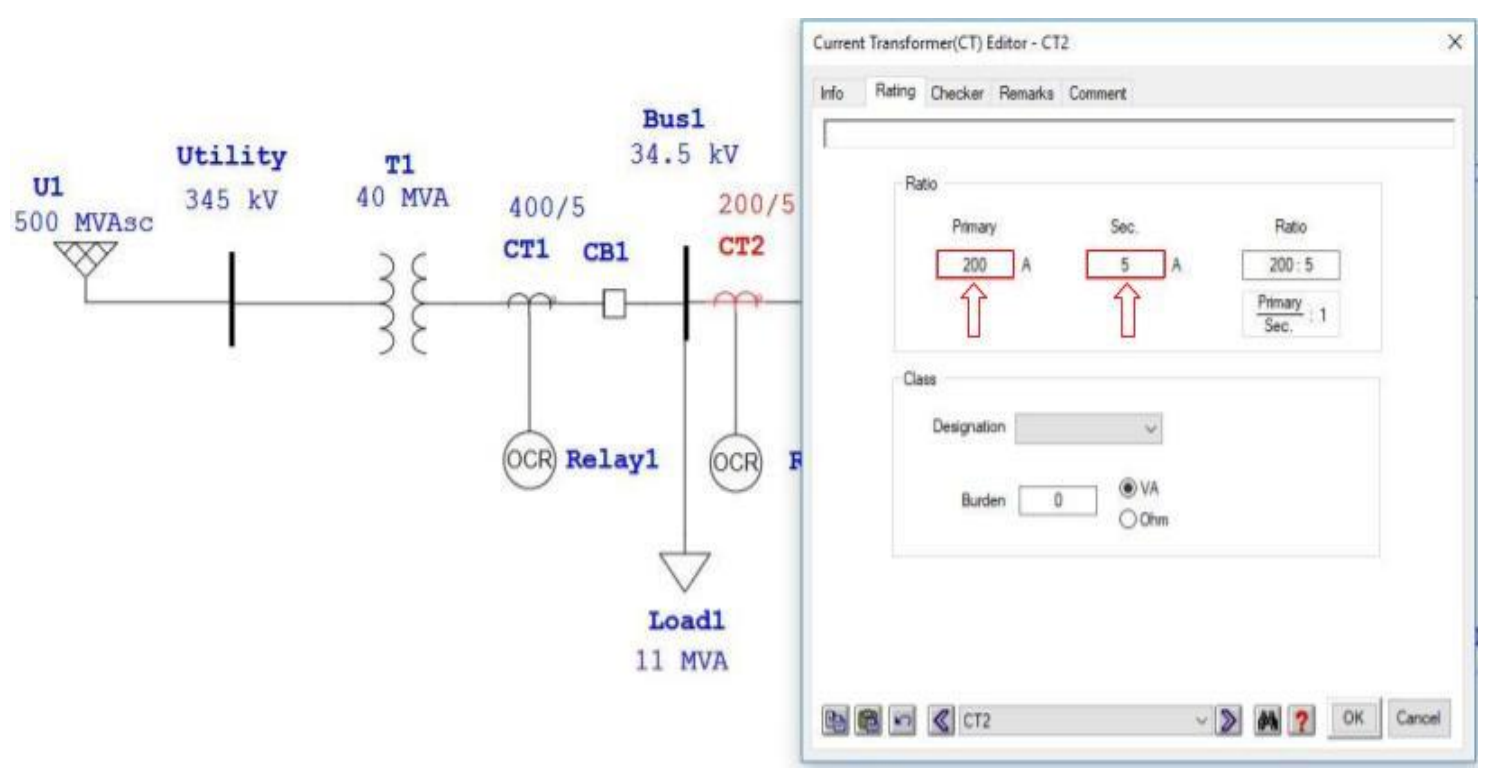

Figure A17: ETAP, Current Transformer settings

We will now verify circuit breaker parameters for purposes of coordination.

Double click CB1 on the one-line and select the Rating page. Select $\mathbf{5}$ under the drop down 'Cycle.' Leave all other parameters as default and hit OK. We have successfully ensured a 5 cycle $(83.3 \mathrm{~ms})$ operating time for the circuit breaker. ETAP has an extensive library of circuit breakers, but we are concerned primarily with the rated interrupting time for purposes of simulation. Repeat the process above for CB2 and CB3. Figure A18 displays an example of setting circuit breaker settings for CB1. 


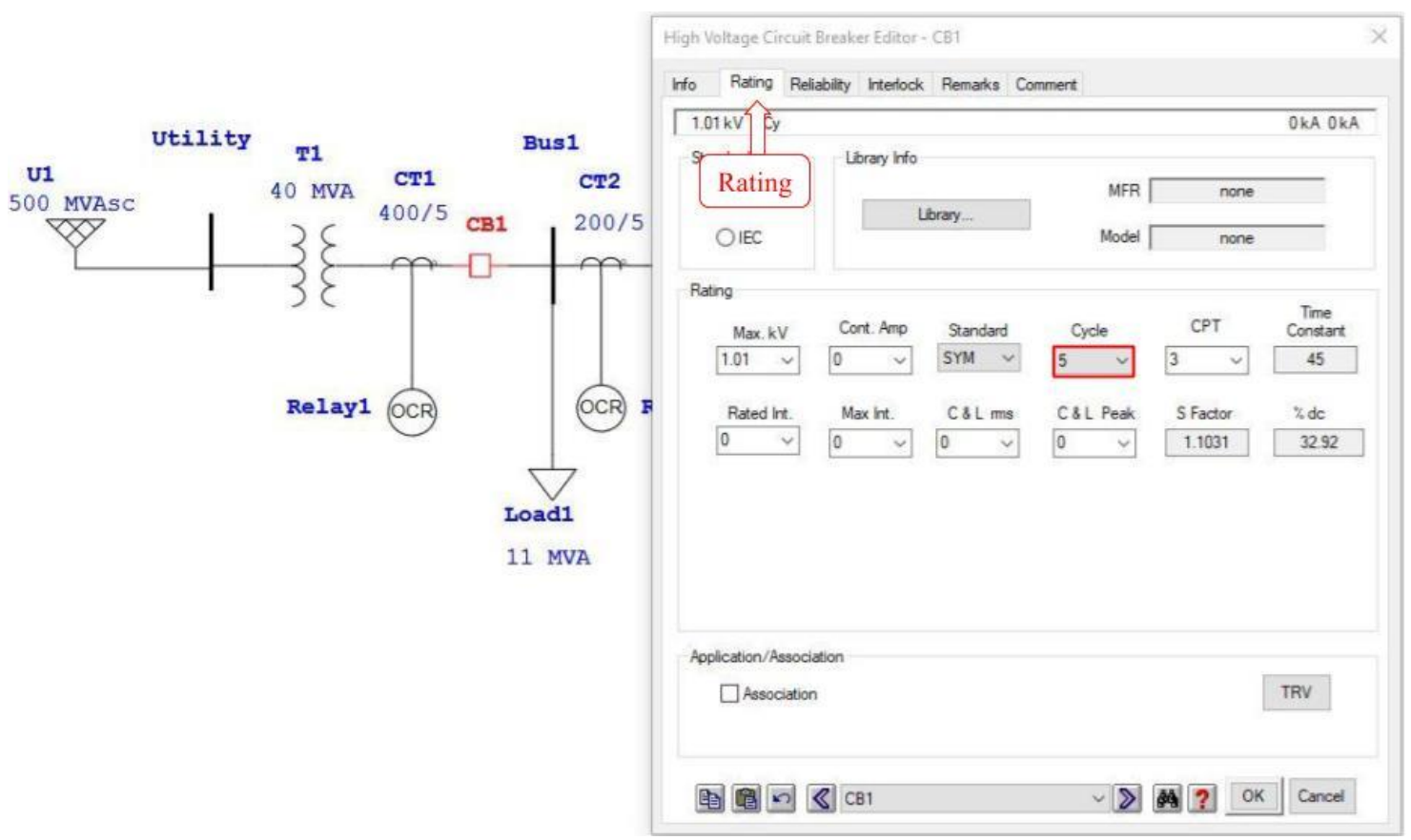

Figure A18: ETAP, CB settings

We will now implement time-overcurrent relay settings to all our relays. Double left click Relay1 to open the Overcurrent Relay Editor and select the OCR page. Click on Library... to open the Library Quickpick - Relay window. Scroll down under the 'Manufacturer' section and select Westinghouse. Scroll down under the 'Model' section and select CO. Hit OK. In the OCR relay page, uncheck 'Instantaneous' settings. In the OCR relay page, check Overcurrent settings if not already checked, and select ' $\mathrm{Curve}$ Type' as CO8 - Inverse from the drop down box. Select 'Pickup Range' as $\mathbf{2}$ - 6 Sec 5A Amps from the drop down box. Select 'Pickup' as $\mathbf{5}$ from the drop down box. Enter $\mathbf{3}$ under Time Dial settings. Select the Output page in the Overcurrent Relay Editor and click Add under the 'Output' section. Select Phase under the drop down box for 'Relay Element'. Select OC1 under the drop down box for 'Level'. Since we are considering an electromechanical relay with single-phase time overcurrent capabilities only, these 
settings will be limited. For more sophisticated relays such as Schweitzer Engineering Laboratories (SEL), many relay elements such as differential, negative sequence, etc. would be available. Click Add under the Interlock section. Select 'Device Type' as HVCB, 'Device ID' as CB1, and 'Action' as Open under the respective drop down boxes. Hit $\mathbf{O K}$. Congratulations, we have successfully programmed current tap and time dial settings for Relay1, and enabled the assertion of trip commands to CB1 in the event of a fault. 


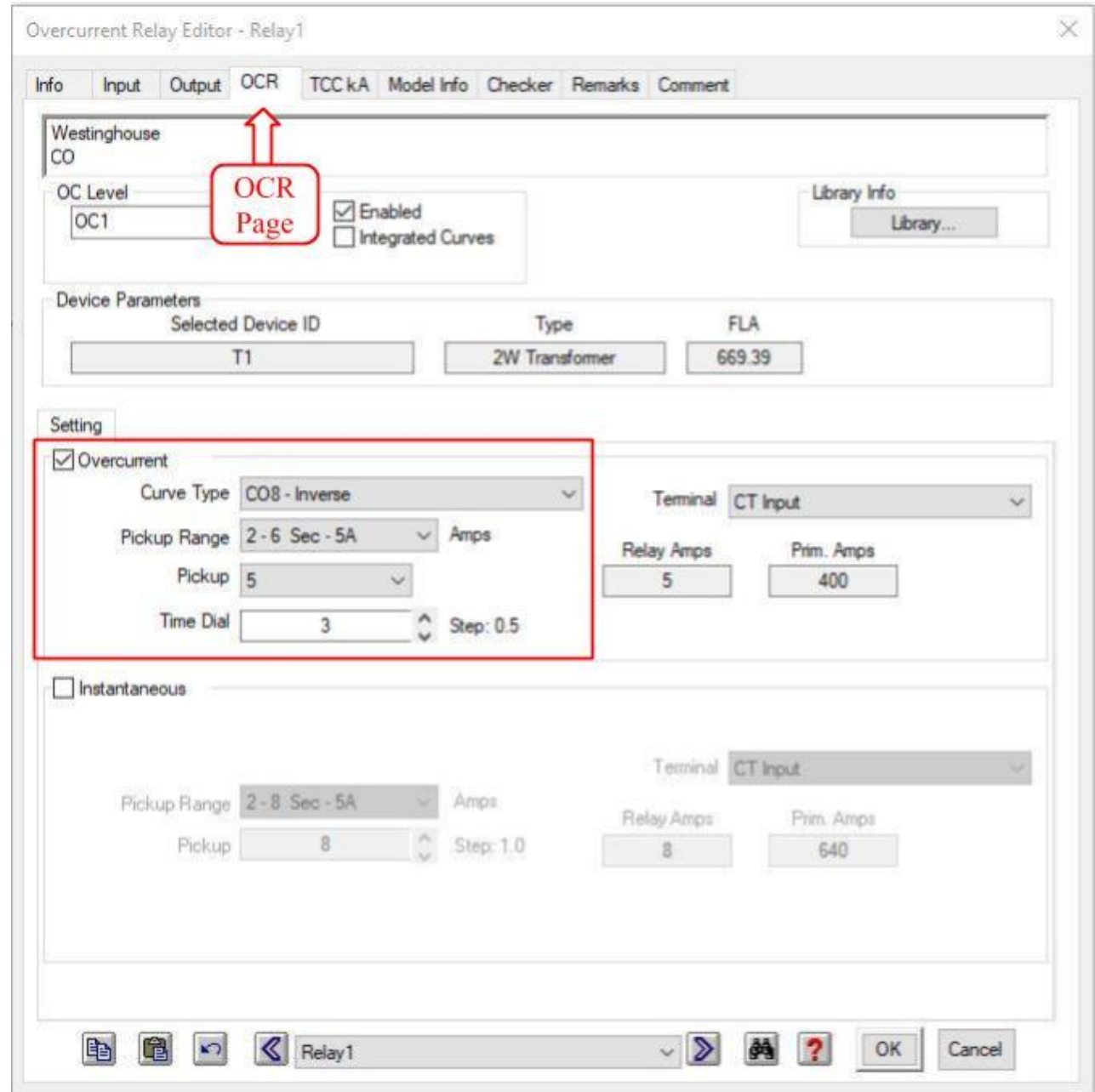

Figure A19: ETAP, Relay OCR settings 


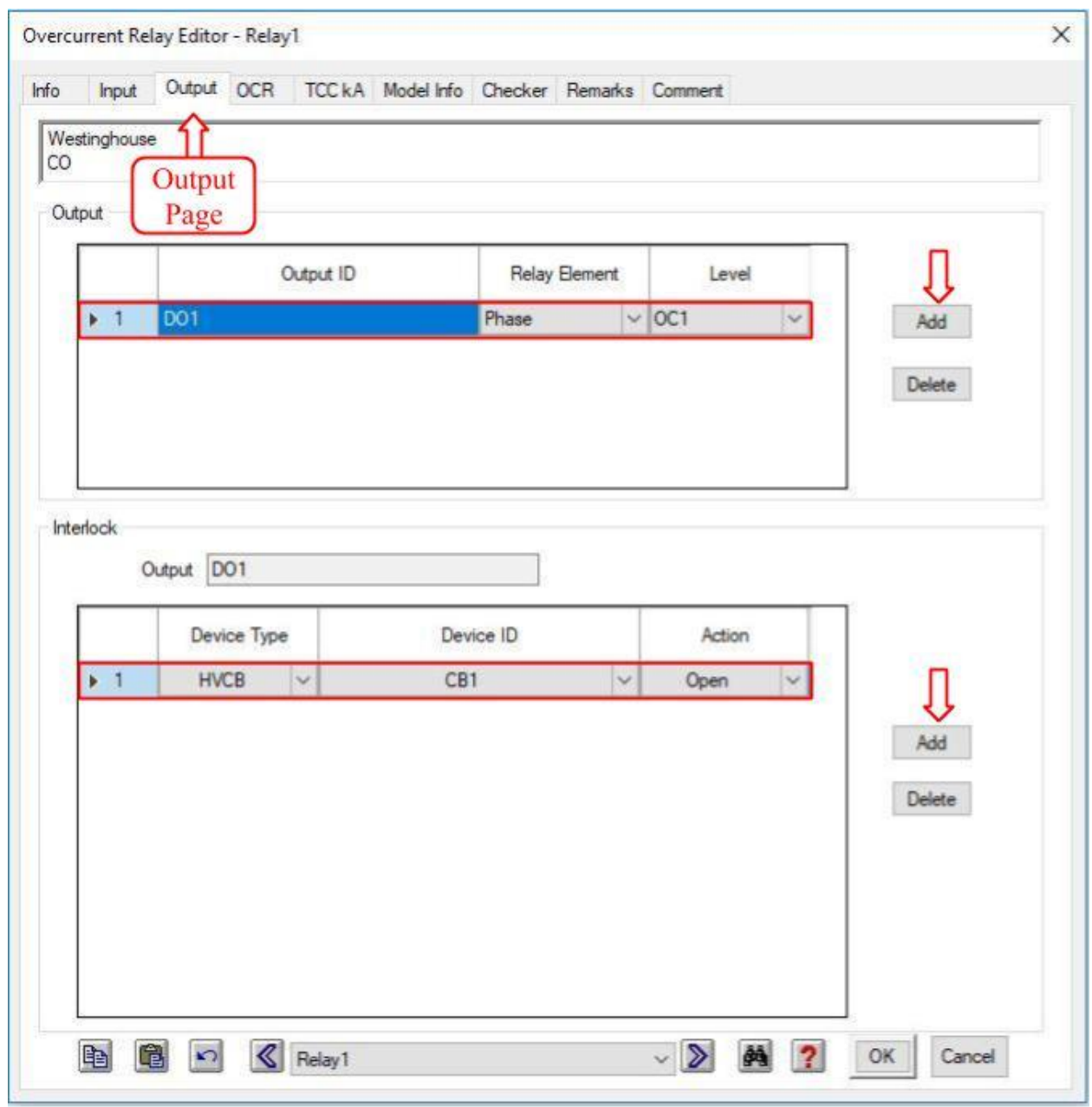

Figure A20: ETAP, Relay Output settings

We will now repeat the process for Relay 2 and Relay3 for their respective relay settings for a Westinghouse CO8 electromechanical relay. Double left click Relay2 to open the Overcurrent Relay Editor and select the OCR page. Click on Library... to open the Library Quickpick - Relay window. Scroll down under the 'Manufacturer' section and select Westinghouse. Scroll down under the 'Model' section and select CO. Hit OK. In the OCR relay page, uncheck 'Instantaneous' settings. In the OCR relay page, check Overcurrent settings if not already checked, and select 'Curve Type' as CO8 - Inverse from the drop down box. Select 'Pickup Range' as 2 - 6 Sec-5A Amps from 
the drop down box. Select 'Pickup' as $\mathbf{5}$ from the drop down box. Enter $\mathbf{2}$ under Time Dial settings. Select the Output page in the Overcurrent Relay Editor and click Add under the 'Output' section. Select Phase under the drop down box for 'Relay Element'. Select OC1 under the drop down box for 'Level'. Click Add under the Interlock section. Select 'Device Type' as HVCB, 'Device ID' as CB2, and 'Action' as Open under the respective drop down boxes. Hit $\mathbf{O K}$.

Double left click Relay3 to open the Overcurrent Relay Editor and select the OCR page. Click on Library... to open the Library Quickpick - Relay window. Scroll down under the 'Manufacturer' section and select Westinghouse. Scroll down under the 'Model' section and select CO. Hit OK. In the OCR relay page, uncheck 'Instantaneous' settings. In the OCR relay page, check Overcurrent settings if not already checked, and select 'Curve Type' as CO8 - Inverse from the drop down box. Select 'Pickup Range' as 2-6 Sec-5A Amps from the drop down box. Select 'Pickup' as 3 from the drop down box. Enter 0.5 under Time Dial settings. Select the Output page in the Overcurrent Relay Editor and click Add under the 'Output' section. Select Phase under the drop down box for 'Relay Element'. Select OC1 under the drop down box for 'Level'. Click Add under the Interlock section. Select 'Device Type' as HVCB, 'Device ID' as CB3, and 'Action' as Open under the respective drop down boxes. Hit OK. 


\section{Part 3: ETAP Protection Analysis}

For the purposes of this custom tutorial, we will generate time-current characteristics (TCC) for the radial power system protection scheme. For the interested reader, ETAP provides a tutorial for its protection analysis capabilities (STAR) by clicking Help > Help Search on the ET AP menu-bar which opens the ETAP Help 16.1.0 window. Select Tutorials $>$ Star Tutorial for extensive background for all STAR basics.

Up until this point we have been operating under the 'Edit' mode to create our radial power system and change power system parameters as needed. We will now switch the ETAP presentation from 'Edit' mode to Star - Protection \& Coordination mode by clicking the icon on the Mode toolbar. Figure A21 illustrates the switching from edit mode to Star mode in ETAP.

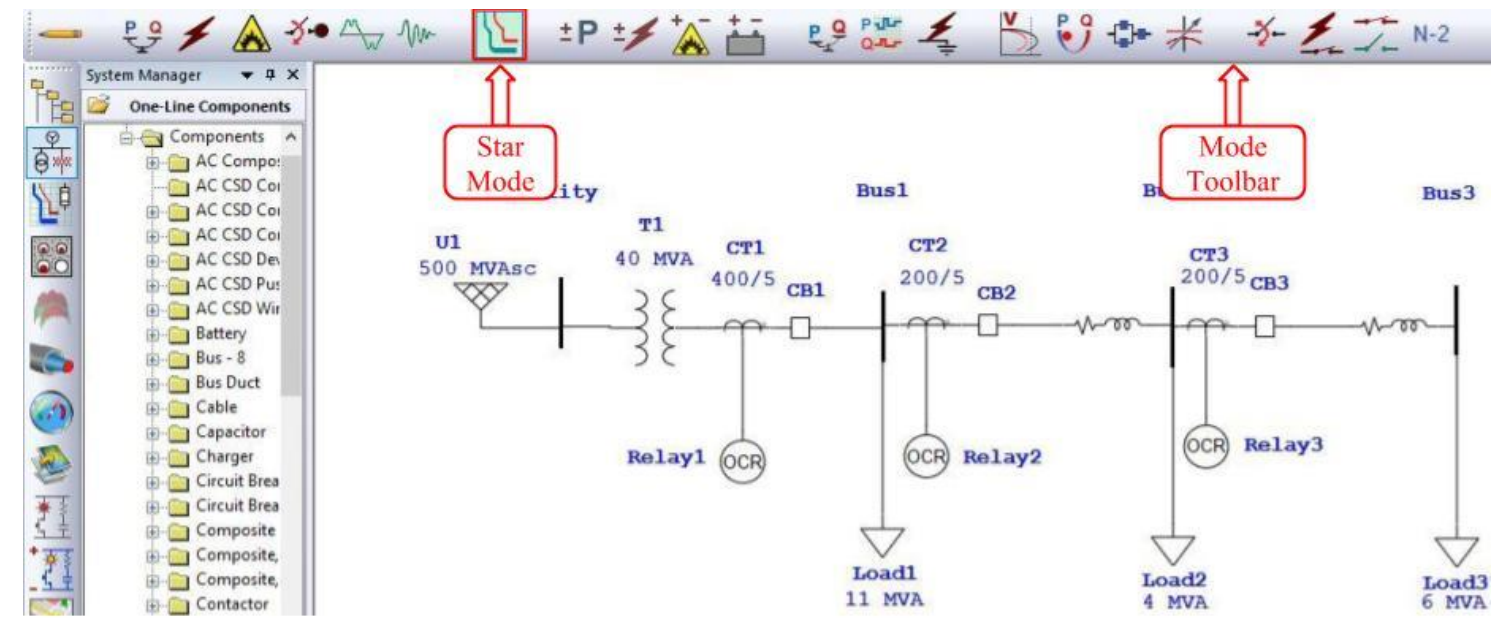

Figure A21: ETAP, Star mode

ETAP allows us to modify the Star Mode study case to adjust parameters such as fault type (3 phase, line-to-line, etc.), fault value (symmetrical/asymmetrical), fault 
impedance, etc. for in depth analysis. For purposes of this tutorial we will consider default ETAP Star parameters e.g. three-phase faulted conditions. Click on Fault Insertion from the STAR toolbar and apply the fault by left clicking the segment to the right of CB3 at Bus2, which is the largest fault current Relay3 will detect (2 kA). If prompted for an 'Output File Name', enter '3phase' or any other name of your choosing. If coordinated correctly, you should observe three circuit breakers marked with an ' $\mathrm{X}$ ' next to a number indicating the order of circuit breaker tripping operation, illustrated in Figure A22.

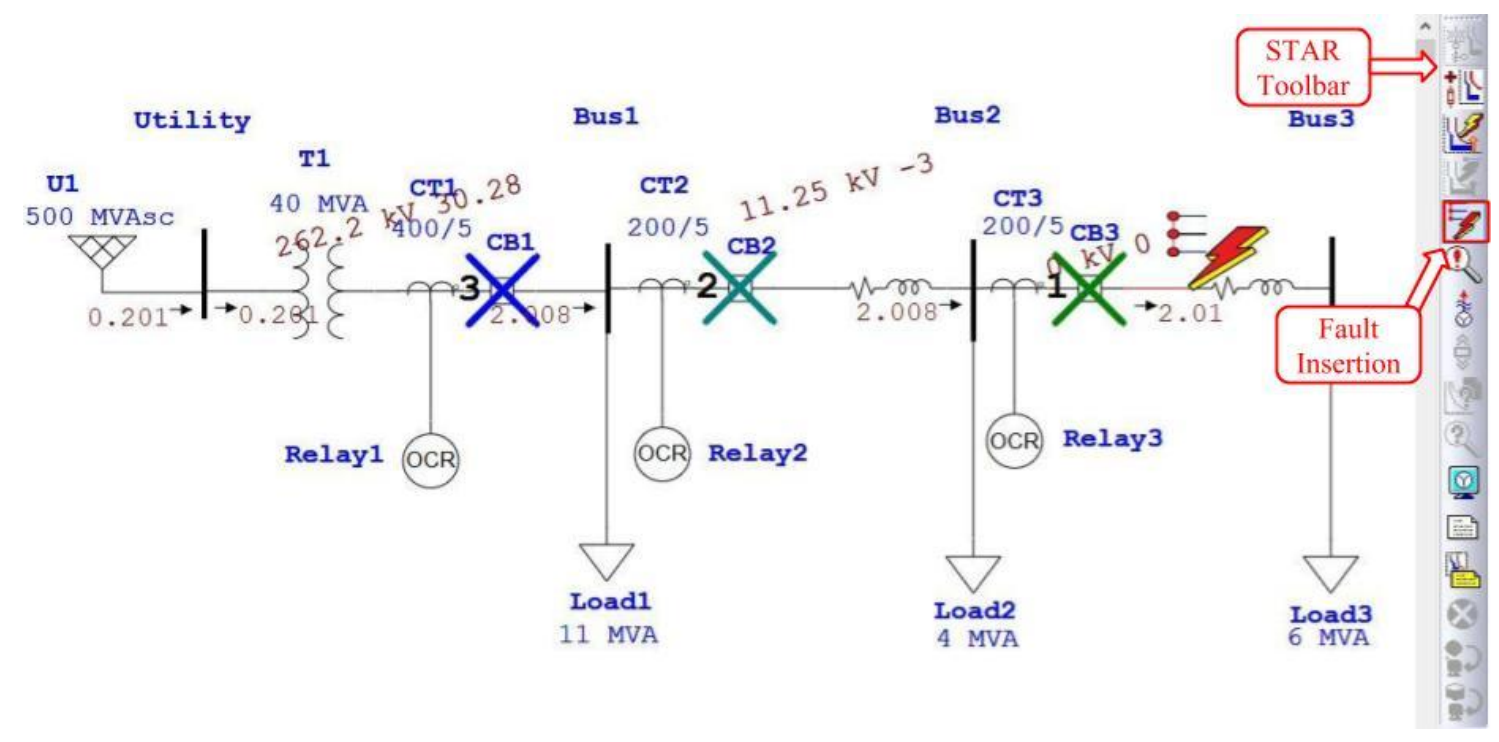

Figure A22: ETAP, three-phase fault, Bus2

For a more analytical description showcasing the sequence of operation of protective elements shown in Figure A22, click Sequence Viewer from the STAR toolbar which opens the Sequence-of-Operation (SQOP) Events window shown in Figure A23. SQOP allows us to systematically confirm if our protective relaying settings and circuit breaker operation adhere to design considerations outlined in the problem 
statement. The Time (ms) column in Figure A22 indicates the time in which certain protective elements have asserted commands. T1 (ms) indicates the operating time of protective elements. For example, at time $69.5 \mathrm{~ms}$, Relay3 has asserted trip commands to open CB3, and at time $153 \mathrm{~ms}$ the fault has been cleared by CB3 (5 cycle clearing time, $83.3 \mathrm{~ms})$. To provide backup protection, Relay2 asserts trip commands at time $450 \mathrm{~ms}$, following by the clearing of the fault of CB2. Finally, Relay1 and CB1 provides a third layer of protection. 


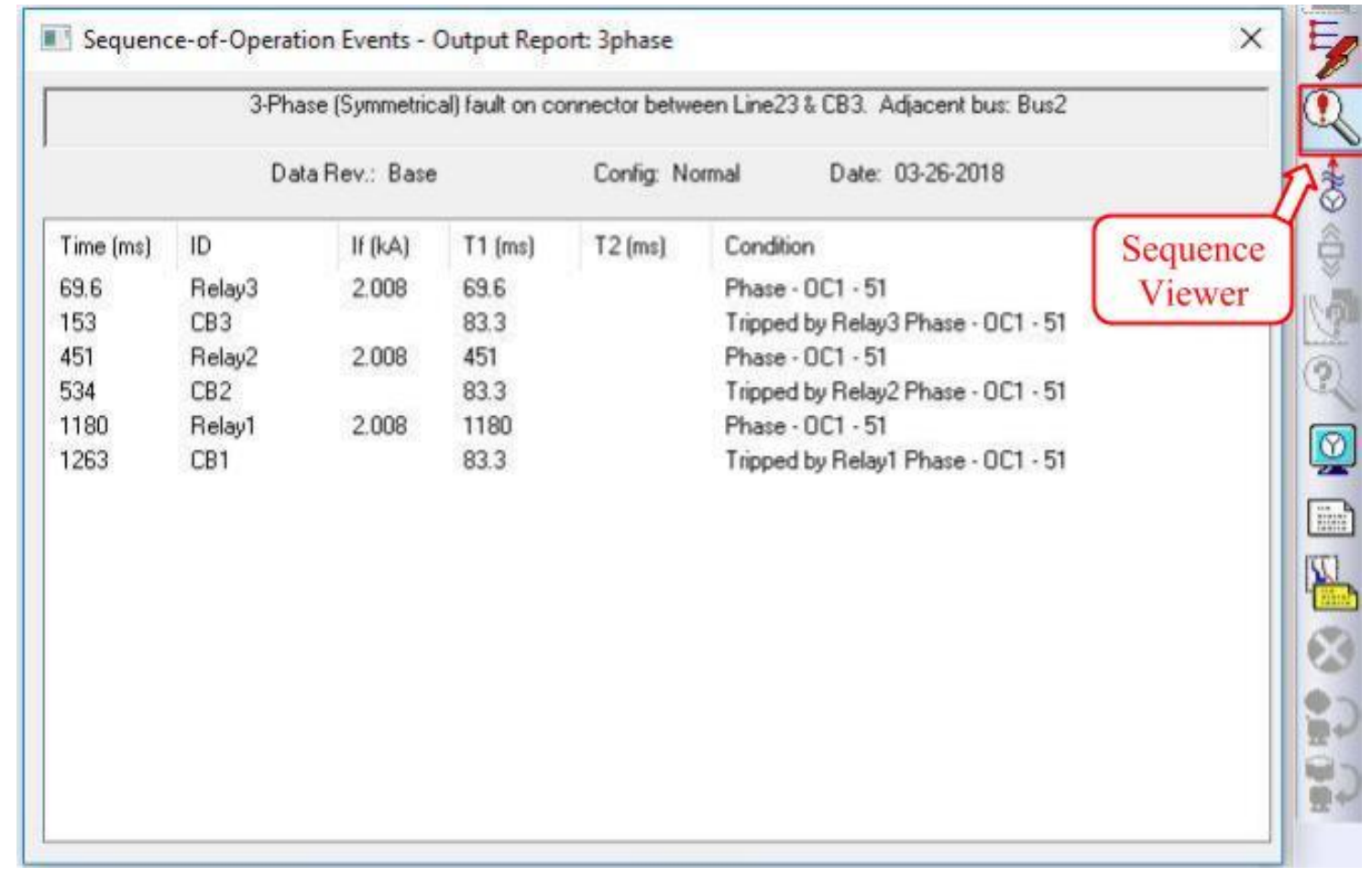

Figure A23: ETAP, Sequence-of-Operation Events, 3 phase fault

To obtain a visual glance of the coordination of relays, we will now generate time-current-curves (TCC). Close the Sequence-of-Operation Events window shown in Figure A23. Hold Ctrl and left click Relay1, Relay2, and Relay3 on the one-line such that they are all highlighted in red. Press Create Star View from the Star toolbar. A new window showcasing three inverse-time overcurrent relays should be displayed. Figure A24 illustrates the highlighting of relays and creating a Star TCC view from the one-line. 


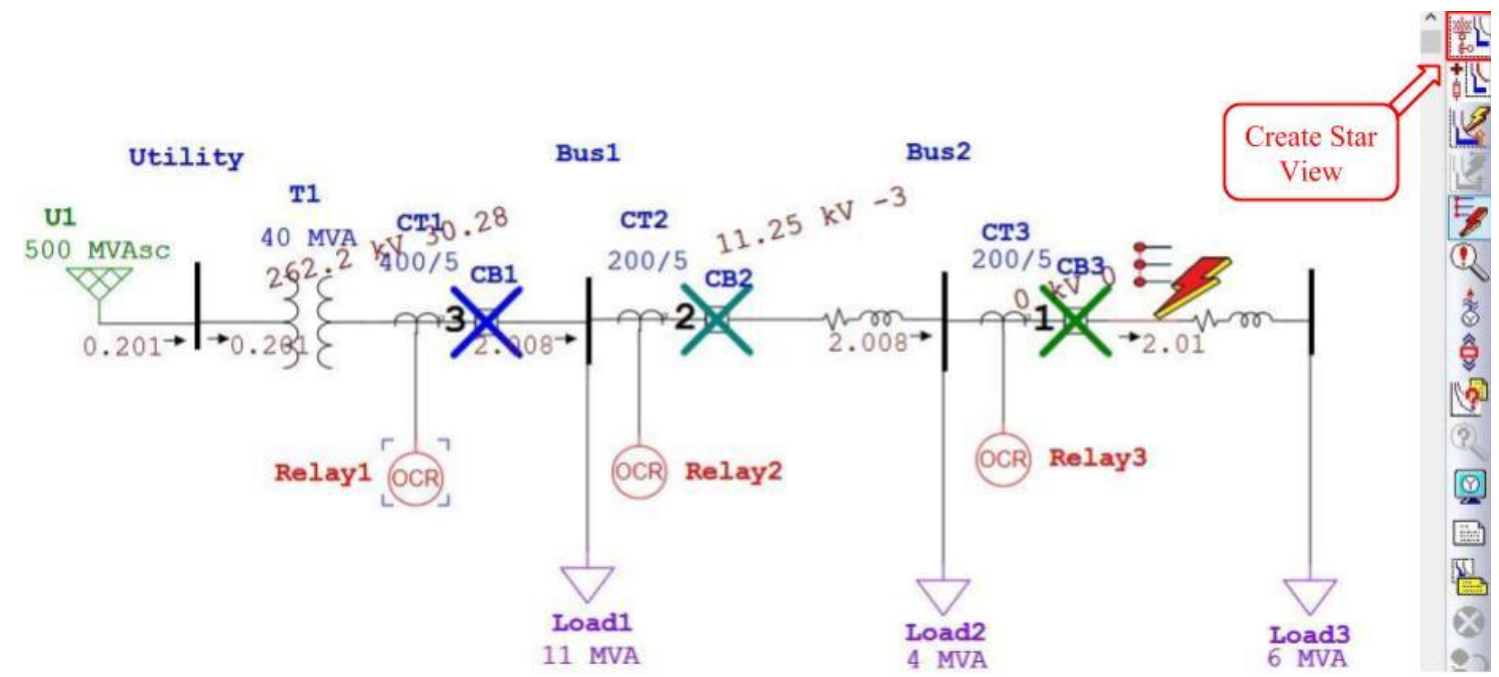

Figure A24: ETAP, Create Star View

Figure A25 displays the corresponding time-current characteristic (TCC) for the specific three-phase fault current injected next to Bus2. Several options are available for further in depth analysis of the system configuration, customized as shown in Figure A25. Clicking One-Line Diagrams on the Systems Toolbar enables users to jump back to the one-line view, and clicking Star Systems on the Systems Toolbar enables users to return to the TCC view. The Star View Toolbar has several options to further alter the TCC view. The vertical red arrow indicates the normalized per unit fault current $(2 \mathrm{kA})$. Clicking Time Difference from the Star View Toolbar and left click the Relay2 curve as it highlights red. While the Relay2 curve is highlighted, select the Relay3 curve. Click and drag the difference of the two curves until it aligns with 1.0 Per Unit on the X-axis. You can delete the time difference and create a new measurement to revert any misoperation. If done correctly, you should observe a time difference delta of approximately $\mathbf{0 . 3 8} \mathbf{s}$. This time difference includes the breaker rated interrupting time (5 cycle $=83 \mathrm{~ms}$ ) added with relay coordination time (300 ms standard). 


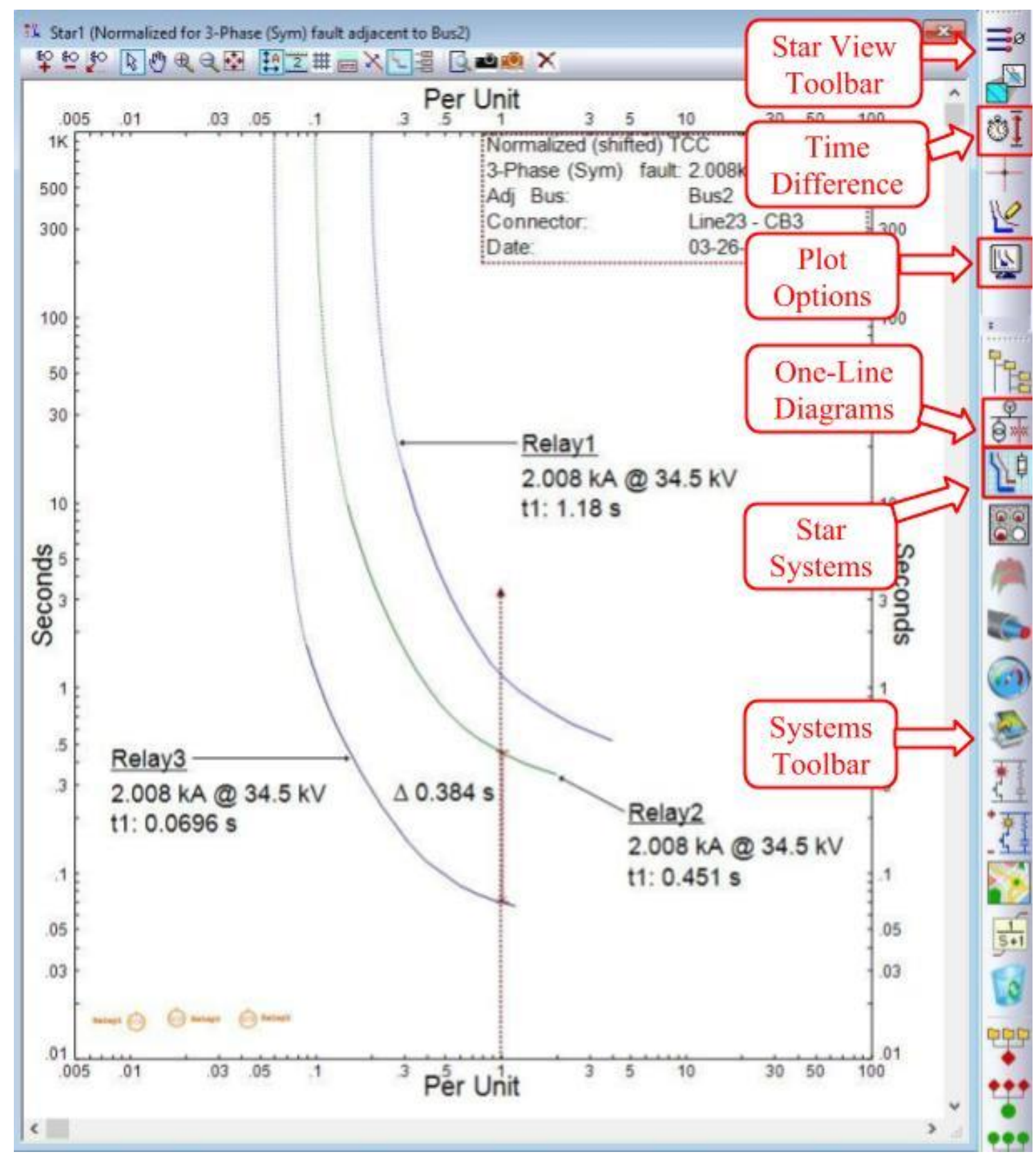

Figure A25: ETAP, Star TCC 


\section{Appendix B: SEL-421 Relay Settings}

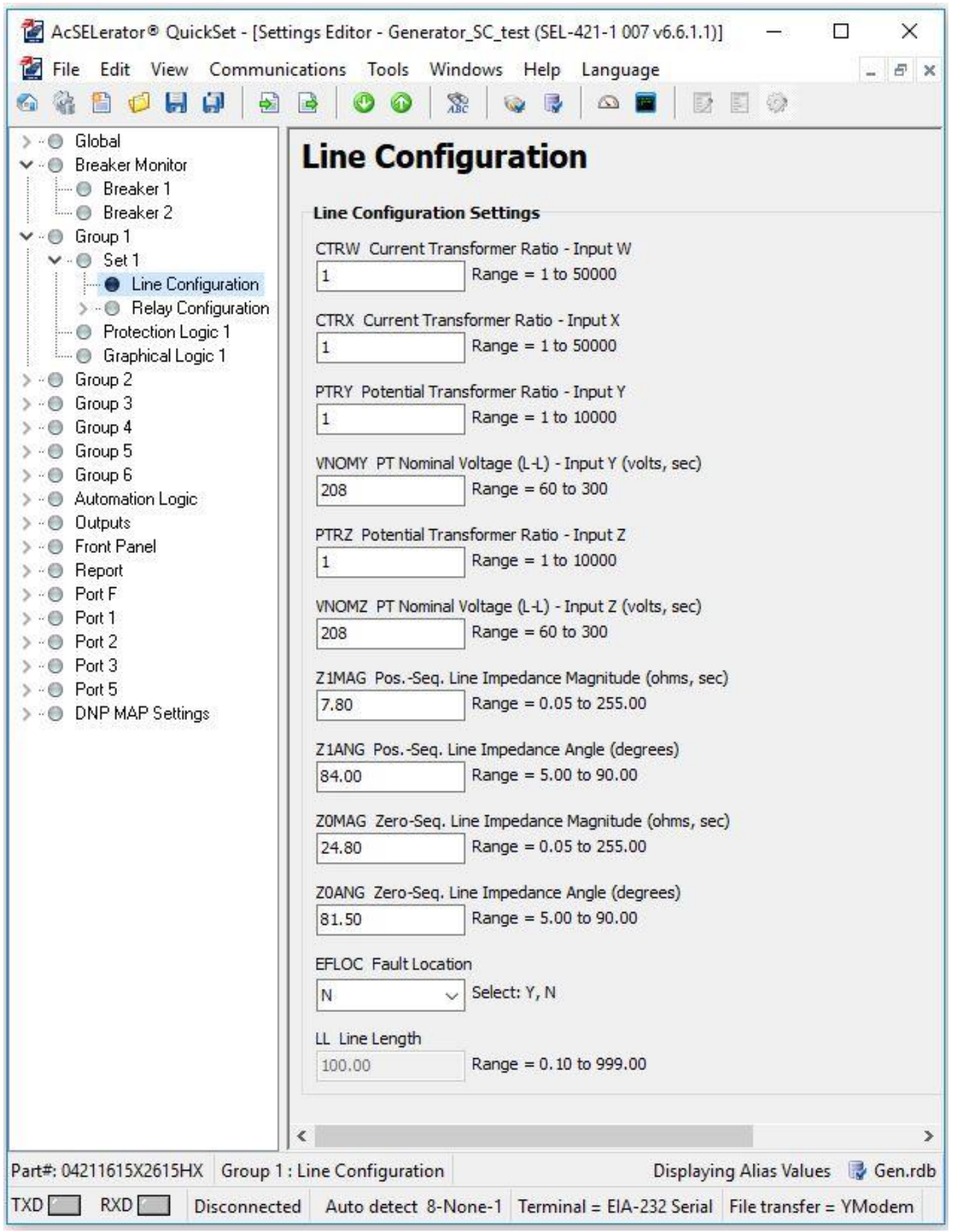




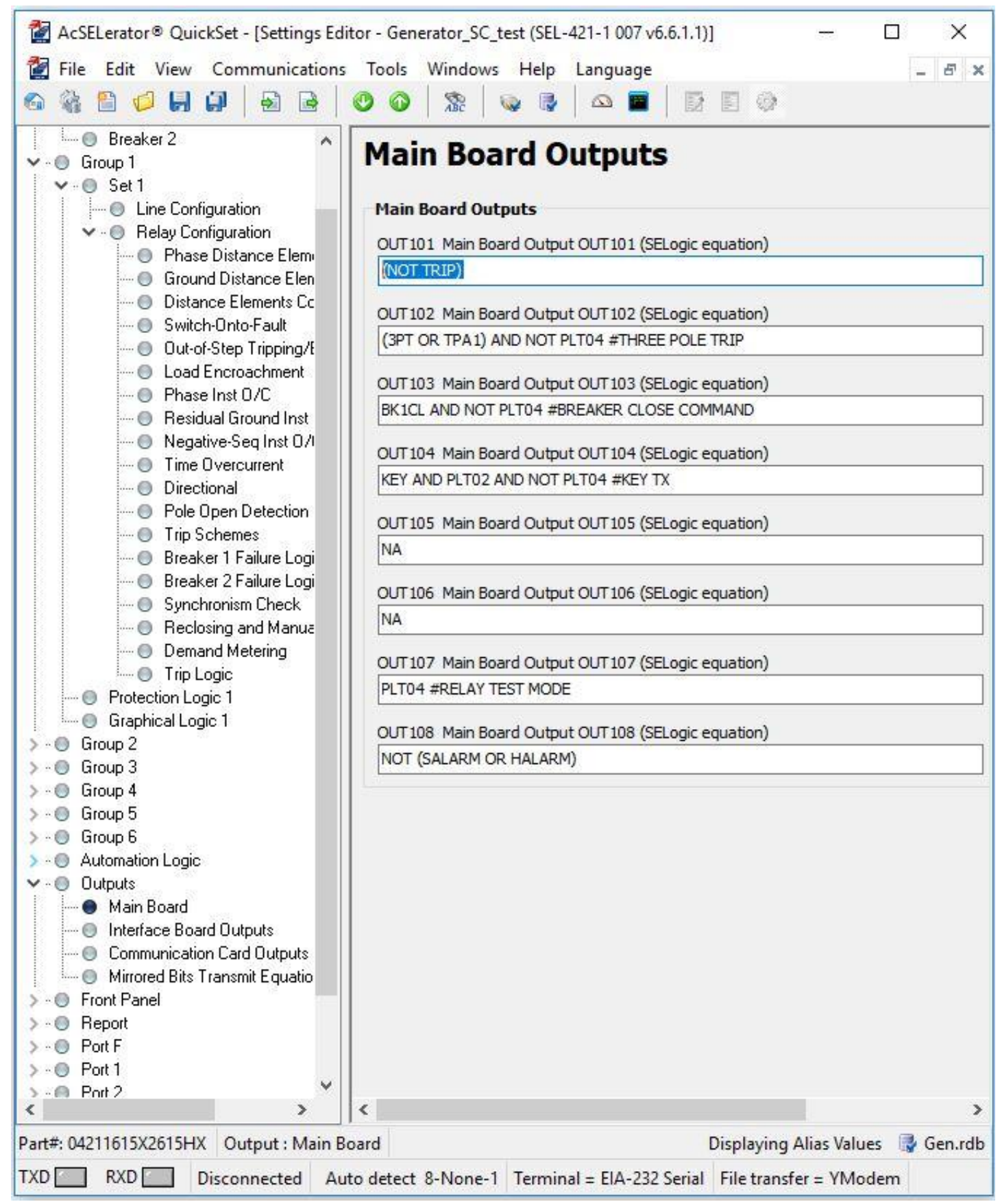




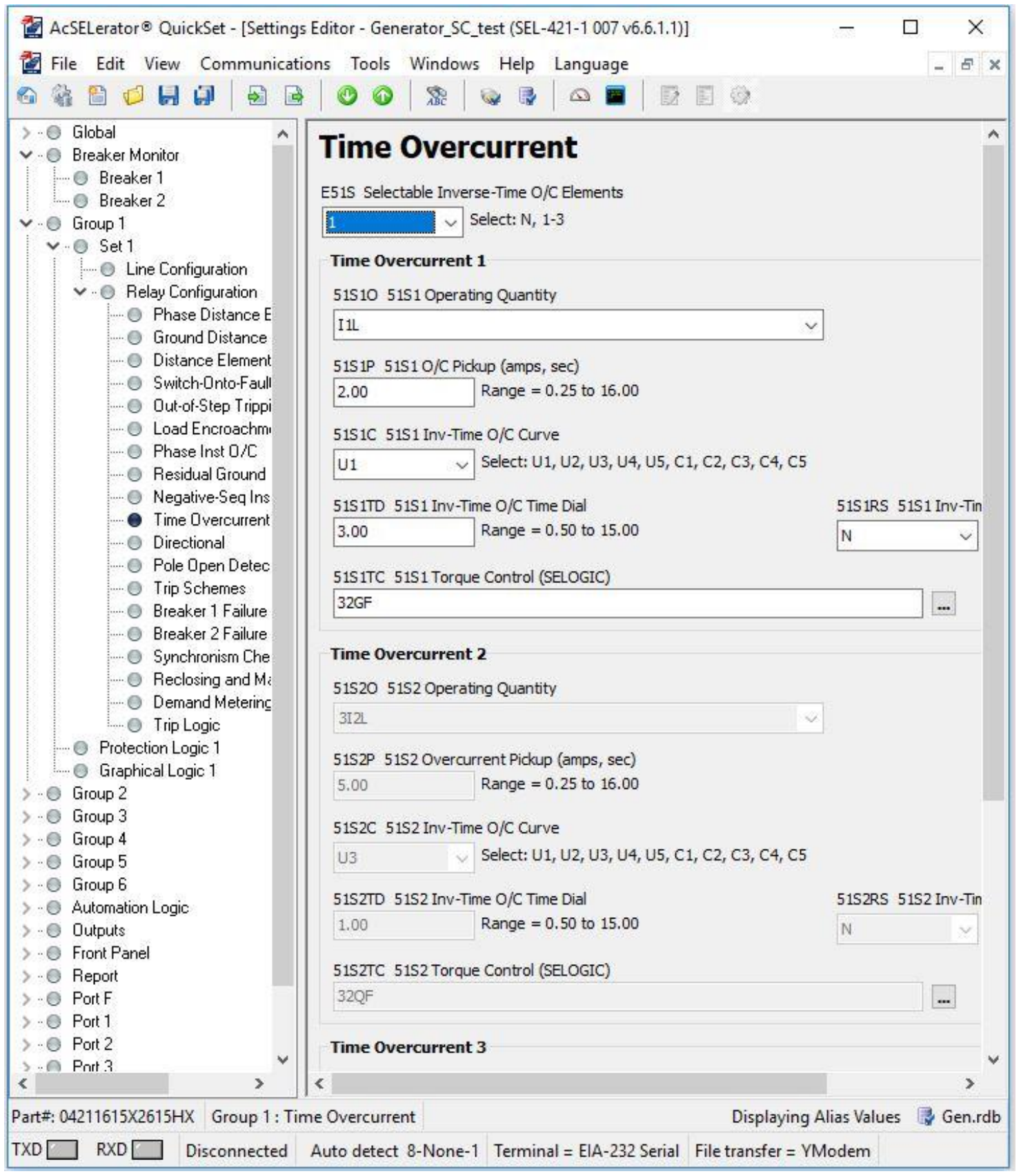




\section{Appendix C: ETAP Short Circuit Data}

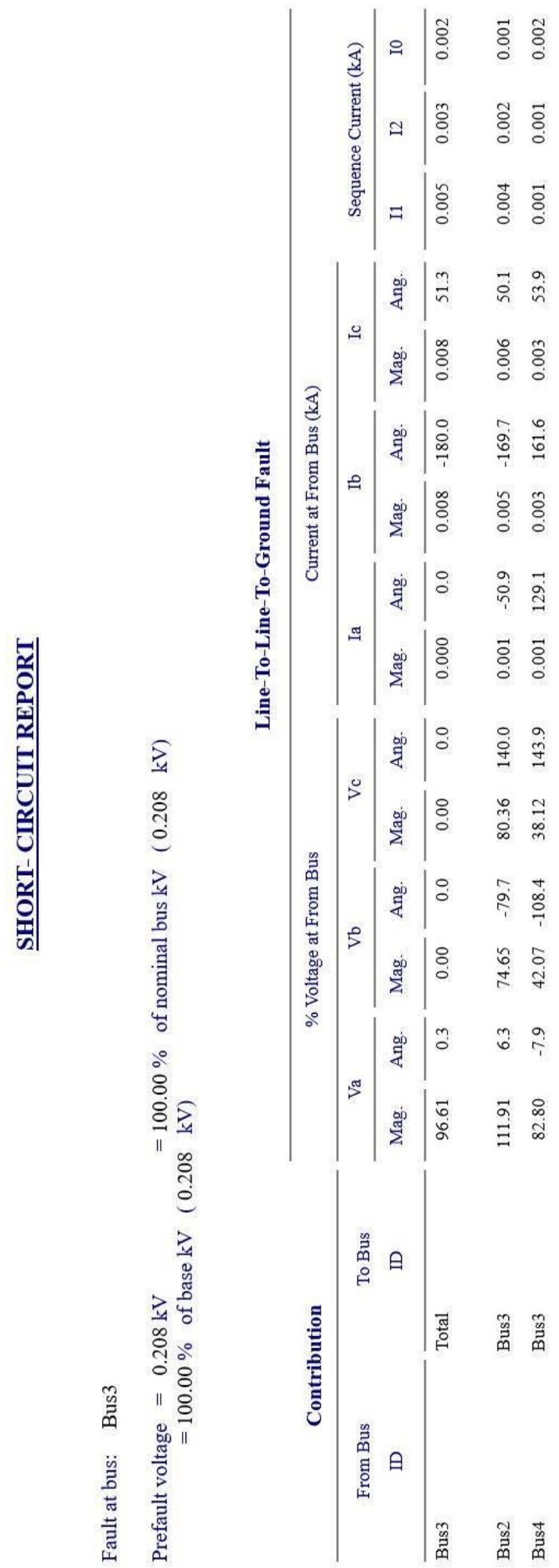




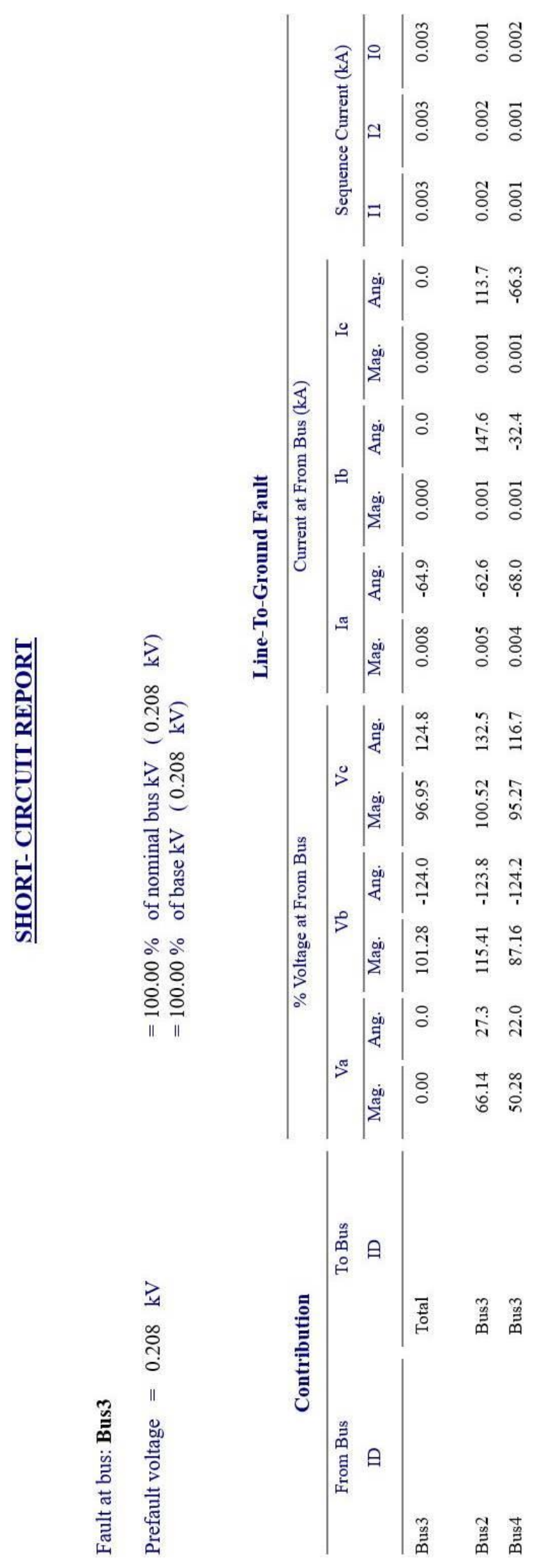




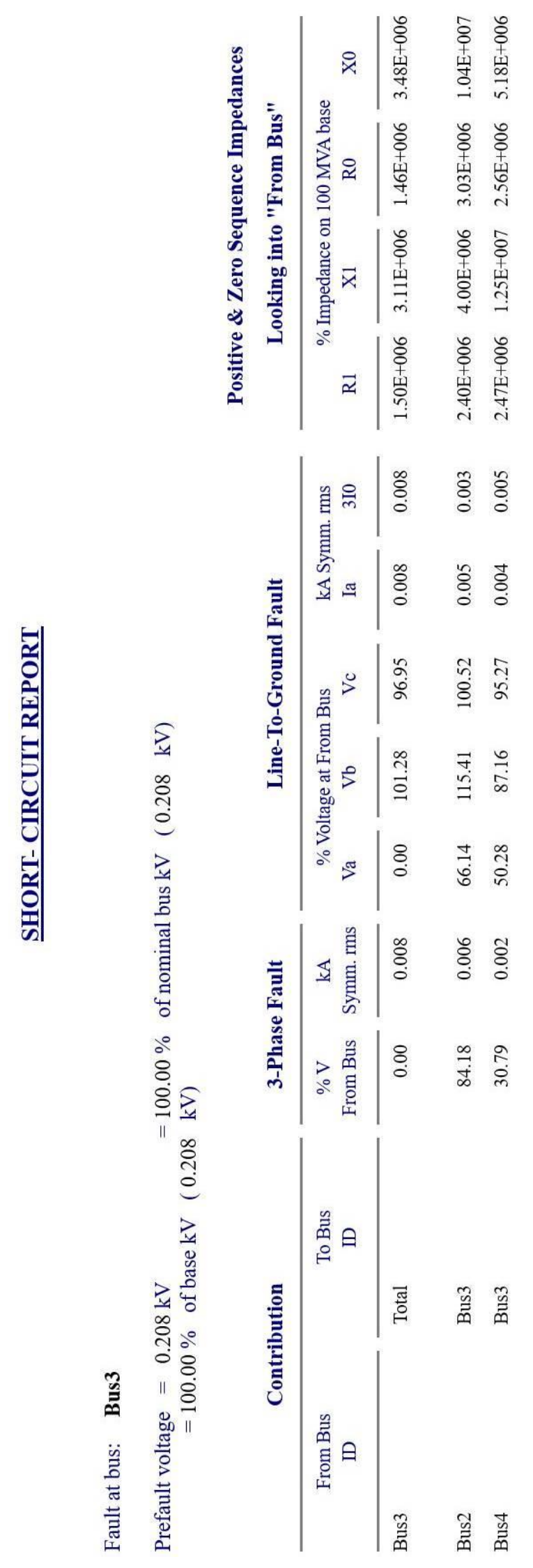




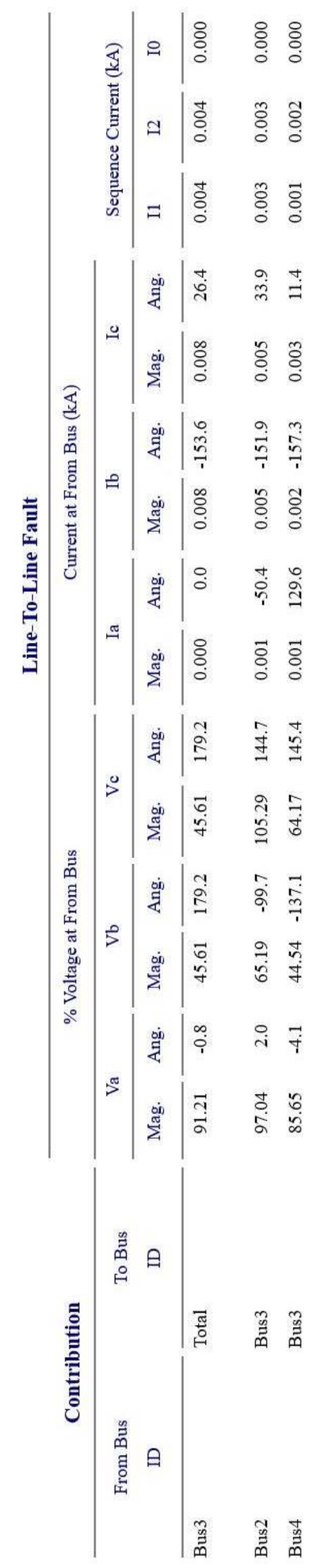




\section{Appendix D: ETAP and SEL Overcurrent Protection settings}

\begin{tabular}{|c|c|c|c|c|c|}
\hline \multirow[b]{2}{*}{ Relay ID } & \multirow{2}{*}{$\begin{array}{c}\text { Trip } \\
\text { Element }\end{array}$} & \multirow[b]{2}{*}{ Curve } & \multicolumn{3}{|c|}{$\begin{array}{c}\text { OCR }(51,50), \text { OLR (49, } \\
\text { Acc.) }\end{array}$} \\
\hline & & & $\begin{array}{l}\text { Pickup } \\
\text { (A) }\end{array}$ & $\begin{array}{c}\text { Prim. } \\
\text { Amps } \\
\text { (A) }\end{array}$ & $\begin{array}{c}\text { Time } \\
\text { Dial } \\
\text { Setting }\end{array}$ \\
\hline SEL-710 & $\begin{array}{c}\text { Overload } \\
\text { Phase }\end{array}$ & & 2.280 & 2.00 & \\
\hline SEL-710 & $\begin{array}{l}\text { Overload } \\
\text { Ground }\end{array}$ & & 0.880 & 0.88 & $0.1 \mathrm{~s}$ \\
\hline SEL-311L-1 & Phase & $\begin{array}{c}\text { U1 - U.S. } \\
\text { Moderately Inverse }\end{array}$ & 4.500 & 4.500 & 0.500 \\
\hline SEL-311L-1 & Neutral & $\begin{array}{c}\text { U1 - U.S. } \\
\text { Moderately Inverse }\end{array}$ & 0.250 & 0.250 & 0.500 \\
\hline SEL-311L-1 & $\begin{array}{l}\text { Negative } \\
\text { Sequence }\end{array}$ & $\begin{array}{c}\text { U1 - U.S. } \\
\text { Moderately Inverse }\end{array}$ & 0.250 & 0.250 & 0.530 \\
\hline SEL-311L-2 & Phase & $\begin{array}{c}\text { U1 - U.S. } \\
\text { Moderately Inverse }\end{array}$ & 2.000 & 2.000 & 0.500 \\
\hline SEL-311L-2 & Neutral & $\begin{array}{c}\text { U1 - U.S. } \\
\text { Moderately Inverse }\end{array}$ & 0.250 & 0.250 & 0.500 \\
\hline SEL-311L-2 & $\begin{array}{l}\text { Negative } \\
\text { Sequence }\end{array}$ & $\begin{array}{c}\text { U1 - U.S. } \\
\text { Moderately Inverse }\end{array}$ & 0.250 & 0.250 & 0.530 \\
\hline
\end{tabular}




\begin{tabular}{|c|c|c|c|c|c|}
\hline \multirow{2}{*}{ Relay ID } & \multirow{2}{*}{\begin{tabular}{c}
\multirow{2}{*}{ Trip } \\
Element
\end{tabular}} & \multirow{2}{*}{ Curve } & \multicolumn{3}{|c|}{ OCR (51, 50), OLR (49, } \\
\cline { 3 - 6 } & & & $\begin{array}{c}\text { Acc.) } \\
\text { (A) }\end{array}$ & $\begin{array}{c}\text { Prim. } \\
\text { Amps } \\
\text { (A) }\end{array}$ & $\begin{array}{c}\text { Time } \\
\text { Dial } \\
\text { Setting }\end{array}$ \\
\hline \multirow{2}{*}{ SEL-587 } & Phase & U1 - U.S. & 2.000 & 2.000 & 0.600 \\
\hline \multirow{2}{*}{ SEL-587 } & Negative & U1 - U.S. & 0.500 & 0.500 & 0.600 \\
& Sequence & Moderately Inverse & & & \\
\hline SEL-387E & Phase & U1- U.S. & 4.500 & 4.500 & 0.600 \\
& & Moderately Inverse & & & \\
\hline SEL-387E & Negative & U1- U.S. & 0.500 & 0.500 & 0.600 \\
& Sequence & Moderately Inverse & & & \\
\hline
\end{tabular}

